Illinois State University

ISU ReD: Research and eData

Theses and Dissertations

6-7-2018

\title{
Learning About And Becoming Aware Of Reading Strategies And Metacognition In English By Adult Second Language Learners
}

Aline Biazotto André

Illinois State University, abandre@ilstu.edu

Follow this and additional works at: https://ir.library.illinoisstate.edu/etd

Part of the Education Commons

\section{Recommended Citation}

Biazotto André, Aline, "Learning About And Becoming Aware Of Reading Strategies And Metacognition In English By Adult Second Language Learners" (2018). Theses and Dissertations. 999.

https://ir.library.illinoisstate.edu/etd/999

This Dissertation is brought to you for free and open access by ISU ReD: Research and eData. It has been accepted for inclusion in Theses and Dissertations by an authorized administrator of ISU ReD: Research and eData. For more information, please contact ISUReD@ilstu.edu. 
LEARNING ABOUT AND BECOMING AWARE OF READING STRATEGIES AND METACOGNITION IN ENGLISH BY ADULT SECOND LANGUAGE LEARNERS

\section{ALINE BIAZOTTO ANDRÉ}

275 Pages

The purpose of the present study was to investigate the need to learn and/or become aware of reading strategies and metacognitive strategies by adult English language learners while making sense of English texts. A mixed method grounded theory (MMGT) in a sequential design (quantitative $\rightarrow$ Qualitative) with a qualitative dominant status was employed to collect and analyze data. In the quantitative phase of this study, data were collected by administrating a background questionnaire and the Survey of Reading Strategies (SORS). Data collected by these tools were statistically analyzed with descriptive analysis and one-way Analysis of Variance. In the qualitative phase of this study, data were collected through retrospective miscue analysis (RMA) and semi-structured interviews. Data collected by these methods were coded in order to verify reading patterns among participants.

Quantitative results demonstrated that second language learners from different language backgrounds and English proficiency levels perceived the use of reading strategies differently. Qualitative results demonstrated that Saudi-Arabian second language learners tend to transfer their reading strategy in relying on small grain size units while reading in English. These results bring a new perspective to the second language reading field by demonstrating that second language learners from different language backgrounds apply 
reading strategies differently based on their initial reading development in their first languages.

KEYWORDS: second language reading, psycholinguistic grain size theory, miscue analysis, retrospective miscue analysis 
LEARNING ABOUT AND BECOMING AWARE OF READING STRATEGIES AND METACOGNITION IN ENGLISH BY ADULT SECOND LANGUAGE LEARNERS

ALINE BIAZOTTO ANDRÉ

A Dissertation Submitted in Partial Fulfillment of the Requirements for the Degree of

DOCTOR OF EDUCATION

School of Teaching and Learning ILLINOIS STATE UNIVERSITY 
Copyright 2018 Aline Biazotto André 
LEARNING ABOUT AND BECOMING AWARE OF READING STRATEGIES AND METACOGNITION IN ENGLISH BY ADULT SECOND LANGUAGE LEARNERS

ALINE BIAZOTTO ANDRÉ

COMMITTEE MEMBERS:

Lara J. Handsfield, Chair

Erin Mikulec

Lydia Kyei-Blankson

Alice Y. Lee

Lisya Seloni 


\section{ACKNOWLEDGMENTS}

A page would not be enough to thank all the people who have contributed to my development as a scholar and as a human being. I have started this journey a long, long time ago, and I carry all those who have been involved in my development in my heart with all my love. To my dearest friends from the teaching course (Normal school) who were the first to support me in this long journey of becoming a teacher, to my undergraduate friends, especially Paula Peixoto and Priscila Rodrigues who have always been present to hear my frustrations and ideas regarding education. To Dale Graca who was my first English teacher in Canada. To my professors and friends from Columbus State University who encouraged me to keep studying and improving my knowledge.

I extend my thanks to my adviser, Lara Handsfield who has been with me throughout this painful process. She has always encouraged me and pushed me to think deeply and outside the box. She taught me more than being a scholar and a professor. She taught me to be brave while facing all the problems that life may bring, and always smile even in the most difficult situations.

I am also grateful to my committee members, who provided me with very thoughtful feedback to help me delve into my research. Without them, I would not be able to have the understanding of research procedures and reading in a second language that I have acquired throughout my doctoral program.

Last but not least, to my parents José Carlos Biazotto and Ana Luisa Brito Biazotto and brothers André Brito Biazotto and Alexandre Brito Biazotto who have always loved and protected me. I would also like to thank my extend husband's family who has always been there for me regardless of what I needed.

I dedicate this dissertation to my best friend and loving husband, Mauro for his constant and persistent support and his belief in me even when I did not believe in myself. 
And to my son Davi, who makes me smile with my whole soul with his sweetness and his curiosity in unveiling his surroundings.

A. B. A. 
ACKNOWLEDGMENTS

CONTENTS iii

TABLES viii

FIGURES $\quad$ x

CHAPTER I: INTRODUCTION 1

Statement of the Problem 3

$\begin{array}{ll}\text { Research Questions } & 4\end{array}$

Conceptual and Theoretical Underpinnings $\quad 5$

$\begin{array}{ll}\text { Reading Strategies } & 6\end{array}$

$\begin{array}{ll}\text { Reading Skill } & 7\end{array}$

$\begin{array}{ll}\text { Metacognitive Awareness } & 7\end{array}$

$\begin{array}{ll}\text { Metalinguistic Awareness } & 7\end{array}$

$\begin{array}{ll}\text { Theoretical Framework } & 7\end{array}$

$\begin{array}{ll}\text { Psycholinguistic Grain Size Theory } & 9\end{array}$

$\begin{array}{ll}\text { Psycholinguistic Theory of Reading } & 10\end{array}$

$\begin{array}{ll}\text { Sociocultural-Historical Theory } & 12\end{array}$

$\begin{array}{ll}\text { Retrospective Miscue Analysis } & 14\end{array}$

$\begin{array}{lr}\text { Summary } & 15\end{array}$

$\begin{array}{ll}\text { Outline of Subsequent Chapters } & 15\end{array}$

$\begin{array}{ll}\text { CHAPTER II: REVIEW OF LITERATURE } & 17\end{array}$

$\begin{array}{ll}\text { Reading Wars Debates } & 18\end{array}$

$\begin{array}{ll}\text { Psycholinguistic Grain Size Theory } & 19\end{array}$

$\begin{array}{ll}\text { Research on L2 Reading } & 21\end{array}$ 
Research with Arabic Speakers in English Reading

Miscue Analysis and Retrospective Miscue Analysis on L2 Reading

The Arabic Language

Summary

CHAPTER III: METHODOLOGY 37

$\begin{array}{ll}\text { Overview } & 37\end{array}$

$\begin{array}{ll}\text { Research Paradigm } & 38\end{array}$

Mixed Method Grounded Theory $\quad 41$

$\begin{array}{ll}\text { Methods } & 44\end{array}$

$\begin{array}{ll}\text { Research Settings } & 44\end{array}$

$\begin{array}{ll}\text { Participants for Phase } 1 & 46\end{array}$

$\begin{array}{ll}\text { Participants for Phase } 2 & 48\end{array}$

Data Collection $\quad 53$

Background Questionnaire and Survey of Reading

$\begin{array}{ll}\text { Strategies (SORS) } & 53\end{array}$

$\begin{array}{ll}\text { Retrospective Miscue Analysis } & 55\end{array}$

$\begin{array}{ll}\text { Semi-Structured Interviews } & 58\end{array}$

$\begin{array}{ll}\text { Data Analysis } & 61\end{array}$

Background Questionnaire and SORS for Phase 1 61

SORS for Phase 2 62

$\begin{array}{ll}\text { Miscue Analysis } & 63\end{array}$

$\begin{array}{ll}\text { Retrospective Miscue Analysis } & 67\end{array}$

$\begin{array}{ll}\text { Interviews } & 70\end{array}$

$\begin{array}{ll}\text { Data Analysis Integration } & 70\end{array}$

$\begin{array}{ll}\text { Trustworthiness and Authenticity } & 71\end{array}$ 
$\begin{array}{ll}\text { Subjectivity and Reflexivity } & 72\end{array}$

$\begin{array}{ll}\text { Ethical Considerations } & 73\end{array}$

$\begin{array}{ll}\text { Limitations } & 73\end{array}$

$\begin{array}{ll}\text { Summary } & 74\end{array}$

CHAPTER IV: QUANTITATIVE RESULTS AND ANALYSIS 76

$\begin{array}{ll}\text { Overview } & 76\end{array}$

$\begin{array}{ll}\text { Demographic Background of Participants } & 77\end{array}$

Research Question 1: What Are the Types of Reading Strategies

That Adult English Learners from Spanish, Asian languages,

Arabic, and Kazakh First Languages (L1) Perceive as the Most

Frequently Used Reading Strategies While Reading English Text?

And to What Extent Does the Frequency of Reading Strategies

Perceived Differ Significantly by Language Background?

Research Question 2: What Are the Reading Strategies That Adult

English Learners at Different English Proficiency Levels

(Beginning, Intermediate, and Advanced) Recognize as the Most

Frequently Used While Reading English Text? And to What

Extent Does the Frequency of Reading Strategies Perceived Differ

$\begin{array}{ll}\text { Significantly by Proficiency Levels? } & 91\end{array}$

$\begin{array}{lr}\text { Focus Group SORS } & 98\end{array}$

$\begin{array}{ll}\text { Summary } & 100\end{array}$

CHAPTER V: QUALITATIVE RESULTS AND ANALYSIS 103

$\begin{array}{lr}\text { Overview } & 103\end{array}$

Participants' Views as Readers and Participants' Views of the

$\begin{array}{ll}\text { Reading Process } & 104\end{array}$ 
$\begin{array}{ll}\text { Miscue Results } & 105\end{array}$

$\begin{array}{ll}\text { Substitution } & 115\end{array}$

$\begin{array}{ll}\text { Partial Omission } & 123\end{array}$

$\begin{array}{ll}\text { Omissions } & 124\end{array}$

$\begin{array}{ll}\text { Partial Insertions } & 125\end{array}$

$\begin{array}{ll}\text { Insertions } & 126\end{array}$

$\begin{array}{ll}\text { Substitution/Pronunciation } & 127\end{array}$

$\begin{array}{ll}\text { Mispronunciations } & 128\end{array}$

L1 Phonological Knowledge 131

L1 Phonotactic Knowledge 131

$\begin{array}{ll}\text { Overgeneralization } & 132\end{array}$

$\begin{array}{ll}\text { Syntactic and Semantic Acceptability } & 133\end{array}$

$\begin{array}{ll}\text { Self-Corrections } & 136\end{array}$

$\begin{array}{ll}\text { Azim } & 136\end{array}$

$\begin{array}{ll}\text { Casper } & 138\end{array}$

$\begin{array}{ll}\text { Haddad } & 139\end{array}$

$\begin{array}{ll}\text { Fadil } & 141\end{array}$

$\begin{array}{ll}\text { Emir } & 142\end{array}$

$\begin{array}{ll}\text { Repetitions } & 144\end{array}$

Retrospective Miscue Analysis and Interviews' Findings 145

Research Question 3: What Reading Strategies Do Adult English

Learners Have to Learn and/or Become Aware of in Order to Make

Sense of English Texts? Of Those, Which Ones Are Most

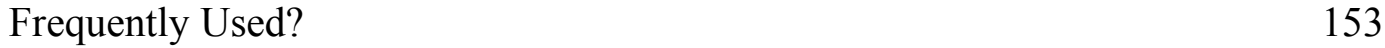

Achieving Comprehension 153 
Research Question 4: How Do Adult English Learners Understand

Their Own Reading Strategies and Metacognitive Awareness?

Role as a Reader

L2 Reading Challenges

Summary

Summary of Findings

Research Question 1

Research Question 2

Research Question 3

Research Question 4

Limitations

Implications for Practice

Implications for Research

Final Thoughts 


\section{TABLES}

Table

Page

1. 2.1 Vowelled and Unvowelled Arabic 32

2. 3.1 Key Dimensions of Mixed Method Designs 44

3. 3.2 Focal Group Participants' Demographics 48

4. 3.3 Participants' Interviews and RMAs 60

5. 4.1 Descriptive Analysis Based on First Language 84

6. 4.2 Comparison of Reading Strategies by L1 Background 91

7. 4.3 Comparing Different Language Backgrounds (using Post Hoc Test) 91

8. 4.4 Descriptive Statistics Based on L2 Proficiency 93

9. 4.5 Comparison of Reading Strategies by Proficiency Level 98

10. 4.6 Descriptive Statistics - Focal Group 99

$\begin{array}{lr}\text { 11. 5.1 Text Features } & 107\end{array}$

$\begin{array}{ll}\text { 12. 5.2 Descriptive MA by Participants } & 108\end{array}$

$\begin{array}{ll}\text { 13. } 5.3 \text { Miscues by Text } & 114\end{array}$

$\begin{array}{ll}\text { 14. 5.4 Percentage of Miscues by Participants } & 135\end{array}$

$\begin{array}{ll}\text { 15. 5.5 Azim's Self-Correction for Text } 1 & 137\end{array}$

$\begin{array}{ll}\text { 16. 5.6 Azim's Self-Correction for Text } 2 & 138\end{array}$

$\begin{array}{ll}\text { 17. 5.7 Casper's Self-Correction for Text } 1 & 138\end{array}$

18. 5.8 Casper's Self-Correction for Text $2 \quad 139$

19. 5.9 Haddad's Self-Correction for Text $1 \quad 140$

20. 5.10 Haddad's Self-Correction for Text $2 \quad 140$

21. 5.11 Fadil's Self-Correction for Text $1 \quad 141$

22. 5.12 Fadil's Self-Correction for Text $2 \quad 142$

23. 5.13 Emir's Self-Correction for Text 1 
24. 5.14 Emir's Self-Correction for Text 2

25. 5.15 Miscues/Text

26. 5.16 RMA-Themes, Categories, and Grounded Codes

27. 5.17 Interview - Themes, Categories, and Grounded Codes 
FIGURES

Figure

Page

1. 4.1 Time in US in Weeks 78

2. 4.2 Reader's Perspective $\quad 79$

3. 4.3 English Reading Challenges 80

4. 4.4 L1/L2 Reading Similarities $\quad 81$

5. 4.5 L1/L2 Reading Differences $\quad 81$

6. 4.6 Easy Genre $\quad 82$

7. 4.7 Difficult Genre $\quad 82$ 


\section{CHAPTER I: INTRODUCTION}

As a child, I was always interested in language acquisition even though I was not aware of it. During my childhood, I was surrounded by different languages and cultures due to my multicultural background. In addition, Brazil has received many immigrants throughout human history due to wars around the world. Thus, having contact with so many cultures and languages is part of Brazilians' everyday life, either through hearing languages other than Portuguese or through experiencing culturally-related misunderstandings.

My personal interest in languages and cultures increased as I started studying other languages at the university level. This opportunity opened my eyes to how languages and cultures increase our understanding of the world as well as expanding our knowledge as human beings. This initial awareness of the power of language made me anxious. Like Faust $^{1}$, I was thirsty for acquiring knowledge about different languages and cultures. This thirst motivated me to travel to other countries.

My travelling brought me to the United States. While my initial knowledge of the English language was sufficient to communicate on an everyday basis, it was still insufficient when I decided in 2010 to pursue an academic career. It was only when I started taking classes at doctoral level in 2013 that reading struck me as a very difficult task. This difficulty with reading pushes me to reflect on my reading process in languages other than Portuguese and English. By revaluating my own reading process in German, Spanish, and Italian, I realized that my textual understanding depended not only on the reading strategies that I was frequently using while reading Portuguese, but also on the acquisition of new reading strategies. For instance, I had to learn that knowing the endings of each case in German would help me to understand the grammatical function of each word so that I could crack the

\footnotetext{
${ }^{1}$ Goethe, J. W. (1992). Faust: Eine Tragödie. Erster Teil. Reclam.
} 
code and start making sense of German texts. In Spanish and Italian, I would have to be careful with grammatical structures, which send me warnings about sentences that "infringe" on my Portuguese grammatical knowledge. These red flags make me use reading strategies such as rereading sentences and/or adjusting my reading speed to assure comprehension. These strategies are not very common while reading in Portuguese.

Personal difficulties with English reading encouraged me to look closely to English reading as a second language. Many theories have been developed to explain the reading process, including psycholinguistic theory (K. Goodman, 2014), informational processing (Gough, 1972), the construction integration model (Kintsch, 1998), interactive model (Rumelhart, 1994), and social constructivist theory (Berger \& Lukermann, 1966), among others.

I understand comprehension as a complex activity, which is influenced by several factors, including linguistic knowledge (word identification, grammar, pragmatics) (Bernhardt, 2011; Ellis, 2008; Goodman, 2014; Koda, 2005, 2007) psychological factors (attitude, motivation, and memory) (Dörnyei \& Ryan, 2015; Gardner, 2010; Masgoret \& Gardner, 2003; Noels, Pelletier, Clément, \& Vallerand, 2003) and sociocultural knowledge (Vygotsky, 1978). Furthermore, comprehension is achieved through a transactional process in which the reader interacts with the text to construct meaning from the text (Rosemblatt, 1994). In this process of comprehending the text, a reader's cognitive and social knowledge are equally important, and they occur simultaneously (Bernhardt, 2011).

Second language (L2) reading has initially been explored from a first language (L1) perspective. That is, $\mathrm{L} 1$ reading research studies have been initially used as a base to further knowledge about second L2 reading. By contrast, this study builds on cross-linguistic studies, which advocate the idea that each language imposes the need to learn specific reading 
strategies in order for readers to achieve their ultimate goal, which is deep textual comprehension.

\section{Statement of the Problem}

Several researchers (Cummins, 2007; Goldenberg, 2011; Gunning, 2013; Jiménez, 1997; Koda, 2005, 2007; Nation, 2001; Zhang, 2010) have investigated the potential of reading strategies and metacognitive awareness to enhance reading comprehension among L1 and L2 learners. These studies have demonstrated that both reading strategies and metacognitive awareness are essential for comprehension, while supporting language development. Regarding the use of reading strategies and metacognitive awareness, most of these studies, have assumed that: (i) L2 learners come to the L2 reading situation with a toolkit of reading strategies to draw on while reading, and (ii) L2 learners are aware of the use of such strategies to achieve reading comprehension.

As a language learner who has learned to read in different languages, I sought to find out if English language learners have to learn and/or become aware of reading strategies. This would support better comprehension of English texts given that all languages have their cultural and linguistic particularities, which may influence the development of reading strategies that are necessary to comprehend texts in English.

Cross-language research has also shown that there are variances in the consistency of how phonology is represented in orthography. For instance, Spanish and Italian have a transparent connection between the spoken language and the writing system (Ziegler \& Goswami, 2005, 2006). As a result, learners may be able to rely more on the phonemes while reading in those languages (Goldenberg, Tolar, Reese, Francis, Ray Bazán, \& Mejía-Arauz, 2014). Those languages are more transparent, and readers can rely on small grain size units. However, there are languages such as English and French in which the phonologyorthography connection is not so transparent. As a result, learners have to rely more on rimes 
and whole word recognition than on phonemes. These grainsize variances result in the development of different reading strategies by learners (Ziegler \& Goswami, 2005, 2006).

There are several research studies examining the importance of reading strategies and metacognitive awareness in supporting L2 reading comprehension. However, these studies have not investigated whether or not adult English learners need to learn new reading strategies and/or become aware of additional reading strategies that are essential in understanding English texts, but that are non-essential for reading in their L1. The purpose of this study is to investigate the strategies adult English learners have or need to learn in order to comprehend English texts and their level of awareness of these strategies. It is the assumption of this study that adult L2 learners acquire a significant number of reading strategies in their educational process within their L1. As a result, they become independent readers who can successfully apply reading strategies to comprehend a text. Within this assumption, adult L2 learners already bring some reading strategies to the table while reading any text. However, it is not certain that these strategies are adequate to render English text meaningful.

\section{Research Questions}

In order to explore the complexities of second language reading comprehension among adults reading English as an additional language, I asked the following questions:

1. What are the types of reading strategies that adult English learners from Spanish, Asian languages, Arabic, and Kazakh first languages (L1) perceive as the most frequently used reading strategies while reading English text? And to what extent does the frequency of reading strategies perceived differ significantly by language background?

2. What are the reading strategies that adult English learners at different English proficiency levels (beginning, intermediate, and advanced) recognize as the most 
frequently used while reading English text? And to what extent does the frequency of reading strategies perceived differ significantly by proficiency levels?

3. What reading strategies do adult English learners have to learn and/or become aware of in order to make sense of English texts? Of those, which ones are most frequently used?

4. How do adult English learners understand their own use of reading strategies and metacognitive awareness?

Gaining knowledge about factors such as reading strategies and metacognitive awareness that might support or impede L2 comprehension is important for adult L2 learners who venture out in pursuing a higher degree in a language other than her/his own native language. It also influences L2 teachers who may or may not spend pedagogical time teaching strategies that are already well-known and used by adult L2 learners. College professors may also benefit from this research given the increased population of L2 learners at college level (Bernhardt, 2011; Koda, 2007). Knowing how to assist L2 learners might assist college professors to more successfully address their L2 learners' strengths and needs in order to achieve a deep comprehension of academic texts. This study is also important for the field of L2 research because it may shed light on our understandings of L2 reading. As a result, more appropriate and nuanced L2 reading models may be proposed.

\section{Conceptual and Theoretical Underpinnings}

In order to avoid misconceptions, it is important to first define the understanding of our main topic. In this study, the concept of reading is understood as the ability to gain access "to meaning from printed symbols" (Ziegler et al., 2006, p. 429) and as a sociocultural activity that is influenced by time and context (Alexander \& Fox, 2013; Bloome, 1985) and which "takes place in complex human relationships" (Bloome \& King-Dail, 1997, p.610) that 
are influenced by different ideologies (Freire, 2005). In this process, the reader adopts an active and sociopolitical role in constructing meaning from the text.

In this section, I clarify the terms reading strategy, reading skills, metalinguistic awareness and metacognitive awareness, as well as placing them in the context of second language acquisition research. This clarification is necessary due to the lack of consistency in the use of such terms in the field of literacy research (Afflerbach, Pearson \& Paris, 2008a, $2008 \mathrm{~b}$ ), and in order to elucidate how such terms are operationalized in this research study.

\section{Reading Strategies}

Reading strategies refers to the deliberate use of reading strategies to make sense of texts. In other words, expert readers are aware of the use of reading strategies when they apply them and the reason for applying them (Afflerbach et al., 2008a, 2008b). Some examples of reading strategies include: reading slowly, rereading, breaking down compound words, inferencing, summarizing, identifying cognates, translating, among others (Ellis, 2008; Mokhtari \& Perry, 2008; Mokhtari, Sheorey, \& Reichard, 2008). Cognitive research has identified these strategies by investigating how knowledge is represented in our minds as well as how such representations enable the use of that knowledge (Rumelhart, 1980), and more specifically by examining how the reader's mind works in order to understand a text. Nevertheless, it is important to remember that the use of reading strategies may not always be effective if not tailored to readers' specific reading goals, sociopolitical context, and the linguistic elements of the languages involved. Thus, some readers may not apply useful reading strategies to achieve comprehension (Bernhardt, 2011). Also, not all readers will find the same strategies equally useful for the same text. This may happen due to lack of knowledge of a more appropriate reading strategy to achieve comprehension and/or lack of prior knowledge of the content being read. 


\section{Reading Skills}

Reading skills refer to the automatic application of reading strategies (Afflerbach et al., 2008a, 2008b). As a result of this automaticity, readers are not aware of their use. This unawareness may pose challenges to research given that it is difficult for the reader to verbalize when they are using such tacit reading strategies, and for the researcher to observe their use.

\section{Metacognitive Awareness}

Metacognitive awareness refers to the awareness of the use of reading strategies and the constant monitoring of comprehension by the reader to enhance their comprehension (Ellis, 2008; Handsfield, 2016; Ruddell \& Unrau, 2013). In other words, readers are aware when meaning breaks down and when they need to use strategies in order to render the text meaningful. It also refers to the readers' knowledge about themselves as readers as well as the reading process. Furthermore, the readers' understanding that each task should be approached differently in order to achieve comprehension (Sheorey \& Mokhtari, 2008).

\section{Metalinguistic Awareness}

Metalinguistic awareness refers to the ability to manipulate and reflect on language (Homer, 2009; Koda \& Zehler, 2008; Nagy \& Scott, 2013). While reading, readers use their metalinguistic awareness to comprehend a text. In other words, successful readers know about the structural regularities of the language, social situations, and context. Differences across languages might influence L2 readers' capabilities to comprehend a text given that readers' metalinguistic awareness may be different or more or less sophisticated in different languages.

\section{Theoretical Framework}

A theoretical framework outlines the researcher's assumptions regarding the phenomena under investigation and ideas about how those phenomena should be studied. 
Merriam (2001) pointed out that "the theoretical framework is derived from the orientation or stance that you bring to your study" (p. 45). It is a roadmap that will guide the researcher through the study, and it is applied in order to understand a phenomenon (Anfara \& Mertz, 2006). I characterize my theoretical framework broadly as sociocognitive (Atkinson, Churchill, Nishino \& Okada, 2007; Bateson, 1972; Lemke, 1997). I draw on a range of theoretical perspectives that account for information processing, meaning construction, as well as sociocultural influences on reading comprehension. A sociocognitive framework assumes that "L2 development takes place through such articulated mind-body-world activity" (Atkinson, 2002, p. 69). More specifically, I understand language learning as encompassing a cognitive process that takes place in a social environment. In this intertwined process, L2 learners are actively engaged in making sense of the world. More specific to reading, learners are actively engaged in making sense of the text. The cognitive and the social are not dichotomous, but rather they are integrated to form one circuit (Atkinson et al., 2007; Bateson, 1972; Lemke, 1997). In this framework, knowledge is seen as a continuous process, which changes depending on time, context, and participants who are active learners in constructing and shaping knowledge by using their cognition and the cultural tools available to them (Vygotsky, 1978).

In this section, I outline my theoretical framework for this study. Within a broad sociocognitive framework, more specific theories and theoretical commitments inform my methodology and interpretations. First, I summarize psycholinguistic grain size theory (Ziegler et al., 2006), which explains L1 reading based on the relationship between size and regularity of graphophonemic units of languages. Second, I discuss psycholinguistic theory (Goodman, 2014) and examine retrospective miscue analysis as both an assessment and research tool to further our understandings of L2 readers' metacognition and strategy use. Finally, I argue that it is important to elicit and hear L2 readers' voices regarding their 
reading comprehension processes in order to develop a more comprehensive framework for strategic second language reading.

\section{Psycholinguistic Grain Size Theory}

While studying the development of reading acquisition across languages, Ziegler and Goswami (2005) noticed that children from different first languages apply different phonological recoding processing depending on the phonology-orthography relationships in each language; that is, depending on the psycholinguistic grain size of each language. As a result, learners will apply different reading strategies to cope with the text. For instance, children learning Greek, German, Italian or Spanish rely on grapheme-phoneme strategies because their correspondences are consistent. In German the phoneme /ai/ will always be represented with the grapheme [ei] like in Eigelb /argclp/ (yolk) and Einblick /arnblik/ (insight). Whereas children learning English which has a less consistent grapheme-phoneme correspondence have to rely on large grain size units such as word families, letter patterns, and onsets and rimes (Ziegler et al., 2006).

Although psycholinguistic grain size theory may not look at all elements of the complex act of reading (e.g., syntax, lexical features), it elucidates how languages vary in the consistency in which phonology is represented orthographically (Ziegler et al., 2006). In other words, this theory offers a first glance at the differences of the phonologicalorthographic connections across languages and how these differences affect reading. This theory takes a further step in explaining the reading process outside of the English-centric view given that most information-processing theories do not attend to cross-linguistic differences and how they impact reading and reading instruction. Stated differently, grain size theory clarifies that the differences in the grain size of language result in "developmental differences in the grain size of lexical representation and accompanying differences in developmental reading strategies" (Ziegler et al., 2006, p. 3, emphasis added). Thus, speakers 
from different L1s learn different reading strategies influenced by their languages. The development of reading strategies impact readers' comprehension (Ellis, 2008; Koda, 2005, 2007; Jiménez 1997; Jiménez, Garcia \& Person, 1995, 1996).

Understanding the problems that L1 readers may face while acquiring the written system is essential for teachers as they provide empirical foundations upon which to design instruction. While considering the learning process of L2 readers, it becomes clear that the psycholinguistic grain size theory may bring some insights to the field given that L2 learners may have to learn additional reading strategies imposed by the L2 or they may have to, at least, become aware of additional reading strategies to improve/raise their comprehension. While considering this hypothesis, it becomes evident how grain size theory must be taken into consideration while focusing on the teaching of L2 reading as well as L1 reading.

Therefore, it is important to be aware of phonological-orthographic grain sizes in different L1s and whether such differences impact the development of additional reading strategies needed to read in English or the need to become aware of reading strategies in English that may not be of great value in a reader's L1.

\section{Psycholinguistic Theory of Reading}

This theory was proposed by Kenneth S. Goodman in an attempt to shift from the idea that reading was simply a process of accurate word recognition to a view of reading as a process of meaning construction in which the reader actively applies strategies to create meaning from the text (Bernhardt, 2011). Reading is seen as a selective process, "guessing game", in which the reader uses language cues and prior understandings to construct meaning from printed text. In this guessing game, thought and language are intertwined in order to select efficient cues to "produce guesses which are right the first time" (K. Goodman, 2014, p. 104). 
By analyzing miscues made during reading-aloud by students, "Goodman was discovering: that readers put their own meaning into the text while comprehending and that what they understand can alter what they "see" (printed words). The more readers are involved in comprehending, the higher the probability of increased miscues" (Bernhardt, 2011, p. 23). In other words, miscues are not random, but the result of a complex transaction between the reader and the text. In this transaction, readers use information available to them, such as graphophonic, syntactic, semantic, and pragmatic cues (K. Goodman \& Y. Goodman, 2014; Y. Goodman, Watson \& Burke, 1987).

Miscue analysis offers both teachers and researchers insights into an individual's reading processes (K. Goodman et al., 1987). It is an assessment designed to analyze how students draw on language cueing systems to make sense of printed material (K. Goodman, 2014). According to Goodman (2014), miscue analysis is a window into the reading process because it offers “insights into the reader's knowledge of language cueing systems and his or her proficiency in using reading strategies. Miscues also provide evidences that the readers make the text more accessible and meaningful to themselves" (Y. Goodman, 2014, p. 206).

Goodman et al. (1987) assert that miscue analysis has advantages over other assessment instruments because it provides both a quantitative and a qualitative analysis. This is important because reading assessment tools that are only quantitative interpret all errors as having equal weight (i.e., strategies such as self-corrections and reread are seen as problematic). However, a qualitative analysis looks at miscues as an opportunity to understand the strategies that the reader brings to the text while attempting to construct meaning from it. In this sense, miscue analysis is process oriented rather than product oriented. As Goodman et al. (1987) explained:

When diagnoses instrument results only in quantitative analysis, all errors have equal weight because exactness is the goal; deviations are considered random and irrational, 
and the reader is expected to attack written material in a prescribed manner. Because quantitative analysis examines surface behavior, strategies such as self-correction and regressions, which are in fact necessary for proficient reading, are often treated as problematic instead, qualitative analysis, on the other hand, evaluates why miscues are made and assumes that they derive from the language and thought that the reader brings to the written material in the attempt to construct meaning from reading. Such analysis allows the teacher/researcher to interpret and understand what miscues reveal about the reading process (p. 4).

In other words, the quantitative portion of miscue analysis evaluates miscues using a quantitative scoring system by analyzing the ratio between a reader's errors and accuracy rate. This analysis enables teachers/researchers to determine at what level a reader is comprehending a text which can be at the frustration level in which accuracy is less than $89 \%$; the instructional level in which accuracy is between $90 \%-94 \%$; and the independent level in which accuracy is higher than 95\% (Gunning, 2013; Rasinski \& Nageldinger, 2016). The qualitative portion of miscue analysis adds more information to this initial analysis regarding the reader's uses of the cueing systems. In this process, different types of miscues may occur, such as substitution, (partial) omission, (partial) insertion; repetition, mispronunciations, and self-corrections. These miscues indicate the reading strategies that the reader uses to make sense of the text while considering their semantic and syntactic acceptability.

\section{Sociocultural-Historical Theory}

Other important aspects of reading that gained attention at the end of $20^{\text {th }}$ century were the social and cultural aspects of reading. Researchers' interests in the social aspects of reading converged into social-cultural historical theory (Handsfield, 2016; Rogoff, 1995, 2003). This theory builds on Vygotsky's work, which assumes that human 
development/learning takes place through social interaction and culturally- and historicallysituated activity (Vygotsky, 1978). During social interactions novice learners are scaffolded by experts (more experienced peers, teachers) into particular communities. In a reading context, scaffolding through the use of language and other cultural tools (e.g. signs and symbols) mediates the construction of textual meaning. It also mediates peoples' learning of how to be a reader in culturally and historically situated ways (Rogoff, 1998; Vygotsky, 1978). As Bloome (1985) pointed out, reading is a social process that involves people “establishing social groups, ways of interacting, gaining or maintaining status as social position as well as acquiring culturally appropriate ways of thinking, problem solving, valuing, and feeling" (p. 134, emphasis added). That said, it seems likely that any language impacts and is impacted by social context, so this is a two-way street (Street, 2003). Given that each language has its own ways to mold/shape thinking, reading constitutes "culturallybound ways of thinking” (Bloome, 1985, p. 138).

This understanding of reading as a set of social and cultural practices is essential in the context of second language acquisition. The unexpected responses to the text (i.e. miscues), in that readers' reading does not follow the linguistic norms of the language or render the text meaningful suggest the reader's attempt to engage "in the expected social and cultural practices" (Bloome et al., 1997, p. 612). However, L2 learners' more limited social and cultural knowledge of the target language and culture may result in "unexpected" reading responses because L2 learners may rely on social and cultural knowledge tied to their L1, which may be less effective in an L2 reading situation (Bloome et al., 1997). In light of this, language plays an important role in enabling cognitive development and intermediating learning (Tracey \& Morrow, 2012; van der Veer, 2014) given that language is used to communicate and explore ideas (Smagorinsky, 2013). 


\section{Retrospective Miscue Analysis}

Retrospective miscue analysis (henceforth RMA) expands miscue analysis by bringing the reader's voice to the analysis. It follows the initial steps of miscue analysis in which the reader reads a text aloud while the teacher/researcher takes notes of the reader's miscues. The reading is recorded for further analysis to determine patterns of miscues and the reader's strategy use. These steps are followed by an interview with the reader in which s/he works together with the teacher/researcher to notice and explain his/her own miscues.

RMA was developed through the work of Chris Worsnop (1996), who was trying to share his work of Reading Miscue Inventory (henceforth RMI) with teachers in the 1970s (Y. Goodman et al., 2014; Worsnop, 1996). While working with teachers in workshops about miscue analysis, Worsnop noticed that teachers had gained insights into the reading process as well as shifting their attitudes towards learners' miscues from correctors to encouragers. This shifting in teachers' attitudes resulted in more pedagogical emphasis on meaning construction rather than surface level correctness (Worsnop, 1996).

These positive results with teachers encouraged Worsnop to work with students who could benefit from the analysis of their own miscues. His work with seventh, eighth and ninth graders had a significant impact on students' attitudes towards reading, students' positive identity as readers, and their overall reading comprehension (Worsnop, 1996). These initial procedures were the stepping stones for what came to be known later as 'retrospective miscue analysis, in which readers are involved in the analysis of their own reading processes (Goodman et al., 2014).

RMA is a designed instructional strategy that engages readers in the process of analyzing and evaluating the quality of their own oral reading miscues. In this process, readers increase their awareness of the reading process while listening to the recording of their reading aloud, and being involved in the discussion of the probable reasons for their 
own miscues (Goodman et al., 2014; Goodman \& Market, 1996; Wurr, Theure \& Kim, 2008).

Although RMA, like miscue analysis, embodies a cognitive constructivist approach, the social interaction animates aspects of sociocultural-historical theory, and the notions of self-assessment, self-awareness, agency, and voice. Therefore, the involvement of readers in the understanding of their own miscues takes place in a reading event that scaffolds novice readers in constructing meaning from printed text. This reading event involves readers on a cognitive activity as well as a socialcultural activity particularly when an RMA event requires cross-cultural communication.

\section{Summary}

Within this theoretical framework, second language reading is seen as a complex activity that involves cognitive and social factors. Within this view, it is necessary to pay special attention to the process of reading by the reader as well as the context in which reading is taking place. Therefore, in this study, I focus on exploring the different reading strategies and metacognitive strategies that adult English learners apply while making sense of English text by applying the Survey of Reading Strategies (SORS), conducting retrospective miscue analysis (RMA), and interviewing adult English learners.

\section{Outline of Subsequent Chapters}

In chapter two, I review the research literature on reading in a second language by focusing on five elements. First, I explain how research on grain size theory has demonstrated the need to be informed by the range of perspectives offered by several reading theories while teaching to read. Second, I review research in the area of reading comprehension in L2. Third, I briefly review research on RMA with L2 learners. Fourth, I present some information about how the Arabic language is similar to and differs from 
English. Finally, I present the limitations of the existing literature and explain how my proposed study begins to fill these gaps.

In chapter three, I outline the research design and methodological frame I used to conduct the study. First, I summarize my research paradigm, explaining the ontological (what is true) and epistemological (methods of figuring out those truths) stances in which I approach this study. Second, I explain the tools I used to collect data. I finish chapter three by presenting a discussion of how I analyzed the data.

In chapter four, I present my quantitative results by addressing the first and second research questions. The results are discussed in relation to the literature in the area of second language acquisition regarding the administration of the Survey of Reading Strategies (henceforth SORS).

In chapter five, I present the qualitative results by addressing the third and fourth research questions. This chapter then focuses on the reading strategies that six Saudi-Arabian male L2 learners were using and were aware of using while reading English texts.

Furthermore, it presents those reading strategies that Saudi-Arabian speakers were not aware of using while reading English texts, which may have impeded their comprehension on occasion.

In the final chapter, chapter six, I review and summarize the findings in relation to all of my research questions as well as the significance of this study for teaching and research in L2 reading. I finish the chapter by discussing the limitations as well as the implications of this study for the field of second language teaching and research on second language acquisition. 


\section{CHAPTER II: REVIEW OF LITERATURE}

According to information processing models, reading is a complex activity that activates several parts of our brain due to its multisensorial character, and due to the need to activate several skills such as decoding and comprehension in order to make sense of the text (Dehaene, 2010; Ellis, 2008; Hruby \& Goswami, 2013; Koda, 2007). Besides being a complex brain activity, the complexity of reading is also influenced by other factors, such as its sociocultural and sociopolitical contexts (Lantolf, 2000), including the purpose of specific reading events, the manner or situation in which a person reads (silent or aloud reading; alone or with others), the level of difficulty of the text or the genre (Alexander \& Fox, 2013; Bloome, 1985).

This complex activity is intensified when reading in a second/foreign language (henceforth L2/FL) because there are more variables to take into consideration, such as the influence of L1 on L2 and vice-versa, the influence of L2 knowledge on L2 reading (Bernhardt \& Kamil, 1995; Bialystok, 2007; Cummins, 1991; Ellis, 2015, 2008; Lanauze \& Snow, 1989), and psychological factors such as motivation, self-confidence, learning and cognitive styles, creativity, anxiety, among others (Cui, 2008; Dörnyei, 2015; Guo \& Roehrig, 2011; Koda, 2005; Nergis, 2013).

Research into L2 reading can also be very complex as it may be driven by many different factors. For instance, at the cognitive level, word recognition, syntax, prosody, metacognition, bilingualism, and multilingualism are all elements that have a direct impact on reading. At the social level, reading is impacted by motivation, positionality, agency, age, social class, among other factors. Hence, studies conducted from sociocultural and cognitive theoretical perspectives have informed our understanding of reading in a second language and moved the field forward. These studies have also presented incongruous findings. 
In the following pages I review the research in three major areas: (1) how grain size theory elucidates our theoretical understandings regarding teaching reading; (2) L2 reading comprehension; and (3) RMA with L2 learners. Finally, I end this chapter by identifying gaps in the literature to further inquiry and propose research methodologies that might fill the gaps in the $\mathrm{L} 2$ reading literature

\section{Reading Wars Debates}

For decades, there have been debates about how reading is best taught. These multiple debates suggest the existence of the "Reading Wars", in which theorists have fiercely argued between the benefits of using the phonics-based approach versus a whole language approach to reading instruction(Pearson, 2004). In these "battles", theorists have articulated conflicting conceptualizations of the process of reading and of the role of the reader.

In the phonics approach, teaching reading is understood as a mechanical act in which readers start at the bottom of the reading process by learning the names and shapes of letters, the consonants sounds, followed by simple and then more complex vowel correspondence. A phonics approach makes intensive use of basal books to achieve its goal in teaching phonics. These series are organized to make the process of learning to read easier by breaking the complex task into component skills in order to develop vocabulary and reading skills in a determined sequence. In the phonics approach, readers have a more passive role in acquiring the knowledge of phonics taught by the teacher (Kantrowitz \& Hammill, 1990) given that the emphasis is on the text and not on the reader's prior knowledge and language abilities (Gunning, 2013).

On the other side of the reading wars, there are those who believed that the best approach to teaching reading involves a whole language approach, whereby the meaning of words should be figured in relation to the context in which they appear (Pearson, 2004). Hence meaning is considered more important than word decoding. In this top-down 
approach, the reader is in the center of the reading process because $\mathrm{s} /$ he brings meaning to the text by using her/his background knowledge and language abilities. Therefore, the whole language approach advocates the use of authentic materials which can be more appealing to readers (Kantrowitz et al., 1990). In this approach, phonics and phonemic awareness are taught in context. Consequently there is not an overemphasis on these skills through the use of decontextualized drills.

More recently, this battle has been seen as an "artificial dichotomy." Increasingly, there is a consensus that it is important to have a balance between these two approaches (Kim, 2008). Furthermore, a balanced approach encompasses the importance of phonemic awareness, phonics, fluency, vocabulary, and comprehension (National Reading Panel, 2000).

\section{Psycholinguistic Grain Size Theory}

Ziegler's and Goswami's (2005) theory supports the idea that a balanced approach for teaching reading is important. Through a cross-language study, Ziegler and Goswami demonstrated that depending on the grain size of each language, different instructional approaches need to be taken in consideration while teaching reading. Thus, students may use more adequate reading strategies to access the meaning of the text.

The orthographic depth theory has defined the relationship between the graphophonic system in a continuum between deep and shallow written language systems, in which a shallow orthographic system would be classified as having a high consistency and regularity between the letter-sound relationship. A deep orthographic system, on the other hand, would be classified as having a low consistency and regularity between the graphophonic system. English has a deep alphabetic orthographic system with complex syllable onsets (ex. street CCCV:C; through CCCVV as opposed to Spanish CV); unclear syllables boundaries (ex. the syllabic structure of ea+ting) (Alvarez, Carreiras, \& Taft, 2001; Gottardo \& Mueller, 2009); 
and morphological relationships between root words and derivatives (e.g., nation, national) at the cost of grapheme-phoneme correspondences (Seymour, Aro, and Erskine 2003). As a result, native English speakers pay close attention to onset-rime segments (DeCara \& Goswami, 2003). These English language characteristics result in moderate availability and lower consistency in the graphophonic system (Gottardo et al., 2009).

Psycholinguistic grain size theory added to the orthographic depth theory by examining children at the early years of their learning reading process. It emerged from a massive study that looked at reading in different languages such as Greek, Finnish, German, Austrian German, Italian, Spanish, Swedish, Dutch, Icelandic, Norwegian, French, Portuguese, Danish, and Scottish English (Goswami, 2010). By examining the different processes that children went through while learning to read, researchers have noticed that the differences in the consistence of the graphophonic system of each language poses a problem for reading development (Ziegler et al., 2006). In this daunting research study, scientists from 14 European countries examined how children at foundation years (children between 5-7 years old) would progress in their learning to read in the continuum of shallow-deep orthographic system by applying three sets of lists to measure letter knowledge, word identification, and decoding of simple nonwords. Findings demonstrated that learning to read in a deep orthographic system produced a wider disparity in the rate of initial development than does learning to read in a shallow orthographic system (Seymour et al., 2003). As a result, children from different orthographic system would have to rely on different grain sizes to learn to read. Languages with a very inconsistent orthographic systems compel children to develop a multiple grain-size mapping in which they may rely on different strategies to learn to read such as phonemes, rhymes, onset-rimes segments, word families, among others. Consequently, greater development flexibility and extra cognitive architectures are needed (Abu-Rabia \& Sanitsky, 2010; Goswami, Gombert, \& Barrera, 1998). 
Several studies have used psycholinguistic grain size theory to explain reading acquisition in other languages than the initial study that generates this theory (Éva \& Réka, 2013; Haigh, Savage, Erdos \& Genesse, 2011) as well as the phonological advantages of bilingual learners learning a third language (Abu-Rabia et al., 2010). However, there is a gap in the literature applying this theory to research on second language reading among adult learners. If children develop different reading strategies depending on the grain size of their first language, could this mean that adult learners would have to develop and/or become aware of different reading strategies to read in English?

\section{Research on L2 Reading}

Past research in the field of reading in a second language has focused its attention on factors that affect comprehension, such as phonemic awareness, vocabulary awareness, syntax awareness, metacognitive awareness, role of L1 in L2, and psychological factors such as motivation, self-determination and anxiety. Hypothesis such as The Linguistic Interdependence Hypothesis (LIH) and The Linguistic Threshold Hypothesis (LTH) have been used as a good parameter to explain some of the research results. The LIH claims that L1 knowledge can be transferred to L2 situations regardless of the level of L2 knowledge. The LTH claims that L2 learners need to attain a certain level of L2 knowledge in order to transfer their L1 knowledge into L2 contexts (Cui, 2008; Gail, 2006).

These research studies have furthered our understandings of second language reading, but their findings have also contributed to contradictions in the field of English as a Second Language (ESL) reading. For instance, Gail (2006) investigated the influence of L1 and L2 grammar and reading skills on ESL reading comprehension in 55 adults, all native Spanishspeakers and English language learners. Four tests were applied to participants who were categorized as traditional readers (high linguistic academic development) and non-traditional readers (low linguistic academic development). The data analyses demonstrated that there 
was a significant correlation between Spanish reading skills and English reading skills as well as English grammar and English reading. Nevertheless, the study did not find any direct correlation between Spanish grammar and English reading. These results suggested that L1 grammatical knowledge does not directly influence reading in L2. Although L1 grammatical knowledge may not directly influence L2 reading, the researcher noted that the awareness that L2 grammar differs from L1 grammar may facilitate comprehension. The participants' metalinguistic awareness demonstrated that they may have already accommodated the specific properties of English language and its writing system by understanding the structural regularities of the language, social situations, and context. An example of this would be understanding that adjectives and nouns in English and Spanish are ordered differently within a sentence. This knowledge could help Spanish L2 learners, and other L2 learners whose L1 follows the same grammatical rule, figure out the functions and meanings of words. The results of this study supported the LIH, which posits about the transferability of L1 reading knowledge to the L2 situation as well as the LTH, which posits about the importance of L2 skills, in this study grammar, impacting comprehension.

Guo and Roehrig's (2011) study followed the same lines as Gail's study. The researchers sought to investigate the role of general language knowledge (metacognitive awareness) and L2 knowledge (vocabulary awareness and syntactic awareness) on English L2 reading comprehension. Six different types of tests (two vocabulary tests; two syntactic awareness tests, and two comprehension tests) and two metacognitive awareness questionnaires were applied with 278 Chinese college students. Participants were identified as less skilled readers and more skilled readers based on their TOEFL scores. Results demonstrated that L2 specific knowledge (syntactic awareness and vocabulary) was a stronger predictor for reading comprehension while comparing to metacognitive awareness. These findings support the LTH hypotheses, which posits the need of acquiring a certain 
level of L2 knowledge to enable any L1 knowledge transference to a L2 situation (Bernhardt \& Kamil, 1995). These results suggest that participants may not have yet reached the needed threshold in L2, otherwise they would be able to transfer their metacognitive awareness of reading to the L2 situation. Nevertheless, these results contradict other studies (Auerbach \& Paxton, 1997; Jiménez, Garcia, \& Pearson, 1996; Sheorey \& Mokhtari, 2001), which have attested to metacognitive awareness as contributing to reading achievement among bilingual or $\mathrm{L} 2$ readers.

Regarding the L2 specific knowledge of Guo and Roehrig's (2011) study, the results demonstrated that vocabulary knowledge had a stronger correlation with reading comprehension when compared to syntactical knowledge. Nevertheless, these results should be interpreted with caution because tests are not always representative of reality, such as participants' ability to use the target language in real situations. Therefore, it would be important to expand the study to evaluate participants' language abilities in authentic situations as well as in different sociocultural environment. Moreover, to confirm these claims, it would be necessary to further investigate this issue given that several facts could have influenced such results. For instance, the syntax tests could have been at a much higher level of difficulty than the L2 learners' (participants) levels at the time of the study. The results could also be influenced by the order in which the tests were applied. Considering that learners had to respond to six tests in one sitting, they could have been fatigued while taking the last tests. The results could also be influenced by researcher biases that seeped into the study design given that it is a common assumption that vocabulary knowledge plays an important role in reading.

Nergis (2013) also sought to investigate factors, such as depth of vocabulary knowledge, syntactic awareness, and metacognitive awareness, that influence L2 reading comprehension in English. Four tests (one for reading comprehension, one for depth of 
vocabulary, one for syntactic awareness, and one for metacognitive reading strategies) were applied with 45 Turkish undergraduate students. The results demonstrated that depth of vocabulary was not a predictor for reading comprehension, whereas syntactic awareness and metacognition were valid predictors for reading comprehension. These results support Gail's (2006) study regarding the importance of syntactic awareness in reading comprehension, but contradict Gail's and Guo's (2011) studies given that metacognitive awareness was considered an important predictor for reading comprehension.

Studies such as those described above continue to produce different results. It is important to investigate whether the results are different because of (i) the different populations that have been assessed, (ii) background language differences, (iii) measurement tools (tests), (iv) procedures, and/or (v) these studies have not considered specific metacognitive and reading strategies needed to read in English given that each language has its own language set of specific rules (Koda, 2007). Furthermore, these studies seem to assume that all L2 learners share the same metacognitive and reading skills. This would contradict psycholinguistic grain size theory, which has demonstrated that children from different language backgrounds rely on different strategies in order to successfully learn to read in their L1.

These studies have focused on the same factors influencing L2 reading - vocabulary knowledge, syntax knowledge and metacognitive awareness, but with different population samples. All participants from these studies were at college level; however, each study involved participants that speak a different L1s - Gail's study tested Spanish-speakers, Guo's study tested Chinese speakers, and Nergis's study tested Turkish speakers. These differences may have influenced the results because these languages may prompt different metacognitive and reading skills necessary to read in participants' L1s, but that may not facilitate reading in L2/English. It is also necessary to take into consideration the fact that reading comprehension 
will vary in relation to the task at hand (Koda, 1998), the genre of the text and the type of questions raised to check comprehension, all of which affect results. Another important factor to bear in mind is that readers bring their previous knowledge to the text in order to make sense of it (Anderson \& Pearson, 1984; Koda, 2005, 2007) as well as the different purposes and stances (Rosenblatt, 1994).

In addition to the previous concerns, the amount of time that participants had contact with English may also have influenced the studies' results. None of these studies described participants' daily contact with English, the motivations that led participants to pursue learning English, and how motivated they were in developing or demonstrating their knowledge. Although these studies mentioned the importance of speaking English, they did not describe the historical, cultural, and social contexts of the participants and their environments with respect to speaking English, which are both crucial in students' final outcomes regarding participants' general language knowledge (metacognitive awareness) and L2 knowledge (vocabulary awareness and syntactic awareness).

Cui (2008) reviewed the literature regarding the LIH and the LTH and found that most of the research in this area advocated in favor of the LTH. In practice, this would mean that L2 teachers should first support the development of some L2 linguistic knowledge in order to achieve L2 reading proficiency instead of emphasizing the application of their L1 reading knowledge to a L2 situation. This study is important in that it provides an overview of the different types of research studies that have been conducted and their major findings. However, it is important to be cautious while interpreting the study's findings even though it is just a review of literature in the English reading as a second language because the study only brings a summary of the literature regarding the use of these two hypotheses (the LTH or LIH while reading) without offering the perspective to look at the reading process in an L2 from a different lens and/or frame. 
Cui's (2008) study may illustrate that despite the focus on quantitative research, the creation of this dichotomy (LIH versus LTH) may have encouraged a scenario in which researchers seek to determine who is right and who is wrong, without considering the possibility that each theory may lead to different outcomes. Therefore, research may also be used as a mirror to what we may have been overlooking and, therefore, provide evidence to what we may need to deliberate further. It may be the case that these two hypotheses alone are not sufficient for understanding L2 reading comprehension.

Zhang's (2010) study took a different direction than the previous studies. It applied a qualitative design, which gave voice to L2 learners. The study analyzed reading comprehension in an L2 language situation from the learners' perspectives. By interview 20 Chinese college students, Zhang was able to verify students' perceptions about the factors that affected their reading comprehension in L2. His study also focused on L2 learners' metacognition, which was framed as a dynamic system that supports the achievement of success. Interview analyses demonstrated that less successful L2 readers tended to focus on the importance of linguistic factors such as vocabulary and grammar knowledge in order to comprehend a text. More successful readers, however, pointed out that in order to comprehend a text, it is also important to have some knowledge of different genres, and L2 culture embedded in the text. This revealed that L2 college learners who were successful readers were aware that texts reflect the culture of the target language, which is important to consider in order to achieve high levels of reading comprehension. It is also important to emphasize that Zhang was working with both novice and expert readers. The former seem to subscribe to a more bottom-up reading model while the latter subscribe to a more top-down reading and/or an interactive reading model.

Zhang's (2010) findings are interesting in that they demonstrate the social aspects of reading, which do not feature in the previous studies mentioned in this review. By bringing 
students' voices to the issue, Zhang called attention to the fact that collecting data by only using tests may not be enough to understand the factors influencing L2 reading comprehension. Moreover, Zhang's study indicated that L2 learners may not be able to demonstrate their linguistic knowledge and/or metacognitive awareness in tests, but they may be able to convey their thinking during interviews. Nevertheless, it is important to stress that interviewing participants separately from the reading process or activity itself may also be insufficient given that students have to recall reading procedures such as reading strategies used in different reading events. RMA can help fill this gap given that students talk about their reading process while dealing with the task of trying to make sense of the text.

\section{Research with Arabic Speakers in English Reading}

Studies with Arabic speakers have also applied a quantitative design to identify which elements of English language may influence and/or challenge Arabic speakers. These studies have applied surveys and/or tests to evaluate participants' English abilities. For instance, Malcolm's (2009) study applied the SORS with 160 Arabic medical students to verify their perceived use of reading strategies. The results demonstrated that participants have a tendency to prefer problem-solving reading strategies (PSRS), which refer to localized strategies to solve comprehension breakdowns (ex. rereading, adjusting speed, guessing word meaning, etc), over support reading strategies (SRS), which refer to strategies to aid reader's comprehension (ex. dictionary use, highlighting, take notes, etc), and global reading strategies (GRS), which refer to metacognitive awareness (ex. previewing the text, use textual features to support comprehension, etc). The study also found that less proficient students use translation more often than more proficient students.

Alsheikh and Mokhtari's (2011) study investigated the perceived use of reading strategies by Arabic speakers in English and in Arabic by applying the SORS with ninety Arabic speakers. Results demonstrated that Arabic speakers tend to use more PSRS and SRS 
when reading in English than in Arabic although no statistical difference was reported between the use of reading strategies in English and Arabic. Furthermore, participants reported using more reading strategies in English than in Arabic. This result could be due to the fact that participants were more aware of their use of reading strategies in English than in Arabic given that the former may be more demanding, while the latter may be more automatic knowledge (Kintsch, 1998). This result demonstrates that L2 learners are more aware of cognitive processes in an L2 situation (Hosenfeld, 1978). This result is also consistent with the fact that learning a foreign/second language is "conscious and deliberate from the start" (Vygotsky, 1986, p. 206)

Alsheikh and Mokhtari's (2011) study took a step further by incorporating a thinkaloud (qualitative design) to understand the actual use of reading strategies by Arabic speakers when reading in English and Arabic. The results of this study demonstrated that differences between participants' perceived use of reading strategies and the actual use of reading strategies. Results also demonstrated that participants used fewer reading strategies than they previously reported in the SORS.

Think-aloud protocols are very useful to collect data. However, they may force participants to use strategies that are not part of their everyday reading given that they may be aware of the researcher's goal in collecting a specific kind of data. A miscue approach may be better for collecting data regarding L2 learners' use of reading strategies because participants may be operating at the automatic level while reading aloud. As a result, more authentic data may be collected given that L2 learners may apply the most frequent reading strategies while reading English. An important aspect of Alsheikh's et al. (2011) study is that it demonstrates the need for more mixed method studies, which triangulate data in order to contradict and/or support results, so that more accurate claims about reading in a second language can be made. 


\section{Miscue Analysis and Retrospective Miscue Analyses on L2 Reading}

While there is an extensive literature base on the use of MA and RMA with first language learners and children at a young age, only a few studies have been conducted with adult L2 learners. These studies have produced important findings about L2 reading. This is especially true with respect to adult L2 readers' positive self-identities regarding reading in an L2, and their deep understanding of the reading process in both their L1 and L2.

Keh (2017) sought to investigate how miscues analysis made by eight adolescent English learners (AELs) between the age of 14 and 17 and attending public high school in the U.S support a better understanding of English learners' reading process and inform teaching practice. The participants' level of English language proficiency varied from beginning to advanced, and they came from different L1 backgrounds in which they were proficient speakers. Each participant read one narrative text of his/her choice, and then retold it. After reading, RMAs was conducted with each participant. Participants' miscues revealed partial vocabulary knowledge, nonnative phonology, and developing grammar knowledge. Some miscues were influenced by attention and learning experiences. Findings demonstrated that AELs' oral reading differences were not always miscues, but derivations from participants' interlanguage; and as native speakers, AELs were also able to construct meaning despite miscues. Furthermore, partial word meaning understanding contributes to AELs' comprehension.

Wang's and Gilles's (2017) study explored the reading process of two adult Mandarin-speaking English learners enrolled in undergraduate programs in the U.S. while reading two simplified Chinese texts (one fiction and one non-fiction) and two English texts (one fiction and one non-fiction). Findings demonstrated that RMA supported (i) the awareness of participants' metacognition about their reading process; (ii) confidence to read; 
(iii) the acquisition of agency; (iv) uncovered reading strategies; and (v) learning about the English language.

Mikulec (2015) sought to investigate what miscue analysis reveals about L1 and L2 reading by comparing reading in English (native language) and Spanish (second language) of two native English speakers and proficient Spanish speakers enrolled in a graduate program in applied linguistics. Findings from miscue analysis of the reading of two folktales (one in English and one in Spanish) demonstrated that miscues differed in each language, and miscue in L2 reading impacted readers' comprehension.

Kim (2010) conducted a study to investigate the beliefs of five Korean L2 learners regarding the effects of Korean L2 learners' reading beliefs while reading L1 (Korean) and L2 (English) as well as their evaluation of themselves as L1 and L2 readers; how participants' beliefs affect their reading process, and how their beliefs changed after participating in RMA sessions. Participants chose to read three texts which could be narratives or non-fiction for each language. Results showed that participation in RMA sessions contributed to participants' changes in their beliefs about reading while gaining confidence in their reading skills.

Wurr, Theurer, and Kim (2009) conducted research that examined the benefits that proficient adult L2 readers would gain in becoming more aware of their reading processes by collecting data through RMA. Data analyses of three multilingual adult English L2 learners from different L1 (Korean, Spanish, and Italian) demonstrated that RMA sessions support the development of English reading by increasing awareness of universal reading processes (syntactic, semantic, graphophonic and pragmatic), confidence in participants' L2 reading abilities, and metacognitive awareness and L1 knowledge.

These studies demonstrated that MA and RMA with adult L2 learners have supported learners' improvement of their self-identities as L2 readers as well as the development of 
reading skills. However, very few of such studies have been conducted, and data have not been collected to demonstrate whether L2 learners have to learn and/or only become aware of reading strategies relevant to read in English. An important aspect that should be considered while conducting MA and RMA are the cultural differences that may emerge during these events given that readers from different cultural backgrounds may approach such activities differently. These events happen in specific sociocultural-historical contexts, which shape the event, and consequently, data collection. Indeed, this was the case in the present study.

\section{The Arabic Language}

The purpose of this section is to describe the differences of Arabic language when compared to English. This is necessary because participants for phase two were all SaudiArabians who speak Arabic as their first language. Research studies have already explored the difficulties that Arabic speakers face when learning to read in their first language (AbuRabia,1995; 1997; 1998; 1999; 2001). These difficulties may be due to (i) vowelled and unvowelled Arabic; and (ii) diglossia. The process of acquiring Arabic reading start with novice readers learning vowelled Arabic, which is a shallow system (Frost, Katz, \& Bentin, 1987) with expert readers reading unvowelled Arabic, which is an opaque system.

In vowelized Arabic, short vowels are represented with diacritics above or below the consonants (See Table 2.1 below). As a result, readers can rely on grapheme-phoneme strategy while decoding words. Thus, vowelled Arabic is considered a shallow/transparent orthographic system. In other words, the phoneme-grapheme relationship is more transparent because of its consistency and regularity. This system is used with children to start their reading development (Taouk \& Coltheart, 2004).

In unvowelled Arabic, diactric marks are absent and the reader has to restore the missing phonological information to identify the word. Unvowelled Arabic is considered deep/opaque (Taouk et.al, 2004). In other words, phoneme-grapheme relationship is not clear 
and/or transparent because of inconsistencies and irregularities. Thus, knowledge of the morphological structure of a word (recognition of the word-pattern) is important to decoding unvowelled words (Saiegh-Haddad \& Geva, 2008). Using context to identify word meaning is another important skill to be developed while reading in unvowelled Arabic (Abu-Rabia, 1999; 2001; Ryan \& Meara, 1992).

Table 2.1

Vowelled and Unvowelled Arabic

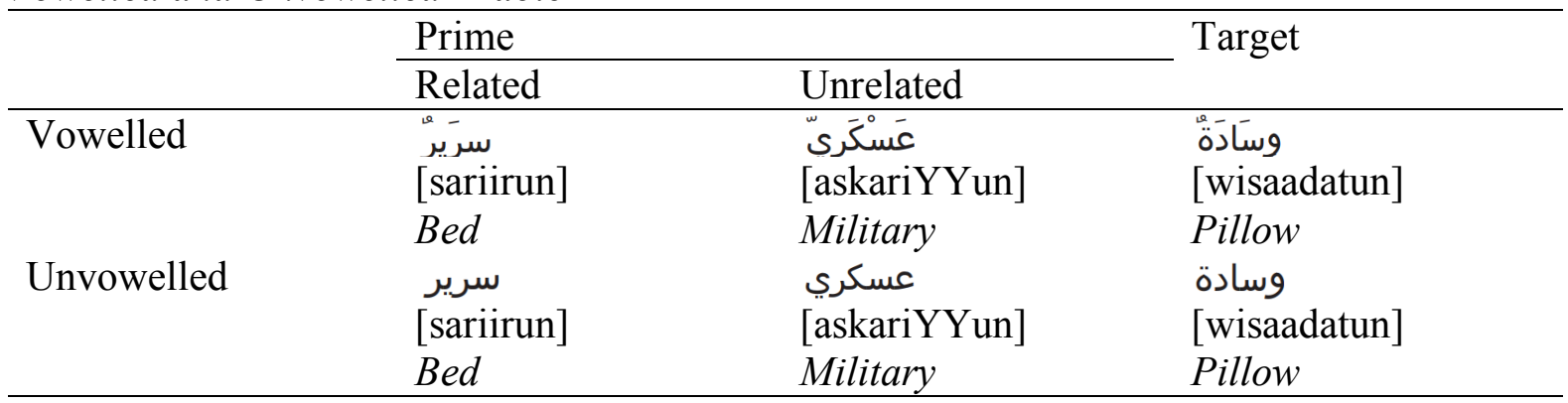

Note. For each example, the word in Arabic, a phonological transcription using IAP symbols and an English gloss are indicated; Retrieved from "Vowelling and semantic priming effects in Arabic" by Mountaj, N., Yagoubi, R. E.,. Himmi, M., Ghazal, F. L., Besson, M., \& Boudelaa, S., 2015, International Journal of Psychophysiology, 95(1), 46-55.

Diglossia refers to the use of two varieties of the same language in different social conditions/contexts. Arabic speakers have contact with the local spoken vernacular variety in their everyday lives while their initial contact with Modern Standard Arabic (MSA) may happen only in the school environment. This variation of Arabic is used for formal situations such as speeches, formal writing, and religious sermons. These two varieties are characterized by different phonological systems and different phonotactic constraints (i.e., limitations in different language about sound sequences). The two varieties share some lexical items, which can have an identical phonological representation "as small as a single inflectional vocalic alteration (ex. /same! a/ versus /seme!/ - he heard), or as big as an alteration of both the phonemic and the syllabic structures of the word (ex. /qalb/ versus /Galeb/ - a heart)" (Saiegh-Haddad, 2003, p. 434). There are also differences at the syntactic and morphosyntactic levels. For instance, MSA follows the verb, subject, object order (VSO) 
while colloquial Arabic tends to follow a subject, verb, object order (SVO) (Saiegh-Haddad, 2003). Diglossia may impact reading development given that children have to learn a new variety that resembles local language only in some aspects.

This situation is also common in the US schools. Children from different English dialects such as AAVE, Chicano English, Gullah, Louisiana Creole, among other dialects may have their first contact with standard English only at school settings (Wolfram \& Schilling-Estes, 2006). Nevertheless, Share and Daniels (2016) defend that Arabic diglossia is more complex than any English dialect.

While learning to read in English as a second language, Arabic speakers may appear to have more difficulties than other L2 learners due to the differences in the two language systems (Hayes-Harb, 2006; Ryan \& Meara, 1992). Specifically, English and Arabic differ in their orthographic systems (deep English X shallow vowelized Arabic) as well as their morphological systems (shallow English X deep Arabic) (Saiegh-Haddad et al., 2008).

Alphabetic orthographic systems (like Spanish, Czech, Turkish, English) differ in the regularity and consistency of graphophonic relationships. Shallow/transparent orthographies have a consistent and regular relationship between oral language and written language (ex. Italian). As a result, readers rely more on grapheme-to-phoneme strategies, that is, they rely on reading strategies at small grain size units. Deep/non-transparent alphabetic orthographic systems (English), by contrast, have an inconsistent and irregular relationship between grapheme and phonemes. As a result, readers rely on large grain size units such as rimes or morphemes. In the case of the Arabic language, readers initially rely on small grain size as they learn to read in a vowelled system. However, in unvowelled systems, readers rely on large grain size units as morphemes (Saiegh-Haddad \& Geva, 2008).

The morphological system refers to "the degree to which sounds (and the meaning) of a complex word may be recovered from its internal morphological structure" (Saiegh-Haddad 
et al, 2008, p. 484). For instance, English utilizes a linear morphological system by adding affixes to a free stem at the beginning (prefix) and/or end (suffix) of a word so a new word can be created as in 'unemployment'. Thus, readers may be able to comprehend word meaning by analyzing its morphemes. In this example, the word maintains its phonological and orthographic form. However, this is not always the case in English, which can undergo phonological and/or orthographic shifts (ex. sign X signal - phonological shift; easy X easily - orthographic shift; decide X decision (phonological-orthographic shift). Arabic, however, is a non-linear morphological system with a highly synthetic root-based morphology, in which word formation requires the fixation of two linguistic units: (i) a consonantal root; and (ii) a word-pattern such as in kataba (he -wrote), kitaab (book), maktaba (library), maktab (office) (Hayes-Harb, 2006). These affixations result in unique lexical items. Therefore, morphological awareness, that is, the ability to manipulate and reflect on the morphological structure of a word, also contributes to the ability to link a word to its meaning in Arabic.

Considering that consonants are more prominent in Arabic than in English given that consonants provide information to access the Arabic lexicon, Arabic speakers need to recognize that vowel information distinguishes words in English. Words such as bat, bit, bite, boot, and bait may all look the same for an Arabic reader because they all have the same consonant structure (B -T) (Hayes-Harb, 2006).

According to Koda $(1995,1996)$, reading strategy transference from L1 to L2 is common among L2 learners. In other words, native language influences the use of reading strategies in L2 reading (Bernhardt, 2011). However, reading problems may emerge when L1 and L2 employ different orthographies, such as Arabic and English (Caravolas \& Bruck, 1993; Geva, 1995; Koda, 1995). Therefore, it is essential to help Arabic learners to pay close attention to vowels in English, and to highlight how they provide information to distinguish lexical items. 


\section{Summary}

Research in the field of second language reading has been focusing on factors such as phonemic awareness, vocabulary awareness, syntax awareness, metacognitive awareness, the role of L1 in L2, and psychological factors such as motivation, self-determination and anxiety that may impact L2 reading comprehension. These research studies have some communalities such as the use of the linguistic threshold hypothesis or the linguistic interdependence hypothesis to explain results. These hypotheses have contributed to furthering our knowledge in the field of second language. Nevertheless, it is also important to bring different perspectives and/or look at the issue through different lenses so that a deeper understanding of reading in a second language can be achieved. In this sense, psycholinguistic grain size theory encourages researchers to observe how the development of lexical representations and metacognitive strategies in readers' first language may impact reading in a second language from an orthographic perspective.

All the studies mentioned in this review of literature indicate that vocabulary knowledge, syntax knowledge, metacognitive awareness, and self-identity as readers are important aspects of the L2 reading process. However, these studies do not explore whether L2 learners have to learn additional reading strategies or become aware of reading strategies that are imposed by the English language to understand English texts. Based on these studies, it appears that research in the field of L2 reading assumes that L2 learners use similar metacognitive strategies while reading in an L2 regardless of their L1. If our L1 imposes the development of our lexical representation and metacognitive strategies, then it stands to reason that L2 learners from different L1s would use and/or be aware of different metacognitive strategies to make sense from the text. For instance, L2 Arabic learners rely on consonants to identify/decode a word in English without noticing that they should also look closely to vowels to differentiate items such as paint, pint, point. This skill is acquired earlier 
by native speakers of English. If this is the case, it is necessary to conduct research to fill this gap in the literature in order to verify what reading strategies are necessary for L2 adult English readers to read English texts.

The review of literature also revealed that few studies have applied RMA to study adult L2 reading. Furthermore, it showed a positive impact of using RMA with adult L2 learners regarding changes in their own perspective as readers. Using RMA with Arabic speakers is a useful research tool to explore the different linguistic aspects of Arabic as compared to English.

Furthermore, the majority of these studies on L2 reading applied quantitative designs, which collect data by tests and/or surveys. Although these are valuable tools to collect data, they may not provide a whole picture of the issue of reading in a second language. A few mixed method studies in the area have already demonstrated that data from quantitative methods may contradict data from qualitative methods suggesting a discrepancy between data, and participants' inaccuracy in describing precisely their perceived and actual use of reading strategies by only answering surveys and tests. Therefore, the field is in need of mixed method studies that can offer better and deeper insights into L2 reading in English. In light of this, this study examines the need of learning and/or becoming aware of reading strategies by adult L2 learners by employing a mixed method to collect data. The following chapter explain my procedures in data collection and data analysis. 


\section{CHAPTER III: METHODOLOGY}

“Your research participants' actions and statements teach you about their worlds, albeit sometimes in ways they may not anticipate" (Charmaz, 2013, p.51)

\section{Overview}

This chapter details my methodology for data collection and analysis and establishes the positionality that I bring to this study as a researcher and an adult L2 reader of English. As aforementioned, previous studies on L2 reading comprehension have not attended to the fact that L2 learners may have to learn new reading strategies and/or become aware of reading strategies necessary for reading English texts. Hence, this study attempts to fill these gaps in the research by answering the following research questions:

(RQ 1) What are the types of reading strategies that adult English learners from Spanish, Asian languages, Arabic, and Kazakh first languages (L1) perceive as the most frequently used reading strategies while reading English text? And to what extent does the frequency of reading strategies perceived differ significantly by language background?

(RQ 2) What are the reading strategies that adult English learners at different English proficiency levels (beginning, intermediate, and advanced) recognize as the most frequently used while reading English text? And to what extent does the frequency of reading strategies perceived differ significantly by proficiency levels?

(RQ 3) What reading strategies do adult English learners have to learn and/or become aware of in order to make sense of English texts? Of those, which ones are most frequently used?

(RQ 4) How do adult English learners understand their own use of reading strategies and metacognitive awareness? 
To describe the most used reading strategies perceived, the need to learn and/or become aware of reading strategies by L2 learners as well as L2 readers' understanding of their own reading strategies and metacognitive awareness while reading English texts, I employed a mixed method grounded theory in a sequential design (Quantitative $\rightarrow$ Qualitative) with a qualitative dominant status (Creswell \& Clark, 2011; Johnson \& Onwuegbuzie, 2004; Shannon-Baker, 2016).

\section{Research Paradigm}

According to Johnson and Christensen (2004), a philosophical paradigm is a set of "assumptions, values, and practices" that influence the researcher while thinking about and doing research. It is the lens/stance or set of lenses/stances that the researcher uses to make sense of her/his research (Greene, 2008, 2010; Maxwell, 2011; Maxwell \& Mittapalli, 2010; Teddlie \& Tashakkori, 2009). Paradigms include the researcher's ontology (what can or cannot be real), epistemology (what and how we know about reality) and methodologies (methods for seeking knowledge) (Denzin \& Lincoln, 2000; Guba, 1990; Guba \& Lincoln, 1994; Willis, 2007).

Ontology is a philosophical branch concerned with the nature of being, reality and the relationships between the different aspects of society. According to Willis (2007), ontological positions reflect what can or cannot be real, that is, how a researcher defines the nature of the world either externally or internally (Taylor \& Medina, 2013). This worldview influences how researchers place themselves in this reality, and how they relate with their surroundings. Epistemology refers to the issue of what counts as knowledge and knowing. Its focuses on what and how we can know about reality (Willis, 2007), and the relationship between the knower and known (Guba, 1990; Guba \& Lincoln, 1994).

It is important to reflect on one's understanding of the nature of being, truth, and knowledge, and on how we as researchers position ourselves regarding these uncovered 
and/or constructed understandings as these perceptions impact the methodological decisions we make. Bearing this in mind, I came to this research from a postpositivist-constructivist paradigm.

At first glance, these two paradigms may be seen as incommensurable given their distinct ontological and epistemological nature (Guba, 1990; Guba \& Lincoln, 1989, 1990; Johnson, 2011; Maxwell \& Mittapalli, 2010). A postpositivist paradigm assumes an ontological belief that reality exists, but an epistemological belief that reality or natural laws cannot be completely apprehended by researchers/individuals (Guba, 1990; Guba \& Lincoln, 1985, 1994; Onwuegbuzie, Johnson \& Collins, 2009). This paradigm has been most commonly associated with quantitative research designs (Johnson \& Gray, 2010). On the other hand, a constructivist paradigm assumes an ontological belief of multiple realities which are the product of human intelligence. In other words, these realities change depending on each individual. An epistemological belief within this paradigm assumes that these realities are created by the interaction of researchers and participants (Guba, 1990; Guba \& Lincoln, 1989, 1994; Onwuegbuzie et al., 2009). This paradigm has been most commonly associated with qualitative research designs (Johnson \& Gray, 2010).

Although these two paradigms differ in their ontological and epistemological beliefs, there are those who argue that philosophical paradigms do not need to be viewed as incommensurable in order to solve specific problems in theory and research, and that paradigms should be understood as heuristic, conceptual tools (Abbott, 2004; Maxwell at al., 2010). Furthermore, research can and should be informed by one or more paradigms (Greene, 2000). The pluralism of paradigms offers the possibility of working with divergent paradigms in a dialectical approach (Greene, 2007; Johnson, 2008; Teddlie \& Johnson, 2009) to solve tensions, paradoxes and contradictions in order to come to a new understanding of the problem at hand (Greene and Hall, 2010; Shannon-Baker, 2016). Although it is difficult to 
do, taking on multiple paradigms enables a level of reflexivity that might not otherwise be achieved.

It is important to bear in mind that "these lenses are essential for our understanding, but their provided views are fallible and incomplete. Therefore, multiple lenses are needed "to attain more valid, adequate, in-depth knowledge of the phenomena we study" (Maxwell, 2011, p. 29). Furthermore, paradigms should not be seen as static perspectives, but as like fluid perspectives with some overlaps (Freshwater \& Cahill, 2013; Greene, 2007; Greene \& Hall, 2010; Maxwell at al., 2010; Morgan, 2007; Shannon-Baker, 2016).

A postpositivist paradigm supports my understanding that previous research serves as a stimulus for further inquiry which contributes to enlarging our knowledge through empirical research (Greene, 2010). A constructivist paradigm provides me with the understanding that knowledge is socially constructed, that is, that realities may change depending on participants, and on contexts (Lincoln \& Guba, 1985; Willis, 2007). With these paradigms, research does not generate general laws, but rather small theories given that a truth is changeable depending on time, context and participants (Greene, 2010).

Furthermore, a postpositivist-constructivist paradigm grants me the understanding that in an educational setting, findings are constructed from the interactions between the researcher (inquirer) and the participants (inquired) (Lincoln \& Guba,1994). In this context, participants are active learners who use their cognitive and cultural tools to construct and shape knowledge. Similarly, learners take part in society while shaping it and being shaped by it. Therefore, "the constructivist paradigm complements the findings of the postpositivist paradigm by bringing nuances of the learner" (Lincoln \& Guba, 1994, p.113).

The discussion above is needed in order to clarify the implications of endorsing paradigms for a mixed method grounded theory design (Greene, 2008; Shannon-Baker, 
2016), which employs multiple, and sometimes divergent techniques for data collection and analysis. As Johnson (2011) has pointed out:

If you take the MMP (Mixed Method Perspective), you will attempt to systematically dialogue with, engage, understand, respect, and combine/integrate multiple concepts and perspectives (e.g., about meaning, epistemology, ontology, what is "seen," what is important, emic vs. etic viewpoints, etc.). This kind of thinking is dynamic and the thinker is always listening to learn something different, challenging, and new. The thinker is not afraid of difference, contradictions, and lack of certainty ( $\mathrm{p}$.

In other words, researchers using a MMP traverse thorough multiple theories and viewpoints. This multiplicity of theories and viewpoints contribute to an analytical and reflexive analysis of the problem. Hence, this study uses multiple concepts and perspectives by applying a mixed method to access the complexities of reading in a second language.

\section{Mixed Method Grounded Theory}

The mixed method design is desired when either a qualitative design or quantitative design alone prevent us from addressing the complexity of a phenomenon. In this case, mixed method design is required because it provides a deeper understanding of the phenomenon at hand (Creswell \& Plano Clark, 2011; Johnson, McGowan, \& Turner, 2010; Morse \& Niehaus, 2009). According to Johnson and Onwuegbuzie (2004) "a key feature of mixed methods research is its methodological pluralism or eclecticism" (p. 14). This methodological pluralism provides the possibility of mixing different research designs and methods that may initially have been associated with specific research design. For instance, grounded theory has been associated with qualitative design. As a result of housing grounded theory as an 
exclusive qualitative method, the testing of theory has been deemphasized, which is another key feature of grounded theory (Glasser \& Strauss, 1967).

Nevertheless, Glasser and Strauss (1967) have argued that grounded theory would work well with both research designs (quantitative and qualitative) given that it offers analytical strategies for gathering and analyzing data as well as working back and forth between data and theory in order to generate new theories (Johnson et al., 2010). Strauss and Corbin (2008) share a similar understanding, in which grounded theorists can apply quantitative data or combine qualitative and quantitative techniques of analysis. Nevertheless, it is important to bear in mind that grounded theory includes theory generation as well as theory testing (Charmaz, 2010). Furthermore, theory should be grounded in and emerge from empirical data (Johnson, 2010).

Charmaz $(2000,2010)$ suggested two versions of grounded theory (GT): (i) Objectivist (classical GT) and (ii) constructivist based on epistemological foundation. The objectivist GT is based on the work of Glasser and Strauss (1967), Glaser (1992), and Strauss and Corbin (2008). Although there are some disagreements among these scholars regarding the purpose of grounded theory as theory generation (Glaser) or theory testing (Strauss \& Corbin), both endorse a realistic ontology and positivist epistemology (Charmaz, 2010).

Constructivist GT is based on Charmaz's $(2011,2014)$ work, in which reality is seen as multiple, arises from the interactive process between researcher and respondent(s), and depends on cultural, temporal, and structural contexts (Johnson et al., 2010). In this way, grounded theory is used to learn about the world and its participants so that we are capable of developing theory that assists us in understanding the world and its participants. However, such a theory is an "interpretive portrayal of the studies world, not an exact picture of it" (Charmaz, 2014, p. 10). 
Although grounded theory has been incorrectly associated with a specific research design (qualitative), its origins do not suggest that it should be solely used to analyze qualitative data. On the contrary, it could and should also be employed in examining quantitative data. Furthermore, the mix of different methodologies and methods provide us with the best possibilities to answer important research questions (Johnson \& Onwuegbuzie, 2004; Onwuegbuzie, Johnson, \& Collins, 2009; Onwuegbuzie, 2003, 2007; 2010)

As Guba (1990) has pointed out, "if objectivity can never be entirely attained (by human sensory and intellective mechanisms), relying on many different sources makes it less likely that distorted interpretations will be made" (p. 21). Therefore, MM-GT researchers use different data collection techniques from the array of quantitative and qualitative research designs, and to mix them accordingly so that a phenomenon is better described. Nevertheless, it is also important to keep in mind that the different data collection methods should be complementary in their strengths while not overlapping their weaknesses (Creswell, 2014; Johnson \& Turner, 2003).

In this sense, this study used a mixed method grounded theory with a sequential approach (quantitative $\rightarrow$ qualitative) and a qualitative dominant status (Johnson, McGowan, \& Turner, 2010) with an initiation purpose that "seeks the discovery of paradox and contradiction, new perspectives of frameworks, the recasting of questions or results from one method with questions or results from the other method" (Greene, Valerie, \& Grahan, 1989, p. 259). The rationale for this purpose is "to increase the breadth and depth of inquiry results and interpretations by analyzing them from the different perspectives of different methods and paradigms" (Greene et al., 1989, p. 259). Table 3.1 summarizes the key dimensions of this study with respect to this design. 
Table 3.1.

Key Dimensions of Mixed Method Design

\begin{tabular}{cl}
\hline Design Dimension & \multicolumn{1}{c}{ Description } \\
\hline Independence/interaction & $\begin{array}{l}\text { Methods are implemented independently. } \\
\text { Mix happens primarily at the end - drawing } \\
\text { of inferences }\end{array}$ \\
Status & $\begin{array}{l}\text { Qualitative dominance (Unequal) } \\
\text { Timing }\end{array}$ \\
& $\begin{array}{l}\text { Methods are implemented sequentially } \\
\text { (quan } \rightarrow \text { QUAL) }\end{array}$ \\
\hline
\end{tabular}

Note. Adapted from Greene, 2008

\section{Methods}

In order to address the research questions of this study, data collection occurred in two phases. For phase 1, data collection procedures included: (i) Background Questionnaire, and (ii) Survey of Reading Strategies (SORS). For phase 2, data collection procedures included: (i) Miscue Analysis (MA); (ii) retrospective miscue analysis (RMA); and (iii) semistructured interviews with 5 Saudi-Arabian L2 learners.

\section{Research Settings}

I collected data on English language programs established in universities for international students. The main goal of these programs is to prepare international students to take classes at the college level. Therefore, their purpose is in assisting international students to develop academic skills in English. In this context, English grammar, reading, writing, and listening are reinforced as essential components of language.

I first obtained permission from program directors to speak with learners from international language programs from the ISU English Language Institute and the Intensive English Program at the University of Illinois at Urbana-Champaign. These sites were contacted because of their similarities in the teaching of English as a second language, and due to their convenience. Once I obtained permission, I contacted ESL teachers, and then learners during class time to explain the research project and solicit their consent to participate in the project. 
As stated on the program website, Illinois State University’s English Language Institute's program focuses on practical learning and special needs of adult ESL learners (English Language Institute - Academics, n.d.). The program has a communicative approach which asserts that language is acquired in use (Actflorg, 2016; Hadley, 2001). The program offers courses five days a week in reading, writing, speaking, and listening, focusing on developing academic skills. Academic lecture courses conducted by university professors from different areas are also offered by the program. In addition, students are also partnered with native English speaking American students for conversational purposes at weekly meetings.

The classroom teachers described their reading-writing classes as very dynamic classrooms in which communication among learners is a key component. Teachers aim to develop learners' reading fluency and accuracy in comprehension. They explicitly teach reading strategies such as skimming, scanning, inferring, predicting, determining meaning from context, among others. In this environment, learners work individually, in pairs, and in small groups. They are exposed to a variety of texts such as novels, newspaper articles and academic articles, among others.

As stated on the program website, the intensive English program at University of Illinois at Urbana-Champaign (UIUC) (Intensive English Institute - Programs, n.d.) focuses on developing academic skills in English. The program offers classes in reading, listening, speaking, grammar, and pronunciation. There are extra activities such as a Test of English as a Foreign Language (TOEFL) and International English Language Testing System (IELTS) prep groups, a vocabulary group which reinforces curricular vocabulary and learning new idiomatic expressions, and conversational partners which matches students in the program with university students, staff, faculty, and community members interested in meeting students from other countries. 
Students enrolled in these programs are international students from different first language backgrounds. Usually, the ultimate goal of these students is to improve their English skills in order to enroll or succeed at college level. Hence, these programs often enroll students from diverse English proficiency levels who need to pass an English proficiency test (e.g. TOEFL, IELTS) in order to be accepted into university programs.

\section{Participants for Phase 1}

This study aimed to investigate metacognitive awareness as well as specific reading strategies needed to comprehend English texts. Therefore, the basic criteria for the initial selection of participants were: (i) they should be international students to whom English is a second language; (ii) participants should be interested in pursuing programs at the university level so that they would have to develop academic reading skills; (iii) they use English actively for academic purposes given that they pursue either a masters program or an undergraduate program in the United States, as well as for their personal daily usage.

Researchers have to consider the appropriate sample size for the quantitative phase as well as for the qualitative phase. According to Onwuegbuzie and Collins (2007), a sample size should be informed by "the research objective, research question(s), and, subsequently, the research design" (p. 288). Moreover, they suggested that two criteria should be used: (i) the time orientation, and (ii) the relationship between the quantitative and qualitative samples. As stated previously, this is a sequential (quan $\rightarrow$ QUAL) study, and it uses a nested relationship, which implies that sample members selected for the qualitative phase comprise a subset of the participants for the quantitative phase.

For the initial phase of this study, 36 participants were recruited. Participants were recruited at two moments. I first recruited 25 participants from ISU and UIUC during the summer term of 2016. However, due to the low number of participants, it was necessary to have a second person recruiting more participants. Thus, in the fall term of 2017,11 
participants were recruited form ISU English language institute. These participants were all Spanish speakers. Among the 36 participants, 19 were enrolled at ISU - English language institute, and 17 at the UIUC - Intensive English Program. Within this group of participants, 14 participants were women, and 22 were men. At this initial phase, L2 learners demonstrated their willingness to participate in the second phase of the study, which consisted of two interviews and two retrospective miscues sessions.

Sample size is a more crucial issue for qualitative designs because the researcher needs to keep in mind that the sample size should be neither so small so that data saturation, theoretical saturation or informational redundancy is too difficult, nor so big so that a deep, case oriented analysis is too difficult (Sandelowski, 1995). Nevertheless, the sample size should generate some data saturation in order for the researcher to be able to make some inferences regarding the population under study (Onwuegbuzie \& Leech, 2007). Furthermore, the purpose of qualitative studies is in-depth analysis rather than broad analysis (Boddy, 2016), so that insights into a phenomenon are promoted (Onwuegbuzie et al., 2007). Therefore, a homogeneous subset sample was chosen from the pool of participants in the SORS. A homogeneous subset is based on individuals' similarities and/or specific characteristic (Creswell, 2013; Onwuegbuzie et al., 2007).

Besides the initial criteria to participate in the initial part of this study, participants should also fulfill all the following criteria to participate in the second phase of this study: (i) share the same L1 - Arabic; and (ii) have been previously enrolled at college level in their home country. These criteria were necessary in order to verify: (i) whether learners from the same language background would have to learn similar or different reading strategies in order to comprehend English texts; and (ii) to make sure that learners have been in contact with academic texts in their L1. The Survey of Reading Strategies (SORS) was used to confirm that all recruited participants checked all the eligibility requirements of the study. 


\section{Participants for Phase 2}

Participants who answered the SORS demonstrated in their informed consent their willingness to participate in the second phase of the study. Considering participants for phase two, I bore in mind that reading is a complex process, and although L2 readers may share some similarities such as same language background and having being enrolled in college, they also have a range of different reading experiences and life experiences. These elements may result in a great variety of meaning construction and mental representations of texts.

Six participants were drawn from a subset of the original sample. The six participants were at intermediate level, spoken the same first language (Arabic), and shared the same goal to apply for college, either on undergraduate or graduate programs, in the future. The original group consisted of five men, and one women who withdrew after the first reading aloud. So, only data from five male participants were analyzed.

Table 3.2 .

Focal Group Participants' Demographics

\begin{tabular}{|c|c|c|c|c|}
\hline Participant & L1 & Age & L2 Proficiency & Major \\
\hline Azim & Arabic & 24 & Intermediate & $\begin{array}{c}\text { Electrical } \\
\text { Engineering }\end{array}$ \\
\hline Casper & Arabic & 25 & Intermediate & $\begin{array}{c}\text { Electrical } \\
\text { Engineering }\end{array}$ \\
\hline Haddad & Arabic & 30 & Intermediate & $\begin{array}{c}\text { Health } \\
\text { Information }\end{array}$ \\
\hline Fadil & Arabic & 33 & Intermediate & Business \\
\hline Emir & Arabic & 24 & Intermediate & Biochemistry \\
\hline
\end{tabular}

Note. $\mathrm{L} 1$ = first language; $\mathrm{L} 2=$ second language

Participants shared a similar understanding of the reading process. For instance, they believed that their role as a reader was to read every single word so that they would be able to understand the text. This is a very passive view of reading, in which the reader's job is to depict meaning from the text. In light of this, the reader may not engage in any reading strategy to raise her/his comprehension (Afflerbach et al., 2008a, 2008b). Participants for phase 2 also shared the perspective that they were not "very good" readers in English because 
they could not pronounce all the words. Participants' perspectives demonstrate a strong belief that to be "good" at a second/foreign language, it is important to use the target language with a native like fluency. In other words, they should become close to native speaker otherwise they believed they had failed in their learning process. Cook (1999) demonstrates that this concept of becoming the ideal native speaker is problematic because native speakers also vary in their competencies and repertoires of using their own language. Furthermore, this concept challenges the idea that one variety of the same language is better than another (Cook, 1999). In other words, this concept oppresses those who do not speak the standard language while disregarding the fact that in today's world English is a lingua franca (Crystal, 2003).

Both their perspectives on the reading process and on their roles as a reader started to change at the end of our last RMA. Nevertheless, their MA indicated that they were being strategic and active readers even though they were unable to articulate that view at the beginning of the study and/or to value their efforts to understand a text.

Azim was the first participant for phase 2. He graduated from the university with an Electrical Engineering degree. His goal was to apply to a graduate program in the same subject area. He did not see himself as a good reader because he was not interested in reading. He explained that he would only read for school purposes, that is, to get a higher grade and/or to have a better understanding of the subject. Nevertheless, he was very committed in improving his English reading skills which would support his language development in other language areas such as writing, speaking, as well as expanding his vocabulary. In other words, he was committed to his learning process and to developing more effective reading skills to attain a deep comprehension. He also explained that developing his reading skills would probably help him get a high score on TOEFL. Although he was committed in developing his reading skills, he also recognized that there was room for 
improvement in his commitment to his reading development. For instance, he thought that he should develop a reading routine so that he would become a better reader given that he believed that the more someone reads, the better s/he becomes as a reader. His perspective about his reading changed at the end of our last RMA. He started to realize that he does not read every single word on the paper. Furthermore, he assumed and/or became aware of his active role as a reader in which he brings meaning to the text as well. RMAs assisted Azim to be more aware of the reading strategies that he was applying while reading in order to comprehend a text. His awareness resulted in a very positive identity as a reader, and increased his self-efficacy, and motivation to read. Azim was the only participant in phase two to demonstrate an interest in a language other than English and Arabic. He clarified that he was also trying to learn some Spanish with his Spanish peers from the language program. He identified himself as a beginner Spanish learner.

Casper joined the study in a heartbeat, but we had difficulties arranging an appropriate time for our interviews and RMAs due to his packed schedule. He graduated from university with an Electrical Engineering degree. However, after working in the field for a few years, he decided to change majors. He was interested in applying for a business program at undergraduate level. So, to achieve his goal to apply for an undergraduate program in the US, he would need to get a high score in international English tests. He was a quiet participant who thought he did not have much to offer about his reading process given that reading, in his view, was a very straight forward activity of decoding all the words in the text to understand it. He saw himself as not a "good" reader, but he could pronounce the "strange" (unknown/unfamiliar) words when he slowed down his reading speed. Casper explained that his favorite genre was political news and scientific articles. Interviews and RMAs contributed to his starting to shift his view of reading from accurate word recognition to a view of reading as a process of meaning construction. Furthermore, he started to realize 
that he uses few reading strategies while reading English texts. However, he had not totally embraced the idea of miscues as "windows" into the reader's reading process (Goodman, 2014). He kept seeing miscues as errors that should be corrected in order to better comprehend the text as well as for his audience to understand what he was saying.

Fadil was eager to improve his language skills. His bachelor's degree was in Information Technology. For his graduate studies, he was interested in applying for a Master of Business Administration (MBA). Before coming to the US, he had lived three months in New Zealand where he had also enrolled in an international English program. He saw vocabulary and pronunciation as his biggest challenges in understanding English texts. He explained that even though he liked to read he did not read a lot in English because English reading was time consuming given that his English language skills were not "perfect" and he needed more time to read, and to comprehend a text. His view of reading as rendering the text accurately, rather than meaning construction, was similar to that of the other participants. He was also very committed to learning as well as to understanding his reading process. Our interviews and RMAs helped Fadil to deepen his understanding of himself as a reader and the reading process.

Haddad was the last participant to join the study. His major was in Health Information. At the time of the study, he had not finished his degree. So, his goal was to improve his English skills, go back to his country to finish his degree, and then apply to a graduate program in the US in the area of Health Management. Like the other participants, he was eager to improve his reading skills. He constantly asked me for suggestions for improving his reading. His major concern with English was his pronunciation, which he described as "not so good". He was extremely aware of his difficulties in pronouncing English vowels. He also pointed out that English is not a transparent language, and that is another problem when it comes to pronunciation, which in his view affects comprehension. 
He admitted that he did not read a lot in English because, most of the time, he was not interested in the readings assigned by the program. Nevertheless, he seemed to be very interested in world news, which he tried to read every day in his own language, and one or two articles in English. Unlike the other participants, he was not very concerned with international English tests and reading at the college level, at that moment, because this was a problem for the future. However, he shared a similar interest with his peers in getting a high score at the international test, so that he would be able to apply to graduate programs in the near future.

Emir was one of the first participants to sign up for the second phase of the study. $\mathrm{He}$ had been in the program for over a year. He explained that he had some English instruction in his home country. However, he only studied for school tests, and after the tests he would forget everything. He also explained that he did not use English in his social life as he was now doing in the US. According to Emir, using and being in contact with English on everyday basis supports his language development. His bachelor's degree was in Biochemistry, and he was interested in applying for graduate school in the same subject area. He was very confident about his English language skills. He explained that he faced only a few problems while reading in English such as long and complex sentences and vocabulary. He saw himself as an adviser/tutor for the other Arabic students. He had ample knowledge of English vocabulary, which he strived to use during our conversations. He could talk fluently with a few interruptions due to difficulties in remembering a word, and on a smaller scale due to pronunciation issues. His over concern with pronouncing words like a native speaker surfaced as a problem for his textual comprehension. Our conversations were not always productive because he tried to save face by protecting this image of himself as a good English learner. So, miscues and mispronunciations were seen as "mistakes" that should be avoided. Besides the goal of getting a high score in international English tests and applying to a 
graduate program, he also wanted to sound like a native speaker. At times, it seemed that he had developed an ideal native speaker in his mind who he was trying to be.

\section{Data Collection}

In the following section, I explain the instruments used to collect data. For phase 1 these include: (i) the Survey of Reading Strategies (SORS); and (ii) a background questionnaire; and for phase 2: (i) a Miscue Analysis (MA); (ii) a retrospective miscue analysis (RMA); and (iii) semi-structured interviews with L2 learners.

\section{Background Questionnaire and Survey of Reading Strategies (SORS)}

The SORS (See Appendix B) was applied to answer research questions one and two, which inquire about the most perceived use of reading strategies by L2 learners while reading English texts. The main goal of the survey was to describe trends in the L2 learner population. The survey and questionnaire were administered to obtain data regarding specific characteristics of L2 learners such as attitudes, behaviors, and/or opinion (Clark \& Creswell, 2010) in order to be able to generalize or make claims about this specific population (Creswell, 2013). The advantages of this design are: (i) its economy, and (ii) the rapid turnaround in data collection (Creswell, 2012). The survey plays an important role in the grounded theory research design as it may reinforce or contradict the findings reported in the qualitative portion of this study by encouraging a reflection that in turn support the formation of a theory.

The SORS was developed by Mokhtari and Sheorey (2002) in their attempt to assist ESL teachers to increase their L2 learners' metacognitive awareness while reading academic texts. According to Mokhtari, Sheorey, and Reichard (2008), the survey was developed for three reasons. First, the strong research on the impact of learners' metacognitive awareness on reading. Second, the inexistence of an instrument to assess L2 learners' metacognitive awareness and perceived use of reading strategies while reading academic texts. Third, to 
assess strategies that are particularly used by L2 learners such as translation, use of cognates, and differential attention to syntax, among others.

The SORS has been field-tested on several occasions with non-native English speakers as well as native English speakers (Boudreaux, 2016; Mokhtari, 2008; Sheorey \& Baboczky, 2008; Sheorey, Kamimura, Freiermuth, 2008; Sheorey \& Mokhtari, 2008; Yüksel \& Yüksel, 2012). Furthermore, its psychometric properties as validity and reliability has an Alpha $=.93$ (See Mokhtari \& Sheorey, 2002 for more information), which is desirable reliability when conducting a quantitative survey design.

The survey consists of 30 items on a Likert-type scale that ranges from 1-point (I never or almost never do this) to 5-points (I always or almost always do this). The 30 items measure three broad categories of reading strategies: (1) global reading strategies (GRS henceforth), which refers to intentional and planned strategies used to monitor or manage reading; (2) problem solving strategies (PSRS henceforth), which refers to actions and procedures taken during reading so that textual information can be comprehended; and (3) support reading strategies (SRS henceforth), which refers to strategies that increase/raise comprehension. Learners are asked to read statements and circle the one that best represents the frequency that they might use it.

A background questionnaire was also included with the survey in order to collect data regarding learners' L1, age, gender, self-rated ability in reading in English, self-ratings of their oral proficiency in English, and the amount of English training that they may have received in their home country before coming to the U.S. I used this background questionnaire to collect data regarding participants' own understandings of their perceived use of reading strategies, to have a bigger picture of the most perceived used of reading strategies, and whether their L1 or language proficiency levels influence in the use of reading strategies (See Appendix A). Later, these data were used to establish participants' 
demographics as well as for statistical purposes, such as analyzing differences in participants' responses depending on L1 and language proficiency level.

The survey and background questionnaire were applied with all L2 English learners at the two research sites who agreed to participate in the study. These instruments were also used to identify potential participants for the second phase of data collection. The initial surveys also informed the second phase of the study by providing information about possible reading strategies used by L2 learners at intermediate and advanced proficiency levels. During the administration of the background questionnaire and survey, English instructors and I were present in case students needed clarification about any question.

\section{Retrospective Miscue Analysis}

In order to collect data for the second part of this study, I conducted two RMA sessions. I used RMA in order to answer research questions three and four, which inquire about the reading strategies that L2 learners have to learn and/or become aware of in order to comprehend English texts.

A RMA session was composed of three events. At the first event, participants read a nonfiction text aloud (See Appendices D and E), which I chose in cooperation with the participants' English classroom teachers. At the second event, I analyzed participants' miscues. At the third event, participants and I talked about their miscues. During these conversations, participants tried to explain their process of coming to understanding the texts based on my prompts. I started our conversations with a high-quality miscue. Later, participants and/or I decided which miscues were to be the focus of the conversation. For instance, we talked about the miscue "all" for "whole" regarding the words' meaning and the impact of the miscue on readers' comprehension. More details about our conversations are provided in chapter five. 
The two RMA sessions were scheduled at participants' convenience. They lasted for at least thirty minutes each (see Table 3.2), and all meetings were audio recorded and transcribed by me. According to Goodman et al. (1987), recordings are desirable for marking the miscues because it offers the researcher the possibility of re-listening to the reading several times in order to be sure that each miscue has been accounted for and properly marked.

Before conducting the two RMA sessions, some textual features have to be taken into consideration. For instance, it is necessary that texts are new to the participants, meaning it is the first time they are reading the text; it is also necessary that texts are at least 500 words long so that they may produce enough miscues for analysis (Goodman et al, 2014). Furthermore, the chosen texts have to be at a level that it is neither so challenging that readers give up trying to understand the text, nor so easy that it would not provide enough miscues and/or demotivate readers from engaging in the reading (Kintsch, 1998).

All five participants read the same two texts aloud: "The transcendental revelations of astronauts" (See Appendix D) and "The scientific case for being super busy" (See Appendix E). The teachers recognized that: (i) the two texts may be difficult for students; nevertheless (ii) they may have a pretty good understanding of the articles, meaning that participants would be able to grasp the main idea of the text.

The two texts were retrieved from the online magazine The Week. The magazine intends to inform its readers regarding weekly news such as politics, economy, current events, science, art, among others. These two specific texts were related to science. They are authentic material, meaning that they have not undergone any type of procedure to simplify the language. They are similar to texts in English language tests (TOEFL, IELTS) for second language speakers who intend to apply to college. 
The first text authored by Hullinger (2016) has its title "The Transcendental Revelations of Astronauts" at the top of the page followed by a picture of space, earth and a space shuttle. The text comes after picture. It has 952 words, 16 paragraphs, and 52 sentences. Its Flesch-Kincaid Grade level is 10.3 and Flesch-Kincaid Reading ease is 51.1. So, its readability is fairly easy to read. The text is about the emotional experience of astronauts going into space, seeing the earth from space and how this experience may change their view of life. This emotional experience is referred as the overview effect.

The author of the second text is Kennon (2016). The text has a similar design to the first one. The title "The Scientific Case for Being Super Busy" is provided at the top, followed by an abstract picture of post-its on a wall, and the text itself. The text has 808 words, 19 paragraphs, and 45 sentences. Its Flesch-Kincaid Grade level is 11.2 and FleschKincaid Reading ease is 45.8 . So, its readability level is difficult at college level. The text is about the fact that modern life has become increasingly busy, and describes the benefits and downsides of busyness for humans.

Flesch-Kincaid score has been used as a readability measure tool for native speakers. This measurement tool considers the average number of words per sentence and the average number of syllables per word to classify the level of difficulty of a text as its variables (Ozaca, Weir \& Fukui, 2007; Vajjala \& Meurers, 2013, 2012; Xia, Kochmar \& Briscoe, 2016; Yoshimi, Kotani, Isahara, 2012). Nevertheless, researchers in the second language field have pointed out that this tool may be inappropriate for measuring readability in a second language given that L2 learners may have to deal with different difficulties related to semantic, grammatical, phonological, lexical and pragmatic systems particular during oral reading. Furthermore, L2 learners may perceive text comprehensibility differently than a native speaker (Handsfield \& André, 2016; Ozaca et al., 2007; Xia et al., 2016). 
I asked participants to read aloud both texts. I specifically orientated them to focus on comprehension rather than pronunciation given that at the end of their reading they would have to explain and/or summarize the text. While participants were reading, I followed their reading and marked participants' miscues on my typescript as faithfully as I could. I also recorded participants' reading aloud for later verification of miscues that I may not initially have noticed during reading aloud.

\section{Semi-Structured Interviews}

In order to answer research questions 3 and 4, I conducted two semi-structured interviews (Mertens, 1998) with each of five participants in the summer semester of 2016. The first interviews happened before the first reading-aloud and RMA session. The last interviews happened after the two RMA sessions. The interviews were coordinated with participants' schedules in mind, and lasted approximately thirty minutes each (see Table 3.2). They were audio recorded and transcribed by me. The interviews took place in a classroom in the International English Institute. This setting was chosen because of participants' easy access to it and familiarity with the environment. My goal in choosing this site was to provide an environment in which participants felt comfortable and safe talking about their challenges while reading English text.

The first semi-structured interview was conducted (i) to develop an initial rapport with participants, (ii) to collect some data regarding participants' understandings of the reading process, and (iii) to understand their views of themselves as readers. According to Glesne (2006), "rapport is marked by confidence and trust" (p. 110). Once rapport is achieved, participants may feel more willing to share their perceptions of challenges that they may face while reading English texts as well as strategies that they may be aware of using while reading in English. In order to achieve my second goal, I asked participants questions such as: (i) their perceptions about themselves as readers; (ii) challenges and/or frustrations 
that they may have experienced when reading English texts; (iii) the textual genre that they feel successful reading; (iv) for how many hours they read in their native language and in English; among other questions (See Appendix C).

There were moments during the interviews when I needed to prompt participants to clarify and/or to expand their responses by asking "what do you mean by that?", "could you clarify this point?", or "could you give me an example of what you are saying?". These prompts gave me a better understanding of what participants were trying to convey. As a result, more specific and narrowed down questions were asked to each individual.

For each participant, I conducted the last interview after the two RMA sessions. The purpose of this interview was: (i) to revisit participants' perceptions about themselves as readers; (ii) to revise participants' perceptions about the reading process; (iii) for final remarks in which participants may clarify some data from the RMA sessions; and (iv) to talk about anything else participants think may be relevant for this study. 
Table 3.3

Participants' Interviews and RMAs

\begin{tabular}{|c|c|c|c|c|c|c|c|c|c|c|c|c|}
\hline \multirow[t]{2}{*}{ Participants } & \multicolumn{2}{|c|}{$1^{\text {st }}$ Interview } & \multicolumn{2}{|c|}{$\begin{array}{c}1^{\text {st }} \text { Read- } \\
\text { Aloud \& } \\
\text { Explanation }\end{array}$} & \multicolumn{2}{|c|}{$1^{\text {st }}$ RMA } & \multicolumn{2}{|c|}{$\begin{array}{c}2^{\text {nd }} \text { Read } \\
\text { Aloud \& } \\
\text { Explanation }\end{array}$} & \multicolumn{2}{|c|}{$2^{\text {nd }} \mathrm{RMA}$} & \multicolumn{2}{|c|}{$\begin{array}{c}\text { Last } \\
\text { Interview }\end{array}$} \\
\hline & Date & Time & Date & Time & Date & Time & Date & Time & Date & Time & Date & Time \\
\hline Azim & $06 / 24$ & $49 m$ & $06 / 24$ & $23 \mathrm{~m}$ & $06 / 26$ & $77 \mathrm{~m}$ & $07 / 01$ & $25 \mathrm{~m}$ & $07 / 03$ & $38 \mathrm{~m}$ & $07 / 03$ & $24 \mathrm{~m}$ \\
\hline Casper & $07 / 05$ & $30 \mathrm{~m}$ & $07 / 05$ & $18 \mathrm{~m}$ & $07 / 07$ & $42 \mathrm{~m}$ & $07 / 08$ & $17 \mathrm{~m}$ & $07 / 08$ & $31 \mathrm{~m}$ & $07 / 08$ & $11 \mathrm{~m}$ \\
\hline Haddad & $06 / 27$ & $40 \mathrm{~m}$ & $06 / 27$ & $14 \mathrm{~m}$ & $06 / 30$ & $40 \mathrm{~m}$ & $07 / 07$ & $15 \mathrm{~m}$ & $07 / 07$ & $42 \mathrm{~m}$ & $07 / 07$ & $24 \mathrm{~m}$ \\
\hline Fadil & $06 / 30$ & $36 \mathrm{~m}$ & $06 / 30$ & 20 & $07 / 08$ & $55 \mathrm{~m}$ & $07 / 11$ & $15 \mathrm{~m}$ & $07 / 11$ & $37 \mathrm{~m}$ & $07 / 11$ & $23 \mathrm{~m}$ \\
\hline Emir & $06 / 24$ & $35 \mathrm{~m}$ & $06 / 24$ & $14 \mathrm{~m}$ & $06 / 29$ & $42 \mathrm{~m}$ & $07 / 07$ & $23 \mathrm{~m}$ & $07 / 07$ & $21 \mathrm{~m}$ & $07 / 07$ & $33 \mathrm{~m}$ \\
\hline
\end{tabular}




\section{Data Analysis}

As with the data collection, the data analysis was also broken down into steps: Background Questionnaire and SORS (quantitative), and MA, RMA and interviews (qualitative). These analyses were later integrated for interpretation in chapters 4 and 5 . It is important to bear in mind that although the data analysis has been presented here in a linear manner, the analysis started before all data had been collected. Data collection, data analysis and data interpretation are interactive processes in mixed methods (i.e., it is a recursive and nonlinear process; Onwuegbuzie \& Teddlie, 2003). I came to this data analysis with the understanding that "the interaction between the researcher and participants "produces the data, and therefore the meanings that the researcher observes and defines" (Charmaz, 1995, p. $35)$.

\section{Background Questionnaire and SORS for Phase 1}

In order to answer research questions 1 and 2, two statistical analyses were performed to analyze the data collected with the background questionnaire and SORS: (i) a descriptive analysis; and (ii) a one-way Analysis of Variance (ANOVA). First, a descriptive analysis was performed so that an overview of data was presented in a meaningful way, making it possible to verify patterns that emerged. As Clark and Creswell (2010) pointed out, this initial statistical analysis may not support any conclusion, but it provides a summary of the central tendency (overall tendencies in the data), an assessment of the variability (how varied the scores are), and provides insights into a relative stand (where one score stands in comparison with others). With this approach, simpler trends such as describing (i) the obtained scores of each question (mean) and (ii) the most frequent score in the survey (mode) is possible.

While describing the central tendency, the mean was calculated in order to verify the average score among all participants regarding the use of the three possible reading strategies $($ mean $=M)$. The range of scores and the standard deviation $(S D)$ were calculated to verify (i) 
the difference between the highest and lowest scores for the three possible reading strategies: GRS, PSRS, and SRS, and (ii) how dispersed each variable is from the $M$ value. Both of these procedures were conducted while considering participants' L1 and English proficiency levels. By running this initial statistical analysis, it was possible to get an overview of participants' use of reading strategies.

Second, the one-way Analysis of Variance (ANOVA) was performed to examine whether: (i) the data collected reported any statistical significant differences among the four different groups of L1 while considering the three types of reading strategies assessed in the SORS survey, and (ii) the data collected reported any statistical significant differences among L2 learners with different English proficiency levels while considering the three types of reading strategies assessed in the SORS survey. One-way Analysis of Variance (one-way ANOVA) identifies if there are statistical differences between the means of two or more independent groups (Green \& Salkind, 2011).

\section{SORS for Phase 2}

In order to crosscheck information from SORS, MA, RMAs and interviews, I performed two statistical analyses with the five participants that participated in all forms of data collection. Within the data collected with SORS, the following statistical analyses were performed: (i) descriptive analysis; and (ii) one-way ANOVA to answer research questions 3 and 4. First, a Descriptive Analysis was performed to compare whether information given by participants regarding their preference in the use of reading strategies assessed by SORS was similar to those mentioned during RMAs and Interviews. Second, a one-way ANOVA was performed to verify whether there were any statistical differences among the three types of reading strategies assessed by SORS. 


\section{Miscue Analysis}

In order to count the miscues, the widely-accepted norms already established were used (Y. Goodman, 2014; Y. Goodman et al., 2005) Substitutions, (partial) omissions, (partial) insertions, mispronunciations, and self-corrections were coded to verify any pattern among participants. Substitutions refers to participants reading a different word than the one indicated in the text (e.g. there instead of where). Partial omission refers to participants not reading part of a word (e.g. car instead of cars). Omission refers to participants skipping an entire word. Partial insertion refers to participants adding a prefix or suffix, which results in a different word (e.g. actual turns actually). Insertions refers to participants inserting a new word in the text. Mispronunciation refers to participants reading a word differently than any English variation. Self-correction refers to participants going back to correct their miscues (Goodman et al., 1987; Goodman et al., 1996).

Regarding mispronunciation miscues in which participants were unable to pronounce a word even after breaking it down into syllables, it is hard to affirm whether it was an unknown word or not, as the RMA sessions revealed. There are at least three possibilities to explain a mispronunciation. First, there were cases in which the mispronunciation was an unknown word, and participants were unable to pronounce it even after a few attempts, they were also unable to figure out its meaning. An example of this would be the words transcendental and cognition. Second, there were cases in which the mispronunciation was a known word, but participants needed more time to retrieve its meaning. An example of this would be the words meditation and busyness. Finally, there were cases in which mispronunciations were completely unknown, and participants were not able to link the word with its concepts. Nevertheless, these words may not contribute to meaning making. An example of this would be the words staggeringly and eerily. Because it is difficult to affirm how much mispronunciation affected participants' comprehension, they were not counted as 
miscues, although they were coded to verify any pattern among participants. While dealing with the challenge of mispronouncing a minimally-rehearsed word, participants frequently used their phonological knowledge to break words into syllables.

Partial omissions, and partial insertions were not considered while evaluating participants' textual comprehension given that these types of miscues did not impact participants' comprehension as they argued in their RMAs sessions. For instance, most of the partial omissions neglected some morphological information such as plural marker (s), third person singular marker (-s), past tense marker (-ed), and present progressive marker (-ing), which were found to be common miscues among the participants. Research studies have also demonstrated that these are common miscues among L1 and L2 learners (Y. Goodman et al., 2005; Jiang, 2004, 2007; Keh, 2017). Furthermore, because not all of the participants' miscues fell under the already established coding of this miscue system, it was important to refine the coding of the miscues in order to fit the participants' miscues. Along these lines, four types of coding relating to pronunciations emerged from the data: (i) pronunciation/substitution miscue; (ii) L1 phonological knowledge miscue; (iii) L1 phonotactic knowledge miscue; and (iv) L2 overgeneralization.

Pronunciation/substitution miscues refer to participants' difficulties in pronouncing a word, resulting in a substitution. In other words, participants knew at least the printed word in the text and/or the pronounced word while reading aloud. Nevertheless, participants would be able to realize their mispronunciation/substitution if they were to allow themselves more time to process the text without being concerned with speed and fluency. This shows a limitation of this study. In other words, results may differ while participants read silently (Lems, 2003). A comparative study is needed to fill this gap. This type of miscue was counted as affecting comprehension because it shows that participants may not be, at that moment, comprehending the text. 
Related to pronunciation, phonological knowledge miscues refer to participants applying their first language phonological knowledge to read an English word. For instance, Arabic speakers do not differentiate $/ \mathrm{p} /$ and $/ \mathrm{b} /$ sounds. As a result, words with the $/ \mathrm{p} /$ sound were frequently pronounced as $/ \mathrm{b} /$. There was a great amount of effort by the participants to pronounce words with /p/ sounds. Another example was the distinction between /v/ and /f/ sounds. Words with /v/ were sometimes pronounced as /f/. Although Arabic does not differentiate these two sounds, participants have less difficulty in producing the /v/ sound than differentiate the $/ \mathrm{p} /$ and $/ \mathrm{b} /$. Differentiating the two "G" sounds in English was also problematic for participants. Participants were able to differentiate the hard /g/ (as in gap) and soft /dze/ (as in gentle) sounds in case words were familiar for them (Ali, 2015; Hassan, 2014; Lev-Ari \& Peperkamp, 2013; Rajab, 2013). In case the word was unfamiliar and/or it was the first time it was seen, they pronounced the hard /g/ sound. This was an influence of participants' L1 language given that Arabic has only the hard /g/ sound. This type of miscue was not counted as affecting comprehension given that participants demonstrated during the RMAs that they were aware of the word meaning even though they read something different. Furthermore, all of them recognized their difficulties in pronouncing words with these sounds.

L1 phonotactic knowledge miscues refer to when participants slightly changed an (un)known word to better fit the Consonant-Vowel structure of Modern Standard Arabic at the initial position of a word (Hayes-Harb; 2006; Saiegh-Haddad \& Geva, 2007). For example, words such as instance would be pronounced as "inestance" (with a long i sound, as in hive) inspiration as "inespiration", spiritual as "sepititual”, and so on. As participants pointed out during RMAs sessions, these miscues may or may not have influenced their comprehension depending on their knowledge of word meaning. Nevertheless, they were not 
counted as impacting participants' comprehension due to their scarcity in participants' oral reading.

L2 overgeneralization of pronunciation refers to the use of a sound where it does not apply. For instance, a common miscue of overgeneralization among participants was "C" being pronounced as $/ \mathrm{k} /$. So, words like accelerate would be pronounced as "akelerate", and transcendental as "transkendental". This type of miscue was extremely rare in the data set. This type of miscue falls under the same situation of the L1 phonotactic miscues, which may or may not have affected comprehension depending on participants' knowledge of word meaning. Due to the difficulty in determining its impact on comprehension, they were not counted as impacting comprehension although they were coded in order to get a fuller picture of participants' reading patterns.

Proper nouns were not counted as miscues given that participants were able to identify them as proper nouns, and they knew that they were referring to a person, a place, or an institution.

Finally, all miscues were classified as a: (i) meaningful miscue, or (ii) significant miscue. Meaningful miscues refer to miscues that do not change meaning, but that may not carry all the syntactic and semantic information of a word. Examples of meaningful miscues were changing tenses, omitting third person markers, omitting plural markers, substituting a definitive article for an indefinite article and vice-versa, substituting words with similar meanings, among other miscues. Significant miscues refer to miscues which do alter meaning. Usually, this type of miscues were substitutions in which participants read a totally different word from the written input. For instance, mountain for motion, seeing for sing, among others. Furthermore, substitutions in which participants changed the syntactical structure of a sentence were categorized as significant miscues. For instance, "theory" for "through"; "form" for "from", "your" for "you", among others. 


\section{Retrospective Miscue Analysis}

In order to answer research questions 3 and 4, the data collected during the RMA sessions were broken down in two separate data analyses: Miscue analysis and RMA analysis.

As previous explained, the miscue analysis sessions were recorded in two ways typescripts and tape-record. First, I marked participants' miscues onto the typescripts (See Appendix F). As Goodman et al. (1996) has pointed out, it is important to mark as many miscues as possible during a read-aloud because it assures authenticity given that some nuances of reading such as pauses, deep breathing, or pronunciations may not be very clear on tape. Second, I re-listened to the audio-recordings soon after participants' read-aloud to ensure that I had not overlooked any of their miscues.

The miscues that were marked on the typescript were: substitutions, insertions, corrections, repetitions, and omissions. There were mispronunciations, meaning that participants did not pronounce some words like a native speaker would. Nevertheless, as described earlier, their mispronunciations were not considered miscues. Once all participants' miscues were identified, I transferred them to a coding sheet (See Appendix G) to evaluate whether or not the miscues were grounded in syntax, semantics, and/or graphic similarity. Accordingly, I could verify individuals' patterns in their uses of specific cue systems individually as well as across participants for miscues and self-corrections.

The RMA analysis started with the recordings being initially transcribed, and then analyzed using an inductive coding approach (Creswell, 2014). The inductive approach looks for patterns that may suggest a hypothesis to be later tested in order to develop a theory. The inductive approach was applied in order to verify whether participants mentioned the need to learn and/or become aware of reading strategies to comprehend a text in English. Although there is a prevalence of the inductive approach in data analysis, it is important to bear in mind 
that data analysis is also determined by the researcher's objectives. In other words, the researcher looks to data deductively, i.e., to categories that may answer their research questions.

According to Charmaz (2010), inductive coding involves following rigorous procedures which lead to the emergence of conceptual categories. Creswell (2012) argues that there are two types of systematic procedures for inductive coding. The 'Objectivist methods' of Strauss and Corbin $(1990,1998)$ and the 'Constructivist methods' of Charmaz $(2005,2006)$. In the 'Objectivist methods' the researcher seeks to develop a theory to explain action, interaction, and/or process on a topic. In the 'Constructivist methods', the researcher develops theories that depend on the researcher's views of learning that relates to diverse types of experiences, including but not limited to hidden networks, situations, and relationships, establishing hierarchies of power, communication, and opportunity (Creswell, 2012). Unlike the objective approach, the constructivist approach emphasizes diverse realities, ranging from the complexity of particular words, actions and views. In this scenario, emphasis is put on the views, beliefs, values, assumptions, feelings, and ideologies of individuals (Charmaz, 2010).

While coding, the researcher looks for the emergence of categories which are constantly compared with the raw data (Merriam, 2001; Onwuegbuzie, Leech \& Collins, 2010, Strauss \& Corbin, 2008), so that relevant characteristics of the data are captured (Merriam, 2001). Furthermore, these initial coding procedures assist researchers in developing “more specific focus or more relevant questions" (Glesne, 2006, p.150).

In order to code my data, I used the following procedures: (i) open coding; (ii) focused coding; (iii) axial coding; and (vi) selective coding. These coding procedures were used in order to achieve two main goals: (i) to reduce data to a level that is manageable by the researcher; (ii) to identify patterns/categories which assists drawing and reporting 
conclusions of the phenomenon under study (Caudle 2004). It is important to bear in mind that these procedures are being presented in a linear manner. Nevertheless, they may happen in a non-linear manner. For instance, subcategories may emerge before having a clear defined category.

I initially coded my data using a line-by-line technique and a low-inference coding approach (Carspecken, 1996). The line-by-line technique was useful for identifying (un)recognized assumptions, to focus on data while having analytical barriers or blocks (Strauss \& Corbin, 2008) as well as sparking new ideas that can be pursued (Charmaz, 2014). In this phase, I also used in vivo coding (Charmaz, 2013; Strauss \& Corbin, 2008), also referred to as low inference code (Carspecken, 1996), as much as possible. These coding procedures focus on using participants' own words. Charmaz (2014) argues that "staying close to the data and, when possible, starting from the words and actions of your respondents, preserves the fluidity of their experience and gives you (the researcher) new ways of looking at it. These steps encourage you to begin analysis from their perspective" (p. 49). This procedure may also help ensure that the grounded theory reflects an insider's view (participants' view) rather than an outside's view. Furthermore, it enhances researchers' authenticity and the trustworthiness of their perceptions regarding the reading process. In this initial coding phase, I also collapsed codes that were similar. For instance, participants referring to their miscues "I am not sure" and "I have no idea", or participants referring to their unconventional use of grammar "tense is different, but not meaning" and "same meaning, different grammatical use.”

I then applied focused coding to select codes that were more significant and/or frequent, such as those codes that stand up from the data in order to delineate my data into categories (Charmaz, 2014) (See Table 5.12 for more details). This procedure was followed by an axial coding procedure, which consists of relating categories with subcategories while 
specifying the properties and dimensions of a category in order for me to understand how categories and subcategories were related. In other words, the axial coding process serves to establish relationships among similar ideas/concepts within a single category, facilitating understanding. For instance, the category "meaning over grammar" agglutinated the following open coding topics: "Concentrate in meaning not in grammar"; "Tense is different, but not meaning"; "Similar meaning, different grammatical use". Finally, I adopted a selective code approach to generate themes.

\section{Interviews}

Interviews were audio-recorded, transcribed and coded following the same steps described above. I used line-by-line coding to get a general idea of what was going on in my data. This step was followed by a focused coding approach which assured an analytical direction to answer my research questions. Then, I used axial coding to establish a link between categories and subcategories. For example, the category "Good Reader" agglutinated the following open coding topics: "Reads a lot"; "Has no mispronunciation"; and "Is motivated to read".

\section{Data Analysis Integration}

The findings for the quantitative and qualitative portions of this study were initially analyzed separately. Finally, these findings were integrated at the end of data analysis in order to verify similarities and/or differences among reading strategies that L2 learners may use and/or be aware of while reading English texts. Integration made possible a more complete picture of the problem once data were compared and contrasted. For instance, results from the analysis of SORS demonstrated that L2 learners have a preference and/or are more aware of support reading strategies, problem solving reading strategies, and global reading strategies respectively. The focal group SORS analysis did not result in any statistical difference regarding the use of these three types of reading strategies by participants in the 
second phase of this study. Nevertheless, their reading-aloud and RMA demonstrated that participants have a preference for PSRS, SRS, and GRS. These results demonstrate that L2 learners may be able to list several reading strategies, and to classify their use in a survey, but this does not necessarily mean that they are making use of these reading strategies.

\section{Trustworthiness and Authenticity}

I used three methods to ensure trustworthiness: (i) member checking; (ii) peer debriefing; (iii) and triangulation. Member checking is the process in which participants are asked to evaluate reported research findings derived from the interviews which had been conducted with them. In this study, member checking was conducted at the end of the analysis in order to verify that the interpretations drawn by the researcher were not misinterpretations or misrepresentations (Creswell, 2013; Lincoln \& Guba, 1985).

Peer debriefing is the process in which a disinterested peer (a researcher that is not involved in the study, and therefore without any conflicts of interest) checks the findings that were drawn from the data analysis. In the present study, the peer debriefing was conducted to check if there were any different interpretations when creating the codes from the RMA and interview transcripts. In this peer debriefing, I invited five colleagues ("Critical Friends" Rossman \& Rallis, 2003, p. 69) from different areas of knowledge (two foreign language acquisition professors and three physical education professors) to read my data collection and compare their analyses with my analyses. Whenever disagreements occurred, both researchers argued to reach consensus (Lincoln \& Guba, 1985). I also invited colleagues to read and provide feedback on chapters of the dissertation.

Triangulation refers to the process in which data from different sources (SORS phase 1, SORS phase 2, semi-interviews, miscue analysis, and RMA) are compared and contrasted, so that a deep interpretation is possible to verify whether results from these different sources support and/or contradict each other (Clark \& Creswell, 2010). According to Maxwell et al. 
(2010), triangulation may reduce the risk of bias(es). Nevertheless, there is still the need to evaluate the methods to collect data carefully so it is not assumed that those tools are free of $\operatorname{bias}(\mathrm{es})$

\section{Subjectivity and Reflexivity}

According to Creswell (2014), our writing is a reflection of our interpretations of the world, which are based on the cultural, social, class, gender and personal politics that we bring to the research. In this sense, "all writing is "positioned" and within a stance" (Creswell, 2014, p. 179). In light of this, I kept a research journal which served to document my thinking, feelings, and reactions throughout the data collection and analysis process. For instance, participants from phase two would typically talk with me about their weekends and/or what they would be doing during the rest of their day. In light of these conversations, I wrote comments such as: "participants seemed to see me as an insider. This may help me to gain more information about their reading process.” Nevertheless, in other instances, participants seemed to distance themselves from me when we started talking about reading. At one such moment, I wrote: "This view of me as a knower may impede participants to open up, and try to save face during reading aloud and/or interviews."

This journal provided a space for me to reflect on my own biases, and how my positionalities were shaping the study (Creswell, 2014). Research journals are valuable tools that assist researchers to have a better understanding of the impacts of the research on ourselves as well as on the participants. In Kleinman's (1991) words, “we must write about why we chose the setting, who we are at the moment, and how our identity affects our reactions to the setting and its participants" (p. 195) given that it may be difficult to separate what we are doing intellectually to what we are experiencing as a person (Mills, 2010). These reflections enabled me to view my data and interpretations reflexively. 


\section{Ethical Considerations}

While conducting research, it is important to think about ethical considerations, which do not end with consent, but remain pertinent throughout the research (Creswell, 2014; Glesne, 2006; Spradley, 1980). In this process, it is important that the researcher takes actions to protect the integrity of participants. In order to insure participants' integrity, I took several steps. First, I gained approval from Illinois State University’s Internal Review Board, followed by approval from the coordinator of the English programs as well as the classroom teachers included in this study. Second, I ensured that the recruitment letter and the informed consent clearly stated the intent and scope of the study as well as detailed information about the procedures of data collection, data analysis, transcription, and dissemination.

Furthermore, these documents also articulated the possible risks of participating in the study, such as breach of confidentiality. In order to minimize the risk of breaching of confidentiality, participants' names were not used. Pseudonyms were used instead of real names. The recruitment letter and the informed consent also stated the potential benefits of participating in this study.

\section{Limitations}

The first limitation to be taken into consideration is that different university English language teaching programs may have different procedures to identify their students' proficiency levels. This research assumes that the proficiency levels of participants on different English programs are somewhat similar, but there may be subtle differences.

The SORS is presented as an important instrument employed in this research due to its potential to provide findings that may bring enlightenment to the question as to whether L2 learners from different L1s and language proficiency levels perceive the use of reading strategies differently. However, its usefulness is not unhindered from limitations. The survey 
collects data regarding the perceived use of reading strategies, which may not reflect the actual use of reading strategies by L2 learners while reading different English genres.

Retrospective miscue analysis (RMA) is presented as an important method for producing findings that may bring enlightenment to the question that L2 learners from different L1s have to learn and/or become aware of different reading strategies. However, as with the SORS, its usefulness is limited. While reading a text in an RMA session, learners may engage in different reading strategies from those that they employ while reading silently (Clarke, 1979). Therefore, it may be difficult to determine all the reading strategies that L2 learners may have to learn, apply, and/or become aware of. The constructivist paradigm is reinforced here in the sense that reality is constructed depending on the interactions stablished between the researcher and her/his participants (Lincoln \& Guba, 1985; 1994; Guba,1990; Onwuegbuzie et al., 2009; Willis, 2007).

Another important limitation pertains to the subjectivity of coding the miscues. The analyst must make somewhat subjective decisions as to whether a miscue is syntactically and semanticallly acceptable. While this limitation will be minimized by peer-debriefing, it is also important to bear in mind that participants may not be able to name certain reading strategies or talk about them due to the limitations of their English language proficiency. In this case, I tried to assist them in understanding the processes they go through while using a reading strategy, and innaming the strategy.

\section{Summary}

In this chapter, I outlined the research paradigms that I brought to this study as well as the mixed method grounded theory. I also detailed my research design by including the setting, participants, data collection, and data analysis. I attended to issues of trustworthiness and addressed the ethical dimensions of research. In the next chapter, I provide a more 
detailed description of my participants' demographics as well as the results from quantitative data analysis. 


\section{CHAPTER IV: QUANTITATIVE RESULTS AND ANALYSIS}

\section{Overview}

The main purpose of this study was to investigate the strategies adult English learners perceive as the most used to comprehend English text and their level of awareness of these strategies. A mixed method grounded theory in a sequential design was applied (quantitative - Qualitative) with a qualitative dominant status (Creswell \& Clark, 2011; Johnson et al., 2004; Shannon-Baker, 2016). This chapter presents the results of data collection and data analysis from the quantitative phase of this study. This initial phase sought to answer the following research questions:

(RQ-1) What are the types of reading strategies that adult English learners from Spanish, Asian languages, Arabic, and Kazakh first languages (L1) perceive as the most frequently used reading strategies while reading English text? And to what extent does the frequency of reading strategies perceived differ significantly by language background?

(RQ -2) What are the reading strategies that adult English learners at different English proficiency levels (beginning, intermediate, and advanced) recognize as the most frequently used while reading English text? And to what extent does the frequency of reading strategies perceived differ significantly by proficiency levels?

In order to answer these questions, I collected data by administrating a background questionnaire and the Survey of Reading Strategies (SORS) with L2 learners enrolled at international English programs in two local institutions: (i) The English Language Program at Illinois State University; and (ii) The Intensive English program at University of Illinois at Urbana-Champaign (UIUC). After I collected data, I performed three statistical analyses with all participants from phase 1: (i) descriptive statistics of background questionnaire; (ii) descriptive statistics of the SORS; and (iii) one-way ANOVA with SORS. These statistical 
analyses were performed to help determine descriptive and inferential patterns which emerged from the participants' survey data regarding backgrounds and perceived use of reading strategies. The results from the analysis of the data are described in this chapter first by the participant background and then by research question.

\section{Demographic Background of Participants}

The background questionnaire was first coded and then the codes were later used to support findings and draw conclusions about English language learners. These codes and survey responses were transferred into a statistical software, Statistical Package for Social Sciences - SPSS 2015 version. Descriptive, and one-way ANOVA analyses were conducted. The descriptive statistics, which involved means and percentages were used to report the basic characteristics of participants while offering insights of possible patterns within the data as well as to examine participants' responses regarding the perceived use of individual reading strategies. One-way ANOVA is an inferential statistic typically used to deduce statistical significant differences across groups or scores (Salkind, 2010; Salkind, 2014). In this study, this inferential statistic was used to determine whether there were significant statistical differences among L2 learners from different language backgrounds, at different English language proficiency level, and regarding the use of the three types of reading strategies (global reading strategies (GRS); problem solving reading strategies (PSRS), and support reading strategies (SRS).

Thirty-six participants answered the SORS, 22 men (8 Saudi-Arabian; 1 Chinese; 2 Japanese; 4 Kazakh; 4 Korean; 2 Panamanian and 1Venezuelan) and 14 women (1 SaudiArabian; 3 Chinese; 1 Korean and 9 Panamanian). Participants were on average 28.20 years old and ranged from 19 years old to 42 years old. Language proficiency level was coded as: 1 for beginner, 2 for intermediate; 3 for advanced, and 4 for fluent. The level of English proficiency was mainly at the intermediate level. Four participants identified themselves as 
being at the beginner level of proficiency even though they were placed at the intermediate level in their program; 19 participants identified themselves as being at the intermediate level of proficiency, and 11 participants identified themselves being at an advanced level of proficiency. Twenty-three participants were graduate students, seven participants were undergraduate students, five participants answered 'other', and one participant did not answer the question (See Appendix A). Participants' areas of interest were quite diverse: electrical and civil engineering, psychology, health information, international law, geophysicist, sports, biology, biochemistry, technology, piano performance, communication, translation, education and business. Nine participants reported knowing another language besides English and their L1. These languages were: Chinese, Spanish, Japanese, Russian, Portuguese and German. Participants' answers regarding the number of years studying English varied considerably.

Among the 36 participants in this study, there was significant discrepancy regarding the amount of time in US in weeks. Sixteen participants reported being in US between 1 to 4 weeks; 7 participants reported being in US between 5 to 9 weeks; 7 participants reported being in US between 10 to 26 weeks; and 6 participants reported being in US between 27 to 100 weeks (See Figure 4.1).

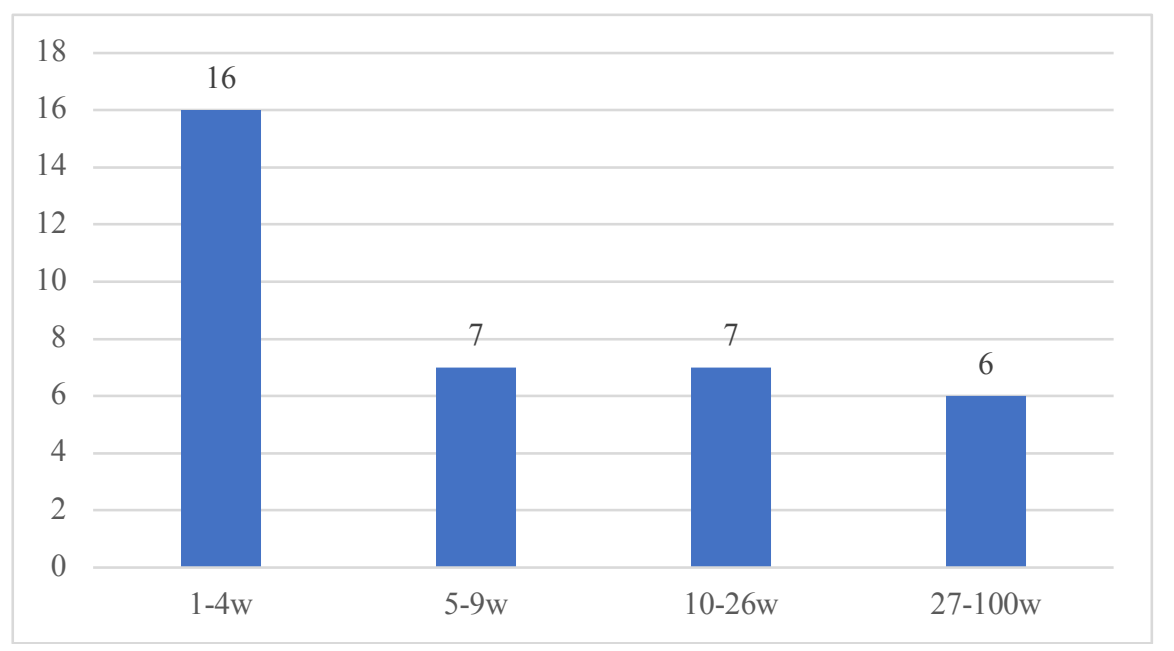

Figure 4.1. Time in US in Weeks

Regarding the number of hours studying English in their home country, data were coded as: 1 for none; 2 for 1 to 5 hours; 3 for 6 to 10 hours; and 3 for 11 and above hours. 
Eight participants reported not having taking any English classes in their country. Eighteen reported taking between 1 to 5 hours of English classes in their country. Two reported taking more than six hours of English in their country. Eight reported taking eleven or more hours of English classes in their country.

When asked about their view of themselves as readers (see Figure 4.2); 17 participants reported a positive view such as: reader in improvement; good reader; pretty good reader; strategic reader; experienced reader; and persistent reader; 13 participants reported a negative view such as: slow reader; bad reader; weak reader; unknowledgeable reader; confused reader; non-persistent reader and beginner/inexperienced reader. 5 participants talked about the reading process in itself. 4 participants reported the reading process as a positive experience such as "love reading", "interested in reading", and "read to acquire knowledge". Only 1 participant reported the reading process as a negative experience by stating the difficulty of reading in English.

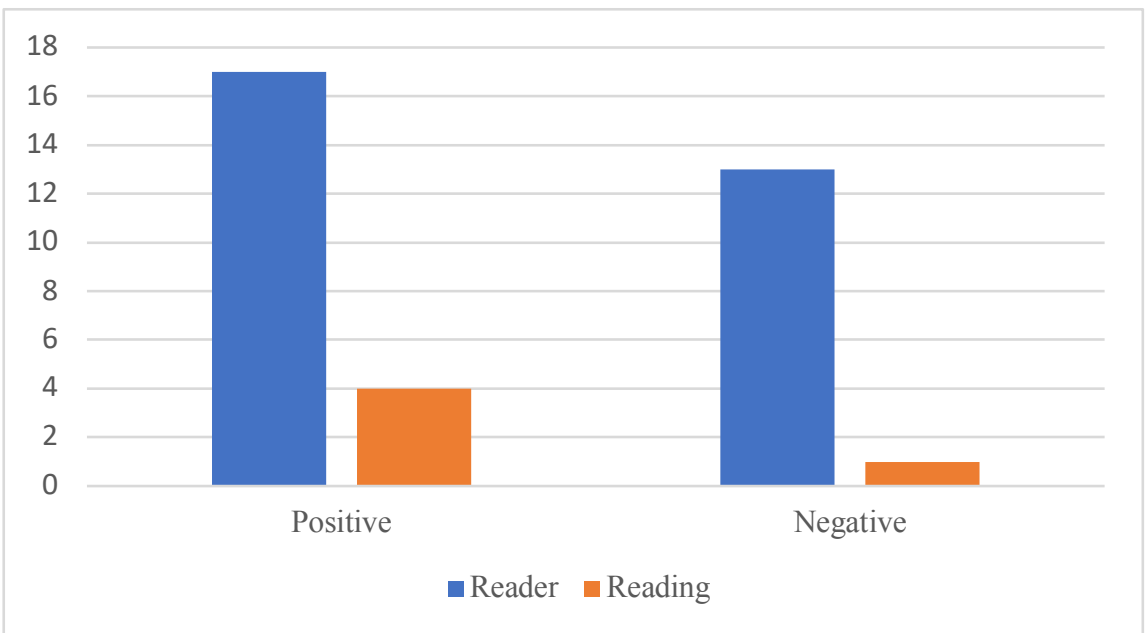

Figure 4.2. Reader's Perspective

When asked about the challenges faced while reading English texts, 39\% reported vocabulary as the most challenging aspect of reading; $22 \%$ reported fluency as the most challengeable aspect of reading; 14\% reported grammar as the most challengeable aspect of reading; $13 \%$ reported comprehension as the most challengeable aspect of reading, and $12 \%$ 
fell under the miscellaneous categories which included: self-confidence; improve reading skills and academic reading.

\section{English Reading challenges}

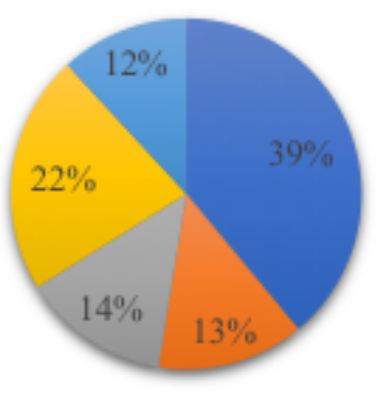

-Vocabulary $\quad$ - Comprehension $₫$ Grammar

EFluency $\quad$ Miscellaneous

Figure 4.3. English Reading Challenges

When asked about the similarities between reading in participants' L1 and English, $34 \%$ reported vocabulary as the most similar aspect of reading in their first language and in English; 19\% reported that there was no similarity between reading in their first language and in English; $16 \%$ reported grammar as the most similar aspect of reading in their first language and in English; $16 \%$ also reported textual features as the most similar aspect of reading in their first language and in English; 9\% reported pronunciation as the most similar aspect of reading in their first language and in English; and 6\% fell under miscellaneous which included responses such as: "no idea", there are only differences" and there are some similarities". 


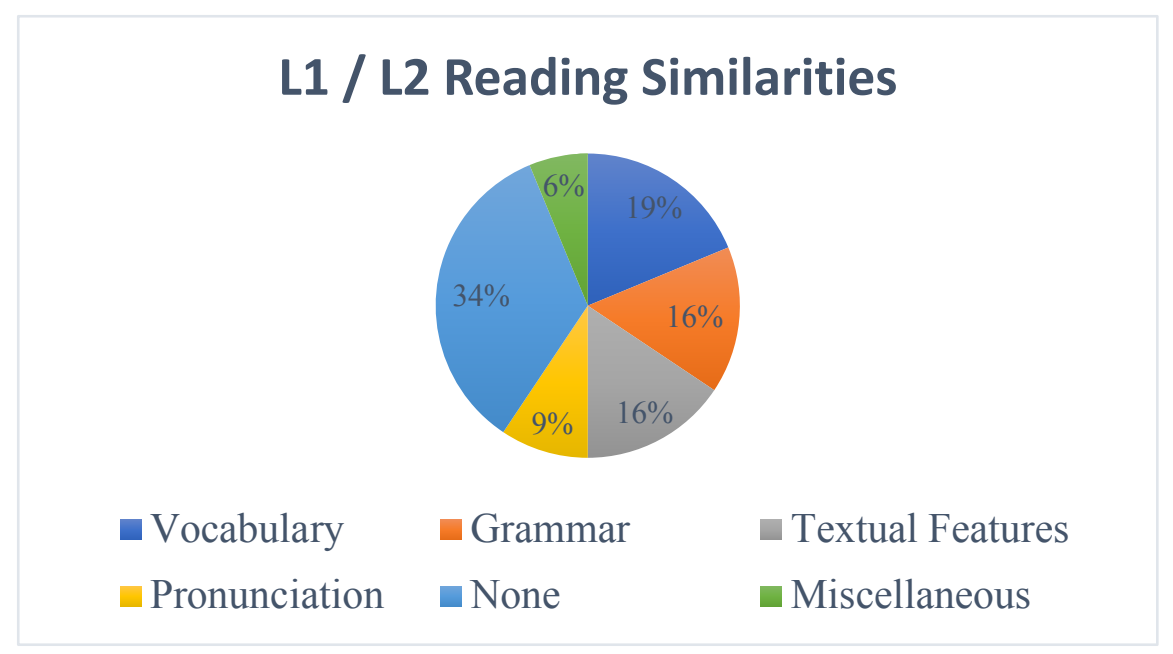

Figure 4.4. L1/L2 Reading Similarities

When asked about the differences between reading in participants' first language and English, 48\% reported grammar as the most important difference in reading between their first language and in English; 17\% reported time consuming (demanding) as the most important difference while comparing reading in their language and reading in English; 17\% responses fell under the miscellaneous category which included: "no idea" and "some differences"; $6 \%$ reported vocabulary as the most important difference in reading between their first language and in English; and 3\% reported no difference in reading between their first language and in English.

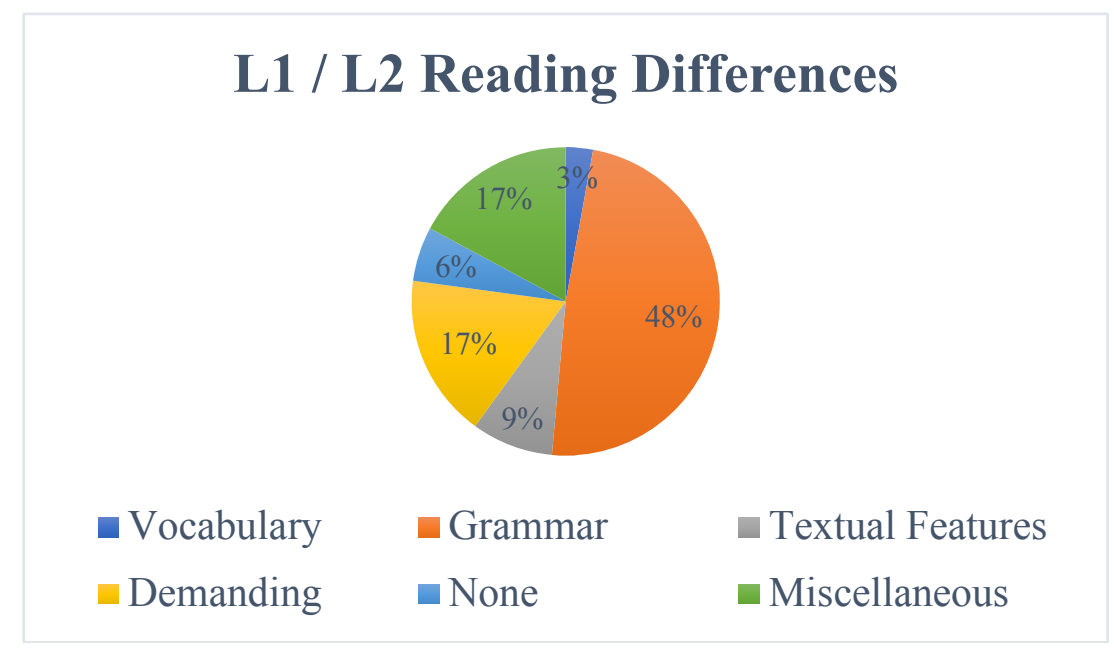

Figure 4.5. L1/L2 Reading Differences

Question 15 in the background questionnaire (See Appendix A) was an open-ended question. Therefore, each individual could give multiple answers. As a result, the total 
number of answers may be greater and/or inferior than the number of participants and consequently, the percentage is calculated according to the total number of answers and not the total number of participants. Only two participants did not answer this question. There were a total of 22 responses regarding the easier genre to read, $46 \%$ reported news, $27 \%$ reported biography, 18\% reported fiction, and 9\% reported academic text (See Figure 4.6). There were a total of 29 responses regarding the more difficult genre to read, $35 \%$ reported news, $31 \%$ reported fiction, $24 \%$ reported academic texts, and 10\% reported biography (See Figure 4.7). Participants' reasons to classify a genre as easier and/or more difficult were based on: (i) new vocabulary; (ii) familiarity with topic; (iii) interest in the topic; and (iv) use of language.

\section{Easy Genre}

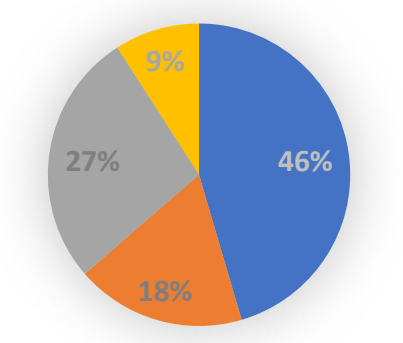

News Eiction Biography $\square$ Academic

Figure 4.6. Easy Genre

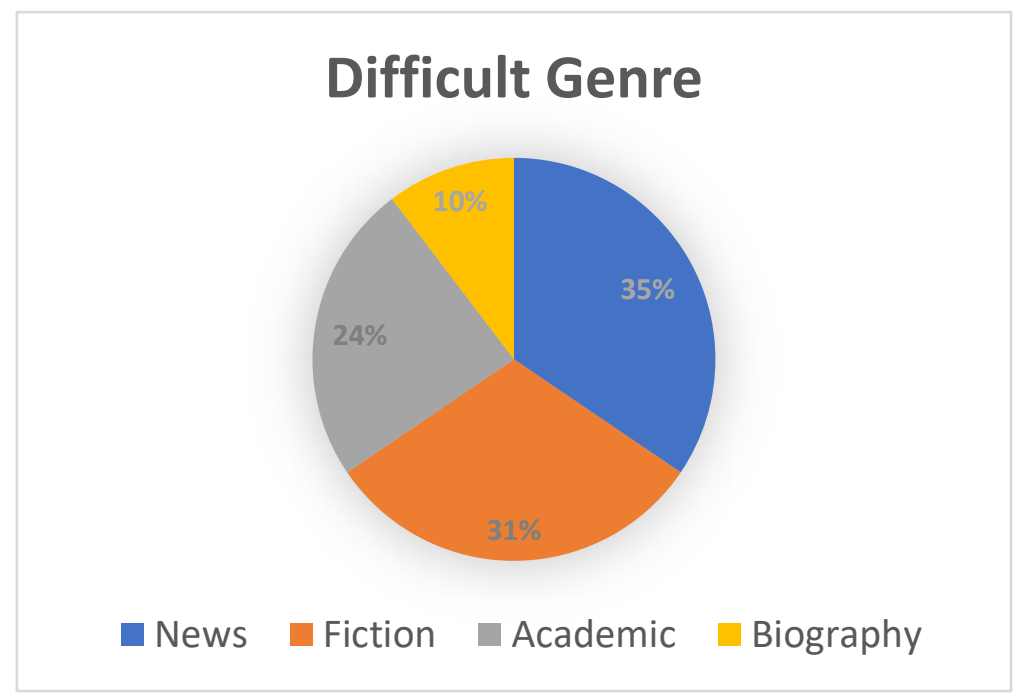

Figure 4.7. Difficult Genre 
Research Question 1: What Are the Types of Reading Strategies That Adult English

Learners from Spanish, Asian languages, Arabic, and Kazakh First Languages

(L1)Perceive as the Most Frequently Used Reading Strategies While Reading English Text? And to What Extent Does the Frequency of Reading

Strategies Perceived Differ Significantly by Language

\section{Background?}

In order to answer the first research question, which asked, what are the types of reading strategies (global reading strategies; problem-solving reading strategy, and supportive reading strategies) that adult English learners from different L1s (Spanish, East Asia, Arabic, Kazakh) perceive as the most frequently used while reading English texts, participants' responses were initially examined for individual strategies. The participants answered a 30 questions survey using a 5-point Likert-Type scale. In total, 36 participants $($ Females $=14$, Males $=22)$ were invited to answer the questions, however, a few participants skipped a few questions. Skipped questions were not calculated when conducting the descriptive analysis, and one-way ANOVA. Table 4.1 displays the results of the descriptive statistic for each individual question on the SORS based on participants' L1s 
Table 4.1

Descriptive Analysis Based on First Language

\begin{tabular}{|c|c|c|c|c|c|}
\hline Questions & $\begin{array}{c}\mathrm{N}^{\circ} \text { of } \\
\text { Participants }\end{array}$ & $\begin{array}{l}\text { Spanish } \\
\text { M(SD) }\end{array}$ & $\begin{array}{l}\text { Asian } \\
\text { M(SD) }\end{array}$ & $\begin{array}{l}\text { Arabic } \\
\text { M(SD) }\end{array}$ & $\begin{array}{l}\text { Kazakh } \\
\text { M(SD) }\end{array}$ \\
\hline Q1- I have a purpose in mind when I read. & 36 & $4.08(.793)$ & $3.18(1.079)$ & $3.89(1.167)$ & $4.25(.957)$ \\
\hline Q2 - I take notes while reading to help me understand what I read. & 36 & $3.67(1.155)$ & $2.18(1.250)$ & $2.22(.972)$ & $3.00(1.414)$ \\
\hline Q3 - I think about what I know to help me understand what I & 36 & $3.83(.835)$ & $4.09(.944)$ & $3.67(1.414)$ & $3.25(.500)$ \\
\hline $\begin{array}{l}\text { Q4 - I take an overall view of the text to see what it is about before } \\
\text { reading it. }\end{array}$ & 36 & $3.50(.674)$ & $3.27(1.009)$ & $3.33(1.500)$ & $4.50(.577)$ \\
\hline $\begin{array}{l}\text { Q5 - When text becomes difficult, I read aloud to help me understand } \\
\text { what I read. }\end{array}$ & 36 & $3.33(1.371)$ & $1.91(1.221)$ & $1.89(.928)$ & $2.75(1.500)$ \\
\hline $\begin{array}{l}\text { Q6 - I think about whether the content of the text fits my reading } \\
\text { purpose. }\end{array}$ & 36 & $.651)$ & $3.27(1.191)$ & $3.67(1.000)$ & 316) \\
\hline $\begin{array}{l}\text { Q7 - I read slowly and carefully to make sure I understand what I am } \\
\text { reading. }\end{array}$ & 36 & $4.67(.651)$ & $4.09(1.044)$ & $4.11(1.054)$ & $4.00(.816)$ \\
\hline $\begin{array}{l}\text { Q8 - I review the text first by noting its characteristics like length and } \\
\text { organization. }\end{array}$ & 36 & $3.42(.900)$ & $3.09(1.136)$ & $3.44(1.236)$ & $3.50(1.291)$ \\
\hline 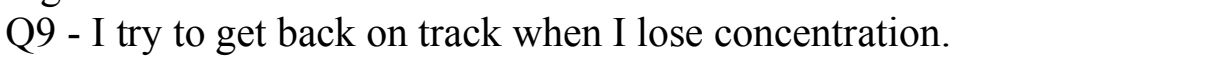 & 36 & 4.58 & 4.45 & 527) & $4.25(.500)$ \\
\hline $\begin{array}{l}\text { Q10 - I underline or circle information in the text to help me remember } \\
\text { it. }\end{array}$ & 35 & $4.17(1.193)$ & $3.40(1.174)$ & $4.00(1.000)$ & $3.75(1.258)$ \\
\hline 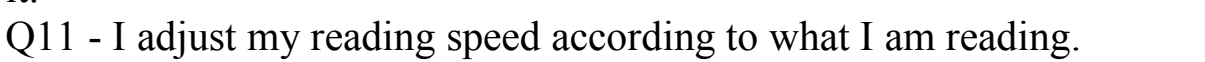 & 3 & & & & 4.0 \\
\hline Q12. & 36 & 2.83 & 3.3 & 2.0 & 957) \\
\hline $\begin{array}{l}\text { Q13 - I use reference materials (e.g. a dictionary) to help me } \\
\text { understand what I read. }\end{array}$ & 36 & $4.75(.452)$ & $3.91(1.300)$ & $3.67(1.658)$ & $4.00(.816)$ \\
\hline Q14 - When text becomes difficult, I pay closer attention to wl & 36 & $4.67(.492)$ & $4.00(.894)$ & $3.56(1.509)$ & $4.50(.577)$ \\
\hline
\end{tabular}




\begin{tabular}{|c|c|c|c|c|c|}
\hline Questions & $\begin{array}{c}\mathrm{N}^{\circ} \text { of } \\
\text { Participants }\end{array}$ & $\begin{array}{l}\text { Spanish } \\
\mathrm{M}(\mathrm{SD})\end{array}$ & $\begin{array}{l}\text { Asian } \\
\mathrm{M}(\mathrm{SD})\end{array}$ & $\begin{array}{l}\text { Arabic } \\
\mathrm{M}(\mathrm{SD})\end{array}$ & $\begin{array}{l}\text { Kazakh } \\
\text { M(SD) }\end{array}$ \\
\hline $\begin{array}{l}\text { Q15 - I use tables, figures, and pictures in text to increase my } \\
\text { understanding. }\end{array}$ & 36 & $4.00(1.128)$ & $3.00(1.000)$ & $3.11(1.537)$ & $3.50(1.000)$ \\
\hline Q16 - I stop from time to time and think about what I am reading. & 36 & $3.42(.996)$ & $3.45(1.214)$ & $2.89(1.364)$ & $3.00(.816)$ \\
\hline $\begin{array}{l}\text { Q17 - I use context clues to help me better understand what I am } \\
\text { reading. }\end{array}$ & 36 & $3.33(1.155)$ & $3.45(1.128)$ & $3.78(1.302)$ & $3.75(.500)$ \\
\hline $\begin{array}{l}\text { Q18 - I paraphrase (restate ideas in my own words) to better understand } \\
\text { what I read. }\end{array}$ & 36 & $3.50(.905)$ & $2.82(1.168)$ & $2.78(1.394)$ & $3.00(1.155)$ \\
\hline $\begin{array}{l}\text { Q19 - I try to picture or visualize information to help remember what I } \\
\text { read. }\end{array}$ & 36 & $4.25(1.138)$ & $3.82(.751)$ & $4.25(.707)$ & $4.25(.957)$ \\
\hline $\begin{array}{l}\text { Q20 - I use typographical features like bold face and italics to identify } \\
\text { key information. }\end{array}$ & 36 & $3.50(1.000)$ & $3.27(1.009)$ & $3.33(1.000)$ & $3.25(1.500)$ \\
\hline $\begin{array}{l}\text { Q21 - I critically analyze and evaluate the information presented in the } \\
\text { text. }\end{array}$ & 36 & $3.17(.718)$ & $3.00(.894)$ & $3.22(1.202)$ & $3.25(.957)$ \\
\hline $\begin{array}{l}\text { Q22 - I go back and forth in the text to find relationships among ideas } \\
\text { in it. }\end{array}$ & 36 & $3.58(.669)$ & $3.45(1.128)$ & $3.22(1.202)$ & $4.25(.957)$ \\
\hline Q23 - I check my understanding when I come across new information. & 36 & $3.83(.718)$ & $3.55(.934)$ & $3.33(1.118)$ & $4.50(.577)$ \\
\hline Q24 - I try to guess what the content of the text is about when I read. & 36 & $3.75(1.055)$ & $3.82(.751)$ & $4.00(1.225)$ & $4.00(.816)$ \\
\hline $\begin{array}{l}\text { Q25 - When text becomes difficult, I re-read it to increase my } \\
\text { understanding. }\end{array}$ & 36 & $4.50(.522)$ & $4.36(.505)$ & $4.44(.726)$ & $4.75(.500)$ \\
\hline Q26 - I ask n & 3 & 3.64 & 2.55( & $2.25(1.282)$ & $2.91(1.164)$ \\
\hline Q27 - I check to & 36 & 3.67( & 2.91(. & $3.11(1.537)$ & $3.33(1.121)$ \\
\hline Q28 - When I read, I guess the meaning of unknown words or phrases. & 36 & $3.83(.937)$ & $3.55(.934)$ & $3.89(1.054)$ & $3.75(.937)$ \\
\hline Q29 - When reading, I translate from English into my native language. & 36 & $3.42(1.311)$ & $3.45(1.214)$ & $3.89(1.167)$ & $3.56(1.182)$ \\
\hline $\begin{array}{l}\text { Q30 - When reading, I think about information in both English and my } \\
\text { mother tongue. }\end{array}$ & 36 & $4.17(1.115)$ & $3.82(1.168)$ & $3.67(1.118)$ & $3.97(1.082)$ \\
\hline
\end{tabular}


According to Oxford and Burry-Stock (1995), reading strategies scored in an average of 3.5 or above are considered high-frequency usage, between 2.5-3.4 are considered moderate frequency usage, and below 2.4 are considered low-frequency usage. The following survey questions are under the global reading strategies category: Q1; Q3; Q4; Q6; Q8; Q12; Q15; Q17; Q20; Q21; Q23; Q24; Q27. The following survey questions are under the problem-solving reading strategy category: Q7; Q9; Q11; Q14; Q16; Q19; Q25; Q28. The following survey questions are under the support reading strategy category: Q2; Q5; Q10; Q13; Q18; Q22; Q26; Q29; Q30.

For the 12 participants from a Spanish language background, data reported a mean strategy that ranged from a high of 4.75 to a moderate 2.83 usage of reading strategies. Regarding GRS, participants reported that $9(69 \%)$ fell in the high usage group, and 4(31\%) fell in the moderate usage group. There were no low-frequency GRS reported by this group of participants. Regarding PSRS, participants responded that $7(87.5 \%)$ fell in the high usage group, and $1(12.5 \%)$ fell in the moderate usage group. Once again, there were no lowfrequency PSRS reported by this group. Regarding SRS, participants reported that 7(78\%) fell in the high usage group, and 2(22\%) fell in the moderate usage group. Spanish speakers did not report low-frequency SRS usage. For this group, the most perceived used reading strategy reported was an SRS: "I use reference materials (e.g., a dictionary) to help me to understand what I read" (Q13), followed by other problem-solving reading strategies: "I read slowly and carefully to make sure I understand what I am reading" (Q7), and "when text becomes difficult, I pay closer attention to what I am reading" (Q14). The least perceived used reading strategy reported was a global reading strategy: "when reading, I decide what to read closely and what to ignore" (Q12).

For the 11 participants from an Asian language background data reported a mean strategy that ranged from a high of 4.45 to a low 1.91. Regarding GRS, participants reported 
that $3(23 \%)$ fell in the high usage group, and $10(77 \%)$ fell in the moderate usage group. There were no low-frequency GRS reported by this group of participants. Regarding PSRS, participants responded that $7(87.5 \%)$ fell in the high usage group, and $1(12.5 \%)$ fell in the moderate usage group. Once again, there were no low-frequency PSRS reported by this group. Regarding SRS, participants reported that 2(22\%) fell in the high usage group, 5(56\%) fell in the moderate usage group and $2(22 \%)$ fell in the low-frequency usage group. For this group, the most perceived used reading strategies reported were three PSRS: "I try to get back on track when I lose concentration" (Q9); "I read slowly and carefully to make sure I understand what I am reading" (Q7); and "when text becomes difficult, I pay close attention to what I am reading" (Q14); and the global reading strategy: "I think about what I know to help me understand what I read" (Q3). The least perceived used strategies were SRS: "when text becomes difficult, I read aloud to help me understand what I read" (Q5), and "I take notes while reading to help me understand what I read" (Q2). Having Q7 and Q14 as the most perceived used reading strategies is consistent with previous research that has demonstrated that $\mathrm{L} 2$ readers tend to read more slowly than native speakers given that L2 readers encounter numerous challenges such as unknown words and cultural references (Alhaqbani \& Riazi, 2012).

Data from the 9 Arabic speaker participants reported a mean strategy that ranged from a high of 4.44 to a low 1.89. Regarding GRS, participants reported that $5(38.5 \%)$ fell in the high usage group, 7(54\%) fell in the moderate usage group, and 1(8\%) fell in the lowfrequency usage group. Regarding PSRS, participants responded that $7(87.5 \%)$ fell in the high usage group, and $1(12.5 \%)$ fell in the moderate usage group. There were no lowfrequency PSRS reported by this group. Regarding SRS, participants reported that 4(44.4\%) fell in the high usage group, $2(22.2 \%)$ fell in the moderate usage group and 3(33.3\%) fell in the low-frequency usage group. For this group, the most perceived used reading strategies 
reported were three PSRS: "when text becomes difficult, I re-read it to increase my understanding" (Q25), followed by the GRS: "I try to guess what the content of the text is about when I read" (Q24), and the SRS: "I underline or circle information in the text to help me remember it" (Q10). These two strategies were rated as $\mathrm{M}=4.00$, the second highest score. The least perceived used strategies were SRS: "when text becomes difficult, I read aloud to help me understand what I read" (Q5), and GRS: "when reading, I decide what to read closely and what to ignore" (Q12).

Having the GRS - Q24 for this group is consistent with previous research. According to Abu-Rabia (1997, 1999), Arabic speakers have to first understand at the sentence level to later understand the word given that diacritic markers that signal vowels are omitted as Arabic learners progress in their reading learning process.

The data from the 4 Kazakhstanis participants reported a mean strategy that ranged from a high of 4.75 to a moderate 2.75 . Regarding GRS, participants responded that $9(69 \%)$ fell in the high usage group, and $4(31 \%)$ fell in the moderate usage group. There were no low-frequency GRS reported by this group of participants. Regarding PSRS, participants responded that $7(87.5 \%)$ fell in the high usage group, and $1(12.5 \%)$ fell in the moderate usage group. Once again, there were no low-frequency PSRS reported by this group. Regarding SRS, participants responded that 5(55.5\%) fell in the high usage group, and $4(44.5 \%)$ fell in the moderate usage group. There were no low-frequency reposted. For this group, the most perceived used reading strategy reported was three PSRS: "when text becomes difficult, I re-read it to increase my understanding" (Q25), and "when text becomes difficult, I pay close attention to what I am reading" (Q14); and the GRS: "I take an overall view of the text to see what it is about before reading it" (Q4). The least perceived used strategy was the SRS: "when text becomes difficult, I read aloud to help me understand what I am reading" (Q5), and "I take notes while reading to help me understand what I read" (Q2). 
The Q25 - "rereading as text becomes difficult" has also been mentioned as an important reading strategy to improve textual understanding, to reflect on content, and to note information that has been previously disregarded as unimportant (Alhaisoni, 2016; Mushait, 2003; Pressley \& Afflerback, 1995).

This initial analysis found that all participants demonstrated a preference for the use of PSRS being the most mentioned reading strategy to read slowly and lay close attention when text becomes difficult. There were a few variances among participants regarding the most perceived used strategy. Nevertheless, there was a consensus when it comes to the least used reading strategy being "Q $\mathrm{Q}$ " regarding reading aloud when text becomes difficult to support better understanding.

After this initial descriptive analysis, I conducted one-way ANOVA with L1s as independent variables and perceived reading strategies as the dependent variables to verify whether there was any statistical significant difference among participants from different L1s regarding their preferences in using the three reading strategies reported in the SORS. Table 4.2 displays the results of the one-way ANOVA.

For GRS, the Levene's test (alpha level of .05) indicated that homogeneity of variance was violated, hence a Welch Robust Test of Equality of Means was conducted. The one-way ANOVA did not report statistical significance among participants from different first language backgrounds regarding their preferences of GRS, $F(3,9.64)=1.64, p=.242$, . Due to the lack of statistical significance no further statistical test was conducted (See Table 4.2).

For PSRS, the Levene's test (alpha level of .05) indicated that homogeneity of variance was also violated, hence a Welch Robust test of Equality of Means was conducted. The one-way ANOVA did not report the statistical significance reported among participants from different first language backgrounds regarding their preferences of PSRS, 
$F(3,12.51)=1.31, p=.313$. Due to the lack of statistical significance no further statistical test was conducted (See Table 4.2).

For SRS, Levene's test indicated that the assumption of homogeneity of variances was not violated, $F(3,28)=1.72, p=.185$. The ANOVA was statistically significant, $F(3,28)=7.37, p=.001$. Additionally, the effect size was large, $\mathrm{n}^{2} .441$ (See Table 4.3). The difference between participants from a Spanish language background and participants from East Asian language backgrounds was statistically significant $(\mathrm{M}=.878, \mathrm{SD}=.201, \mathrm{p}=.001)$ (See Table 4.2) regarding their preferences in using SRS while reading English texts. Another statistical significance was between participants from a Spanish language background and participants from an Arabic language background $(\mathrm{M}=.824, \mathrm{SD}=.268, \mathrm{p}=.018)($ See table 4.3) regarding their preferences in using SRS while reading English texts. There was no statistical significance between Spanish speakers and Kazakh speakers, which could be explained due to the small number of Kazakhstani participants.

Data analysis also reported that Spanish-speaking participants have a high usage of reading strategies with a preference for PSRS, SRS, and GRS, respectively. Participants from Asian language backgrounds, Arabic speakers, and Kazakh speakers demonstrated a preference for PSRS, GRS, and SRS, respectively. Having PSRS as the most perceived used reading strategies is line with previous research with similar results regarding L2 readers (Alhaisoni, 2016; Alsheikh 2009; Alsheik et al., 2011; Malcolm, 2009; Mokhtari \& Reichard 2002, 2004; Wu 2005). Baker and Brown (1984) (as cited in Alhaisoni, 2016) argued that skilled readers use PSRS to increase as well as to monitor reading comprehension. Regarding the results for the Spanish speakers, research studies have also found that for some ESL learners SRS are of great value in increasing text understanding, and that ESL readers place high value on support reading strategies (Sheorey \& Baboczky, 2008; Sheorey \& Mokhtari, 2001). 
Table 4.2

Comparison of Reading Strategies by L1 Background

\begin{tabular}{cccc}
\hline Group & $\mathrm{N}$ & $M(S D)$ & $F$ \\
\hline Global RS & & $3.58(.267)$ & 2.108 \\
Spanish & 12 & $3.21(.593)$ & \\
East Asia & 14 & $3.60(.597)$ & \\
Arabic & 6 & $3.77(.515)$ & \\
Kazakh & 4 & $4.23(.372)$ & \\
Problem-Solving RS & & $3.96(.523)$ & \\
Spanish & 12 & $3.96(.204)$ & \\
East Asia & 12 & $4.06(.239)$ & \\
Arabic & 6 & $3.875^{*}$ \\
Kazakh & 4 & $2.99(.563)$ & \\
Spanish & 11 & $3.04(.542)$ & \\
East Asia & 12 & $3.56(.471)$ & \\
Arabic & 5 & 4 & \\
Kazakh & & & \\
Support & 4 & & \\
\end{tabular}

Note. $\mathrm{N}=$ number of participants. $\mathrm{M}=$ Mean. $\mathrm{SD}=$ Standard Deviation. $F=\mathrm{F}$ value (ANOVA)

$* \mathrm{p}<.05$

Table 4.3

Comparing Different Language Backgrounds (using Post Hoc Test)

\begin{tabular}{lllll}
\hline L1 & Spanish & East Asia & Arabic & Kazakh \\
\hline Spanish & 1 & & & \\
East Asia & $.878^{*}(.201)$ & 1 & & \\
Arabic & $.804^{*}(.260)$ & $.054(.256)$ & 1 & 1 \\
Kazakh & $.313(.281)$ & $.565(.278)$ & $.511(.323)$ & 1 \\
\hline
\end{tabular}

$* \mathrm{p}<.05$

Research Question 2: What Are the Reading Strategies That Adult English Learners at

Different English Proficiency Levels (Beginning, Intermediate, and Advanced)

Recognize as the Most Frequently Used While Reading English Text? And to

What Extent Does the Frequency of Reading Strategies Perceived Differ

Significantly by Proficiency Levels?

To answer the second research question, I performed the same statistical analyses described above, however, participants' responses for individual strategies were analyzed based on their language proficiency level. The same procedures described above regarding participants skipping questions were followed for this analysis. Table 4.5 displays the results 
of the descriptive statistic for each individual question on the SORS based on participants' language proficiency level 
Table 4.4

\section{Descriptive Statistics Based on L2 Proficiency}

\begin{tabular}{|c|c|c|c|c|}
\hline Questions & $\begin{array}{c}\mathrm{N}^{\circ} \text { of } \\
\text { Participants }\end{array}$ & $\begin{array}{l}\text { Beginner (4) } \\
\mathrm{M}(\mathrm{SD})\end{array}$ & $\begin{array}{l}\text { Intermediate } \\
\mathrm{M}(\mathrm{SD})\end{array}$ & $\begin{array}{l}\text { Advanced } \\
\mathrm{M}(\mathrm{SD})\end{array}$ \\
\hline Q1- I have a purpose in mind when I read. & 36 & $4.25(.500)$ & $3.61(1.037)$ & $3.91(1.136)$ \\
\hline Q2 - I take notes while reading to help me understand what I read. & 36 & $3.50(.577)$ & $2.61(1.461)$ & $2.73(1.104)$ \\
\hline Q3 - I think about what I know to help me understand what I read. & 36 & $3.00(.000)$ & $3.89(1.231)$ & $4.00(.632)$ \\
\hline $\begin{array}{l}\text { Q4 - I take an overall view of the text to see what it is about before } \\
\text { reading it. }\end{array}$ & 36 & $3.75(.500)$ & $3.39(.979)$ & $3.45(1.368)$ \\
\hline $\begin{array}{l}\text { Q5 - When text becomes difficult, I read aloud to help me understand } \\
\text { what I read. }\end{array}$ & 36 & $4.25(.957)$ & $2.17(1.150)$ & $2.27(1.421)$ \\
\hline $\begin{array}{l}\text { Q6 - I think about whether the content of the text fits my reading } \\
\text { purpose. }\end{array}$ & 36 & $3.75(.500)$ & $3.33(1.085)$ & $4.00(.632)$ \\
\hline $\begin{array}{l}\text { Q7 - I read slowly and carefully to make sure I understand what I am } \\
\text { reading. }\end{array}$ & 36 & $4.75(.500)$ & $4.28(1.018)$ & $4.09(.944)$ \\
\hline $\begin{array}{l}\text { Q8 - I review the text first by noting its characteristics like length and } \\
\text { organization. }\end{array}$ & 36 & $3.50(.577)$ & $3.11(.963)$ & $3.45(1.368)$ \\
\hline Q9 - I try to get back on track when I lose concentration. & 36 & $4.75(.500)$ & $4.44(.616)$ & $4.55(.522)$ \\
\hline $\begin{array}{l}\text { Q10 - I underline or circle information in the text to help me remember } \\
\text { it. }\end{array}$ & 35 & $4.75(.500)$ & $3.72(1.127)$ & $3.50(1.269)$ \\
\hline Q11 - I adjust my reading speed according to what I am reading & 35 & $4.25(.500)$ & $3.89(.900)$ & $3.60(.966)$ \\
\hline Q12 - When reading, I decide what to read closely and what to ignore. & 36 & $3.00(.816)$ & $2.89(1.132)$ & $2.45(1.293)$ \\
\hline $\begin{array}{l}\text { Q13 - I use reference materials (e.g. a dictionary) to help me understand } \\
\text { what I read. }\end{array}$ & 36 & $4.75(.500)$ & $4.06(1.392)$ & $4.00(1.183)$ \\
\hline $\begin{array}{l}\text { Q14 - When text becomes difficult, I pay closer attention to what I am } \\
\text { reading. }\end{array}$ & 36 & $4.25(.500)$ & $4.28(.958)$ & $4.00(1.342)$ \\
\hline Q15 - I use tables, figures, and pictures in text to increase my & 36 & $4.25(.957)$ & $3.50(1.043)$ & $3.09(1.578)$ \\
\hline
\end{tabular}
understanding.

table continues 


\begin{tabular}{|c|c|c|c|c|}
\hline Questions & $\begin{array}{c}\mathrm{N}^{\circ} \text { of } \\
\text { Participants }\end{array}$ & $\begin{array}{l}\text { Beginner (4) } \\
\text { M(SD) }\end{array}$ & $\begin{array}{l}\text { Intermediate } \\
\mathrm{M}(\mathrm{SD})\end{array}$ & $\begin{array}{l}\text { Advanced } \\
\text { M(SD) }\end{array}$ \\
\hline Q16 - I stop from time to time and think about what I am reading. & 36 & $3.50(.577)$ & $3.00(1.414)$ & $3.45(.688)$ \\
\hline $\begin{array}{l}\text { Q17 - I use context clues to help me better understand what I am } \\
\text { reading. }\end{array}$ & 36 & $3.50(1.291)$ & $3.17(1.200)$ & $3.82(.751)$ \\
\hline $\begin{array}{l}\text { Q18 - I paraphrase (restate ideas in my own words) to better understand } \\
\text { what I read. }\end{array}$ & 36 & $3.75(.500)$ & $2.78(1.263)$ & $3.00(1.000)$ \\
\hline $\begin{array}{l}\text { Q19 - I try to picture or visualize information to help remember what I } \\
\text { read. }\end{array}$ & 36 & $4.75(.500)$ & $4.12(.697)$ & $3.91(1.221)$ \\
\hline $\begin{array}{l}\text { Q20 - I use typographical features like bold face and italics to identify } \\
\text { key information. }\end{array}$ & 36 & $3.75(.957)$ & $3.22(.943)$ & $3.36(1.120)$ \\
\hline $\begin{array}{l}\text { Q21 - I critically analyze and evaluate the information presented in the } \\
\text { text. }\end{array}$ & 36 & $3.00(.816)$ & $3.00(.767)$ & $3.27(1.191)$ \\
\hline $\begin{array}{l}\text { Q22 - I go back and forth in the text to find relationships among ideas } \\
\text { in it. }\end{array}$ & 36 & $3.25(.500)$ & $3.28(1.018)$ & $4.00(1.095)$ \\
\hline Q23 - I check my understanding when I come across new information. & 36 & 3.25 & 907) & $3.91(.944)$ \\
\hline Q24 - I try & 36 & $3.50(.577)$ & $3.89(1.023)$ & $3.91(1.044)$ \\
\hline $\begin{array}{l}\text { Q25 - When text becomes difficult, I re-read it to increase my } \\
\text { understanding. }\end{array}$ & 36 & $4.25(.500)$ & $4.44(.616)$ & $4.64(.505)$ \\
\hline Q26 - I ask myself questions I like to have answered in the text. & 34 & 3.50 & 2.88( & $2.70(1.337)$ \\
\hline Q27 - I check to & 36 & $3.50(.577)$ & $3.22(1.215)$ & $3.55(1.214)$ \\
\hline Q28 - When I read, I gu & 36 & $3.501(.000)$ & $3.83(.985)$ & $3.64(.924)$ \\
\hline Q29 - When reading, I tral & 36 & $2.75(.708)$ & $4.00(1.029)$ & $3.27(1.104)$ \\
\hline $\begin{array}{l}\text { Q30 - When reading, I think about information in both English and my } \\
\text { mother tongue. }\end{array}$ & 36 & $3.50(1.000)$ & $3.67(1.188)$ & $4.45(.820)$ \\
\hline
\end{tabular}


As Table 4.5 displays, data from the 4 beginner participants reported a mean strategy ranging from a high of 4.75 to a moderate 2.75. Regarding GRS, participants reported that 9 $(69 \%)$ fell in the high usage group, and $4(31 \%)$ fell in the moderate usage group. There were no low-frequency GRS reported by this group of participants. Regarding PSRS, participants responded a high usage of PSRS, that is, all the 8 questions fell in the high usage group. There were no moderate or low-frequency reading strategies reported by this group of participants. Regarding SRS, participants responded that 7 (77.7\%) fell in the high usage group, and $2(22.2 \%)$ fell in the moderate usage group. No low-frequency usage was reported by this group once again. The most used reading strategy by this group was two PSRS: "I read slowly and carefully to make sure I understand what I am reading" (Q7), and "I try to get back on track when I lose concentration" (Q9). The least used strategy reported by this group was a SRS: “when reading, I translate from English into my native language” (Q29). This response is not in line with other studies that have demonstrated the high usage of this strategy by L2 learners (Malcolm, 2009).

Data from the 18 intermediate participants reported a mean strategy that ranged from a high of 4.44 to a low 2.17 (See Table 4.5). Regarding GRS, participants reported that $5(38.5 \%)$ fell in the high usage group, $8(61.5 \%)$ fell in the moderate usage group. Among the beginner group, there were no low-frequency GRS reported. Regarding PSRS, participants responded that $7(87.5 \%)$ fell in the high usage group, and $1(12.5 \%)$ fell in the moderate usage group. There were no low-frequency PSRS reported by this group as well. Regarding SRS, participants reported that 3(33.3\%) fell in the high usage group, $5(55.5 \%)$ fell in the moderate usage group and $1(11.1 \%)$ fell in the low-frequency usage group. For this group, the most used reading strategy reported was two PSRS: "I try to get back on track when I lose concentration" (Q9), and "when text becomes difficult, I reread it to increase my understanding" (Q25). These two strategies were rated as $M=4.44$. The least used reading 
strategy was an SRS: "when text becomes difficult, I read aloud to help me understand what I read" (Q5). The most frequently and least perceived used reading strategies were also mentioned by participants from different L1s. As discussed previously, research has already demonstrated that L2 learners adapt their reading by slow down and/or by making sure they are keeping track of their reading.

Data from the 11advanced participants reported a mean strategy rangeing from a high of 4.55 to a moderate 2.70 (See Table 4.5). Regarding GRS, participants reported that $6(46.1 \%)$ fell in the high usage group, $6(46.1 \%)$ fell in the moderate usage group, and 1(7.7) fell in the low-frequency usage group. Regarding PSRS, as the intermediate group, advanced language proficiency level participants also responded that $7(87.5 \%)$ fell in the high usage group, and 1(12.5\%) fell in the moderate usage group. There were no low-frequency PSRS reported by this group as well. Regarding SRS, participants reported that $4(44.4 \%)$ fell in the high usage group, $4(44.4 \%)$ fell in the moderate usage group, and $1(11.1 \%)$ fell in the lowfrequency usage group. For this group, the most used reading strategy reported was also a PSRS: "I try to get back on track when I lose concentration" (Q9). The least used reading strategy was an SRS: "I ask myself questions I like to have answered in the text" (Q26).

This initial analysis demonstrated that there was a consensus among participants from different language proficiency levels regarding the most perceived used strategy (Q 9). Participants varied in their perceived use of the least used strategy. Once again, data showed a preference for PSRS among these participants. Research studies have demonstrated that readers tend to report reading strategies at a high-frequency usage (Alhaisoni, 2016). However, it is important to be cautious about participants' perceived use of reading strategies given that it may not reflect the actual use of these reading strategies.

After descriptive analysis, I conducted one-way ANOVA with language proficiency levels as an independent variable and perceived reading strategies as the dependent variables 
to verify whether there was any statistical significance among participants from different proficiency language levels regarding participants' preferences in using the three reading strategies reported in the SORS. Table 4.6 display the results of the one-way ANOVA.

For GRS, the Levene's test (alpha level of .05) indicated that homogeneity of variance was not violated, $F(2,31)=2.07, p=.142$. The ANOVA was not statistically significant, $F(2,31)=.648, p=.530$, i.e, no statistical difference was reported among participants with different English proficiency levels regarding their preferences of GRS. Due to the lack of statistical significance no further statistical test was conducted (see Table 4.6).

For PSRS, the Levene's test (alpha level of .05) indicated that homogeneity of variance was violated, hence a Welch Robust test of Equality of means was conducted. The one-way ANOVA did not report statistical significance, $F(2, .119)=.273, p=.244$, i.e, no statistical difference was reported among participants with different English proficiency levels regarding their preferences of PSRS. Due to the lack of statistical significance no further statistical test was conducted (see Table 4.6).

For SRS, Levene's test indicated that the assumption of homogeneity of variances was violated, hence a Welch Robust test of Equality of means was conducted. The one-way ANOVA did report statistical significance, $F(2,16.33)=6.43, p=.009$ (see Table 4.6). In this case, Brown-Forsythe test was also consulted. The ANOVA did not report statistical significance, $F(2,26.12)=2.20, \mathrm{p}=.130$. Due to the contradictory results, post hoc tests were conducted. Given that the homogeneity of variances was violated, Games-Howell (Field, 2013) was conducted. The ANOVA reported a statistical significance $(\mathrm{M}=.481, \mathrm{SD}=.154$, $\mathrm{p}=.024)$, meaning that beginner and advanced English proficiency level participants differ in their preferences regarding the perceived use of SRS.

It is interesting to observe that participants reported a high to moderate usage of strategies, but none of the independent groups reported GRS as the most used. According to 
Mokhtari and Sheorey (2008), foreign language and second language skilled readers are characterized as being globally aware, that is, they tend to use more GRS than those at the beginning of the reading learning process. Phakiti (2003) has also found that readers who used metacognitive reading strategies more frequently perform better in reading tests.

Table 4.5

Comparison of Reading Strategies by Proficiency Level

\begin{tabular}{lccc}
\hline Group & $\mathrm{N}$ & $M(\mathrm{SD})$ & $F$ \\
\hline Global RS & & & .648 \\
Beginner & 4 & $3.54(.166)$ & \\
Intermediate & 19 & $3.34(.549)$ & \\
Advanced & 11 & $3.55(.538)$ & .732 \\
Problem-Solving RS & & & \\
Beginner & 4 & $4.25(.270)$ & \\
Intermediate & 18 & $3.06(.484)$ & 1.079 \\
Advanced & 10 & $3.78(.157)$ & \\
Support RS & & $3.28(.757)$ & \\
Beginner & 4 & $3.30(.397)$ & \\
Intermediate & 17 & 9 & Advanced
\end{tabular}

Note. $\mathrm{N}=$ number of participants. $\mathrm{M}=$ Mean. $\mathrm{SD}=$ Standard Deviation. $F=\mathrm{F}$ value (ANOVA) $* \mathrm{p}<.05$

\section{Focus Group SORS}

Statistical analysis was also conducted with the survey of participants for phase two. This analysis was important in order to crosscheck information from SORS of phase 1, MAs, RMAs and interviews, so that I could have more insights into the reading process of my participants. The data obtained with the focus group received two forms of statistical analysis: descriptive statistic, one-way Analysis of Variance (ANOVA). The descriptive statistics are presented on Table 4.6, which shows the means and standard deviation of the Global Reading Strategy (GRS), Problem-Solving Reading Strategy (PSRS), and Support Reading Strategy (SRS). 
Table 4.6

Descriptive Statistics - Focal Group

\begin{tabular}{lcc}
\hline Reading Strategies & $\mathrm{N}$ & $M(S D)$ \\
\hline GRS & 5 & $2.93(.481)$ \\
PSRS & 5 & $3.80(.590)$ \\
SRS & 5 & $2.98(.728)$ \\
Total & 15 & $3.24(.696)$ \\
\hline
\end{tabular}

Note. $\mathrm{N}=$ number of participants. $\mathrm{M}=$ Mean. $\mathrm{SD}=$ Standard Deviation.

The descriptive statistical analysis demonstrated that there were similar scores when considering the GRS and SRS, whereas the PSRS had much higher mean scores. While analyzing the mean differences with the descriptive statistical analysis, it appears that participants may have a preference for using PSRS over SRS and GRS. In order to verify this apparent trend, a one-way ANOVA was conducted to verify if there were statistical differences among all three reading strategies while comparing them. In order to assume equal variances across all groups, a Levene's test of homogeneity of variances was conducted. The Levene's test resulted in an F-value of .508, with a p-value of .614, hence indicating that assumption of equality of variance has not been violated. The one-way ANOVA reported no statistical difference, $F(2,14)=3.175, \mathrm{p}=.078$, indicating that although there were differences among all three reading strategies means, they were not statistically significant.

Even though statistical tests did not report any statistical significance among the perceived use of the three reading strategies, reading aloud, RMAs, and interviews suggested that there was a predominance of PSRS used by participants on the second phase of this study. These strategies refer to local strategies to solve a problem right there on the spot. PSRS was followed by SRS and, lastly, GRS as statistics suggested. This second phase of the study, however, demonstrated that Arabic speakers used more PSRS, SRS, and GRS while ANOVA demonstrated a perceived use as PSRS, GRS, and SRS. Therefore, comparing results is essential to deep our understanding of the actual use of these reading strategies. 
These results seem to reinforce the initial ANOVA analysis from phase 1 that verified which of the three types of reading strategies (global, problem solving and support) L2 learners from different L1 background perceived using more. ANOVA analysis from phase 1 also suggested that there was significant difference among L2 learners from different language background regarding the use of support reading strategies. Zhang et al. (2009) argued that the use of support reading strategies depends on context, L2 readers are flexible in their use of reading strategies. In other words, each context requires different uses of reading strategies. For instance, L2 readers are not able to use a dictionary/translator in an international English test. Therefore, they may not rate it highly (5 - I always or almost always do this).

Descriptive analysis on phase 1 reported that one of the least used strategies was the support reading strategy: "when text becomes difficult, I read aloud to help me understand what I read" (Q5). However, all participants on phase 2 mentioned reading aloud as a strategy to raise comprehension. It seems that they can remember someone saying the target word, and mimic that person (Cho, 2016; Cho \& Feldman, 2016; Zhou \& Christianson, 2016 a, b), so that comprehension is achieved.

\section{Summary}

When data were analyzed based on participants' L1, there was a high variation between means. However, when data were analyzed based on participants' proficiency language levels, there was a moderate variation between means. This high variation in means regarding L1 languages suggested that those from different L1s may use and/or perceive the use of different reading strategies differently while approaching a text. This is aligned with previous research that has suggested that learners from different L1s have to learn different reading strategies to cope with text due to language specific challenges (Bernhardt, 2011; Koda, 1995, Ziegler et al., 2005, 2006). As a result, they may transfer L1 knowledge of 
reading strategies to the L2 situation even though the strategy is not appropriated to the L2 situation (Bernhard, 2011; Koda, 2007).

Results also showed a significant difference regarding the perceived use of support reading strategies. Participants' perceived use of reading strategies are also aligned with research on second language reading, which has indicated L2 learners' preferences for PSRS, GRS, and SRS, respectively (Alsheikh, 2009; Alsheikh et al., 2011; Mokhtari, 2008; Zhang $\& \mathrm{Wu}, 2009)$. The only group that did not follow these preferences were participants from a Spanish language background, who seemed to perceive the use of PSRS, SRS, and GRS, respectively. Thus, ANOVA results yielded statistical significance regarding the use of SRS between Spanish speakers and Asian speakers and Arabic speakers. However, this result should be accepted with caution given that this difference may be the result of the different number of participants for each L1 language. Further investigation is needed to explore whether there is any difference in the perceived use of the three reading strategies in the SORS by L2 learners from different L1 backgrounds.

Results from the language proficiency levels indicated that there was no high variation in means. This suggests that participants from the same proficiency level tend to perceive the use of reading strategies similarly. Results also suggested that intermediate and advanced proficiency level learners tend to perceive the use of reading strategies as following: PSRS, GRS, and SRS. Beginning learners, however, differ in their perceived use of reading strategies. They seemed to prefer PSRS, SRS, and GRS, respectively. Nevertheless, ANOVA results did not report any statistical difference among participants from different language proficiency levels regarding their preferences in using these three different types of reading strategies.

Although some results demonstrated statistical significance regarding the perceived use of reading strategies, such results need to be taken with a grain of salt given that there 
was a difference in the number of participants in both L1 participants and L2 proficiency level. Furthermore, self-report surveys are based on participants' perceptions. They may not represent reality. Therefore, it is important to conduct research that also confirms actual use of reading strategies (Alhaqbani \& Riazi, 2012; Malcolm, 2009, Mokhtari, 2008) by applying different methods to collect and analyze data.

The next chapter deals with this drawback of using survey designs by employing a qualitative design to collect and analyze data. In the next chapter, I provide a detailed description of data analysis from the qualitative portion of this study by presenting participants' miscues, RMAs discussion, and interviews. I also present a discussion about the results in relation to he literature in the area of second language reading. 


\section{CHAPTER V: QUALITATIVE RESULTS AND ANALYSIS}

\section{Overview}

The main purpose of this study was to investigate reading strategies used by second language learners while reading in English. As previously stated, studies on L2 reading comprehension have not attended to the fact that L2 learners may have to learn additional reading strategies and/or become aware of reading strategies necessary for reading English texts. This chapter details my qualitative results and analyses by focusing specifically on the following research questions:

(RQ-3) What reading strategies do adult English learners have to learn and/or become aware of in order to make sense of English texts? Of those, which ones are most frequently used?

(RQ-4) How do adult English learners understand their own use of reading strategies and metacognitive awareness?

In order to answer these questions, a mixed method grounded theory in a sequential design was applied (quantitative - Qualitative) with a qualitative dominant status (Creswell \& Clark, 2011; Johnson et al., 2004; Shannon-Baker, 2016). For this qualitative phase, data were collected by reading-aloud and by semi-structured interviews with five Saudi-Arabian male international English students enrolled in the English Language Program at Illinois State University. Data were coded and analyzed for categories and themes. First, I present the findings of each participant's miscue patterns. Even though participants were using the same cueing system (graphophonic similarity, semantic acceptability, and syntactic acceptability) presented by Goodman (1976), there were miscues that did not fit the standard code system of miscue analysis as it has been previously discussed. Therefore, participants' miscues were presented according to their types to verify whether or not they were transferring their RS from their L1 to the L2 situation across types of miscues. It is important to bear in mind that 
although a miscue was used to exemplify one category, this does not mean that the same miscue does not fit another category. Finally, I present the findings of RMAs and interviews inasmuch as they are interwoven and complement one another to answer research questions three and four.

\section{Participants' Views as Readers and Participants' Views of the Reading Process}

Five male Saudi-Arabian intermediate students participated on the second phase of this study. According to English instructors, the intermediate level is compared with the A2B1 proficiency level according to the Common European Framework, and students would have a TOEFL score around 39-59 IBT or 420-490 PBT.

During interviews, participants recognized themselves as good readers in their L1 (Arabic Language). They argued that they do not face problems such as mispronunciation, unknown words, or comprehension issues while reading in Arabic. Nevertheless, this perspective shifted when considering reading in English. According to participants, they are "not so good readers" in English. They shared this perspective regarding English while dealing with unknown words, which they usually translated into their own language in order to better comprehend English texts. However, as participants argued, this strategy does not always work given that sometimes there are several meanings for a single word. For instance, the verb 'set' can have multiple meanings depending on context. They also pointed out that phrasal verbs are also very challenging while trying to understand a text because they have a new and different meaning than the words that form them (ex. look out, give up). As Haddad described: "Also, the English for reading is more complicated because they have phrasal verbs. I hate phrasal verbs. They change the idea. The meaning. Yeah that is the reason because I don't understand" (Interview, 07/07/16). In these cases, they have to look at the context to try to figure out which meaning would be the most appropriate to the task at hand as Fadil explained "I guess, you know? I guess from the whole sentence whole paragraph all 
content" (Interview, 06/30/16). They also affirmed that long texts with more than two pages are challenging because they need to sustain attention over a long period. This results in cognitive fatigue given the cognitive load (Eskey, 2002), in addition to loss of motivation given that input is beyond readers' ability (Dörnyei, 2005; Krashen, 1992, 1985).

Participants also shared a common understanding of reading, which they see as a very straight forward activity in which the reader's job is to decode every single word and understand their meanings to decipher what the writer is trying to transmit to the reader. So, they share a bottom-up view of reading (Afflerbach et al., 2008a, 2008b; Jiménez, 1997; Zang, 2010). This view of reading could limit their comprehension given that idiomatic expressions and other figurative language could be lost in translation. Furthermore, they have a passive view of reading in which they do not acknowledge and/or value actively constructing meaning of the text while reading.

\section{Miscue Results}

For the two read-aloud sessions, I chose two texts with similar characteristics following Goodman, Watson, and Burke's (1987) suggestions regarding text appropriateness. Participants' English instructors were also consulted regarding the appropriateness of the texts. According to English instructors, the two chosen texts would pose some challenges for participants, but they would be able to understand the main idea and some details. These texts were also chosen due to its similarities with texts in international English tests, a genre with which participants were very familiar. The texts were composed of a title, the author's name followed by a picture with its legend, and the text itself (See Appendices D and E). Table 5.1 shows the textual features of the two texts used in the read-aloud. Text 1 (See Appendix D) has a Flesch-kincaid Grade level 10.3 and Flesch-kincaid Reading ease is 51.1 with a readability level comparable to fairly difficult texts at the end of high school, while text 2 
(See Appendix E) has a Flesch-kincaid Grade level is 11.2 and Flesch-kincaid Reading ease is 45.8 with a readability level comparable to college level.

As English instructors foresaw, participants were able to summarize the main idea of the texts and describe some details. In participants' unaided retelling (Y. Goodman et al., 1987) Azim, Haddad, and Emir were able to talk about the astronauts' experiences of seeing the Earth from space and how astronauts felt. Only Haddad was able to mention the specific term used in the text, "the overview effect". Casper was very concise in his explanation, but he was also able to point out the main idea by saying that "seeing the half of the earth from space makes them (astronauts) happy or something (awe)." Fadil understood that astronauts were going to space and that this experience had some effect on the astronauts, but he was unable to identify the strong feeling (awe) of seeing the Earth from the space.

When I prompted participants to expand their retelling (i.e. aided retelling), Azim was the only participant able to add some details to his explanation, such as the fact that the overview effect has been studied at the university of Pennsylvania as well as the fact that the overview effect can also be experienced in Earth. The other participants indicated the overwhelming amount of unknown words in the text. In Fadil's words: "Wow, what are the words here?" (Reading, 06/30/16). Haddad also expressed his fatigue after reading the first text. For the second retelling, all participants were able to identify the main idea as well as some details. For instance, all participants stated that the main idea was about busyness. Regarding the degree of detail recalled, participants pointed out the benefits and the disadvantages of being busy, and how busyness affects people of different ages, levels of education, and gender differently. 
Table 5.1

Text Features

\begin{tabular}{lc}
\hline Text Features & Count \\
\hline Titles & 1 \\
Text 1 & 1 \\
Text 2 & \\
Illustration & 1 \\
Text 1 & 1 \\
Text 2 & \\
Caption & 1 \\
Text 1 & 1 \\
Text 2 & \\
Pages & 2 \\
Text 1 & 2 \\
Text 2 & \\
Words & \\
Text 1 & 956 \\
Text 2 & 809 \\
Paragraphs & \\
Text 1 & 18 \\
Text 2 & 19 \\
Sentences & \\
Text 1 & 52 \\
Text 2 & 45 \\
\hline
\end{tabular}

Table 5.2 displays the descriptive of miscue analysis of each participant for text 1 as well as for text 2. Pseudonyms were used to protect participants' identity. 
Table 5.2

Descriptive MA by Participant

\begin{tabular}{|c|c|c|c|c|c|}
\hline Descriptive & Azim & Casper & Haddad & Fadil & Emir \\
\hline \multicolumn{6}{|l|}{ Words Read } \\
\hline Text 1 (956w) & $945 \mathrm{w}$ & $949 w$ & $945 \mathrm{w}$ & $950 w$ & $945 \mathrm{w}$ \\
\hline Text $2(809 w)$ & $798 \mathrm{w}$ & $782 w$ & $791 \mathrm{w}$ & $798 w$ & 798w \\
\hline \multicolumn{6}{|l|}{ Time on Task } \\
\hline Text 1 & $16 \mathrm{~min}$ & $14 \mathrm{~min}$ & $10 \mathrm{~min}$ & $15 \mathrm{~min}$ & $9 \mathrm{~min}$ \\
\hline Text 2 & $16 \mathrm{~min}$ & $13 \mathrm{~min}$ & $10 \mathrm{~min}$ & $15 \mathrm{~min}$ & $7 \mathrm{~min}$ \\
\hline \multicolumn{6}{|l|}{ Words/Minutes } \\
\hline Text 1 & $59 / \mathrm{min}$ & $68 / \mathrm{min}$ & $94 / \mathrm{min}$ & $63 / \mathrm{min}$ & $105 / \mathrm{min}$ \\
\hline Text 2 & $50 / \mathrm{min}$ & $61 / \min$ & $79 / \mathrm{min}$ & $53 / \mathrm{min}$ & $114 / \mathrm{min}$ \\
\hline \multicolumn{6}{|l|}{ Total Miscues } \\
\hline Text 1 & 128 & 110 & 141 & 119 & 48 \\
\hline Text 2 & 110 & 75 & 105 & 102 & 31 \\
\hline \multicolumn{6}{|l|}{ Miscue/Word } \\
\hline Text 1 & 0.040 & 0.039 & 0.065 & 0.046 & 0.008 \\
\hline Text 2 & 0.026 & 0.035 & 0.059 & 0.059 & 0.010 \\
\hline \multicolumn{6}{|l|}{ Miscues Impacting } \\
\hline \multicolumn{6}{|l|}{ Comprehension } \\
\hline Text 1 & 38 & 37 & 62 & 45 & 8 \\
\hline Text 2 & 21 & 29 & 47 & 38 & 9 \\
\hline \multicolumn{6}{|l|}{ Readers' Reading } \\
\hline Text 1 & $96 \%$ & $96 \%$ & $93 \%$ & $95 \%$ & $99 \%$ \\
\hline Text 2 & $97 \%$ & $96 \%$ & $94 \%$ & $95 \%$ & $98 \%$ \\
\hline
\end{tabular}

Participants differed in the amount of words read because they decided to start their reading from different points. In the first read-aloud, Azim, Casper, Emir, Fadil and Haddad had not read the title, starting their reading from the first paragraph. Casper also did not read the title, but instead started his first reading from the photo caption, followed by the first paragraph. Fadil was the only participant to start reading from the title in both readings. He did not read the picture legend. Therefore, in order to come up with the amount of words per text, all words in the texts were counted, including the photo caption. This demonstrates how each reader engages differently with a text in order to start constructing meaning of it.

When I pointed out to Azim and Emir that they had not read the title, but they had started reading from the first paragraph, they affirmed that they had glanced over the title. When I asked Azim why he had not read the title, he said 'I don't know. I just started from 
the passage, and I kept reading" (RMA, 06/26/16). Emir also affirmed that he missed the title, explaining that he learned in school to start reading from the first paragraph.

"Aline: Why did you start reading here in the first paragraph instead of starting reading here?

Emir: I used to it, actually I am used to it. I usually when I read, I read this for myself. I usually start from this was what I was taught in my school, country. We start from the first text.

\section{Aline: Paragraph?}

Emir: Yeah, paragraph that is right. The topic (title), we use to read it, but some I don't know how to say it, but in sometimes I don't know how to say, but usually I use to read the first paragraph.

Aline: Do you think that reading the title would help you to understand the text?

Emir: Yeah, sure. It helps me a lot, but I don't know why I missed it in the first place”.

Casper started his second reading again from the picture legend. He also skipped an entire line in his second reading. Haddad started his second reading from the first paragraph like in his first reading.

Participants spent a similar amount of reading time (See Table 5.2) on both texts. Nevertheless, they affirmed that text 2 was easier than text 1 due to easier vocabulary, while text 1 had a lot of difficult and new vocabulary. Fadil was the only participant to recognize text 1 as a new topic - the transcendental experience of seeing Earth from space, while text 2 was a familiar topic - busyness, which also contributed to a better textual understanding (Kucer \& Silva, 2006). Fadil's explanation demonstrated his awareness of using his background knowledge while reading a text although this awareness may not be activated 
across different genres. In other words, he may have more difficulty activating previous knowledge when texts are out of his area of interest and/or familiarity.

Four participants read more words per minute in text 1 than text 2. Emir was the only participant who read more words per minute in text 2 than text 1 . He argued that text 1 was easier for him than text 2 because he was more interested in the text 1 topic, so he wanted to finish text 2 as soon as possible. This demonstrates that Emir's motivation played an important role in his reading. In other words, he may apply himself more when he is motivated to read a text (Guthrie \& Wigfield, 2000) As a result, he may be able to understand the text better.

Participants reasoned that there are a lot of unknown words in text 1; in comparison to text 2. All participants considered astronauts, transcendental, and awe as the most challenging words in text 1 . These words posed problems regarding pronunciation as well. Participants used the delayed reading strategy (Kintsch, 1998), in which readers use any encounter with the unknown word in the text to delineate its meaning. For instance, the word 'awe' appeared eleven times in the first text. In the following segments:

"No amount of prior study or training can fully prepare anybody for the awe and wonder this inspires," wrote space shuttle astronaut Kathryn D. Sullivan”. (Text1, Page 1, Line 11)

"The Overview Effect elicits a sense of awe in its purest, most intense form. Emotion researchers have only recently begun studying the effects of awe, but they believe we experience awe when we are confronted with something vast, either physically big (the Grand Canyon, for example) or conceptually huge (like meeting your favorite celebrity)". (Text1, Page 2, Line 7) 
"The Overview Effect seems to contain both of those aspects of awe," Yaden told The Week”. (Text1, Page 2, Line 12)

"Back on Earth, awe has been linked to pro-social behavior, altruism, and inclusive thinking”. (Text1, Page 2, Line 17)

"And indeed, awe can change people's lives". (Text1, Page 2, Line 20)

"Yaden believes the Overview Effect, and the awe it elicits, should be taken into consideration as we consider sending astronauts deeper into space on longer, more isolating missions”. (Text1, Page 2, Line 22)

"We don't need to go to space to benefit from intense experiences of awe," Yaden says". (Text1, Page 2, Line 29)

"Glance up at the stars and ponder your very existence on our own pale blue dot, and let the awe wash over you". (Text1, Page 2, Line 32) Although participants were not able to articulate the exact meaning of this word, they were able to somewhat grasp its meaning. For instance, they were able to determine that 'awe' referred to an exceptional experience that causes amazement.

In text 2 , the most puzzling words were cognitive and cognition, as in the following segments:

"In fact, it might actually improve cognitive function as we age. In other words, being busy may be good for the brain”. (Text 2, Page 1, Line 6)

"To fill that gap, the researchers devised a study to examine the relationship between busyness and cognition”. (Text 2, Page 1, Line 12)

"Then they spent two to three hours over two days undergoing a battery of tests designed to measure various cognitive functions, such as processing speed, reasoning, working memory, and episodic long-term 
memory, which is memory of personal events and their context”. (Text 2, Page

\section{1, Line 15)}

"But it was in comparing the busyness scale with the cognitive testing results where things got really interesting. Greater busyness was directly associated with higher cognition, and this was the case regardless of gender or education. And perhaps most interesting of all, the data showed that this relationship between busyness and cognitive acuity did not vary with age. A busy 89-year-old person had the same cognitive sharpness as someone almost 40 years younger". (Text 2, Page 1, Line 21)

"But it's not clear whether people with higher cognitive function seek a busier lifestyle in the first place, versus the idea that staying active results in improved brain activity”. (Text 2, Page 2, Line 27)

"Even though this study alone can't tell us conclusively that busyness increases cognitive function, maybe it can fundamentally shift our snarky relationship with our bustling lifestyles". (Text 2, Page 2, Line 243)

Here, readers also used a delay strategy in which they took advantage of word encounters to ameliorate their understanding of this unfamiliar word. For instance, Azim while talking about the meaning of cognitive in our RMA session pointed to his head to clarify his understanding of cognitive and cognition. Although he was unable to explain the word meaning with his own words, he was able to demonstrate that he understood that these two words referred to his brain activities.

Both the total of miscues and miscues impacting comprehension were higher in text 1 than text 2. While considering the total number of miscues, most of participants were reading at their frustration level (less than $89 \%$ of accuracy), only Emir was reading at an independent level (over 95\% of accuracy). Accuracy is calculated by the percentage of words 
that were correctly read. The independent level is between $95 \%-100 \%$, instructional level is between $90 \%-94 \%$, and the frustration level is below 89\% (Gunning, 2013; Rasinski \& Nageldinger, 2016). According to Rasinski et al. (2016), accuracy impacts fluency and viceversa, which in its turn impacts comprehension. Although L2 learners may not be able to accurately read a word, they can use other reading strategies to access word meaning such as cognates, morphological analysis, contextual clues, graphics, pictures, among other textual features.

Considering only the miscues impacting comprehension, most of the participants were reading at their instructional level; only Emir was reading the text at the independent level. Although Emir had the fewest number of miscues in both cases, either considering total miscues or considering only miscues impacting comprehension, he had more difficulties in retelling and explaining both texts. So, while focusing on accurate pronunciation, his comprehension suffered (Wright, 1996). In other words, he was reading at the word-level without constructing meaning and/or a situational model in his mind (Kintsch, 2007; Paulson \& Goodman, 2008). Therefore, a native-like pronunciation for L2 learners may not guarantee comprehension (Handsfield \& André, 2016), at least not at this point of his development as an English learner.

Table 5.3 shows the number of different miscues made by each participant in text 1 and text 2. Miscues were coded following the widely-accepted norms (Y.M. Goodman et al., 2005), which classify miscues as substitutions, (partial) omissions, (partial) insertions, repetitions, reversals, mispronunciations, and corrections. However, it was necessary to refine the miscue coding system to better describe participants' miscues. Thus, the following new codes emerged: (i) pronunciation/substitution miscue; (ii) L1 phonological knowledge miscue; (iii) L1 phonotactic knowledge miscue; and (iv) L2 overgeneralization. These 
miscues were identified because they happened in all participants' read-aloud. Table 5.3

displays the amount of these miscues for each participant.

Table5.3

Miscue by Text

\begin{tabular}{|c|c|c|c|c|c|}
\hline Types of Miscues & Azim & Casper & Haddad & Fadil & Emir \\
\hline \multicolumn{6}{|l|}{ Substitution } \\
\hline Text 1 & 28 & 23 & 40 & 29 & 8 \\
\hline Text 2 & 11 & 16 & 33 & 29 & 6 \\
\hline \multicolumn{6}{|l|}{ Partial Omission } \\
\hline Text 1 & 31 & 22 & 5 & 13 & 7 \\
\hline Text 2 & 28 & 17 & 9 & 10 & 5 \\
\hline \multicolumn{6}{|l|}{ Omission } \\
\hline Text 1 & 4 & 11 & 7 & 3 & 1 \\
\hline Text 2 & 2 & 2 & 2 & 3 & 0 \\
\hline \multicolumn{6}{|l|}{ Partial Insertion } \\
\hline Text 1 & 4 & 2 & 2 & 1 & 1 \\
\hline Text 2 & 3 & 0 & 1 & 5 & 0 \\
\hline \multicolumn{6}{|l|}{ Insertion } \\
\hline Text 1 & 1 & 2 & 4 & 10 & 0 \\
\hline Text 2 & 1 & 3 & 5 & 1 & 2 \\
\hline \multicolumn{6}{|c|}{ Substitution/Pronunciation } \\
\hline Text 1 & 5 & 2 & 11 & 7 & 0 \\
\hline Text 2 & 11 & 10 & 7 & 7 & 1 \\
\hline \multicolumn{6}{|l|}{ Self-Correction } \\
\hline Text 1 & 20 & 6 & 8 & 10 & 11 \\
\hline Text 2 & 24 & 13 & 3 & 12 & 9 \\
\hline \multicolumn{6}{|l|}{ Mispronunciation } \\
\hline Text 1 & 21 & 31 & 44 & 34 & 10 \\
\hline Text 2 & 17 & 10 & 37 & 23 & 4 \\
\hline \multicolumn{6}{|c|}{ L1 Phonological Knowledge } \\
\hline Text 1 & 9 & 5 & 7 & 13 & 9 \\
\hline Text 2 & 10 & 5 & 5 & 11 & 3 \\
\hline \multicolumn{6}{|c|}{ L1 Phonotactic Knowledge } \\
\hline Text 1 & 5 & 2 & 2 & 2 & 0 \\
\hline Text 2 & 3 & 0 & 0 & 0 & 0 \\
\hline \multicolumn{6}{|l|}{ Overgeneralization } \\
\hline Text 1 & 0 & 4 & 0 & 1 & 1 \\
\hline Text 2 & 1 & 1 & 1 & 2 & 1 \\
\hline
\end{tabular}

Participants made a higher number of substitutions, omissions, partial insertions, mispronunciations, L1 phonological knowledge miscues, and L1 phonotactic knowledge miscues on text 1 than text 2 . On text 2 , participants made a higher number of partial omissions, insertions, substitution/pronunciation miscues, and overgeneralization miscues. 


\section{Substitution}

Participants' substitutions can be attributed to seven reasons: (i) graphic similarity; (ii) similar consonant pattern; (iii) same consonants, different positions/missing consonant; (iv) similar meaning; (v) facilitating grammar structure; (vi) going through the motions; and (vii) meaning of previous word read still in their minds ${ }^{2}$ (See Table 5.3 for more information).

The most frequent types of substitutions were attributable to graphic similarity, which refers to miscues that look similar (high, partial, none graphic similarity), but may not be syntactically acceptable and/or semantically acceptable. This type of miscue may or may not change the meaning of the sentence. Examples of this type of miscue would be: "the/that"; or/on; or/of; is/in; our/or; pale/plate; death/health.

Text 1, Page 2, Line 38: "Glance up at the stars and ponder your very existence on our own pale blue dot, and let the awe wash over you."

Casper: "Glance up at the stars and ponder your very existence on our own plate blue dot, and let the awe wash over you."

Text 1, Page 1, Line 9: “Overwhelming emotion, a sense of oneness, even transcendence.”

Azim: "Overwhelming emotion, a sense or oneness, even transcendence."

Casper's and Azim's miscues had high graphic similarity given that only one letter is different. Their miscues were semantically and syntactically unacceptable. Casper's miscue also fit the same consonants, different positions/missing consonant category.

The second type of miscue, similar consonant patterns refers to miscues that retain the same consonant patterns of the printed word. Examples of this type of miscue would be:

\footnotetext{
${ }^{2}$ Characteristics are presented according to the frequency in which they appear, from those with most appearances to those with fewer appearances.
} 
“defined/defend (DFND - pattern) 3 "; " birth/breath (BRTH - pattern); "below/blew (blue) (BLW - pattern)"; "beside/ based (BSD - pattern)". This type of miscue could also be seen as high and/or partial graphic similarity which can or cannot attend to semantically or syntactically acceptability. This type of miscues reflects an over attention to consonants while disregarding vowels. Participants seem to transfer this behavior from their L1 to L2 reading given that Modern Standard Arabic keeps the same consonantal structure for family words (Abu-Rabia, 1997; Bentin \& Frost, 1987; Frost \& Benting, 1992; Frost, Katz \& Betin, 1987; Saiegh-Haddad, 2003) while overlooking vowels which are predictable based on contextual clues (Hayes-Harb, 2006). For instance, in Arabic the KTB pattern is associated with words that are related with writing, such as kataba (he -wrote), kitaab (book), maktaba (library), maktab (office) (Hayes-Harb, 2006). This type of miscue had a tendency to infringe syntax and semantics.

Text 1, Page 1, Line 14: "All of history and music and poetry and art and death and birth and love, tears, joy, games, all of it on that little spot out there."

Fadil: "All of history and music and poetry and art and death and breath and love, tears, joy, games, all of it on that little spot out there."

Text 1, Page 1, Line 4: "I took a peek and saw the beautiful blue and whites of the Earth below and the curvature of the horizon."

Haddad: "I took a peek and saw the beautiful blue and whites of the Earth blew and the curvature of the horizon."

Fadil's miscue was syntactically acceptable, but not semantically acceptable. This miscue may have impeded comprehension. Haddad's miscue disregarded both semantic acceptability and syntactic acceptability, so he may have had some problems

\footnotetext{
${ }^{3}$ expected response followed by reader's miscue
} 
in making sense of the text here as he pointed out during RMA his difficultty in pronouncing the target word (below).

The third type of miscue was classified as - same consonants, different positions/missing consonants. This type of miscue refers to miscues that have the same consonants, but in different positions or consonants could be missing. Example of this type of miscues would be: "begin/being (BGN -consonants)"; revealed/relieved (RVLD - consonants)"; “orbit/operate $\left(\mathrm{RB}^{4 *} \mathrm{~T}\right.$ - consonants)”; “purest/part (PRsT - consonants). Once again, these miscues reflect participants' observation of consonants while overlooking vowels. During RMAs, participants shared their concern with pronunciation and the need to pay attention to vowels while reading in English. They argued that they may even have some trouble with vowels in their own language. This difficulty may result from the fact that Arabic differentiates short and long vowels by using diacritics above/below consonants to signal the conventional pronunciation and/or that Arabic can be vowelled during the initial years at the reading learning process and unvowelled at the end of the reading learning process. The Qur'an is an exception for this rule. Furthermore, vowels also carry morphological information in Arabic (Saiegh-Haddad \& Geva, 2008; Taouka, $\&$ Coltheart, 2004). However, Arabic readers use the word consonantal pattern and context to guess a word. This relative blindness to vowels may have negatively impacted participants' comprehension (Ryan \& Meara, 1992; Saigh \& Schmitt, 2012).

The fourth type of miscue was similar meaning, which refers to miscues that share a similar meaning although they may or may not infringe grammar rules. These miscues rarely negatively impacted meaning, and thus are considered high-quality

\footnotetext{
${ }^{4}$ Arabic speakers do not differentiate $\mathrm{P}$ and $\mathrm{B}$
} 
miscues. Examples of participants' miscues would be: "whole/all”; "spot/part". These miscues demonstrate participants' engagement in making sense of the text. According to participants, this type of substitution may have happened because they tried to use words that were more familiar to them so that they would be able to make sense of the text easily. These miscues would not impact comprehension; on the contrary, they would support deep comprehension given that participants were building a situational model in their minds (Kintsch, 1998).

Text 1, Page 1, Line 5: "Getting to experience the whole disc of the Earth from that point of view, truly for me, it was this breathtaking experience." Azim: "Getting to experience the all disc of the Earth from that point of view, truly for me, it was this breathtaking experience."

Text 1, Page 1, Line 16: "In 1987, this phenomenon was given a name: The Overview Effect.”

Fadil: "In 1987, this phenomenon was given a name: The Overall Effect."

The fifth type of miscue was facilitating grammar structure, which refers to miscues in which participants simplify grammar so that they would more easily achieve comprehension. Examples of this type of miscue would be: "those/these"; "nobody/anybody"; "most/more", and verbs, adverbs, adjectives turning to nouns such as: "continued/continue; "inclusive/inclusion". Although these miscues may infringe grammar rules, they do not impact meaning. This demonstrates again that participants' ultimate goal is meaning making, even though they may not attend to grammatical conventions.

Text 1, Page 1, Line 10: "No amount of prior study or training can fully prepare anybody for the awe and wonder this inspires," Haddad: "No amount of prior study or training can fully prepare nobody for the awe and wonder this inspires," 
Text 1, Page 1, Line 21: "the need to create a planetary society with the united will to protect this "pale blue dot " becomes both obvious and imperative."

Casper: "the need to create a planetary society with the unit will to protect this "pale blue dot " becomes both obvious and imperative."

There was also a considerable amount of tense changes in which participants changed the verb tenses from simple past tense to simple present, and from present continuous to simple present. Examples of this type of miscue would be: "got/get; begun/begin; showing/show; shortening/shorten. This can demonstrate a grammar simplification as well as participants applying their L1 knowledge of tenses to the L2 reading situation. In Arabic, there are only two verb tenses: past and present. The other tenses are derivations of these tenses (Wightwick \& Gaafar, 1998).

Text 1, Page 2, Line 18: "The Overview Effect seems to contain both of those aspects of awe," Yaden told The Week."

Emir: "The Overview Effect seems to contain both of those aspects of awe," Yaden talked The Week."

Text 2, Page 2, Line 32: "Even though this study alone can't tell us conclusively that busyness increases cognitive function,"

Fadil: "Even though this study alone can't tell us conclusively that busyness increasing cognitive function,"

The sixth type of miscue was - going through the motions, which refers to when the reader keeps reading the text. This behavior usually happened with unknown words. As a result, participants would make a wild guess, which resulted in non-words. Examples of this type of miscues would be: "bustling/bestling"; "quilting/qualiting". It is hard to say whether participants were making sense of the text or not in these situations or whether they were 
strategically choosing what to read. During RMAs, they demonstrate that there were moments in which they were understanding the text even though they could not pronounce the word, but there were other moments that they were not. Usually, when struggles with pronunciation impacted comprehension, participants would stop and look quickly to the previous text to try to connect the old information with the new information.

Text 2, Page 2, Line 33: "maybe it can fundamentally shift our snarky relationship with our bustling lifestyles."

Haddad: "maybe it can fundamentally shift our snarky relationship with our besting lifestyles."

Text 2, Page 2, Line 17: "For instance, a 2013 study at the Center for Vital Longevity found that sustained engagement in learning new skills such as quilting or digital photography enhanced memory function in older adults." Emir: "For instance, a 2013 study at the Center for Vital Longevity found that sustained engagement in learning new skills such as qualiting or digital photography enhanced memory function in older adults."

The last type of miscue was meaning of preceding word read still in mind which refers to miscues which reflect previous word and/or text read. In other words, readers were still thinking about what they have read while trying to connect the preceding information with the new information. Examples of this type of miscue would be: "year/five"; "mission/emotion". These preceding words could be just a few words before and/or a few paragraphs. For instance, Casper read the word "five" seven words before miscuing "year" by "five": "Astronaut Kjell Lindgren spent close to five months on the International Space Station last year (five) serving as a NASA flight engineer and mission specialist.” Here, he had just started reading the text, and he was already engaged in the process of constructing meaning. Here he was probably thinking about what he had just read while still reading 
aloud. When asked why he thinks he made this miscue, his answer was, "I don't know, but I should have corrected it because I read a different word" (Interview, 07/07/16). His answer demonstrated that he was not checking and/or monitoring his comprehension, but he was still focusing on understanding the previous sentence in order to build a situational model in his mind.

Azim, on the other hand, read "emotion" on the previous paragraph before miscuing “mission” by "emotion". He was able to correct his miscue, though:

"Back on Earth, awe has been linked to pro-social behavior, altruism, and inclusive thinking. But it's also been shown to have positive effects on everything from creativity to physical health. One study linked higher instances of wonder to lower levels of harmful, disease-linked inflammation markers, even more so than other positive emotions like love and joy. And indeed, awe can change people's lives. Many come-to-Jesus epiphany religious or not - have been preceded by staggeringly awesome (wheresome) experiences.

Yaden believes the Overview Effect, and the (2) awe it elicits, should be taken into consideration as we consider sending astronauts deeper into space on longer, more isolating missions. He hopes to work with Space agencies like NASA on mission (emotion, motion, mission) planning. "It's not just about avoiding mental illness," he says. "It's about promoting mental health. So as simple as it may sound, one implication of our research is, if you're gonna send people to Mars, you should have windows."

It is important to bear in mind that Azim was focused on trying to figure out the meaning of the word "awe". It bothered him that he was not able to clarify its meaning. This excerpt also shows Azim's attempts in trying to determine the conventional pronunciation of 
the word "awe", which he read twice in the second paragraph. He demonstrated his frustration with the pronunciation of this word soon after explaining his understanding of the text: "Yeah, this word (awe). It confuses me when I say it. I said it five times, and every time I pronounced it differently because I didn't know how to say" (Interview, 06/24/16).

Furthermore, while explaining the text, he established a connection between "awe" with "feeling":

"I read about $\|\left.\right|^{5}$ one guy he is going with NASA to space and see the Earth like a part of the Earth like he says like explain the view like a disc white and blue the Earth is like a disc like horizon he says the horizon of the Earth and blue like a beautiful view. He enjoys by this feeling, and I think || another guy I don't know if it is another guy or the same guy because I read two names. He talked about like studying from this view the how the human feeling about this view when he saw the beautiful things. I think he is studying at the university of Pennsylvania or something like that".

This later association could result from a previous association between the words "awe" and "emotion". In his first RMA, once again, he demonstrated his frustration with the word "awe" by pointing out that he was unable to say "awesome" which was a known word by him because he did not know how to pronounce "awe”. Azim: "because I said awe (away - /a'weI/) I said wheresome. And I know this word - awesome, but I read it wrong because I read this word (awe)" (Interview, 06/26/16). L2 reading is a very demanding task in which L2 readers are coordinating several skills at the same time, and reading aloud adds more challenges to the task (Koda, 2005). In these miscues, participants demonstrated that while reading aloud, they are still trying to process the preceding text. As a result, they may miscue

\footnotetext{
${ }^{5}$ Interview codes that demonstrates speaker pause while talking
} 
due to comprehension delays. It could also be that readers are using delay strategies (Kintsch, 2007) in which the reader tailors the meaning of a word while reading through the text.

\section{Partial Omission}

Partial omissions were the second most frequent type of miscue made by participants. For text 1, there were a total of 78 partial omission miscues, and for text two, 68 partial omission miscues (for individual miscues see Table 5.3). Participants' partial omissions reflect four characteristics regarding morphological markers: (i) plural; (ii) third person singular; (iii) adverb of manner (ly); and (iv) to be contraction.

The omission of plurals refers to participants not reading the plural morpheme marker (s). Examples of this type of miscues would be: "others/other"; revelations/revelation"; "emotions/emotion"; "schedules/schedule". The omission of third person singular marker refers to reading a third person verb in its neutral form. Example of participants' miscues would be: "rates/rate", "remembers/remember"; "increases/increase". The omission of adverb of manner refers to the "ly" morphological marker. Examples of participants' miscues would be: "actually/actual"; "fundamentally/fundamental"; "typically/typical”. These omissions reflect a simplification of the English grammatical system as well. They do not impact comprehension, but they show participants' attempts in making sense of the text by focusing in these situations on meaning rather than on grammatical rules (Krashen, 1985).

The majority of partial omissions involve plural and third person singular morpheme markers, which are also acquired later among English native speakers (Gass \& Selinker, 2008). Furthermore, studies have shown that omission of these morphemes is normal and natural in the early stages of L2 development (Bailey, Madden, \& Krashen, 1974; Dulay \& Burt, 1973, 1974; Larsen Freeman, 1975)

Another type of partial omission that participants made with some frequency was the omission of the "to be contraction". Example of participants' miscue would be: "here's/here"; 
“people's/people"; “you're/ you”; and "he's/he". This type of miscue could be explained in two ways. First, participants could have ignored the apostrophe for the same reason they did previously with plural and third person morpheme markers, that is, they simplify grammar to attain meaning. Second, there is no verb "to be" in Arabic, so they could have omitted the "to be" verb because they are able to process information without using "to be". So, they are applying Arabic grammar to have a better understanding of an English text. In any of the two possibilities, participants were making sense of the text by focusing on meaning, and not utilizing the English syntactic cueing system.

\section{Omissions}

There was a total of 35 omissions among participants (See Table 5.3). Most omissions were function words such as articles, prepositions, and the pronoun - 'you'. Content words were also omitted, but on fewer occasions. Participants omitted content words mostly on text 1, which was considered by four participants the more difficult text. Examples of omissions would be: "astronauts"; "effect"; "pale"; "says"; "be”. The three first omissions were words that had several appearances in the text. So, participants may have omitted those words, but these omissions do not mean that participants were not making sense of the text. On the contrary, they showed that participants were strategically choosing which words they should spend more time and/or read. As Azim explained, “I don't care about grammar and I concentrate what makes sense for me. Like the word near or it's familiar for me to read I know exactly the meaning and use it in" (Interview, 07/03/16). Fadil defended the same idea: “Yeah, but I think at that time. I wasn't thinking about the grammar. I think that maybe the spelling is similar, and I think the meaning is the same like this" (Interview, 07/11/16). As participants explained during RMAs, text 1 was very demanding given the amount of unknown words, and their unfamiliarity with the topic. So, they experienced cognitive fatigue while reading it as they had to attend to several aspects of reading, such as pronunciation, 
linking word with its concept, making sense of the text as a whole, among others. This may have caused an overload on their short-term memory. As a result, they would read words that add to their understanding instead of continuing to re-read words that they already have in mind.

Regarding the omission of "says", the same explanation can be applied. This omission happened in the following sentence: "We don't need to go to space to benefit from intense experiences of awe," Yaden says." Casper clarified: "when I am reading maybe I was thinking about the word I don't know" (Interview, 07/07/16), it seems that Casper was selfcorrecting some of his miscues silent. Furthermore, this structure (Yaden says) is well-known by readers. So, reading "says" would not aggregate new information to support a better textual understanding.

Omissions of 'astronaut(s)' (text 1) and 'cognitive/cognition' (text2) may have happened because those words appeared several times in text 1 and text 2 respectively. Participants became frustrated trying to pronounce them, therefore, they may have decided to skip the words altogether and/or read them silently/look over them instead of reading them aloud. Furthermore, at the third or fourth appearance of these words, they may have already understood their meaning and what the texts were trying to convey.

\section{Partial Insertions}

There was a total of 19 insertions among participants in relation to both texts (See Table 5.3 for individual's partial insertions). These miscues reflect participants' attempts to maintain the most frequently used verb tense in the text. For instance, text 1 states: "Many of the astronauts discuss this aspect as well, seeing the fragility and the beauty of the planet at once and having this epiphany or realization of how precious the planet is and how much we need to do more to protect it." Participants may have read "discussed" instead of "discuss" because the past tense had been predominant in earlier portions of text 1. Participants had 
been reading in the past tense, but suddenly there was a sentence using the present tense. Further, they may not have realized that this sentence was a direct quotation from one astronaut. Another example would be in text 2 in the following sentence "Perhaps the best takeaway from this new study might be taking a second look at how we think about busy", where Fadil read "thinking" for "think".

There were also plural morpheme maker partial insertions, such as "psychology/psychologies”; “year/years”, "emotion/emotions”. Furthermore, there were two "to be" contraction partial insertions namely "it/it's" and "what/what's", in addition to two adverbs of manner namely "ever/every", and "clear/clearly". As participants clarified, these miscues were just a reflection of what they were more used to saying and/or hearing. In other words, they read what sounded more syntactically familiar to them at that time of reading and/or a syntax that reflects their L1 syntax. Participants also clarified that they read what sounds better to them at the time of the reading aloud.

\section{Insertions}

As Table 5.3 shows, there was a total of 29 insertions in both texts combined. All insertions were functional words, such as articles, pronouns, and preposition. Participants inserted definitive articles and singular demonstrative pronouns in front of nouns. They also inserted prepositions which sound more like an intonation pause, in other words, participants paused for a moment to process previous information and/or to start the pronunciation of a difficult unknown word. Nevertheless, each of these insertions slightly changed the meaning of the sentence in question. There was one insertion in text 2 which Azim read: "In another, the subject to were asked to read aloud a series of words and then try to recall them afterwards" instead of "In another, the subjects were asked to read aloud a series of words and then try to recall them afterwards." Another possible explanation for this insertion is that 
the participant could have inserted "to" because he could be aware of the expression "subject to something".

\section{Substitution/Pronunciation}

There was a significant amount of substitution/pronunciation miscues in both texts (See Table 5.3 for individual's miscues). This type of miscue refers to participants' difficulties in pronouncing a word on the spot. This difficulty resulted in a substitution. In other words, participants knew at least the written word in the text and/or the pronounced word while reading aloud. Nevertheless, participants needed more time to realize their mispronunciation and/or substitution.

Participants' concern with speed and fluency may also have influenced their tendency to overlook the printed words and their pronunciation of them. Emir was one of the participants who was more concerned with reading quickly (See Table 5.2). He reasoned that reading fast was an important skill for international English tests because these types of tests give you a certain amount of time to read, at least, five texts and then answer several multiple choice questions at the end of each reading. When I asked Emir about his reading speed, he compared himself with Chinese readers by arguing that he was not fast: "I remember the ah the target time was five minutes to read an essay. Some of the Chinese read it in four minutes, some of them in six minutes. I read it in nine minutes" (Interview, 06/29/16). The other participants shared a similar understanding about reading fast as a good reading skill specially for international English tests.

This understanding of reading at a certain speed in order to get through the text and respond to questions at the end of reading as fast as possible reflects a need for international English tests. This strategy may not result in comprehension which may or may not be the main goal of these participants while taking international English tests as they may be focused solely on answering the questions. Since the two chosen texts resemble texts in these 
tests, participants may have decided to approach the read-aloud activity as they were used to approaching texts in the international tests, even though, I specifically instructed them to pay attention to their comprehension. It could be that while reading for pleasure participants would have a different attitude to reading. On the second reading, however, they had a different attitude. It was possible to observe that they were reading at a slower pace than text 1 and taking more time to understand unknown/unfamiliar words.

There were more substitution/pronunciation miscues on text 2. As participants argued in their RMAs, text 2 was easier for them to read due to familiarity with the topic. As a result, they appeared to be more engaged with text 2 than text 1 . Nevertheless, their difficulties in pronouncing some words may have compromised their comprehension. These miscues demonstrate a lack of attention to vowels as well as an overreliance on consonant patterns. These miscues impacted semantic and syntactic acceptability. As a result, participants changed the meaning of sentences. For instance, Fadil read the following statement: "By acknowledging the potential benefits of an active life, busy becomes a positive - or at least not all bad" as "By acknowledging the potential benefits of an active life, busy becomes a positive - or at last not all bad". Here, it is possible that his focus was on the consonant patterns while overlooking the vowels.

\section{Mispronunciations}

There was a considerable amount of mispronunciation (See Table 5.3 for details for this type of miscue for each participant), especially in text 1 , which was considered by four participants to be the more difficult text given its unfamiliar topic and the number of unknown words. Nevertheless, it is important to point out that even though participants may have had some difficulties in pronouncing some words and/or were unable to link a word to its concept on the spot, it cannot be argued that they did not know the word. During their RMAs, participants were able to explain some of their mispronunciations as well as the word 
meanings. A good example of this would be the inability of one participant to read the word "specialist" in text 1, but during his first RMA, he broke the word down into 'special-ist' so that he could pronounce it. He was also able to explain its possible meaning.

"Aline: You said specialist which is the word here. Why did you go back to correct the word?

Azim: I like I pronoun my pronunciation was wrong I went back and try to read it again. Specia/list like special, right? I tried to read like special-list (it sounds like last, but he tried to say list) but doesn't count like I said the first time special like the word special I know it. It's familiar. All I use is special, but with the last (list) (specialist) I don't use it. It's like a little bit new and when I tried to read it I didn't get like fast or quickly. I tried to read again as I said the first time I said special, right? Like sometimes when you read you don't read the whole word. You see just a part of the word and your brain gives you the word like you read it. Sometimes that happens in Arabic. Like some sentences, they give you the word it's not exactly the same word they change some letters inside the word, and when you start reading you read the word what you are thinking about not the real word that you see" (RMA, 06/26/16). Azim's explanation demonstrates that partial word meaning understanding contributes to L2 learners' comprehension (Keh, 2017). There were also cases in which participants mispronounced a word several times such as astronaut, transcendental, cognitive, busyness, among others. These mispronunciations did not represent repetitions because participants had a different pronunciation each time they read the same word. This demonstrated that participants were trying to find a conventional/standard pronunciation and/or a pronunciation that would satisfy their needs. Even though they did not seem to be satisfied with their pronunciations, they were able to start drawing some meaning for the unknown/unfamiliar 
word. For instance, Haddad read the word "busyness" in text 2 as "business" when he realized his mispronunciation he went back to correct it, but he had a few attempts before he arrived at a satisfactory pronunciation. When I asked to explain his self-correction, he explained:

"Aline: could you hear what you said here?

Haddad: Yeah, I know busy busyness kind of busyness

Aline: Uh hum uh hum, but you said another word here

Haddad: What I said?

Aline: You said this word here (showing him business).

Haddad: Ya business

Aline: And then you went back and you correct yourself. You read business twice and then you said busyness.

Haddad: Busyness, is it correct?

Aline: Uh hum, you did. Can you tell me why?

Haddad: Busyness, yeah because I think it's similar to because some words are similar to, the sounds. It's a different situation. I am busyness maybe you felt I am very busy but if you say I have a business you know it's different" (RMA, 07/07/16).

As with Azim, Haddad also broke the word into parts that he was familiar with in order to figure out the word meaning. Another good example of this is Casper who pointed to his tongue while explaining the meaning of "taste" (text 2) which he read as "test": "How can we get a test of the Overview Effect without leaving the confines of gravity?". This demonstrates, once again, participants' focus on consonant patterns. Casper was able to differentiate the meaning of these two words by reading them simultaneously several times. 
These examples demonstrate that there is a need for a meticulous study to verify how much L2 learners' mispronunciations may or may not impact comprehension given that L2 learners may use other strategies to figure out word meanings. Pronunciation may not be the first choice as it could be for a native speaker of any language assuming that oral language supports reading development (Goswami, 2001; Gunning, 2013).

\section{L1 Phonological Knowledge}

As Table 5.3 shows, there were some L1 phonological knowledge miscues in which participants' L1 phonological knowledge inhibited L2 pronunciation because of the indiscrimination of equivalent sounds in their L1. For instance, discrimination of $/ \mathrm{p} / \mathrm{and} / \mathrm{b} /$; /f/ and /v/. There was a great amount of effort by participants to produce the $/ \mathrm{b} /$ and $/ \mathrm{v} /$ sounds. The /g/ would be read mostly as the hard /g/ sound like in girl even though sometimes it was necessary to be read as the soft /dze/ sound like in age. Participants were able to discriminate the two sounds of /g/ in English in cases where the word was familiar, but if it was a new word such as "fragility" and "longevity", participants would pronounce the hard sound /g/. This type of miscue did not impact participants' comprehension, especially if the word read was well-known by participants.

\section{L1 Phonotactic Knowledge}

There were a few L1 phonotactic knowledge miscues in which participants applied their L1 knowledge about what sounds are permitted in their own language to read a L2 word. For instance, "inspire" became "inespire"; "spiritual” became "sepiritual”; "inspire/inspiration" became "inespire/inespiration"; and "institute” became "inestitute". These miscues demonstrate an attempt by participants to apply their phonotactic knowledge which does not accept CCV (cluster) as does English. This incongruence between the phonotatic constrains of participants' L1 and L2 resulted in an Arabic-like pronunciation. This demonstrates that L2 learners activate both L1 and L2 knowledge while reading aloud 
resulting in cross-linguistic activation of phonotactic constrains (Bernhardt, 2011; Freeman, Blumenfeld, \& Marian, 2016; Keh, 2017). As earlier mentioned, this type of miscue was not considered as impacting comprehension, as some researchers have also argued. Nevertheless, it is difficult to quantify the extent to which this type of miscue impacts or does not impact comprehension.

\section{Overgeneralization}

There were some overgeneralization miscues in which participants systematized a sound/pronunciation, and continued using it despite the fact that pronunciation was unconventional. The International Phonetic Alphabet (IPA) was used to represent how participants pronounce some words. For instance, Casper frequently pronounced $/ \mathrm{c} /$ as $/ \mathrm{k} /$, this pronunciation would be acceptable with words with double /c/ as in "accelerated" /æk' sclə, reit/, but not in words such as "elicits”/I'lısits/ which was read as "elikts"/عlikts/;

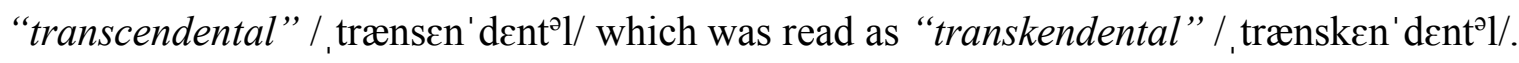
Another example would be with the vowel/I/, which participants systematized as /ai/ like the first singular person pronoun. As a result, "empirically” would be read as /im' pairikəlı/; “inspiration” as/Inspaireı' Jon/.

These miscues did not disrupt comprehension and did not impact semantic and/or syntactic acceptability. Participants asserted that the graphic input offers them the most important information about a word. The phonetic input is a secondary strategy that is used when dealing with an unfamiliar and/or unknown word. In this case, sounding out the word may help them to recognize the unfamiliar word from a conversation, TV program and/or classroom teacher using it. Participants approached this situation with a small grain size unit in mind which was not very helpful here. If they had used large grain size unit such as rimes, morphemes, word families they may have been able to achieve the conventional pronunciation. However, as Haddad mentioned during the interviews, Arabic is a more 
transparent language than English. As a result, these participants may be more aware of small grain size strategies than large grain size strategies. It would be the case to encourage English second language instructors to demonstrate reading strategies that focus on large grain size strategies.

\section{Syntactic and Semantic Acceptability}

Table 5.4 displays syntactic and semantic acceptability of participants' miscues, percentage of meaning changed, graphic similarity, percentage of meaningful miscues, and percentage of significant miscues. Miscues were considered (i) meaningful miscues or (ii) significant miscues. An example of a meaningful miscue would be when Haddad read more for most: "The Overview Effect elicits a sense of awe in its purest (part), most (more) intense form". These types of miscues were semantically acceptable, that is, they did not change and/or change only slightly changed textual meaning, but the main idea was intact. However, they infringe grammatical rules resulting in miscues that were syntactically unacceptable. Thus, meaningful miscues refer to participants adjusting a word slightly to accommodate their textual comprehension. Hence, these miscues do not interfere with meaning. The majority of these miscues resembled the expected response graphically. Azim was the only participant with this type of miscue that did not bear any graphic resemblance of expected response, but it kept textual meaning when he read 'all' for 'whole', 'part' for 'spot' in text 1. According to Goodman $(1965,2014)$, as readers progress to an expert role as a reader, they tend to focus less on graphophonic cues and more on meaning by using contextual clues.

In the same sentence above, it is possible to observe that Haddad made a significant miscue when he read 'part' for 'purest'. This miscue was syntactically and semantically unacceptable. Thus, significant miscues refer to participants reading a completely different word, consequently, changing textual meaning. However, it is interesting to observe that his 
focus was on graphic similarity of the consonant patterns (PuReST X PaRT). This miscue was coded as same consonants, different positions/missing consonant.

Graphic similarity refers to how much words look alike. Miscues due to graphic similarity were classified as high, some and low graphic similarity. High graphic similarity refers to a high degree of correspondence between expected and observed response (ex. Connotation X Connection; Stress X Street), some graphic similarity refers to some degree of resemblance between expected and observed response (ex. Overview X Over-way), and low graphic similarity refers to small degree of resemblance between expected and observed response (ex. Mitigate X Meeting). For Table 5.4, I considered only the miscues that impacted participants' comprehension. 
Table 5.4

Percentage of Miscues by Participants

\begin{tabular}{|c|c|c|c|c|c|c|c|c|c|c|}
\hline \multirow[t]{2}{*}{ Participants } & \multirow{2}{*}{$\begin{array}{c}\# \\
\text { Miscue }\end{array}$} & \multirow{2}{*}{$\begin{array}{c}\% \text { Syntactic } \\
\text { Acceptability }\end{array}$} & \multirow{2}{*}{$\begin{array}{l}\% \text { Semantic } \\
\text { Acceptability }\end{array}$} & \multicolumn{2}{|c|}{$\begin{array}{l}\text { Meaning } \\
\text { Change }\end{array}$} & \multicolumn{3}{|c|}{ Graphic Similarity } & \multirow[t]{2}{*}{$\begin{array}{l}\text { Meaningful } \\
\text { Miscue }\end{array}$} & \multirow[t]{2}{*}{$\begin{array}{l}\text { Significant } \\
\text { Miscue }\end{array}$} \\
\hline & & & & Yes & No & high & some & low & & \\
\hline Azim & & & & & & & & & & \\
\hline Text 1 & 38 (945) & $50 \%$ & $29 \%$ & $63 \%$ & $31 \%$ & $39 \%$ & $22 \%$ & $39 \%$ & $18 \%$ & $82 \%$ \\
\hline $\begin{array}{l}\text { Text } 2 \\
\text { Casper }\end{array}$ & $21(798)$ & $57 \%$ & $14 \%$ & $81 \%$ & $19 \%$ & $42 \%$ & $33 \%$ & $24 \%$ & $10 \%$ & $90 \%$ \\
\hline Text 1 & $37(949)$ & $38 \%$ & $22 \%$ & $81 \%$ & $19 \%$ & $19 \%$ & $27 \%$ & $54 \%$ & $30 \%$ & $70 \%$ \\
\hline $\begin{array}{c}\text { Text } 2 \\
\text { Haddad }\end{array}$ & $29(782)$ & $41 \%$ & $17 \%$ & $72 \%$ & $28 \%$ & $35 \%$ & $21 \%$ & $44 \%$ & $14 \%$ & $86 \%$ \\
\hline Text 1 & $62(945)$ & $43 \%$ & $14 \%$ & $74 \%$ & $26 \%$ & $26 \%$ & $26 \%$ & $48 \%$ & $29 \%$ & $71 \%$ \\
\hline $\begin{array}{l}\text { Text } 2 \\
\text { Fadil }\end{array}$ & $47(791)$ & $36 \%$ & $11 \%$ & $81 \%$ & $19 \%$ & $30 \%$ & $19 \%$ & $51 \%$ & $15 \%$ & $85 \%$ \\
\hline Text 1 & $45(950)$ & $35 \%$ & $15 \%$ & $80 \%$ & $20 \%$ & $35 \%$ & $13 \%$ & $51 \%$ & $13 \%$ & $87 \%$ \\
\hline $\begin{array}{l}\text { Text } 2 \\
\text { Emir }\end{array}$ & 38 (798) & $47 \%$ & $18 \%$ & $81 \%$ & $18 \%$ & $37 \%$ & $16 \%$ & $47 \%$ & $32 \%$ & $68 \%$ \\
\hline Text 1 & $8(945)$ & $25 \%$ & $25 \%$ & $75 \%$ & $25 \%$ & $37 \%$ & 0 & $62 \%$ & $37 \%$ & $62 \%$ \\
\hline Text 2 & $8(798)$ & $12 \%$ & 0 & $87 \%$ & $12 \%$ & $25 \%$ & 0 & $75 \%$ & 0 & $100 \%$ \\
\hline
\end{tabular}


Participants' miscues were most often driven by syntax instead of semantics. In other words, their miscues have a higher percentage in syntactic acceptability than semantic acceptability. As a result, meaning was significantly changed most of the time. It is also important to bear in mind that there were miscues which fell under neither syntactic acceptability nor semantic acceptability. According to participants, the majority of their miscues reflected graphic similarities between expected response and miscue. Most of the participants' miscues were significant miscues, that is, they changed the meaning of a sentence by using a completely different word. These types of miscues hinder comprehension.

\section{Self-Corrections}

There were some self-corrections (See Table 5.5 - 5.14 for individual's selfcorrections) in both texts. Most of the self-corrections were about content words. When asked about their self-corrections, participants explained that they had realized that what they read was not what was on the paper. When asked what made them realize their miscues, they affirmed that: (i) it was because the expected response and the miscue graphical dissimilarity; (ii) the miscue sounded like a different word than the expected response; (iii) the miscue did not make sense; and (iv) they knew the spelling and pronunciation of the miscue which did not fit the spelling of the expected response ${ }^{6}$. Table 5.5 to 5.14 displays participants' selfcorrections and the cue systems they relied on for their self-correction as well as acceptable and unnecessary self-correction.

\section{Azim}

Azim had 20 self-corrections for text 1, in which he relied on different cueing systems. Nevertheless, most of his self-corrections were based on the semantic and graphophonic systems. There was one miscue in which Azim relied on the three cueing

\footnotetext{
${ }^{6}$ from more responses to fewer
} 
system to correct it. While reading text 1 , "Others devote their lives to religion or find a renewed sense of faith", he read the word 'renewed' three times. First as new, then renew, and finally renewed. His self-correction demonstrates that he relied on all cue system:s semantic, syntax, and graphophonic. There were four unnecessary corrections, which reflected Azim's reliance on graphophonic similarity and syntactic acceptability. For instance, he read 'empirical' for 'empirically'; 'isolating' for 'isolation', 'the', 'doc' for 'D.', and he omitted the definitive article 'the' before a noun.

Table 5.5

\begin{tabular}{cccccc} 
Azim 's Self-Correction for Text 1 & & & & \\
\hline Azim_Text1 & Syntactic & Semantic & Graphophonic & Acceptable & Unnecessary \\
\hline Syntactic & 1 & & & $16(80 \%)$ & $4(20 \%)$ \\
Semantic & 1 & 3 & & & \\
Graphophonic & 2 & 9 & 3 & & \\
\hline
\end{tabular}

Azim had 24 self-corrections for text 2 (See Table 5.6) which he relied on different cue systems. His self-corrections demonstrated a reliance on graphophonic, semantic and syntactic decisions, respectively. There were seven unnecessary corrections for which he, once again, relied on graphic and syntactic cues. For instance, he read 'wrote' for 'write', 'improve' for 'improved', 'learn' for 'learning', 'short' for 'shortening', 'acknowledge' for 'acknowledging', 'adult' for 'adults', and 'benefit' for 'benefits'.

It is interesting to compare Azim's self-correction results with the miscues that he was unable to correct because his self-corrections demonstrate an overreliance on semantic and graphophonic decisions followed by syntactic decisions. On the other hand, uncorrected miscues (See Table 5.4) demonstrate an overreliance on syntax decisions, followed by graphophonic decisions and last semantic decisions. He explained during his RMAs that he was not concerned with grammar, unless it helped him to gain a better understanding of the text. In this case, he analyzed a sentence syntactically to identify which part of speech was the unknown word. Nevertheless, to achieve his goal of good comprehension, his focus was 
on meaning at the word level, followed by the sentence level, and then he built his textual comprehension. This demonstrates that as a reader, he changes strategies according to whether or not he is understanding the text.

Table 5.6

Azim's Self-Correction for Text 2

\begin{tabular}{cccccc}
\hline Azim_Text2 & Syntactic & Semantic & Graphophonic & Acceptable & Unnecessary \\
\hline Syntactic & 2 & & & $17(71 \%)$ & $7(29 \%)$ \\
Semantic & 3 & 4 & & & \\
Graphophonic & 2 & 3 & 9 & & \\
\hline
\end{tabular}

\section{Casper}

For text 1, Casper had six self-corrections for which he relied on syntactic and graphophonic cues (3), semantic and graphophonic cues (2), and graphophonic (1) cues, respectively. Among these six self-corrections, two were unnecessary. He corrected 'astronauts' because of pronunciation even though he did not know the meaning of the word. He also self-corrected an article ' $a$ ' by 'the' while reading the following "the paper-thin atmosphere" due to syntax and graphic cues.

Table 5.7

Casper's Self-Correction for Text 1

\begin{tabular}{cccccc}
\hline Casper_Text1 & Syntactic & Semantic & Graphophonic & Acceptable & Unnecessary \\
\hline $\begin{array}{c}\text { Syntactic } \\
\text { Semantic }\end{array}$ & & & & $4(66.6 \%)$ & $2(22.2 \%)$ \\
Graphophonic & 3 & 2 & 1 & & \\
\hline
\end{tabular}

For text 2, Casper had thirteen self-corrections for which he relied on graphophonic (5) cues, semantic (3) cues, semantics and graphophonic (3) cues, followed by syntactic (2) cues. He had one unnecessary correction on text 2. He read 'participant' for 'participants'. This was a self-correction based on syntax and graphic cues. 
Table 5.8

Casper's Self-Correction for Text 2
\begin{tabular}{cccccc} 
Casper_Text2 & Syntactic & Semantic & Graphophonic & Acceptable & Unnecessary \\
\hline Syntactic & & & & $12(92 \%)$ & $1(8 \%)$ \\
Semantic & & 3 & & & \\
Graphophonic & 2 & 3 & 5 & & \\
\hline
\end{tabular}

Casper was a very quiet participant who seemed to see himself as a very ordinary reader who reads every single word of a text so that he is able to comprehend what the writer wants to tell the reader. In text 1 , his self-corrections reflect a reliance on syntactic acceptability, followed by graphophonic similarities, then semantic acceptability. In text 2 , his self-corrections demonstrated a change to graphophonic similarities, followed by semantic acceptability, and, finally, syntax acceptability. It is important to bear in mind that four participants, including Casper, argued during their RMAs that text 2 was easier to understand than text 1 due to its topic familiarity and less complicated words. Casper seems to have more control of his comprehension on text 2 given that his number of self-corrections doubled from text 1 . Furthermore, he made more unnecessary corrections for text 1 than text 2. As he had more control of his comprehension in text 2 , he could rely more on semantics to make more sense of the text.

\section{Haddad}

Haddad had eight self-corrections for text 1 (See Table. 5.9). His self-corrections demonstrate that he relied on graphophonic (4) decisions, followed by semantic and graphophonic (2) decisions, and syntactic (1) decision. Among these eight self-corrections, two were unnecessary. He initially read "the overview effect" as "the overall effect" then he went back to correct his miscue. This self-correction was based on a graphophonic decision. During his RMAs, he realized that these two words share a similar meaning although they are not synonyms.

"Aline: do you know what overall means? 
Haddad: Like general, all, and I think like overview like general

Aline: you said that overall is general, and for overview you also said

it's general

Haddad: Yes! (very emphatic)

Aline: So, these two words have a similar meaning, right?

Haddad: Similar meaning!”

Another unnecessary self-correction occured while reading "awe has been linked" instead of reading 'has' he read 'have', then he went back to correct his miscue which was based on syntax.

Table 5.9

Haddad's Self-Correction for Text 1

\begin{tabular}{cccccc}
\hline Haddad_Text1 & Syntactic & Semantic & Graphophonic & Acceptable & Unnecessary \\
\hline Syntactic & 1 & & & $6(75 \%)$ & $2(25 \%)$ \\
Semantic & & 2 & & & \\
Graphophonic & & 2 & 4 & & \\
\hline
\end{tabular}

For text 2, Haddad corrected three miscues, and all were acceptable corrections (See Table 5.10). In order to correct his miscues, he relied on semantic and graphophonic (2) cues, followed by graphophonic (1) cues. Although he had fewer self-corrections for text 2 which he considered easier than text 1 , he also had fewer miscues for text 2 than text 1 (See Table $5.3)$.

Table 5.10

Haddad's Self-Correction for Text 2

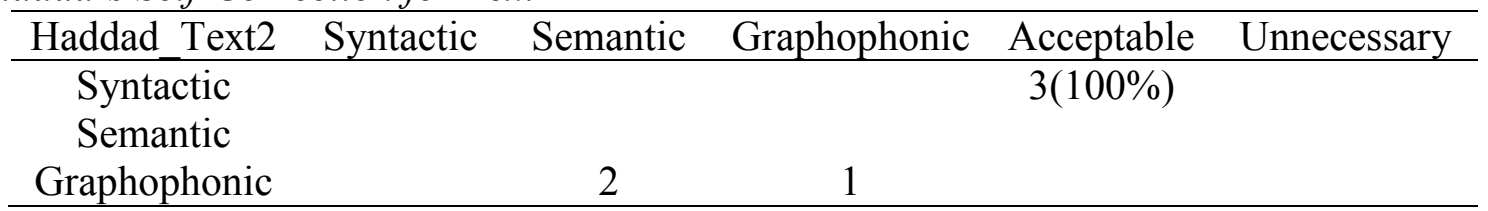

Haddad was a participant who was very concerned with speed. As a result, he tried to get through the text as fast as possible. This concern with speed resulted in a lot of miscues in both texts, specially mispronunciations and substitutions (See Table 5.3). Speed was 
considered a desirable skill by participants because of international English tests, in which test takers have to read as fast as possible to be able to answer multiple choice questions at the end of each reading.

\section{Fadil}

For text 1, Fadil made ten self-corrections which were driven by graphophonic similarities, followed by syntax acceptability, and semantic acceptability (See Table 5.11). Among these self-corrections, three were unnecessary. For instance, he read 'space' as /sbeis/. This self-correction was unnecessary from the comprehension point of view given that participants explained during RMAs that this type of miscue did not affect their comprehension. Reading /p/ as /b/ was common among these participants. They affirmed that in their language there is no /p/ sound. Therefore, they have difficulty in reproducing this sound. This self-correction was due to pronunciation. Another unnecessary correction involved reading 'understand' for 'understood'. Participants, including Fadil, also affirmed during RMA that this type of miscue did not impact comprehension given that it is the same meaning only in a different tense. This self-correction was based on syntax and graphophonic cue. The last unnecessary miscue was 'overall' for 'overview'. This self-correction was based on a graphophonic cue given that he did not know the meaning of 'overview'.

Table 5.11

Fadil's Self-Correction for Text 1

\begin{tabular}{cccccc}
\hline Fadi_Text1 & Syntactic & Semantic & Graphophonic & Acceptable & Unnecessary \\
\hline Syntactic & & 1 & & $7(70 \%)$ & $3(30 \%)$ \\
Semantic & & 1 & & & \\
Graphophonic & 2 & 1 & 5 & & \\
\hline
\end{tabular}

For text 2, Fadil had six corrections (See Table 5.12). His self-corrections were driven by graphophonic similarities as with text 1 , followed by semantic acceptability, and syntax acceptability. There was one unnecessary self-correction while reading 'participants' which was initially read as 'participation'. This correction was based on the three-cue system. 
Table 5.12

Fadil's Self-Correction for Text 2

\begin{tabular}{|c|c|c|c|c|c|}
\hline Fadi_Text 2 & Syntactic & Semantic & Graphophonic & Acceptable & Unnecessary \\
\hline Syntactic & & & & $5(83.4 \%)$ & $1(16.6 \%)$ \\
\hline Semantic & & 2 & & & \\
\hline Graphophonic & & 2 & 1 & & \\
\hline
\end{tabular}

Fadil was a participant with a lot of miscues in both texts (See Table 5.3). During RMAs, Fadil defended his performance by pointing out that he is a visual learner. In other words, he, first, relies on visual inputs to determine word meaning, and then he relies on pronunciation to determine and/or reassure himself of word meaning. The analysis of his selfcorrections demonstrates that graphophonic similarities were indeed very important to him. Nevertheless, it is important to observe that in text 2 , which he had a better comprehension of due to topic familiarity, his self-corrections relied more on semantics than syntax. Yet, selfcorrections in text 1 , which was more difficult for him, reflect a reliance on syntax. His uncorrected miscues (See Table 5.4) also relied on syntactic acceptability which, according to him, would be the last resource while trying to understand a text. So, it seems that like Azim, he relied more on semantics than on syntax when he had a better understanding of the text, but syntax seems to be his preference when he loses track of comprehension.

\section{Emir}

Emir was a participant with few miscues (See Table 5.13). He was very concerned with conventional pronunciation. This over-concern with pronunciation resulted in difficulties in comprehending both texts. For text 1 , he had 11 self-corrections. The majority of his self-corrections were based on graphophonic similarities, followed by syntax and semantic acceptability. There were five unnecessary corrections such as adding the morphological plural mark for 'boundaries', 'powers ', and 'markers '. The remaining unnecessary self-corrections were based on pronunciation. He applied his L1 phonological 
knowledge to read 'planetary' which was initially read as /'blænıtərI/, and 'live' which was initially read as /laifz/. This last miscue was also corrected because of syntax.

Table 5.13

Emir's Self-Correction for Text 1

\begin{tabular}{cccccc}
\hline Emir_Text1 & Syntactic & Semantic & Graphophonic & Acceptable & Unnecessary \\
\hline Syntactic & 2 & & & $6(54,5 \%)$ & $5(45,5 \%)$ \\
Semantic & & & & & \\
Graphophonic & 1 & 1 & 7 & & \\
\hline
\end{tabular}

For text 2, Emir had eight acceptable self-corrections which were driven by semanticgraphophonic decisions followed by graphophonic decisions. There was one miscue 'this' for 'the' that he used all of the three-cue systems to correct it.

Table 5.14

Emir's Self-Correction for Text 2

\begin{tabular}{|c|c|c|c|c|c|}
\hline Emir_Text2 & Syntactic & Semantic & Graphophonic & Acceptable & Unnecessary \\
\hline $\begin{array}{l}\text { Syntactic } \\
\text { Semantic }\end{array}$ & & & & $8(100 \%)$ & \\
\hline Graphophonic & & 6 & 2 & & \\
\hline
\end{tabular}

As it can be observed on Tables 5.13 and 5.14, Emir's self-corrections were driven by graphophonic cues and semantic-graphophonic acceptability. The miscues that he was unable to correct were also made due to graphophonic similarities. He was able to observe the spelling of a word, and pronounce it as a native speaker would. This ability supports a conventional pronunciation of which he was very proud. This was considered a desirable skill by the other participants as well. Nevertheless, his ability in pronouncing words as a native speaker did not reflect on his comprehension. He was concerned with accuracy at the expense of comprehension. As a result, his explanations for both texts were very succinct: he explained the main idea in two or three words. His overconcern with pronunciation also resulted in him reading text 2 twice. 


\section{Repetitions}

Most of the repetitions involved "sounding-out" whereby participants break down the words into syllables so that they were able to pronounce the whole word which could be known or unknown words, and then they would read the word at once. This reading strategy usually support a better understanding. Participants' strategy to break down the words demonstrated that they rely on phonics - small grain size units. There were only a few times that participants relied on morphological knowledge of English in which they would break down words into different parts. For instance, they read "breathtaking” as "breath-taking”, and then read it again as one word. Another example would be "busyness", which participants read "busy-ness". There were some repetitions that signaled participants were thinking about word meaning and/or sentence meaning. These repetitions were frequently preceded or followed by long pauses. Repetitions demonstrated participants' attempts to make sense of the word and text.

In the following section, I present the codes for the RMAs (See Table 5.16) and Interviews (See Table 5.17). Findings from these two data collection methods go beyond my research questions. Besides that, some of the findings were reported only in one data collection method. See Table 5.16 which displays findings from RMAs, and Table 5.17 which displays findings from interviews. Then, I discuss the following identified themes: (i) Achieving Comprehension; (ii) Cross-linguistic Knowledge; and (iii) Difficulty in explain miscues, and (iv) Improving reading in order to answer research question three. Bringing the section to a close I go on to discuss the following themes: (i) Role as a reader; (ii) and L2 Reading Challenges which relate to research question four. 


\section{Retrospective Miscue Analysis and Interviews' Findings}

The number of miscues discussed with participants varies due to: (i) participants' limited time, and (ii) participants' speaking skills. Table 5.15 displays the number of miscues discussed for each text by each participant.

Table 5.15

Miscues/Text

\begin{tabular}{ccc}
\hline Participants & Text $1-\mathrm{N}^{\circ}$ of Miscues & Text $2-\mathrm{N}^{\circ}$ of Miscues \\
\hline Azim & 18 & 12 \\
Casper & 12 & 10 \\
Haddad & 11 & 13 \\
Fadil & 10 & 15 \\
Emir & 7 & 5 \\
\hline
\end{tabular}

I initially chose the miscues to be discussed during RMAs in order to guarantee we would talk about miscues that seemed important for understanding participants' thinking behind their processes of constructing meaning from the texts. Nevertheless, I also instructed participants to stop the recorder any time they noticed any miscue. This was an important instruction because I wanted participants to notice their own miscues given that they had previously demonstrated a more passive role as a reader.

Table 5.16 displays participants' explanation for their miscues which fell under the following themes: (i) Difficult to explain miscue; (ii) Achieving Comprehension; (iii) L2 Reading Challenges; (iv) Cross-Linguistic Knowledge; and (vi) Role as a Reader.

Table 5.16

RMA - Theme, Categories, and Grounded Codes

\begin{tabular}{ll}
\hline \multicolumn{1}{c}{ Categories: } & \multicolumn{1}{c}{ Examples of Grounded Codes } \\
\hline Theme 1: Difficult to explain Miscue \\
Have no explanation & - I cannot explain my miscue \\
& - Skeptical about his miscue \\
Lack of focus & - Not sure about it \\
& - I wasn't pay attention \\
& - I don't see well glasses for nothing
\end{tabular}


- Skipping lines confuses me

- Difficulty with transition from one line to other

- Speed more important

- Not focused

- I cannot hear my own miscues

- I didn't realize it was a different word

- Difficulty focusing on meaning while reading aloud

Attempt to Explain

- My brain is talking

- My personality is getting in the way

- It is very creative

- My brain works without me noticing

\section{Theme 2: Achieving Comprehension}

Miscue does not impact comprehension

Meaning over grammar

Miscue fits reader's comprehension

Self-corrections
- Read a different word, but knew the meaning of written word.

- Miscue not essential to understand meaning

- Miscue doesn't impact meaning because written word is unknown

- Don't care about miscue. I can understand the text

- Miscue can be kept without impacting understanding

- Not concerned with individual miscues because they may not impact overall understanding

- No need to correct miscue because miscue and written word share same meaning

- Concentrate in meaning not in grammar

- Tense is different, but not meaning

- Similar meaning, different grammatical use

- Grammar may not be important for understanding

- Kept same tense mood - focus on past tense

- Miscue makes sense

- Miscue supports better understanding

- More familiar with miscue results in better understanding

- It sounds more familiar than written word even though it has a different grammatical use than written word

- Similar meaning no need to correct miscue

- miscue better known than written word

- Need to correct wrong pronunciation

- Need to correct for better comprehension

- Does not meaning, but knows pronunciation

- Miscue does not make sense

- Miscue infringes grammar rules

- Miscue does not sound familiar

- It sounds better

- Need to correct only if it impacts comprehension

table continues 


\begin{tabular}{|c|c|}
\hline Categories & Examples of Grounded Codes \\
\hline Theme 3: L2 Reading & $\begin{array}{l}\text { - Familiar with the word in text } \\
\text { - Realized it was a different word } \\
\text { - There was a big difference in meaning } \\
\text { allenges }\end{array}$ \\
\hline Graphic similarity & $\begin{array}{l}\text { - Difficulty differentiating words due to similar spelling } \\
\text { (being X begin) } \\
\text { - Guess word based on first and/or last letters } \\
\text { - Guessing words based on graphic similarity }\end{array}$ \\
\hline Phonetic Similarity & $\begin{array}{l}\text { - Homophones } \\
\text { - Shape of letters impacts pronunciation } \\
\text { - Spelling impacts pronunciation } \\
\text { - Similar pronunciation and spelling = difficult in trying to } \\
\text { figure out pronunciation and meaning }\end{array}$ \\
\hline $\begin{array}{l}\text { Difficulty with } \\
\text { Pronunciation }\end{array}$ & $\begin{array}{l}\text { - Previous pronunciation impacts following pronunciation } \\
\text { - Do not know how to pronounce word, but know meaning } \\
\text { - Unknown pronunciation } \\
\text { - Unsure about pronunciation } \\
\text { - Mispronounced due to thinking about meaning of precious } \\
\text { word } \\
\text { - Difficulties with vowels confuse him } \\
\text { - Non-transparent orthographic system } \\
\text { - Couldn't remember pronunciation of the target word } \\
\text { - Easy to say the miscue than the written word } \\
\text { - Mispronunciation }\end{array}$ \\
\hline Uncertainty al & - Past tense/present tense \\
\hline Grammar/vocabulary & $\begin{array}{l}\text { - Grammar structure is unknown/unfamiliar } \\
\text { - Verbs; adjectives; adverbs become nouns } \\
\text { - Thought the miscue meaning was what he read (question } \\
\text { for questionnaire) }\end{array}$ \\
\hline $\begin{array}{l}\text { Unknown/ Unfamiliar } \\
\text { words }\end{array}$ & $\begin{array}{l}\text { - Amount of unknown words result in miscue } \\
\text { - Difficulty in retrieving word meaning } \\
\text { - First time seeing the word, he thought it was right }\end{array}$ \\
\hline \multicolumn{2}{|c|}{ Theme 4: Cross-Linguistic Knowledge } \\
\hline $\begin{array}{l}\text { L1 Knowledge used in } \\
\text { L2 reading }\end{array}$ & $\begin{array}{l}\text { - Arabic does not differentiate } \mathrm{P} \text { and B } \\
\text { - No difference in F/V sound } \\
\text { - Difficulty in distinguishing the two sounds for G in English } \\
\text { (/g/ like in girl; /dze/ like in fragile) } \\
\text { - No differentiating P/B; F/V do not impact comprehension } \\
\text { - Rely on direct connection between letter and sound } \\
\text { - Use of L1 grammar while reading } \\
\text { - L1 knowledge used for abbreviation }\end{array}$ \\
\hline
\end{tabular}

table continues 


\begin{tabular}{ll}
\hline \multicolumn{1}{c}{ Categories } & \multicolumn{1}{c}{ Examples of Grounded Codes } \\
\hline Theme 5: Role as a Reader & \\
Miscue equals mistake & - Miscue doesn't make sense. It has to be corrected \\
& - Miscue is not an attempt to understand text, but a mistake \\
& - Miscues are wrong reading \\
& - It doesn't impact meaning, but it needs to be corrected \\
& because miscue and written input are different words \\
& - Correction is needed for better understanding \\
& reading \\
& - Correction is needed for vocabulary building
\end{tabular}

Table 5.17 displays examples of the grounded codes for interviews, and categories and how they relate to the five generated themes: (i) Role as a Reader; (ii) Achieving Comprehension; (iii) Improving Reading; (iv) L2 Reading Challenges; and (v) Crosslinguistic knowledge.

Table 5.17

Interview - Theme, Categories, and Grounded Codes

\begin{tabular}{ll}
\hline \multicolumn{1}{c}{ Category } & \multicolumn{1}{c}{ Examples of Grounded Codes } \\
\hline Theme 1: Role as a Reader & - Reads a lot \\
Good Reader & - Knowledgeable about reading skills and strategies \\
- Has no mispronunciation & - Is motivated to read \\
- Adapts text for better and fast understanding \\
- Has a better understanding \\
- Good speed and fluency \\
- Reading is automatic (as opposed to chopped reading) \\
- Ability to stablish a connection between different materials \\
- Knowledgeable about different genres \\
- Good background knowledge \\
- Reads slow, no fluency \\
- Reading is a boring activity \\
- Reading is not part of someone's life \\
- Struggle to read \\
- Chopped reading \\
- Good reader \\
- Not bad reader \\
- Not a great/good reader between basic and intermediate \\
- Feel uncomfortable as a reader
\end{tabular}




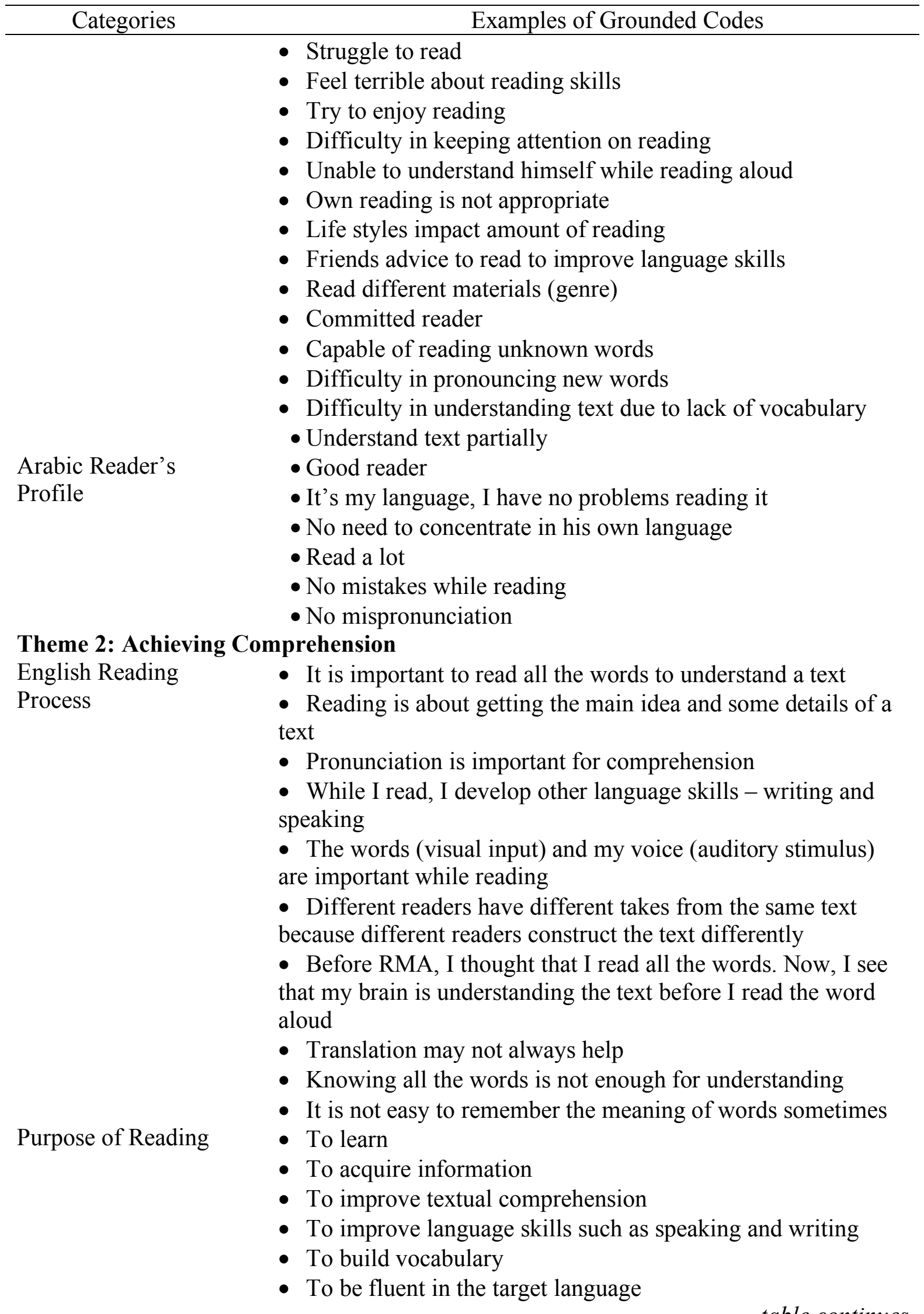

table continues 


\begin{tabular}{|c|c|}
\hline Categories & Examples of Grounded Codes \\
\hline & $\begin{array}{l}\text { - To be a good student } \\
\text { - To get a good grade in school } \\
\text { - To learn new words and grammatical use in context }\end{array}$ \\
\hline \multicolumn{2}{|l|}{ Reading Strategies } \\
\hline \multirow[t]{8}{*}{ GRS } & - Skimming \\
\hline & - Keep reading for later understanding \\
\hline & - Read what is important to answer the question \\
\hline & - Pay attention in key words \\
\hline & - Use context clues to understand an unknown word \\
\hline & - Check my guesses \\
\hline & $\begin{array}{l}\text { - Use different reading strategies for different texts and reading } \\
\text { purposes }\end{array}$ \\
\hline & $\begin{array}{l}\text { - Previous paragraph supports understanding of the following } \\
\text { paragraph }\end{array}$ \\
\hline \multirow[t]{10}{*}{ PSRS } & - Re-read \\
\hline & - Try to keep focus/concentrate on reading \\
\hline & - Try to read with normal speed and fluency \\
\hline & - Skip unknown word and/or unable to pronounce a word \\
\hline & - Stop at unknown words for close attention \\
\hline & - Read slow \\
\hline & - Substitute unknown word by a more familiar word \\
\hline & - Break down words \\
\hline & - Guess pronunciation and meaning \\
\hline & - word' roots support comprehension \\
\hline \multirow[t]{8}{*}{ SRS } & - Translate all unknown words \\
\hline & $\begin{array}{l}\text { - Translate only unknown words that are essential and/or } \\
\text { appears more than once }\end{array}$ \\
\hline & - Use of monolingual dictionary \\
\hline & - Underline/ Highlight \\
\hline & - Summarize sentences on his own words \\
\hline & - Give up \\
\hline & - Read aloud \\
\hline & - Tak \\
\hline \multicolumn{2}{|c|}{ Theme 3: Improving Reading } \\
\hline Improving Text & - TOEFL practices support better comprehension \\
\hline Understanding & - Author and reader have a similar opinion about a topic \\
\hline & $\begin{array}{l}\text { - Understanding details support the understanding of main idea } \\
\text { - RMA helped to understand the texts better }\end{array}$ \\
\hline Improving Reading & - More one reads better reader is \\
\hline Skills & - Reading increases vocabulary knowledge \\
\hline & - Writing summaries to improve comprehension \\
\hline
\end{tabular}

table continues 


\begin{tabular}{|c|c|}
\hline Categories & Examples of Grounded Codes \\
\hline $\begin{array}{l}\text { Improving Reading } \\
\text { Instructions }\end{array}$ & $\begin{array}{l}\text { - Read aloud in the classroom and teacher corrects } \\
\text { pronunciation } \\
\text { - RMA } \\
\text { - Rereading } \\
\text { - Listening stories and others reading support pronunciation } \\
\text { improvement and comprehension } \\
\text { Develop background information about a topic } \\
\text { - Teacher corrects mispronunciation } \\
\text { - Using same questions to interpret a text } \\
\text { - Work with newspaper } \\
\text { - Work more on novel. It is too superficial nowadays }\end{array}$ \\
\hline $\begin{array}{l}\text { Theme 4: L2 Readi } \\
\text { Learning to Read in } \\
\text { English in Home } \\
\text { Country }\end{array}$ & $\begin{array}{l}\text { Challenges } \\
\text { - Teachers use L1 while talking about L2 } \\
\text { - Teachers are not fluent } \\
\text { - English is mandatory in middle school } \\
\text { - Teachers are better now than when I was in school } \\
\text { - There are a lot of translation } \\
\text { - Teachers know just a little bit more than students } \\
\text { - I studied for the test, not to learn } \\
\text { - English classes are about listening, reading, and grammar. } \\
\text { - There is not speaking time } \\
\text { - Now, English teachers are Arabians and Americans } \\
\text { - Learned the alphabet } \\
\text { - Teacher said: "read it" } \\
\text { - Teacher gave small stories (four sentences) } \\
\text { - Father taught } \\
\text { - Few words on TV and play station } \\
\text { - Letters, words (concrete nouns), verbs, pronouns, and } \\
\text { grammar } \\
\text { - Struggled at first, but after a while it got easier }\end{array}$ \\
\hline $\begin{array}{l}\text { Challenges of } \\
\text { English Reading }\end{array}$ & $\begin{array}{l}\text { - Mispronunciations } \\
\text { - Read fast and fluently } \\
\text { - Need more time to comprehend a text } \\
\text { - Reading for English program is not enjoyable/boring } \\
\text { - Reading in the program does not help him in his everyday } \\
\text { life } \\
\text { - Difficult in reading new words } \\
\text { - Not motivated to read } \\
\text { - Lack of knowledge impacts his comprehension } \\
\text { - No intonation } \\
\text { - His Arabic accent gets in the way } \\
\text { - Not native accent } \\
\text { - Grammar, vocabulary, unfamiliar topic }\end{array}$ \\
\hline
\end{tabular}




\begin{tabular}{|c|c|}
\hline Categories & Examples of Grounded Codes \\
\hline Challenges of & - Academic vocabulary \\
\hline Reading at the & - May need to study harder \\
\hline College Level & $\begin{array}{l}\text { - Have not thought about it } \\
\text { - May need a tutor to help } \\
\text { - Need improve fluency due to the amount of reading } \\
\text { - Time consuming initially }\end{array}$ \\
\hline Feelings Towards & - Satisfied when understanding the text \\
\hline English Reading & $\begin{array}{l}\text { - Disappointed after reading and not understanding } \\
\text { - Frustrated when sees a lot of unknown words } \\
\text { - Anxious to improve reading skills } \\
\text { - More confident after RMA } \\
\text { - Interested in reading }\end{array}$ \\
\hline Enjoyable Reading & - Sport books \\
\hline Materials & $\begin{array}{l}\text { - Self-help books } \\
\text { - News about American politics } \\
\text { - News in general } \\
\text { - Philosophy } \\
\text { - Area of interest } \\
\text { - Different types of Novels }\end{array}$ \\
\hline \multicolumn{2}{|c|}{ Theme 5: Cross-linguistic knowledge } \\
\hline Differences in & - We read from right to left \\
\hline $\begin{array}{l}\text { Reading in English } \\
\text { and Arabic }\end{array}$ & $\begin{array}{l}\text { - Arabic reading is more difficult } \\
\text { - It has a more complex grammar } \\
\text { - Harder vocabulary in the Qur'an } \\
\text { - Different grammar structure } \\
\text { - Meaning and pronunciation change when letter have accents } \\
\text { (diactric) }\end{array}$ \\
\hline Similarities in & - It is complete different \\
\hline $\begin{array}{l}\text { Reading in English } \\
\text { and Arabic }\end{array}$ & $\begin{array}{l}\text { - There are no similarities } \\
\text { - There are a lot of differences } \\
\text { - I cannot see any similarity only difference }\end{array}$ \\
\hline Learning to Read in & - First, learn the Arabic alphabet and then start reading books \\
\hline Arabic & $\begin{array}{l}\text { - It is easier than English because it is part of your life (know } \\
\text { the language) } \\
\text { - It is natural } \\
\text { - Schools provide books } \\
\text { - Have reading time } \\
\text { - Read for fun } \\
\text { - Teacher corrects reading } \\
\text { - Teacher focuses is on right reading not comprehension } \\
\text { - In Arabic, the sound is the same, but in English is very } \\
\text { - different }\end{array}$ \\
\hline Reading in Arabic & - Do not care about unknown word \\
\hline
\end{tabular}

table continues 


\begin{tabular}{ll}
\hline Categories & \multicolumn{1}{c}{ Examples of Grounded Codes } \\
\hline & - Understand everything \\
& - Read fast \\
& Use YouTube to understand unknown word in the Qur'an \\
\hline
\end{tabular}

\section{Research Question 3: What Reading Strategies Do Adult English Learners Have to Learn and/or Become Aware of in Order to Make Sense of English Texts? Of Those, Which Ones Are Most Frequently Used?}

Four themes were identified to aid answering research question three: (i) achieving comprehension; (ii) cross-linguistic knowledge; (iii) difficult to explain miscues; and (iv) improving reading. These themes are presented in the following section.

\section{Achieving Comprehension}

Considering that our topic revolved around reading, participants frequently suggested steps to ameliorate their reading skills. They also constantly asked my opinion regarding their reading abilities which I avoided answering so as not to jeopardize the research and cause misunderstandings. This behavior demonstrated that participants may have considered me as a more skilled reader who could give them some advice to improve their reading ability.

In explaining their miscues, all participants demonstrated their sustained effort to maximize their comprehension of the texts. They were being strategic readers and taking decisions while trying to make sense of the text. Their difficulties in explaining some of their miscues, though, demonstrate a lack of awareness to their own procedures to make sense of the text, and/or unfamiliarity with RMA procedures, and/or different cultural understanding of miscues.

During interviews, participants also mentioned strategies that support and/or impede comprehension. For instance, Fadil mentioned the fact that translation may not always support comprehension given that the digital translator may not offer a suitable translation: "sometimes the Arabic translator is not giving me the exactly meaning. Sometimes I try to go 
to get the definition by English because this is the best" (Interview, 06/30/16), and Haddad also argued that translation may not always aid understanding: "Sometimes I translate English to Arabic, but it's also difficult to me to understand" (Interview, 06/27/16). Participants' acknowledgement of translations failing demonstrates that they already have had sufficient experience with reading, and that they have developed other reading strategies to comprehend an English text when translation fails.

Casper, Fadil, and Azim mentioned that "It is important to read all the words to understand a text" (Casper, Interview, 07/05/16). This shows a bottom-up reading model in which the reader needs to go through all the words to understand them. This shared view among all participants about reading as a passive act affected how they approached reading by using more problem-solving strategies as the analysis of the SORS demonstrated (See Chapter 4). In other words, they used strategies to solve local textual problems without acknowledging and/or being aware of their own knowledge about textual features and their background knowledge about the topic at hand.

This shared view of reading as a process of extracting meaning from the text, and the reader's job as a decoder resulted in participants' negative view of themselves as a reader given that they were not able to understand all words in a text. This view was explicit when participants talked about the percentage of the chosen texts they were able to understand in the read-aloud activity. As Fadil indicated in referring to his understanding of text 1 and text 2 respectively: "I got maybe fifty percent" (Interview, 06/30/16); "Ya, I understand the meaning. Maybe fifty percent, I understand it's is talking about busyness, the busy people, but I am not but for some exam or for academic study I will not get any score. This is what I thought” (Interview, 07/11/16). And Azim: "Hum like between fifty to seventy percent" (Interview, 06/26/16) referring to his understanding of text 1 . This percentage was based on the number of words for which participants could quickly retrieve meaning, particularly with 
words that have been rehearsal in several opportunities. Nevertheless, participants also pointed out other factors that support comprehension, such as visual stimulus: "Yeah, I get the information from what I see but I saw by eye not by mind" (Fadil, Interview, 07/08/16), auditory stimulus, and the "right" pronunciation as Casper explained while talking about the read-aloud: "you are like speaking and hearing at the same time. That way you help comprehension" (Interview, 07/05/16). This is consistent with research studies that have demonstrated the power of listening to one's own words in enhancing comprehension (Cho, 2016; Cho et al., 2016; Zhou et al., 2016 a, b).

According to participants, reading also supports the development of other language skills such as writing, speaking and listening since reading builds vocabulary. In Emir's words: "hum, I think in my opinion reading is the key for every skill in English. It's a key for listening, for speaking, for writing” (Interview, 06/24/16). The other participants also defended a similar idea during their RMAs, reasoning that all miscues should be corrected inasmuch as such correction would support future conversations, listening comprehension, writing essays and would also enhance vocabulary acquisition.

Additionally, all participants also mentioned factors that impede their comprehension such as the fact that knowing all the words may not be enough to achieve comprehension. As Haddad put it: "Sometimes, I know word by word if you ask me 'what that word means', I know, but if you ask me 'give me a summary or explain it', it's hard for me to explain" (Interview, 06/26/16). This illustrates participant's awareness of the complexity of comprehending a text, and awareness of the fact that ability to decode may not guarantee comprehension. This same participant attested that translation is another factor that may impede comprehension, especially when one word has multiple translations in the target language and/or in the first language. This demonstrated that this participant was progressing 
from a novice reader role to an expert reader role who does not rely solely on translation, a skill that has been associated with novice readers (Malcolm, 2009).

During the interviews I alluded to the fact that different readers may have different understandings regarding the same text. Participants recognized that different readers may have different understandings of the same text for different reasons, such as background knowledge, better language knowledge, and/or world knowledge. As Fadil mentioned while talking about the fact that he may have a better understanding of Saudi-Arabian History than I, even though the text is written in English: "Because I have the background about the history. I would guess the meaning because I know something about the subject. I have background about that" (Interview, 06/30/16). These responses demonstrate a mature reader who understands that reading involves more than decoding words, and who is in the process of becoming an expert reader by bringing their own knowledge to the reading event (Perfetti, 1992; Share, 2008).

After the RMAs, it was possible to notice a slight change in participants' views of their reading process in English. Participants started to shift their view of reading to a more active process in which the reader works arduously to construct meaning from the text. For instance, while interviewing Azim after our two RMAs, I asked him how he saw himself as a reader after RMAs, and he mentioned: "Before RMA, I thought that I read all the words. Now, I see that my brain is understanding the text before I read the word aloud" (Interview, 07/03/16). Although participants' perspectives of the reading process and themselves as readers have started to shift after RMAs, two sessions were not enough to significantly impact their bottom-up view of reading or their concerns about correctness over meaning.

This slight shift happened after they noticed their reading strategies during RMAs. During the interviews, they also mentioned reading strategies that they perceived as important in reading English text, such as summarizing, looking for key words, and reading 
with a pen, among others. These strategies are presented in the SORS as support reading strategies.

When comparing participants' responses regarding their reading strategies against the SORS survey I noticed that it was possible to establish a link between my participants' responses and the categories in the survey. Translation was the only specific reading strategy of second language learners that they mentioned. This finding is aligned with previous research studies that have demonstrated the importance of translation among L2 learners (Jiménez et al, 1995,1996; Malcolm, 2009). Nevertheless, this strategy is used more by less skilled Arabic readers than by skilled readers (Malcolm, 2009). Nevertheless, two participants, Haddad and Fadil also pointed out the negative or not so helpful aspect of this strategy

The SORS analysis also revealed that Arabic L2 learners perceived the use of PSRS, GRS, and SRS respectively. This finding is aligned with previous research (Alhaisoni, 2016; Alsheikh 2002; Alsheik et al., 2011; Malcoln, 2009; Mokhtari \& Reichard 2002, 2004; Wu 2005). Research studies have demonstrated that skilled readers tend to use PSRS to monitor and increase comprehension (Alhaisoni, 2016). Nevertheless, it is important to recall that the SROS results represent the perceived use of reading strategies and not the actual use of reading strategies.

Furthermore, during interviews, participants mentioned other types of reading strategies that are not represented in the SORS. For instance, for global reading strategies, they mentioned: (i) keep reading to comprehend previous excerpt later; (ii) the previous paragraph supports understanding of following paragraphs; and (iii) the need to use different strategies for different genres. For problem-solving strategies, participants mentioned; (i) guessing conventional pronunciation, which supports comprehension; and (ii) substituting an unknown word by a known word for better comprehension. 'Give up' was also mentioned by 
participants, which I coded under a support reading strategy. This may not be seen as a support reading strategy given that some may think that this strategy may not increase/raise comprehension. However, a strategic reader may have to know when reading an excerpt is not contributing to his/her overall understanding of the text.

The miscue analysis and RMAs demonstrated a more realistic use of reading strategies by participants. Participants' reading strategies demonstrated their footprint from their L1 reading development as suggested by the psycholinguistic grain size theory (Ziegler et al., 2005). For instance, they constantly transferred their L1 phonological knowledge while reading words with sounds that are inexistent in their language like $/ \mathrm{b} /, / \mathrm{v} /$, and $/ \mathrm{g} /$. As a result, "pale" was read as "bale", "vast" as "fast", and "fragile” is pronounced with hard $/ \mathrm{g} /$ sound instead of the soft sound /dz/. In the case of $/ \mathrm{b} /$ and $/ \mathrm{v} /$ sounds, participants affirmed that their comprehension was not affected: "Yeah, fastness vastness, $F$ and $V$, and $P$ and $B$. These is I usually don't care about these pronunciations" (Emir, Interview, 06/29/16). However, the pronunciation of /g/ as /dz/ may impact their comprehension because participants may have more difficulties in linking the word with its meaning. In this case, participants" view about the "right" pronunciation is suitable here in what concerns having a better comprehension. Participants did not present any difficulties with words with $/ \mathrm{g} /$ that have been rehearsed several times and in several situations, such as "engineer", "change", "agencies", "digit”, and "psychology", among others.

Another reading skill applied by participants when reading aloud by participants was their L1 word identification process in which their focus was on consonants while disregarding vowels. In contrast to the English language in which vowels differentiate words, in Arabic it is the consonants that give access to the lexicon (Hayes-Harb,2006). Therefore, participants' overreliance on consonants sometimes resulted in non-comprehension of the text. This specific language strategy transference demonstrates that each L1 language 
requires the development of different reading strategies in order to achieve reading comprehension, and consequently, to become literate and to achieve reading success (Ziegler et al., 2005, 2006).

While reading, participants' focus was frequently on small grain size units due to the consistency of their L1 grapheme-phoneme correspondence, as was evident in Haddad's observation about the transparency of the Arabic language when compared with English: "I think in Arabic the sound is the same in writing not the same in English it's different it's very different, because English some words like 'come' or 'claimed' without E. I can't know" (Interview, 06/27/16). He seemed to be aware that he should not rely only on small grain size while reading in English. However, at that time, he had not yet figure out that he would have to rely on large grain size units to be able to read some English words, consequently achieving better comprehension.

Participants also used a reading skill in which they simplified language, such as vocabulary and grammar, to achieve better comprehension. For instance, using the present tense which was considered the "default tense" by Azim instead of using the past tense as well as substituting words that were more familiar for them such as 'numbers' by 'numerous'; 'whole' by 'all'; 'part' by 'spot', and 'nobody' by 'anybody', among others. Azim also pointed out the use of more familiar words while reading: "my brain is reading like what is familiar for it what I say sometimes change. My personality is affecting on my reading" (Interview, 07/01/16). This revealed an authorial role in which the reader takes control of his own comprehension while drawing on previous knowledge to make sense of a text.

Nevertheless, it was during their read-aloud and more clearly during RMA that participants' reading abilities came alive to them. As a result, they started to understand that 
miscues may not represent a mistake as all of them had initially thought, but an attempt to make sense of the text. Thus, participants started to justify their miscues differently.

For instance, miscues are not essential to understand meaning (See Table 5.16) which demonstrated participants' attempts to make sense of the text even though they may not be aware of their attempts. Azim had a few high-quality miscues while reading both text 1 and text 2. Text $1,1^{\text {st }}$ page, $5^{\text {th }}$ line: "Getting to experience the whole disk"; and Azim read as: 'getting to experience the all disk'. When I asked the participant whether miscue changes meaning or not, his answer was "yes, it does because it is a different word” (RMA, 06/26/16). Then, I asked him about the meaning of the two words. At that moment, he came to realize that the two words share a similar meaning. So, he recognized that using one word instead of other would not impact meaning, on the contrary, it could even support a better understanding given that he had more familiarity with the word "all" than "whole". He was excited about this realization and could not initially believe that he was reading different words, but with similar meanings. In that moment, he said: "I changed some words in the paragraph to understand it" (RMA, 06/26/16). Later on, he explained that "I read what I want to read, not what is written in here on the paper, but sometimes it does make sense. The same meaning. It doesn't change anything, and it's easy for me to understand. Like I use an easy word to me like I use it a lot, and I am sure of its meaning. " (RMA, 06/26/16). His comments indicated his lack of awareness of all the changes he was making in the text to accommodate his own understanding as well as the automatic skills he applied during reading. His realization was supported by the interactive element of RMA. This is consistent with sociocultural-historical theory and the notion of semiotic mediation (Rogoff, 1995, 2003; Vygotsky, 1978).

All participants defended the idea that although they miscued, their focus was on meaning, which is more important than grammar. Participants' comments on the importance 
of meaning over grammar were coded within the category which refers to participant valuing meaning over grammar (See Table 5.17). In this category, participants adapted text to fit their needs so that they had a better textual understanding. This behavior suggests a mature reader.

Participants' disregard of their miscues contradicts their previous argument that miscues should be corrected because accuracy supports better comprehension as well as language development. Therefore, participants' comments have to be compared with their miscues to make sure that they were focusing on meaning and not only saving face during RMAs and interviews.

For instance, on text $1,1^{\text {st }}$ page, $6^{\text {th }}$ line: "I got goosebumps', and "Azim: 'I get goosebumps'. When I asked about how this miscue could impact his comprehension, Azim started explaining his confusion with present and past tense when talking with others: "I do make a lot of mistakes with present and past when I am talking, maybe this affects me when I am reading, and when I read, I read by default" (RMA, 06/26/16). Here, he meant that present tense was his chosen verb tense when talking, writing and even reading. This could be an L1 grammar knowledge transference given that in Arabic there are only two verb tenses: past and present which share a similar stem (KTB - to write, Kataba -past tense to write; Yaktubu - present tense to write), but differ by changing the vowels. He was aware of this type of change, but he admitted that changing the verb tenses would not negatively impact his comprehension, on the contrary, it may raise comprehension assuming that he was making the text easier for himself to understand. He also affirmed that this sentence is not very important to his overall understanding of the text, it is just more detail about how the astronaut felt by seeing the earth from space. This type of miscue was a substitution in which the participant facilitated grammar to achieve comprehension. Similar to Azim, other participants also confirmed that this type of miscue did not negatively affect their comprehension. 
Participants also indicated that there were miscues that fit their situational model (See Table 5.16 - Miscue fits reader's comprehension). Thus, the miscue was appropriated, and it did not impact their comprehension. For instance, on text $1,1^{\text {st }}$ page, $21^{\text {st }}$ line: "the conflicts that divide us become less important and the need to create a planetary society with the united will to protect", and Azim: "the conflicts that divide us become less important and the need to create a planetary society with the united/unit/united will to protect." This was a self-correction whereby the participant read the word three times until he was able to achieve a satisfactory pronunciation and to link word with its meaning. At first, he read the right word, but because the word did not ring a bell in his mind, he applied a reading strategy in which he analyzed the word morphologically. So, he read the word a second time as "unit". At this time, he was able to understand the text, then he read the target word again for syntactic acceptability. During RMA, he affirmed that he knew the meaning of 'unit' better than 'united'. Hence, he used 'unit' to connect the word 'united' with its meaning/concept given that the two words share a similar meaning. Regarding meaning change, he argued that using 'unit' instead of 'united' would not change the meaning, but it would be wrong from a grammatical point of view. His observation about grammar shows that he was not only focusing on word level, which was dominant in his reading, but he was also processing grammatical clues. In other words, while reading he was using different cue systems to adjust his understand. During our initial interview, he acknowledged that he frequently uses part of the speech to figure out the meaning of unknown words. Studies have demonstrated that this is a common reading strategy for Arabic speakers who need to use their grammar knowledge to figure out the meaning of words (Abu-Rabia, 1997; Saiegh-Haddad \& Geva, 2008).

Fadil and Casper made a similar miscue on text $2,1^{\text {st }}$ page, $11^{\text {th }}$ line: "Yet, little scientific work has been done to empirically investigate the construct"', and Fadil and Casper: "Yet, little scientific work has been done to empirically investigation the construct". 
This was a common miscue among participants in which they changed a verb for its noun. According to Fadil, these two words have a similar meaning. He also argued that he was not thinking about grammar, but about meaning. In other words, he was concerned in depicting meaning from the text even though he was infringing syntactic acceptability while pay attention to semantic acceptability and graphophonic cues.

Haddad, in his turn, also affirmed that certain miscues supported his understanding. Text $2,2^{\text {nd }}$ page, $17^{\text {th }}$ line: “engagement in learning new skills such as", and Haddad: "engagement in learned new skills such as". According to Haddad, the text was written in the past, so he kept the same tense. He identified "learn" as a verb, and not as an adjective. This is advanced grammar which may not be known by novice readers. Nevertheless, his miscue demonstrated that his focus was on meaning while taking into consideration semantic and graphophonic cues.

Participants' self-corrections were attempts to achieve comprehension. Observing participants' behavior, it can be said that self-corrections happened in two moments: (i) they knew the meaning of both the expected response and the miscue, and the miscue did not make sense; and (ii) they knew the pronunciation even though they may not have known the word meaning. Nevertheless, they frequently argued that self-corrections were necessary even when the text made sense with the miscue. Furthermore, corrections support language development.

In the following, I present participants' self-correction and their rationale for doing so. Azim read text $2,2^{\text {nd }}$ page, $34^{\text {th }}$ line as: "Doesn't that ready/already sound less stressful?", and text: "Doesn't that already sound less stressful?". This was a self-correction in which he was able to correct after realizing that he had forgotten to read the initial syllable. So, he argued that he went back and corrected his miscue because he knew both words. In 
other words, his focus was on meaning, but graphic cues also helped him to realize that he had miscued.

On text $1,1^{\text {st }}$ page, $11^{\text {th }}$ line: "Yet, little $\underline{\text { scientific }}$ work has been done to empirically investigate the construct of busyness and its associations", and Casper: "Yet, little significant/scientific work has been done to empirically investigate the construct of busyness and its associations"”. When I asked about his miscue, he argued: "(reading) 'little significant'. I don't know why I said that. It doesn't make sense "little significant", therefore, I corrected it." This indicates that he was keeping control of his comprehension while aware of his own listening input.

Haddad also confirmed that knowing the words facilitates correction. For instance, text $2,2^{\text {nd }}$ page, $3^{\text {rd }}$ line: "the data showed that the highly educated", and Haddad: "the date/data showed that the highly educated". Data is a very familiar word for this participant because he has worked in health information management, and he was also interested in studying this subject at the graduate level. This demonstrates that semantic acceptability guided Haddad's self-correction in this case. Furthermore, he was using his background knowledge even though he did not acknowledge any role to his background knowledge during interviews

"Aline: Here you said data and then you corrected yourself and said date.

Haddad: Data?

Aline: Why did you do that?

Haddad: Because I know it

Aline: Do you know what? This word means?

Haddad: Date is like Information"

Emir had self-corrected himself a few times, especially when he noticed that he had mispronounced a word. His sense of audience made him pay attention to accuracy instead of 
comprehension. Nevertheless, his explanations about his miscues would not focus on his overconcern with mispronunciation, but on difficulties that he faces while reading any text. For instance, the sentence "NASA flight engineer and mission specialist" (text1; page1; line1) was read as "NASA fight/flight engineer and mission specialist." He explained that he read 'fight' because the transition from the first line to the second line confuses him, but because the miscue did not make sense in the context, he went back to re-read when he realized he had read a different word.

However, at the end of our first retrospective miscue session, Emir assumed a more authorial role regarding his reading. For instance, in the following miscue "He began practicing transcendental meditation upon his return" (text $1,2^{\text {nd }}$ page, $6^{\text {th }}$ line), and Emir: “He began practicing transcendental mediation upon his return”. Emir explained that even though he had read something different he knew what the text was trying to convey. Therefore, he saw no need for correction. In Emir's words: "I didn't correct because maybe I realized that I pronounced wrong but I just carry on, let's go because I think I know what this means I don't need to bother myself to stop there. Do you know what I mean? To read more sometimes I read I read the first time and I realize I made a mistake but I don't try I guess I just want to carry on. I don't want to correct” (RMA, 06/29/16). Nevertheless, Emir's rationale should be taken with a grain of salt. He was very conscious about his ability to pronounce words like a native speaker. This ability attributes to him status as a good L2 speaker. So, admitting his own miscues which he saw as mistakes was very embarrassing for him. There were moments during RMA sessions that he assumed a self-protective behavior or assumed a certain distance by being quiet while I explained what miscues mean to teachers and researchers.

In another of Emir's self-corrections, on text 1, $2^{\text {nd }}$ page, 6th line: “others devote their lifes (lives) to religion or find renewed sense of faith", when he noticed his mispronunciation, 
he went back and corrected his miscue. He stated that he was able to correct his miscue because he knew the word meaning as well as its usage. Emir: "I knew because I am familiar with this word 'lives' more than meditation. So, I went back and corrected I think. Maybe it's the word sounds not good for me "their lives religion" sounds good for me". This was not the case for other known words such as peek/beek; vastness/fastness on text 1 . His explanation for these miscues was that he did not realize he said a different word when he was reading. He also declared that: "Yeah, fastness vastness, $F$ and $V$, and $P$ and $B$. These is $I$ usually don't care about pronunciation" (RMA, 06/29/16). However, in his second reading, he was very cautious about not making miscues of this type.

Participants were also able to identify some English characteristics that impede their comprehension such as graphophonic similarities that resulted in miscues. Graphic similarity miscues were more common that phonic similarities. This may have happened because of participants' overreliance on consonant patterns while reading. For instance, while talking about the miscue FaRMeD by FRaMeD (text $2,1^{\text {st }}$ page, $4^{\text {th }}$ line), Casper argued that he miscued because of graphic similarity, and also because "framed" is an unknown word for him.

"Aline: so why do you think you said farmed instead of framed

Casper: Because it looks like farm” (RMA, 07/08/16)

It is important to point out that 'framed' was unknown by Casper in text 2 because when I used it in a different context he was fast in understanding its meaning. He drew a frame in the air to explain the meaning of the word. "Aline: "let me write down that you did with your hands. You drew a square in the air with your hands. Just to make sure I remember it” (RMA, 07/08/16). This indicated that he needed scaffolding while reading that particular word. Furthermore, it also demonstrates the power of social interactions while reading and acquiring language (Gass et al., 2008). 
On text $2,1^{\text {st }}$ page, $10^{\text {th }}$ line: "Often busyness carries a negative connotation, as people tend to complain about their hectic schedules"; and Azim, Fadil and Emir who was able to self-corrected his miscue, read the text as: "Often busyness carries a negative connection, as people tend to complain about their hectic schedules". Although this sentence is syntactically correct, it is not semantically acceptable. During the RMA, Azim was able to pronounce the word connotation, but he was unable to explain its meaning. Although he knew the meaning of connection, he could not tell if connotation and connection share a similar meaning. He explained that to read the word he observed the first letters and guessed the word. He also affirmed that there was a graphic similarity between the two words. Both Fadil and Emir argued that the two words share graphic similarities which influenced them to miscue.

On text $1,1^{\text {st }}$ page, $7^{\text {th }}$ line: "humans have been going to space for five decades now and during that time numerous astronauts have returned from orbit with reports early similar too", and Casper: "humans have been going to space for five decades now and during that time numbers astronauts have returned from orbit with reports early similar too". Casper clarified that he could not read the word 'numerous' which was an unknown word to him. Every time he tried to read the word 'numerous', he inserted a "B" between " $\mathrm{M}$ " and "E" resulting in the miscue 'numbers' which is known by him. Casper also defended that these two words do not share a similar meaning, but they are graphically similar, and this similarity influenced him to miscue. Nevertheless, it can be argued that he was making sense of the text given that the miscue makes sense in that context even though he was not aware of it.

On text $1,1^{\text {st }}$ page, $18^{\text {th }}$ line: "long-term memory, which is memory of personal events and their context", and Casper: "long-term memory, which is many of personal events and their context”. Once again, Casper argued about the graphic similarity between the two words. When I asked how similar the words were, he said that the initial letter (M) and last 
letters were the same (Y). He looked at the first and last letter, and figured out the word. This is aligned with Dehaene's (2010) argument that readers look only at a few graphic inputs to read a word.

Fadil also had miscues that he attributed to graphic similarity. On text $1,2^{\text {nd }}$ page, $6^{\text {th }}$ line: "practicing transcendental meditation upon his return", and Fadil: "practicing transcendental medication upon his return". Fadil defended that he thought the word was 'medication' because of its spelling. This miscue also falls under the same consonants, different positions/missing consonant type of miscue (MeDiTaTioN - MeDiCaTioN) indicating once again that these participants were transferring reading strategy from their L1 to L2 context while focusing on consonant patterns.

Haddad was one of the participants who mentioned his difficulties with phonetic similarities even though all of the participants miscued because of phonetic similarity. On text $2,2^{\text {nd }}$ page, $15^{\text {th }}$ line: "But there is a growing body of evidence suggesting", and Haddad: "But there are a growing body of evidence suggesting”. He argued that this was a common mistake until he studied the difference between 'there is' and 'there are' the previous week. So, now he is able to "fix" the problem during writing/speaking, but, apparently, not during reading aloud. He also affirmed that when he sees the word 'there', he automatically thinks that the following word should be "are". His explanation makes one think that he could be having trouble in differentiating homophones such as there/their/ they're. Furthermore, that listening to what he reads has a more important impact on his comprehension that the written input. Nevertheless, he recognized that 'there are' and 'there is' have a similar meaning, but different grammatical uses.

"Aline: Did you hear what you said here?

Haddad: There are

Aline: There are instead of 
Haddad: There are is wrong

Aline: there is. Why do you think 'there are is wrong?

Haddad: Because I changed it before I used there is people and the last week I studied for this for "are" it's plural and for "is" it's singular. I changed to 'there are people', 'there are a lot of stories', 'there are' that is the reason maybe my brain is talking

Aline: Are you talking about from the grammar point of view, right?

Haddad: Yeah, sometimes if I read "there" I think after 'there are', I mean directly, I don't focus.

Aline: I see what you are saying. When you say 'there' you think it's gonna be an 'are'.

Haddad: Yeah

Aline: okay this word here (there) makes you realize that, but do you think the meaning is different? There are and there is?

Haddad: No just the grammar

Aline: Just the grammar? What about the meaning?

Haddad: Yeah, same"

On the title of the second text: "The scientific case for being super busy". Azim read as: "The scientific case for begin super busy". This miscue is a substitution which falls under the same consonants, different positions/missing consonant category - BeiNG/BeGiN. According to Azim, he knew the meaning of both words, but he may have miscued because of graphic and phonetic similarity. He reasoned that he looked at the letters and chose which word he would say (Dehaene, 2010). Haddad and Fadil also miscued with these two verbs. Fadil explained that graphic similarity caused him to miscue. This type of miscue reflects participants' attention to consonants while disregarding vowels. Taking in consideration 
consonant patters seems to be a very important reading strategy while reading in Arabic. Nevertheless, this may be very harmful while reading in English given that vowels in English provide information for differentiating lexical items (Hayes-Harb, 2006).

During RMAs and especially during interviews, participants and I talked about the purpose of reading. My intention was to verify whether participants would mention the fact that readers use different strategies while reading different genres to achieve comprehension. It was interesting that all participants talked about the purpose of reading in supporting language development, and for school/academic purposes such as getting a high grade. None of them mentioned reading as a leisure activity to spend time, at least, not regarding reading in English.

Nevertheless, this attitude changed when they talked about reading in Arabic. It seems that in their own language they tend to look for texts that are more in keeping with their interests such as sports, self-help books, philosophy, and news, among others. Participants mentioned that the reading material in their English program was boring and outside their interest area, which contributed to their lack of motivation to read - "I mean some books like talk about animals. I don't care about animals. It's boring. I want to go to the university and they talk about animals? Why? " (Haddad, Interview, 06/27/16). Research has already demonstrated the power of motivation while learning a language (Gardner, 2010; Dörnyei, 2005, Masgoret \& Gardner, 2003; McClelland, 2013; Noels, Pelletier, Clément and Vallerand, 2000). Therefore, it is important that English programs consider students' goals as well as their interests so that more appropriate material can be allocated to support students' L2 academic reading development. The idea of meaningful learning presented in the critical pedagogy relates closely to these concerns and the lack of interest presented by students (Freire, 2005). It is also important that L2 instructors make clear to L2 learners that they will not always read material that is in learners' interest area as it is the role of schools and 
programs to expand the repertoire of learners whether it be their understanding of genres or of different topics. This is also true of English programs that prepare L2 learners to take international English exams in which L2 learners have to read a plethora of different texts.

\section{Cross-Linguistic Knowledge}

During interviews, I asked participants about the similarities and differences between their own language (Arabic) and the target language (English). Interestingly, none of them could tell of any similarity between these two languages. They could only point out differences which were accentuated during their reading aloud. For instance, there were moments during reading aloud when participants were clearly applying their knowledge of reading in Arabic to read in English. This was especially evident when there were words in the texts that contain sounds that do not exist in Arabic such as /p/;/v/; and soft /g/ as /dzi:/. Participants were also transferring other reading strategies such as focusing on consonant patterns. However, they were not aware of their focus on consonant patterns.

Participants also argued that Arabic is a very difficult language to learn due to its grammar: "in my opinion Arabic is more difficult Arabic grammar is more difficult than English in my opinion, ... as a native speaker, I think that Arabic is easier, but if someone wants to learn English and Arabic, for example, a Japanese wants to learn Arabic and English he will know that Arabic is difficult more difficult than English" (Emir, Interview, 06/24/16). Nevertheless, participants also mentioned that Arabic is a more transparent language than English: "I think in Arabic the sound is the same in writing not the same in English” (Haddad, Interview, 06/27/16). Although participants argued about the Arabic language being a shallow system, research studies have demonstrated that the Arabic language is in the middle of this shallow-deep orthographic system continuum. The vowelled Arabic learned in the initial grades is seen as a shallow system. By contrast, the unvowelled 
Arabic, which is used once students are proficient readers, is considered as a deep system (Taouk \& Coltheart, 2004).

According to participants, their initial process of learning to read in Arabic was a phonic approach in which teachers initially taught students to identify the appropriate sound for each alphabetic letter followed by reading short words. This approach supported the reading of more complex text. Azim:

“We learn first level like primary school, we learn a letter and some words. They give us like you know stories for babies. We read it. We have a lot of books. We read from the Qur'an. We read a little bit. They teach us how to read from the Qur'an because the Qur'an uses the original Arabic. We didn't use we use like slangs, and another accent now. But we use to read by original Arabic from Qur'an, and letter and some vocabulary. You use Arabic all time in your home it's easy than English" (Interview, 06/24/16).

Azim's statement reinforces the idea that oral language supports reading.

Nevertheless, research studies with Arabic speakers have demonstrated that due to diglossia there is high levels of illiteracy in the countries where Arabic is spoken (Saiegh-Haddad, 2003).

All participants had difficulties in pronouncing some English sounds. At these moments, participants would approach the situation by using small grain size units phonemes. Participants' awareness of their difficulties in pronouncing certain sounds in English varied during read-aloud. Casper, Haddad, Fadil, and Azim read the following as: "one of the best, most emotional experience" (text $1,1^{\text {st }}$ page, $11^{\text {th }}$ line) instead of: 'one of the deepest, most emotional experience.” This miscue represents L1 phonological miscues. When words were familiar and participant have had enough encounters with the target word, they would not have any trouble in pronouncing it, otherwise, they would always fall in the 
default mode which was their L1 phonological knowledge. In Haddad's words while explaining this particular miscue: " $P$ is hard for me, it's a new letter. I can say B easy, but $P$ no” (RMA, 06/30/16). Fadil also argued that differentiating /p/ and /b/ is very difficult for him: "I said "the best", ya? Yeah, I remember. It's hard to pronounce, deebest (trying to say deepest) (RMA, 07/08/16)". Thus, words such as 'girl' and 'age' would not be a problem for participants to pronounce when reading. However, words such as 'fragile', 'cognitive', 'longevity', among others, would be challenging for participants. Furthermore, participants also argued that they did not realize that they were miscuing with these letters. Only during RMAs, when participants had more time to listen and reflect on the written word and their oral production, they realized their miscues.

On text $1,1^{\text {st }}$ page, $14^{\text {th }}$ line: "All of history and music and poetry and art and death and birth and love, tears, joy, games, all of it on that little spot out there", and Azim: "All of history and music and poetry and art and death and breath and love, tears, joy, games, all of it on that little spot out there" (RMA, 06/24/16). Although the sentence is syntactically correct, he changed the meaning of it. He argued that there were a lot of similarities between the two words, especially if we think about the fact that Arabic speakers look at consonant patterns to figure out word meaning, it can be said that these words in his eyes appear exactly the same BiRTH X BReaTH.

"Aline: Why do you think you said breath instead of birth?

Azim: long pause. I lot of similar, maybe. The word it comes like." (RMA, $06 / 26 / 16)$

When I asked about the meaning of these two words, he pointed out that they have different meanings: "birth is born", and to explain 'breath' he pointed to his mouth while breathing through it (Azim, RMA, 06/26/16). Another possible explanation for this miscue is that the previous word "death" may have influenced him to say "breath". He may have only 
seen the cluster "BR" and used the ending /eath/ of previous word to keep the same sonority. This may have happened because (i) his attention was on the word level and not on the attempt to construct textual meaning at that moment in the reading; (ii) he could be trying to process previous text while reading the next paragraph, and/or (iii) he could be still trying to link the word 'death' with its meaning.

Reading the word 'framed' as 'farmed' and 'formed' was also a common miscue among participants. On text $2,1^{\text {st }}$ page, $4^{\text {th }}$ line: "We have framed the act of being busy as a burden"”, and Azim read as: "We have formed the act of being busy as a burden". Azim affirmed that he miscued because he looked only at the first letter, and he did not pay attention on the other letters: "I think it's (10:48-11:02) hum. I don't know maybe when I read I said the first letter and I figure out the word" (RMA, 07/03/16). Azim's miscue could also represent an authorial role in which he understood the word 'formed' as 'shaped' and/or 'conceptualized'. In this sense, he was making sense of the text, but he was not metacognitively aware of how he kept control of his understanding. It may be that he was processing the text automatically. As previously discussed, Casper, Fadil, and Emir also miscued with the word 'framed', which they read as 'farmed'. This miscue fell under the similar consonant pattern (FRaMeD/FoRMed/FaRMeD). It is also important to observe that participants maintained the same syntactic structure showing, once again, that when participants did not have control over their comprehension and/or they did not know the meaning of a word, they attended to syntactic acceptability, but not to semantic acceptability.

Fadil also transferred his L1 knowledge to L2 reading while coming across the abbreviation of a middle name on "Text $1,1^{\text {st }}$ page, $11^{\text {th }}$ line: 'wrote space shuttle astronaut Kathryn D. Sullivan”, and Fadil: “wrote space shuttle astronaut Kathryn doctor Sullivan”. Here, Fadil argued that the letter " $\mathrm{D}$ " is used to abbreviate doctor in Arabic language, thus, he read 'doctor' instead of ' $D$ '. 
"Fadil: Doctor or before?

Aline: Yeah, you said doctor? Why did you say doctor?

Fadil: Because of D

Aline: Because of D.? Is D. short for doctor?

Fadil: Yeah for us

Aline: For us? In Arabic?

Fadil: in my county, yeah" (RMA, 07/08/16)

Haddad was the participant who made very clear his difficulties in differentiating B/P; $\mathrm{V} / \mathrm{F}$, and $\mathrm{G}$, and in pronouncing the English vowels. On text $1,1^{\text {st }}$ page, $20^{\text {th }}$ line: "national boundaries vanish", and Haddad: "national boundaries finish". This is a substitution/pronunciation miscue in which the participant should be able to identify his miscue given that he may know at least one of the two words. According to Haddad, this miscue is a result of his difficulty in differentiate the "V" and "F" sound. This difficulty in differentiating these two sounds was common among participants. This is a reflection of Arabic which does not differentiate these two sounds (Ali, 2015; Hassan, 2014; Lev-Ari \& PeperKamp, 2013; Rajab, 2013). Nevertheless, he also changed the initial vowel from "A" to "I" showing once again his lack of attention to vowels and/or, as he had argued over and over during our RMAs sessions, his difficulties in pronouncing and distinguishing the vowels in English: "It's hard for me the vowels. I don't have a strategy for like the vowels, the sound" (Haddad, RMA, 06/30/16). Distinguishing vowels in English is a common problem among L2 learners given that there are more sounds for vowels than graphic representation of vowels (Ali, 2015; Hassan, 2014; Perez, 2005).

\section{Difficult to Explain Miscues and Improving Reading}

Difficult to explain miscues and improving reading are complementary themes. In the first theme, participants were unable to explain their own miscues. This difficult may have 
happened because RMA was a new procedure to participants. In participants' understanding of reading, they were reading everything on paper as it was presented. So, initially, they could not believe their miscues or my explanations as to how miscues could inform a teacher and/or researcher about a reader's reading process of understanding a text. Therefore, at the beginning of our RMAs, participants had difficulties in explaining their own miscues. Nevertheless, as we started talking and thinking about their miscues, participants also started to understand their own thinking behind each of their miscues. Therefore, our initial RMA resulted in three categories: (i) "Have no explanation", (ii) "Lack of focus", and (iii) "Attempt to Explain Miscue".

The first category - have no explanation - refers to participants' difficulties in explain their own miscue. This may have happened because of participants' lack of familiarity with this procedure as well as the fact that they may never have been asked to talk about their own reading process. All participants gave this answer at some moment in their RMAs.

Casper read: "For sentence, a 2013study at the Center for Vital Longevity found that sustained" instead of "For instance, a 2013study at the Center for Vital Longevity found that sustained" (text $1,2^{\text {nd }}$ page, $17^{\text {th }}$ line). Initially, he could not retrieve the meaning of 'for instance', but after I used it in a sentence, he was able to use its synonym - 'for example'. This demonstrates that Casper knew this structure, but during read-aloud he was probably trying to make sense of the previous text by connecting previous information with the next paragraph. He affirmed that he had no explanation for his miscue. Nevertheless, he argued that he should have corrected the miscue. All participants seemed to value accuracy over meaning making. This thought seems to be a reflection of their initial school years in which they had to read aloud in the classroom, so that the teacher could correct their pronunciation. Haddad also mentioned a number of times that he could not explain his miscue. On text $1,2^{\text {nd }}$ page, $15^{\text {th }}$ line: "to learn more about human consciousness", and "Haddad read as: 
"to learn more about human consequences." This was a common miscue among participants. Azim made the same miscue while Casper and Fadil had problems in pronouncing this word. Casper was able to produce something as 'consencious', and Fadil's production was not intelligible. For Haddad and Azim, this miscue represents a substitution while for Casper and Fadil, it was a mispronunciation. Haddad knew the word 'consequences', but 'consciousness' and 'conscious' were unknown. Furthermore, he could not link the word with its meaning. When I asked him why he made the miscue, he could not explain it. Nevertheless, it is interesting to observe that here he had not attributed his miscue to his lack of attention, which was another common explanation for this participant. Azim, in turn, emphasized that this type of miscue was a result of "his brain" looking at/pay attention to the initial letter only, and trying to guess the word. Azim was focusing only on a few letters to guess words (Dehaene, 2010). Here, both Azim and Haddad relied on syntactic cues, but they failed to consider semantic cues as well.

The second category - lack of focus - refers to participants attributing their miscues to not paying attention to the words in the text. This was a common explanation among participants, especially Fadil. For instance, while reading: "I took a peek and saw the beautiful blue and whites of the Earth below and the curvature of the horizon" (text $1,1^{\text {st }}$ page, $4^{\text {th }}$ line), he substituted 'below' for 'blue/blew'. Fadil explained that he was not focusing on the word, and that he had forgotten the word below: "I said I didn't focus about this. Iforgot this word, you know? Now you remembered me 'below' but before when I saw it I didn't remember it" (Fadil, RMA, 07/08/16). However, Fadil also argued that he did not see this as a mistake given that he did not think that the miscue was important to his overall understanding: "Yeah I didn't care about it. I think it wasn't important Like this, and I don't know I am not thinking that this is a mistake, you know? I didn't care about the word." (RMA, 07/08/16). Indeed, this word was not very important to his overall understanding. 
However, his miscue demonstrates that he was still processing previous information with the word 'blue' and/or establishing a connection between the words: 'blue' and 'earth'.

On text $1,1^{\text {st }}$ page, $16^{\text {th }}$ line: "In 1987 , this phenomenon was given a name: The Overview Effect", and Fadil: "In 1987, this phenomenon was given a name: the overall/overview Effect”. According to Fadil, 'overall' was a known word, but 'overview' was not. After my explanation of overview and overall, he realized that the two words have a similar meaning. I asked why he corrected his miscue, and he argued that after re-focusing, he realized that he had said a different word than the one in the text, therefore, he corrected himself. He also argued that he is very visual. In other words, visual input is more important than auditory input. He explained that he corrected 'overall' because his pronunciation of 'overview' was wrong. Here, it is possible to argue that, even at this early stage of his reading aloud, he was already making sense of the text even though he was not aware of it.

On "text $2,1^{\text {st }}$ page, $11^{\text {th }}$ line, the text was: "the authors write.", and Fadil read as: "the another write". Fadil explained that he was not focusing on reading. Nevertheless, it seems once again that Arabic readers seem to pay attention to only a few consonants, and then try to figure out the word. Observing each letter, it is possible to argue that the only letters that he missed in the target word was "O" and "S" given that he could have seen "u" upside down which would look like an "n".

Fadil also substituted the word 'educated' for 'education' on 'text $2,2^{\text {nd }}$ page, $3^{\text {rd }}$ line: 'the data showed that the highly educated (education) consistently reported the highest". Once again, he attributed his miscue to a lack of focus. However, he also clarified that he knew what the writer was trying to convey, therefore, there was no need to correct miscue. Nevertheless, he had read 'education' (text $2,2^{\text {nd }}$ page, $1^{\text {st }}$ line) just a few lines before reading 'educated'. This may have contributed to his miscue because he still had the word meaning in his mind and/or was still trying to comprehend previous text. 
Casper also attributed some of his miscues to a lack of focus. On text $1,1^{\text {st }}$ page, $1^{\text {st }}$ line: 'Astronaut Kjell Lindgren spent close to five months on the International Space Station last year serving as a', and Casper replaced 'year' for 'five'. According to Casper, he should have corrected not only this miscue, but all the previous miscues because what he said did not match the text. His response to this miscue was also that he did not pay attention while reading this sentence. However, as Fadil in the previous example, Casper had also read the word 'five' a few words before. It could be that he was still processing the previous text while reading ahead. As a result, he may have said a word/idea that was still in his mind.

The third category - attempt to explain miscue - refers to the initial attempts of participants to explain their miscues. It is categorized as an attempt because participants were unable to offer a full explanation for their miscues, however, they had understood that they were processing the text somehow.

On text $2,1^{\text {st }}$ page $15^{\text {th }}$ line: "how often they are so busy they have to go to bed (bit) later", Fadil replaced the word 'bed' for 'bit'. He attributed this miscue to his creativity by saying: "Yeah, I think it's very creative. 'Bit' is very creative. 'To go to bed later than normal'. I don't know why I said bit"' (RMA, 07/11/16). This miscue could be because of: (i) his attention to consonants while overlooking vowels (Ryan et al. 1992) given that $/ \mathrm{t} / \mathrm{and} / \mathrm{d} /$ have the same point of articulation, the only difference is that $/ t /$ is voiceless and $/ d /$ is voiced, and/or (ii) he knew the expression 'bit later' and guessed the expression without fully attending to the words. This demonstrates that readers do not pay attention to each single word as all participants seemed to believe, but reading is, indeed, a guessing game.

While reading text $1,1^{\text {st }}$ page, $2^{\text {nd }}$ line: "NASA flight engineer and mission specialist", Azim tried to read the word 'specialist' three times by breaking it down into two part - special/ist. He was unsuccessful however, as he was not able to pronounce the vowel 'I' as /I/, in all his attempts he said /ar/. Here, he looked at the word "specialist" and 
associated it with "special," which his brain, as he said, could retrieve the meaning of quickly because he was familiar with the word 'special'. While reading, he was able to approximately link the word "specialist" with its meaning. While explaining his attempt to say 'specialist', he clarified: "like sometimes when you read you don't read the whole word. You see just a part of the word and your brain gives you the word like you read it. Sometimes that happens in Arabic. Like some sentences, they give you the word it's not exactly the same word they change some letters inside the word, and when you start reading you read the word what you are thinking about not the real word that you see" (RMA, 06/26/160). His explanation indicates that he was explaining how the Arabic language works by adding prefixes and suffixes to a root so that verb tenses and new words can be formed (Hayes-Harb, 2006).

It was interesting to observe that although participants were unable to explain their initial miscues, they could indicate steps to be taken in order to improve their reading skills. These conversations about improving their reading skills resulted in the identification of three categories: (i) improving text understanding, (ii) improving reading skills, and (ii) improving reading instruction.

In the first category - improving text understanding, few participants mentioned factors to improve text understanding. Azim, Emir, Haddad and Fadil mentioned that TOEFL practices were very helpful in improving textual comprehension. This answer reflects participants' need to get a certain score in international English tests in order to enroll in a U.S. universities.

Casper also mentioned that sharing a similar view with the writer may facilitate comprehension given that reader has the same view about the topic: "I mean like if I read an article and the author said the situation he had been before and he solved by his way, and I have been in the same situation before I read this passage and I solved like not exactly the 
same way he did. Then I say oh yeah, he is right" (Interview, 07/08/16). Casper's argument is aligned with research studies that contend that the more writers and readers share/ have in common, the easier it is for the writer to write the text and easier for the reader to understand it (Kucer et al., 2006).

Azim declared that understanding the details of a text facilitates the understanding of the main idea: "Some details, so when you are talking to support the main idea" (Interview, 07/03/16). Haddad recognized the importance of RMA in supporting better textual understanding: "I like your idea (talking about RMAs). I think when the teacher here is the same way (use RMA) my reading skills would improve, now I feel a little bit improved" (Interview, 07/07/16).

In the second category - improving reading skills, all participants recognized having a routine for reading, and reading as much as possible, as the most effective way to achieve better reading skills. Fadil said: "I think I should read more books, so I would have more vocabulary" (Interview, 07/11/16). Haddad had a similar argument: “I think when I read every day and you (teacher) must correct me because I am a student, this is my second language I don't know if you don't correct me I keep making mistakes (mispronunciation)" (Interview, 07/07/16). In participants' view, better reading also refers to the ability to read with conventional pronunciation, speed, fluency and prosody. Participants may have focused on these issues due to the nature of our activity - reading aloud. Perhaps, if they had to read silently, they would mention different issues. The participants' responses demonstrate a concern with bottom-up reading procedures rather than a meaning-based process. This may suggest that participants are still novice readers when reading in English. Nevertheless, their commitment to their learning process, and the discoveries that they made during RMA indicate that they were shifting their theories of reading — what they believe reading is toward reading as a more active and even agentic process. 
In the third category - improving reading instruction, participants mentioned few aspects of their reading classes that could be improved. Haddad was the most critical participant when it came to improving reading instructions. He gave several suggestions regarding this issue such as working with reading material that interests students, teachers correcting mispronunciation, and developing a deep work with the book chosen by the English program. He was also very emphatic about the use of RMA in the classroom. Furthermore, he argued that participating in the RMAs facilitated better textual comprehension as well as enabling him to gain a better understanding of the reading process and of himself as a reader (Wang et al., 2017).

All participants mentioned that to improve reading instructions, the teacher should correct their mispronunciation so that they would improve as a reader. Haddad: "I want read and the teacher correct me" (Interview, 07/07/16). Casper: "If the teacher makes us read together all of us and start correcting us. I think when the teacher corrects us this is helpful, correct the pronunciation” (Interview, 07/07/16), and Fadil

"Fadil: I think maybe reading in the class, so the teacher would correct us Aline: Reading aloud in the classroom?

Fadil: Yeah yeah

Aline: But how this would help you to be a better reader?

Fadil: Because to correct me how we can read, how read to correct reading

Aline: But || she would be correcting only the pronunciation |||, right?

Fadil: Yeah

Aline: But how this would help you?

Fadil: Because I wounld maybe it's easy to read more, the speed, I will understand the word quickly 
Aline: Why do you think that having the right pronunciation would help you to understand the word quickly?

Fadil: (long pause) Because I understand the meaning is quickly."

This procedure to improve their reading skills in which the teacher corrects L2 readers could result in L2 learners raising their affective filters. Research studies have demonstrated that it is important not to raise students' affective filters such as motivation, anxiety, selfconfidence, and/or attitude (Gass et al., 2008; Krashen, 1985) otherwise learning may not take place. Nevertheless, based on participants' descriptions of their experience of learning to read Arabic, it appears that being corrected by their Arabic teachers while reading aloud was a common procedure. Therefore, these participants may feel comfortable with this procedure, and believe that their reading skills will improve as a result of the teacher correcting their pronunciation. However, this may not be a good approach for L2 learners from different cultures (Lee \& Handsfield, 2018). Furthermore, this procedure values accuracy over meaning making. Therefore, in cases where English instructors decide to use this approach to fulfil the needs of these particular L2 learners, they should be careful to not emphasize accuracy at the expense of meaning making.

\section{Research Question 4: How Do Adult English Learners Understand Their Own Reading Strategies and Metacognitive Awareness?}

In order to answer research question four, two themes were identified: (i) Role as a reader; and (ii) L2 Reading Challenges. These themes are presented in the following section.

\section{Role as a Reader}

Participants' responses regarding themselves as readers focused on their struggles while reading, and in classifying themselves in a continuum between good-bad readers. The majority of them recognized themselves in the middle of this good-bad reader continuum. 
Casper, for instance, identified himself as "not so bad reader" (Interview, 07/05/16 and 07/08/16) because he is able to pronounce even the 'strange' words: "Not bad. I can read some like the strange words" (Interview, 7/5/16). Haddad, on the other hand, identified himself as "not a good reader" (Interview, 06/27/16) because he struggles in pronouncing unfamiliar words: "Actually, sometimes when I read I feel uncomfortable. I struggle to read. Yeah, sometimes I make mistakes when reading, ya and some words are hard for me to pronounce" (Interview, 6/27/16). Research studies have demonstrated that evaluative statements such as the above impact readers' decisions regarding the use of reading strategies, which can be based on these identity models of what makes "good" and "poor" readers (Hall 2010, 2012). It is important to bear in mind that these available identities (good reader, not so bad) depend on social contexts, including relationships, policy, and social constructions of differences such as class, race, gender, language, etc.

Fadil and Azim attributed the limited amount of time spent reading in English as an obstacle to the development of their ability to read. Fadil emphasized that he likes to read, but because of his difficulties with the English language he does not read a lot: "you know I like to read, but I read in Arabic in my country I like to read, but here I don't read more because you know my language is not very advanced now. I think when I read I need more time to understand. I am slowly when I read." (Interview, 6/30/16). Fadil's acknowledgement shows his awareness of the need to improve his knowledge of the target language in order to have more pleasure during reading. This line of argument supports the linguistic threshold hypothesis. According to Dörney (2015), language development can support reading motivation. In Fadil's case, it could also be that he was reading materials that were above his ability, which resulted in reading less and becoming demotivated (Krashen, 1992).

Azim recognized that he has just started reading more. According to him, he was used to reading only for school purposes: "I see like ah I am not great I am not ah like I used to 
read a lot in my country. I read what I have to read like for school or some like that like for reading I didn't read I started reading like this year or the previous year. I started reading like books stories something like that" (Interview, 6/24/16). Azim's last statement indicates that he had already established the understanding that reading would support his language development.

Only Emir recognized himself as a good reader who faces some challenges while reading in English. Sometimes, he opts to give up reading when he feels he is not understanding the text: "As a reader, actually, I am a good reader, but sometimes when I read the only problem that I face is the long sentences and sometimes there are complex vocabulary that I don't understand only it's hard or I haven't see this word before ah actually there are some specific topics that I read I feel uncomfortable reading the topic and I change it because I don't understand anything, but there are some topics that I feel comfortable reading ah like like something funny or interesting these kind of topics I find myself there" (Emir, Interview, 06/24/16). This view of himself results from the fact that his pronunciation is impeccable, meaning that he is able to emulate native English pronunciation. Nevertheless, his impeccable pronunciation did not guarantee comprehension since his attention was focused on conventional or native like pronunciation, and not on comprehension. As a result, his comprehension suffered in comparison to his peers. His excessive concern with pronunciation resulted in reading text 2 twice in order to comprehend it. It is important to mention that all the other participants considered the second text the easier text to comprehend because there were less unknown words and the topic was familiar (Busyness). Research has shown that unfamiliar contexts, meaning lack of background knowledge about a topic (as text 1), hinder comprehension more than an unfamiliar text structure (Kucer et al., 2006). Emir could identify the main topic for both texts, but the other 
participants used some details to explain the main topic. Furthermore, they could also identify where they had difficulties in comprehending the texts. That was not the case for Emir.

On the last interview, however, Emir changed his attitude a little bit regarding his reading abilities: "I thought before I am a good reader but when you told me try aloud I am terrible. I mean like my pronunciation is terrible. For me, as I told before when I read to myself it should be I have to understand I don't care about the pronunciation but when I read aloud to I have an audience I have to take care of them I have to pronounce the word well, so I usually take care of this point more than the first point (comprehension) '” (Interview, 07/07/16). Nevertheless, his focus was once again on pronunciation. The other participants, on the other hand, seemed to have a very modest view of themselves as a reader even though they have achieved better comprehension when compared with Emir.

This need for correction and/or good pronunciation was also overemphasized during RMAs. All participants argued that they should have gone back to correct their miscues because they had read a different word. Participants initially had difficulty in embracing the idea that miscues were not mistakes, but "a window to the reading process" (Goodman, 2014). The need for correction reveals participants' perspective regarding what makes a good and/or bad reader, and as a result, the strategies that they may use while approaching a text. However, it is important to mention that participants' views may have been different if it had been a silent reading activity.

Casper was very emphatic regarding the need to correct his miscues. He affirmed that it is important to correct his miscues because he has to say the words 'right' - as in the text, so that people can understand what he says when talking with them. Here, he was thinking about his audience. There was also the issue of seeing miscues as mistakes. This influenced his emphasis on the importance of accuracy. Nevertheless, in the last RMA and interview, he started to put forward the view that sometimes there is no need to correct miscues, especially 
if he understands the passage. This indicates that by the end of our meetings, his view of himself as a reader had shifted to that of a more active reader who takes ownership of the text, and who brings meaning to the text rather than merely decoding words.

On "text $1,1^{\text {st }}$ page, $13^{\text {th }}$ line: "is everything that means (meanings) anything to you", Fadil replaced 'mean' for 'meanings'. As with previous miscues, he could not explain the reason for his miscue. Nevertheless, he knew the meaning of both words, and he understood that the two words share a similar meaning. He explained that he miscued because he wasn't focused. He also reasoned that he should have corrected the miscue because he had an audience, and he needed to read "right". If the situation had involved reading for himself, he would not have corrected his miscue as he was able to make sense of what he was reading. Later on, he said: "You know all the words I corrected have the same meaning" (RMA, 07/08/16). This shows that as a reader, he was adjusting the text to enhance his understanding. Furthermore, this adjustment may mean using words that are more familiar to him. It is interesting to observe that Fadil was aware of the fact that he uses different reading strategies depending on the type of reading - aloud or silent. His awareness of using different reading strategies depending on genre influences his approach to read. For instance, being aware of the importance of accuracy while reading aloud.

On text $2,1^{\text {st }}$ page, $5^{\text {th }}$ line, Haddad substituted the word 'active' for 'activity': "So, can we say that living an active (activity/activeti/active/activity) lifestyle after 50 means better brain function?" As can be seen, there were a few attempts to say the expected response. However, in his last attempt, he kept 'activity'. Haddad's explanation was that it was easier for him to say activity than active, perhaps because he had more contact and experience with the word 'activity' than 'active'. The two words are also graphically similar. Once again, he pointed out his difficulties with vowels. He also explained that these two 
words have a similar meaning, but are different parts of speech. Therefore, he argued that the miscue should be corrected given that they infringed on grammatical rules.

During RMAs and interviews, all participants overemphasized the need for accuracy, especially when reading aloud. This view of precision seems to reflect their shared cultural background. According to participants, their school teachers corrected them while reading aloud in the classroom. Nevertheless, participants also pointed out they may not correct miscues during silent reading in cases where it does not disrupt their comprehension.

In the first RMA, it was possible to observe that Azim and Haddad were very excited about their high-quality miscues. As Azim enthusiastically said: "Yeah, it's a good thing but like all that I read I changed some words in the paragraph to understand it" (RMA, 26/06/16). During this moment in the RMA, Azim was very excited, talking very fast and with a high pitched voice while laughing because he just realized his high-quality miscue (whole for all) which in his initial understanding of reading would be impossible given that, in his understanding of reading, he was reading all the words exactly as they appeared in the text. Later on, he described his own reading as: "Crazy reading! (laughing) I read what I want to read, not what is written in here on the paper" (Interview 26/06/16). Haddad also gave a very emphatic answer when he realized his high-quality miscue while also being astonished by it:

"Aline: Do you know what overall means?

Haddad: Like general, all, and I think like overview like general Aline: Uh hum

Haddad: Ya

Aline: So, you said: "overall is general”, and you said: "overview is also general"

Haddad: Yes! 
Aline: So, they have similar meaning?

Haddad: Yes. Similar meaning." (Interview, 30/6/16)

Azim's and Haddad's comments indicate their lack of awareness of the fact that they, as readers, construct meaning from the text by modifying it. Although it was possible to observe this amazement in these two participants, it was only on the second RMA that participants started to take ownership of their own miscues. As a result, they changed their view of reading to a more active process, and their view about themselves as readers. They started to see themselves as active readers who not only decode words and render the meaning of a text, but also as someone who brings meaning to the text by using their background knowledge either knowledge of the English language or knowledge about the topic. As Fadil argued while talking about text 2: "The topic is for busy, and how busyness affects you. Like when you read you remember this situation (being busy) has happened with you” (Interview, 07/03/16). By participating in the RMAs, participants started noticing that they were constructing meaning as well as integrating their own knowledge so that they could construct their own textual model (Kintsch, 2013; Kintsch, 2007, Rosenblatt, 1994).

This change in participants' perspectives on reading and on themselves as readers was also observed in the second interview in which participants exhibited a slight shift in their answers towards a more confident view of themselves as readers. Haddad said: "now I feel a little bit improved, more confident” (Interview, 7/7/16), and Fadil: “Now, I am thinking I am a medium I am not good for the English" (Interview, 7/11/16). This answer may sound like a negative view of himself as a reader, but when contrasted with his initial answer, it is possible to notice that he now recognized himself as an intermediate reader, whereas before he only saw his struggles in reading English.

Casper's and Emir's responses in the second interview indicates that they were still focusing on pronunciation. Casper said: "I am not bad because I can read some not some, 
most of the English words" (Interview, 7/8/16), and Emir: "I thought before I am a good reader, but when you told me try aloud I am terrible. I mean like my pronunciation is terrible." While Azim also focused on pronunciation, he recognized his ability in comprehend the text as well: "I am low in the reading part (talking about fluency and pronunciation), but on the understanding the message, I have the meaning for the message the main idea" (Interview, 7/3/16). Azim's comment suggests that he valued comprehension over other reading issues that he may face while reading English texts. This is a mature reader who understands that even though a reader may have some difficulties while reading a text in a second language, s/he can still grasp the text main idea of the text.

Another typical reaction of participants regarding their miscues involved a long pause followed by "I don't know" the explanation, and then, an attempt to explain their miscues: “(12:00 -12:10 pause). I don't know maybe when I read I stopped there (short pause) 'he still remembers "that' I said I stopped after that" (Azim, Interview, 06/26/16). This demonstrates that RMA was a new procedure for these participants. Therefore, talking about their own miscues was very difficult for participants because they would have to first overcome the idea that they were reading something other than the words in the text. Apparently, Azim was the only participant who bought the whole idea of miscue. At our last RMA and interview, he demonstrated an understanding that he may be making sense of the text even though he is not aware of it. Interestingly, even though the other participants slightly changed their minds about themselves as readers and about the reading process, the characteristics of good and bad reader remained the same even after the RMAs. These characteristics of "good" and "bad" reader almost mirror each other. In other words, participants' perspective of readers was a binary perspective in which a person could be said to be on one side or on the other. Nevertheless, identity as a reader as well as the understanding of the reading process are 
constantly shifting depending on different social contexts, purposes for reading, and power relationships, among others.

Participants maintained that a good reader is someone who reads a lot without anyone pressuring her/him to read. In other words, a good reader is self-motivated to read. Research studies have already mentioned the power of free voluntary reading among second language learners (Cho, \& Krashen, 1995; Krashen, 2004; Lee, Cho, \& Krashen, 1997). Furthermore, participants strongly believe that the more someone reads, the more s/he develops her/his abilities in reading. When I asked Haddad what makes a good reader, his answer was: "Because I think he reads a lot of books, and he has a good knowledge” (Interview 27/06/16). Azim's perception of himself as a reader was also associated with the idea of reading a lot:

Because I didn't use to read a lot in Arabic or in English before that. I just read during reading. I read for a reason like I have a reason I have a subject I need to know about it and I go to read but for like spend time reading or something like that I didn't do it (Interview, 24/06/16).

Later on, he kept arguing:

I know one guy who encourages me all the time he sees me like "keep reading" like and send me books on Facebook, or names of books, or files of books. "read this", "this is good" and "you are like a beginner this is good for you read it”.

Aline: And why do you think this person is a good reader? Azim: "I think he is a good reader because he reads a lot. He likes to read. Reading is part of his daily life. Because for me like it doesn't, it is not part of my routine. I try to read, but sometimes I feel bored and sleepy. I wanna sleep when I read (Interview, 24/06/16). 
Casper also defended the importance of reading a lot which supports reading fast:

Casper: the reader is able to comprehend fast

Aline: how can you achieve this goal of reading fast?

Casper: Reading a lot.

Aline: Why do you think that reading a lot would help you?

Casper: Because practicing is good for reading” (Interview 5/07/16).

Emir also supported the idea of reading a lot, but to develop background knowledge: "I think you need to have a foundation. A good reader has to have a good foundation in his mind like for example I remember when I was young I used to read everything that falls on my hand anything no matter what" (Interview 24/06/16).

Fadil acknowledged that what someone reads is also important:

"Because I like to read a lot (in Arabic) and I am not very good in the reading (in English)".

Aline: But just because I person likes to read, does that make this person a good reader?"

Fadil: "Yeah, I think that doesn't make a person a good reader, but what he reads. When he reads something that is good, he is a good reader. When he reads a lot of books he is a good reader" (Interview 30/06/16).

Issues concerning mispronunciation and a "good" pronunciation were constantly highlighted by participants. They defended the view that the conventional pronunciation (native like pronunciation) supports comprehension because "it confuses you if I read it wrong" (Azim, Interview, 06/26/16). Furthermore, conventional pronunciation aids understanding, as Emir put it: "The pronunciation helps me to understand the text. I use this 
if I want to know the word. If don't know what the words mean I know from the pronunciation" (Interview,06/24/16). Pronunciation may have been foremost among participants' concerns due to the nature of our activity - reading-aloud. In the case of a silent reading, it may be that issues with mispronunciation would not come to the fore in this manners. Furthermore, participants also argued that while reading silently they would skip and/or not care about the pronunciation of an unknown word. As Casper argued: "like when I am reading silent I start reading like when I find a difficult word to read I use to read wrong or just read no matter what, but when I am reading aloud I stop by the word, when I see a hard word I stop and I try to read it like partly (Interview, 07,05,16). Emir gave the same explanation regarding silent reading: "if I read silently I don't care about the pronunciation I just know the word by looking it, I know what this means" (Interview,06/24/16). This indicates that accuracy may not play a very important role for L2 learners to understand a text, but the awareness that reading a word/text aloud sometimes may support comprehension. As Azim pointed out the importance of reading an unknown word aloud to support comprehension: "if I don't have anyone around me I read aloud a little bit. If I listen to what I read it helps me" (Interview, 06/24/16). Research has also demonstrated the importance of reading an unknown word aloud to retrieve word meaning (Mokhtari, 2008; Mokhtari, \& Reichard, 2004; Mokhtari, \& Sheorey, 2008; Mokhtari, \& Sheorey, 2002; Sheorey, \& Mokhtari, 2001). This strategy seemed to be useful when participants had previously heard an unfamiliar word at least one time during conversations, watching TV, listening to music, among others. Readers can recall the moment that they heard an unknown word, and emulate the speaker voice/accent, consequently, attaching the label with its meaning (Kurby, Magliano, Rapp, 2009; Zhou \& Christianson, 2016). Nevertheless, findings from the SORS demonstrated that reading aloud to support understanding (Q5) was the least perceived used reading strategies by Arabic speakers $(M=1.89 ; S D=.928)$, Asian language 
speakers $(M=1.91 ; S D=1.221)$ and Kazakh speakers $(M=2.75 ; S D=1.500)$. By cross-checking data, it was possible to notice the importance of combining different data collection methods to verify the use of perceived RS and the real use of RS. Combining data collection methods supports the development of a more accurate view about the use of reading strategies by L2 learners, and where L2 learners need scaffolding to apply RS while reading in a second language.

Participants' views of a bad reader are opposite to their views of a good reader. Once again, participants emphasized the amount of reading (Grabe, 2009; Krashen, 2011; Kirchhoff, 201). In other words, a bad reader is someone who does not read a lot because s/he does not have a pleasant while reading, sees reading as a boring activity and/or does not have time to read. These characteristics could be influenced by the reading material that readers have access to, that is, reading material pitched too far beyond participants' abilities, and/or outside participants' areas of interest. Participants also mentioned fluency as a barrier to the enjoyment of reading.

Participants' perspective regarding reading and themselves as readers changed while talking about reading in Arabic. Casper, Emir and Fadil affirmed that they do not face any problem while reading in Arabic. As Emir put: “Actually, in Arabic I don't think I have any problem reading an Arabic text. I don't have any problems. I only take notes. I am not I didn't have any problem in understanding anything because I understand perfectly" (Interview, 06/24/16). Casper also argued that he has no problem reading in Arabic; "in my language, Arabic language I don't have to concentrated. I just read, and then I understand" (Interview, 07/05/16). Participants' responses demonstrate that they may not need to monitor their comprehension as frequently as in English (Kucer et al., 2006). Furthermore, they may have developed some reading skills which are automatic (Afflerbach et al.,2008 a, 2008b). Thus, they may not be completely aware of their comprehension monitoring in Arabic. 
Haddad also affirmed initially that he has no problem reading in Arabic:

"Aline: How do you see yourself as a reader in Arabic?

Haddad: Arabic I think I am good

Aline: Why do you think you are good in Arabic? What makes you a good reader in

Arabic?

Haddad: Because it's my language.

Aline: Well, you can be not a good reader even in your own language.

Haddad: I mean I can read in Arabic without any mistakes

Aline: What do you mean by mistakes?

Haddad: Like without mispronunciation”. (Interview, 16)

Nevertheless, later on, he mentioned his difficulty while reading the Qur'an. In this case, he uses YouTube videos to have a better understanding of those texts. Azim also pointed to his difficulties while reading the Qur'an. In these moments, he needs to appeal to "Atlas" (dictionaries providing full explanations of a word, including etymology) (Azim, Interview, 06/24/16).

Participants' arguments seems to suggest that they do not read challenging texts in Arabic given that they strongly defended that they have no problems while reading in Arabic. However, any L1 presents several texts that are very difficult to render even to an expert reader, as Haddad pointed out the Qur'an. Furthermore, participants' discussion of this topic also suggests that they are not aware of the strategies that they may be using while reading in Arabic because those are automatically applied. Their responses also suggest that they may be reading English texts that may be above their reading level which can discourage some students to read. According to Krashen (1992), students should have access to input (a text) that is just one level above their abilities $(i+1)$ otherwise students could give up learning a language. However, this type of thinking should not stop English teachers from presenting 
materials that are still above students' ability which could also stimulate students to invest time in their learning process in order to access desirable reading materials, such as reading Virginia Woolf, Jane Austin, William Shakespeare, George Orwell, or J.K Rowling, among others.

\section{L2 Reading Challenges}

The challenges faced when reading in English was a "hot" topic in our conversations in the sense that participants frequently mentioned their challenges not only in reading in English but also their difficulties in improving their reading skills, which participants were eager to do for their international English tests.

During RMAs, participants explained some of their miscues due to difficulty with pronunciation, uncertainty about grammar, and unknown/unfamiliar words. Participants also mentioned the lack of conventional pronunciation and intonation affecting their comprehension and motivation to read. Then, they mentioned textual features that inhibit comprehension, such as new, complex and long words, long and complex sentences, and unfamiliar topics. Finally, they alluded to the role of motivation while reading English materials.

All participants had the opportunity to start their English learning process during their childhood and/or teenage years in their country of origin. According to participants' descriptions, teachers' instructions were reminiscent of the grammar-translation method, in which grammar and translation were emphasized in the classroom (Hadley, 2001). Participants' descriptions of learning English suggested a progress from the alphabet, concrete nouns, small sentence with basic grammar; followed by reading short stories. At higher grades, teachers would focus on reading, listening and grammar, but there was little opportunity for students to speak: "we didn't practice speaking English to be exactly, but the most things like grammar, reading and listening, they were good" (Casper, Interview, 
07/05/16). Nevertheless, participants recognized that this scenario has changed over the years. Nowadays, schools have Arabic teachers as well as native English speakers (Americans) teaching English as a foreign language - "some of them are Americans and some of them are from Saudi-Arabia" (Casper, Interview, 07/05/16). Besides learning English in school, participants also mentioned the influence of family members and technology - "My daddy taught me” (Casper, Interview, 07/05/16) and Azim:

"First time I read in English when I was in primary school, my father he likes to sometimes like to say some words in English for us when we were children like "Apple", "Book" and from the television I got how it is called the letters the alphabet I got the alphabet from television. Some channels they teach like for babies for children, and I just sat and "ABCDE" with the melody", and "I got some words when I play PlayStation” (Interview, 06/24/16).

Azim also recognized his lack of interest at that time because of his immaturity in understanding the importance of English as a global language in today's word (Crystal, 2003).

Regarding participants' difficulty with pronunciation, all of them argued that native like pronunciation supports reading comprehension. During Azim's reading, I noticed his difficulties in pronouncing certain words which were visible due to his hesitation in reading, his deep breathing, and his troubled facial expression. These difficulties were bothering him because his mispronunciations were interfering with the pronunciation of other known words. For instance, on text $1,2^{\text {nd }}$ page, $27^{\text {th }}$ line: “And indeed, awe can change people's lives. Many come- to-Jesus epiphany - religious or not - have been preceded by staggeringly awesome experiences.”, and Azim: “And indeed, awe can change people's lives. Many come- to-Jesus epiphany - religious or not - have been preceded by staggeringly wheresome experiences." Here, Azim created a new word. According to him, the pronunciation of the previous word 
'awe' which he pronounced differently in every encounter influenced his pronunciation of 'awesome' which is a familiar word for him. Nevertheless, the mispronunciation did not impact his comprehension.

"Aline: What did you say?

Azim: wheresome because I said awe (away - /o 'weI/) I said wheresome. And I

know this word - awesome, but I read it wrong because I read this word (awe)"(RMA, 06/26/16).

Casper also attributed his miscues to difficulties in pronouncing previous words. On text $1,1^{\text {st }}$ page, $4^{\text {th }}$ line: "I took a peek and saw the beautiful blue and whites of the Earth below and the curvature of the horizon", and Casper: "I took a peek and saw the beautiful blue and whites of the Earth blue/blew and the curvature of the horizon." He initially affirmed that he had previously read the word 'sky', therefore, he read 'blue' instead of 'below'. Then, he restated his argument by saying that he read the word 'Earth' which had appeared previously in the text. He had also read the word 'blue' in the same sentence. So, reading 'earth' and 'blue' previously influenced him to read 'blue/blew' instead of 'below'. He argued that there were a lot of words in this initial paragraph that he couldn't pronounce, and this confused him: "I think I was confused because I found a lot of words here I don't realize or can't read. I don't know how to say it" (RMA, 07/07/16). Nevertheless, he knew the meaning of most of the words that he could not pronounce. This demonstrates that L2 readers may feel more overwhelmed when reading aloud due to pronunciation issues. Furthermore, comprehension may suffer due to overload attention on pronunciation.

Haddad and Fadil made the same miscue as Casper (below/blue/blew). Haddad was also unable to pronounce the word 'below'. Every time he tried to say 'below', he read as 'blew'. When I asked him to write down the word he was saying, he wrote 'blow'. On several occasions, he had talked about his difficulties with English vowels. When asked about his 
difficulties with English vowels, he could not give an explanation, but he kept repeating that he has difficulties with English vowels. Research has demonstrated this difficulty with English vowels among Arabic speakers (Keh, 2017; Hayes-Harb, 2006).

Casper also faced issues with pronunciation while trying to read the word 'taste' which always came out as 'test'. On text $1,2^{\text {nd }}$ page, $30^{\text {th }}$ line: "How can we get a taste (test) of the overview effect without leaving the confines of gravity?" During RMA, he also kept saying 'test' for 'taste', and this mispronunciation confused him because when I pointed to the word 'taste' and he said 'test' he associated this word with 'quiz'. As the word sounds for him, he was right in associating with the word quiz. So, I started to point to the words: 'taste' and 'test' as I said them to guarantee he was linking the words with their pronunciations. After I did that, he pointed to his tongue to explain taste. So, both words were known to him, it was just a case of pronunciation which affected his comprehension. This demonstrates the importance of scaffolding in L2 reading events, and how interactions support better comprehension as well. Furthermore, it demonstrates that pronunciation does impact comprehension. Nevertheless, it is not clear how much and when it impacts L2 learners' comprehension. Future studies are needed in this area in order to develop a better understanding of the role of pronunciation in L2 reading.

During all RMAs and interviews, participants overemphasized the importance of native like pronunciation in supporting reading comprehension. It appears that when they were able to have conventional pronunciation they could activate the word meaning faster since during reading they have the print input as well as the auditory input. As Fadil explained:

"Aline: - you are saying that you may have more fluency when you have the right pronunciation?

Fadil: Ya, and I will understand the word quickly 
Aline: Why do you think that having the right pronunciation would help you to understand the word quickly?

Fadil: (long pause) Because I understand the meaning is quickly." (Interview, $07 / 11 / 16)$

Research studies have demonstrated that readers may be able to mimic/reproduce pronunciation as a specific reader, consequently linking word with its meaning (Cho et al., 2016; Lems, 2003; Zhou et al, 2016 a, b). Furthermore, this overemphasis on conventional pronunciation may also be due to the process by which they learned to read. According to participants, in their country, teachers correct their reading aloud. Thus, reading with conventional pronunciation seems to be culturally valuable for these participants.

Participants also mentioned their uncertainty regarding the use of certain grammar structures which emerged as a difficulty while trying to make sense of the texts, and in comprehending a text when they find too many unknown and/or unfamiliar words. Haddad mentioned this difficulty while explaining his miscue 'mountain' for 'emotion' on text $1,1^{\text {st }}$ page, $9^{\text {th }}$ line: "there are tales of profound inspiration and an overwhelming emotion (mountain) a sense of oneness even transcendence." His rationale for this miscue was that there were a lot of unknown words in this sentence which resulted in his difficulty to read as well as to process what the text was trying to convey. His explanation coincides with the literature on reading in a second language, which suggests that when short term memory is overloaded with decoding words, comprehension suffers (Eskey, 2002). In other words, the fact that there were too many unknown words combined with the need to read aloud contributed to Haddad's difficulties in constructing his situational model (Kintsch, 2007; Paulson \& Goodman, 2008).

Still on text $1,1^{\text {st }}$ page, $18^{\text {th }}$ line: "the overview effect refers to the experience of seeing first-hand the reality of the earth", and Haddad: "the overview effect refuse the 
experience of seeing first-hand the reality of the earth". When I asked about the meaning of the two words, he explained that both words were unknown. Then, I used the word 'reference' during our conversation, and he replied saying that he knew the word 'reference'. In order to explain the meaning of 'reference', he used it in an example: "Put the reference for the link" (Haddad, RMA, 06/30/16). Nevertheless, he was unable to establish any link between the words 'refers' and 'reference' which share morphological similarities as well as similar meaning, although they belong to different parts of speech, the first being a verb and the second a noun. His argument was that he was not focusing on his reading at that time. This was a common explanation among participants regarding their miscues. Haddad mentioned during his first interview his difficulty in paying attention while reading. He argued that sometimes his mind flies away.

“Haddad: I am gonna mention something it's about myself. Sometimes when I read I try to enjoy, I am enjoying, but then my head I don't know I try to read it and my head, my head goes away, ya. I don't know what happens. I think my focus is zero. Actually, when I read, and I went like this, and I read just I want to finish without mistake but I don't understand" (Interview, 06/27/16).

However, as noted previously, the literature on Arabic reading demonstrates that Arabic readers have a tendency to pay close attention to consonants while disregarding vowels (Abu-Rabia, 1997; Bentin et al., 1987; Frost \& Bentin, 1992; Saiegh-Haddad, 2003) in contrast to reading in English, given that concentrating on and differentiating vowels give access to English lexicon. When prompted about the need to correct the miscue, Haddad argued that it was necessary to correct it because it was "wrong". Again, it seems that his earlier interactions with the process of learning to read influenced him in overvaluing accuracy which seems to have high cultural value for him.

"Aline: do you think it would be necessary to correct your miscue here? 
Haddad: Yaaa

Aline: Why?

Haddad: Because I want to know. Now, because maybe I said refuse, I thought no problem with the word, but now I know this word refers

Aline: Do you think that using refuse would change the meaning of this sentence?

Haddad: Yes

Aline: So, it would be necessary to go back and correct this?

Haddad: Yeah, correct because ah develop

Aline: Develop?

Haddad: my writing, skills reading skills”

Haddad also affirmed that correcting the miscue would support the development of his English language skills in other areas such as writing and speaking. This indicates that Haddad sees reading as a tool to improve his language abilities, but he may not be aware of his need to develop reading strategies to achieve a better comprehension.

On text $2,1^{\text {st }}$ page, $3^{\text {rd }}$ line: "We're constantly bombarded with headlines screaming at us...", and Azim: "We're constantly bombarded with headness/headline/headlines screaming at us...". This was a self-correction in which the participant attempted to read three times until getting it right on the third time. According to Azim, he was able to correct this miscue because the words 'head' and 'lines' were familiar for him. So, he broke down the word "headlines" into two different words, so that he was able to pronounce it. His ability to explain this self-correction shows that he was operating at a conscious level while reading this except. Nevertheless, he could not, at first, explain the meaning of the word, but as soon as I mentioned newspaper, he quickly retrieved the meaning of headlines. He associated the word headlines with 
subject/topic. This demonstrates that although a participant may know the meaning of this particular word, he may not have too much experience and/or too many encounters with it. As a result, he may need more time to retrieve its meaning. In order to be able to understand this word, he used his morphological knowledge of L2. In most instance when using this reading strategy, he was able to pronounce an unknown word as well as to being able to figure out word meanings on a few occasions. Furthermore, this shows the mature reading behavior of someone who applies reading strategies to comprehend a text. This strategy seems to be specific to the English language given that he would probably use a more phonological knowledge in Arabic (Fender, 2008, 2003) and/or a syllabic knowledge (Hayes-Harb, 2006). In other words, he was operating at a large grain size while reading English (Ziegler et al, 2005, 2006).

Casper, while reading Text $1,2^{\text {nd }}$ page, $21^{\text {st }}$ line replaced the word 'aging' for 'again': 'An ever-increasing number of studies proclaim at the harmful effects of stress, everything from accelerated aging (again) to shortening lifespans." Azim and Haddad made the same miscue. Fadil made a similar miscue in which he read 'again' for 'aged', and 'against' for 'aging'. Casper argued that the two words were graphically similar. During RMA, he associated the word 'aging' with 'age', but he said that 'aging' was being used as a verb. Here, he analyzed the word grammatically as well as morphologically. This miscue is interesting because it shows that the participant was not only paying attention on consonants, but also to vowels, which seems to be an uncommon behavior among Arabic readers. Future studies are needed to investigate what triggers Arabic speakers to pay attention to English vowels.

\section{Summary}

Data lead us back to RQ3 which asked about the use and/or awareness of reading strategies by English learners as well as what reading strategies are most used by them. 
RMAs and interviews demonstrated that participants were aware of reading strategies, meaning that they could make a list of them, but this should not be interpreted as evidence that participants were making use of all the reading strategies that they were able to mention during interviews, especially regarding the use of global reading strategies which were the least frequently used strategies during their readings.

Participants were able to use reading strategies when break downs on their readings happened, but there were also situations in which participants would just go through the motions, that is, they would keep reading even though they were not making sense of the text. This was observed when they increased their reading speed and/or did not pay attention to their pronunciation which participants argued to be essential for better comprehension. Findings also demonstrated that participants relied more on semantic acceptability and graphophonic cues over syntactic acceptability when they were comprehending the text. Nevertheless, this scenario changes when comprehension fails. In other words, participants tend to rely more on syntactic acceptability when not comprehending a text.

Findings also revealed an over-concern by participants regarding pronunciation which, in participants' opinion, supports comprehension. This over-concern is legitimate given that English has a deep orthographic system and Arabic a shallow orthographic system. This difference in both languages results in different uses of reading strategies at different grain sizes. As a result, participants applied their L1 phonological knowledge and they overrelied on consonant patterns while reading in English. These two cross-linguistic reading strategy transfers impacted participants' comprehension to different extents. Another reading strategy used less often by participants was analyzing a word morphologically by breaking it into small words so that they could understand the meaning separately. This reading strategy is specific to the English language given that such a strategy would not support understanding in their own language. 
The focal group statistic data (See chapter 4 for more information) demonstrated that Arabic participants perceived the use of problem solving reading strategies as the most frequently used while reading English text. Read-alouds and RMAs also revealed participants' preferences for problem solving reading strategies (PSRS), support reading strategy (SRS) and global reading strategy (GRS), respectively. These results differed from the initial data collection from phase one (SORS) which demonstrated that Arabic second language English learners perceived the use of reading strategies as problem solving reading strategy (PSRS), global reading strategy (GRS), and support reading strategy (SRS), respectively. These conflicting results indicate the need for different data sources regarding the use of reading strategies by L2 learners given that the perceived use of reading strategies does not necessarily represent the actual use of reading strategies.

Regarding research question 4, which asked how adult English learners understand their own reading strategies and metacognitive awareness, participants were aware of how to deal with local problems during their readings. In those cases, they applied problem-solving strategies, but they were unaware of how to approach a text by using global reading strategies which suggest metacognitive awareness. The only global reading strategy that they were apparently applying was to have a purpose in mind while reading. This purpose can be translated as the requirement to answer questions at the end of the text. This reflects the participants' need at the time of this research to get a high score in international English tests such as TOEFL and IELTS.

The participants were not aware of transferring reading strategies from their own language to English. They became aware of L1 phonological knowledge miscue during RMAs, but they argued that those types of miscues did not affect their reading. This would be true for $\mathrm{P} / \mathrm{B}$ and V/F letters, but not with $\mathrm{G}$ which has two distinguished sounds $/ \mathrm{g} / \mathrm{and} / \mathrm{d} z /$. On participants' second reading aloud, they were more careful in pronouncing these sounds, 
but "G "still posed problems for them. They were able to pronounce "G" when they knew the word, but not in the case of an unknown word. In this case, they would fall into the default mode which was the hard /g/ sound as in "girl". The participants also transferred their overfocus on consonants to English. As a result, they miscued and infringed semantic acceptability most of the time, and syntactic acceptability in some cases. During RMAs, participants were not able to recognize their reading strategy transfer from their L1 to L2 reading event as they were able with $\mathrm{L} 1$ phonological knowledge miscues.

Another important finding revealed in the miscue analysis was the need to refine and/or expand the miscue system in order to accommodate the miscues produced by these participants for whom Arabic is their first language given that few of their miscues would not be completely described if only classified as substitutions and/or graphophonic similarity. By analyzing participants' miscues, four new codes regarding issues with pronunciation emerged from data analysis: (i) pronunciation/substitution miscue; (ii) L1 phonological knowledge miscue; (iii) L1 Phonotactic Knowledge miscue; and (iv) L2 overgeneralization. The pronunciation/substitution miscues and L1 Phonotactic Knowledge miscues seemed to negatively affect participants' comprehension, while L1 phonological knowledge miscues and L2 overgeneralization miscues seemed to not impact comprehension all the time, as participants affirmed during their RMAs as well as during interviews. 


\section{CHAPTER VI: CONCLUSION}

This study sought to shed light on the need of adult L2 learners to learn and/or become aware of additional reading strategies necessary to comprehend English texts. More specifically, it sought to answer the following research questions:

(RQ 1) What are the types of reading strategies that adult English learners from Spanish, Asian languages, Arabic, and Kazakh first languages (L1) perceive as the most frequently used reading strategies while reading English text? And to what extent does the frequency of reading strategies perceived differ significantly by language background?

(RQ 2) What are the reading strategies that adult English learners at different English proficiency levels (beginning, intermediate, and advanced) recognize as the most frequently used while reading English text? And to what extent does the frequency of reading strategies perceived differ significantly by proficiency levels?

(RQ 3) What reading strategies do adult English learners have to learn and/or become aware of in order to make sense of English texts? Of those, which ones are most frequently used?

(RQ 4) How do adult English learners understand their own use of reading strategies and metacognitive awareness?

By employing a grounded-mixed design in a sequential design (quantitative -

Qualitative) with a qualitative dominant status, data were initially collected by administrating a background questionnaire and SORS with thirty-six (14 females and 22 males) L2 learners at two international English programs. Then, I performed descriptive analysis, and one-way ANOVA to address research questions 1 and 2. For the qualitative part of this study, I collected data through interviews, miscue analysis and RMAs of a focus group of five Saudi- 
Arabian male speakers to address research questions 3 and 4 . The summary of findings are presented according to each research questions in the following section.

\section{Summary of Findings}

\section{Research Question 1}

My first research question addressed the issue of the perceived use of reading strategies by L2 learners from different L1s, and to what extend the perceived use of reading strategies differ significantly by L1. Data analysis demonstrated that L2 learners from different L1s perceived the use of reading strategies as being between high and moderate. In other words, participants make intensive use of reading strategies while reading English texts. Nevertheless, the data demonstrated that participants from different L1s may perceive the use of reading strategies differently by emphasizing one strategy over other. For instance, Spanish speakers rated the support reading strategy "I use reference materials (e.g., a dictionary) to help me to understand what I read" (Q13) as high usage, while other participants reported a high usage of global reading strategies. The use of this support reading strategy, however, would depend on context (Zhang et al., 2009). For instance, participants would not be able to use a dictionary in international English tests.

ANOVA confirmed this result of descriptive analysis regarding the different use of perceived reading strategies. ANOVA results revealed that participants from Asian, Arabic and Kazakh language backgrounds perceived their use of reading strategies as the following PSRS, GRS, and SRS in order of frequency of use, while Spanish speakers perceived their use of reading strategies as the following PSRS, SRS, and GRS. Thus, the only statistical difference among participants in their perceived use of reading strategies related to support reading strategies.

Interestingly, there was agreement among Asian, Arabic and Kazakh participants regarding what was perceived as the least reading strategy, which was a support reading 
strategy: "When text becomes difficult, I read aloud to help me understand what I read"

(Q5). Participants may not realize that they are using this strategy while reading in their own language because, in their own language, they may be able to hear their inner voices.

Research studies have already demonstrated the benefits of using such a strategy (Cho et al., 2016; Lems, 2003; Zhou, 2016 a, 2016b). Thus, it may be the case that this strategy should be explicitly taught to learners from these L1s in international English programs.

Although statistical analysis demonstrated an important aspect of the perceived use of reading strategies of L2 learners from different L1s, further research with a larger number of participants from different L1s is needed in order to confirm and/or refute such findings, so that our knowledge regarding reading in a second language by L2 learners from different L1s may be extend.

Furthermore, participants in the qualitative portion of this study had mentioned reading strategies that were not presented in the SORS. Therefore, there is a need to revise the survey in order to accommodate reading strategies used by this group of participants such as: (i) keep reading for later understanding; (ii) previous paragraph supports understanding of following paragraphs; and (iii) the need to use different strategies for different genres; (iv) guessing conventional pronunciation, which supports comprehension; (v) substitution of unknown word/grammatical structure by a known word/grammatical structure; and (vi) giving up reading excerpts when they do not contribute to textual understanding. It is also important to test the use of these strategies with L2 learners from different language backgrounds. By going back to the field to test the reading strategies mentioned by participants on the second portion of this study, as MMGT proposes, research will extend our knowledge of reading strategies used by L2 learners from different L1 backgrounds. This is one of the aspects of grounded theory (testing theory) that has been set aside in exclusively qualitative designs. By adding the reading strategies mentioned by the Arabic participants in 
the second phase of this study to the SORS, additional research would enable us to verify

whether those reading strategies are exclusively used by Arabic speakers or whether they are also used by speakers from other L1s as well. Although such research should bear in mind that it is also important to collect data qualitatively in order to contrast the perceived use of those strategies mentioned by the Arabic participants of this study with the actual use by participants from different L1s. Furthermore, qualitative data collection would also demonstrate whether participants from different L1s make different miscues than the Arabic participants of this study and/or English native speakers. In this way the field of L2 reading research would be able to verify whether there is a need to expand/refine the codes for L2 learners' miscues from different L1s. Such research would also show whether L2 learners from different L1s transfer their knowledge of their L1 grain size units while reading in English. It would also be important to analyze how the explanations for their miscues by L2 learners from different L1s would vary and how those explanations might relate to sociocultural differences. It is important to bear in mind that such research would need to be conducted in a reflexive manner bearing in mind researchers' positionality as co-constructors of the data.

\section{Research Question 2}

My second research question addressed the issue of the perceived use of reading strategies by L2 learners with different English proficiency levels, and the extent to which the perceived use of reading strategies differs according to levels of proficiency. Data analysis demonstrated that the frequency of usage of reading strategies by participants differs depending on their level of proficiency. Participants at the beginning and advanced levels attributed high to moderate usage of reading strategies, means between 4.75 and 2.70. Participants at the intermediate level attributed high usage to low usage of reading strategies, means between 4.44 and 2.31. Interestingly, all groups perceived the problem-solving reading 
strategy (Q9) to be the one they used most frequently: "I try to get back on track when I lose concentration". This strategy was also mentioned by participants in the second phase of this study. Participants in the second phase argued that they frequently lose their concentration while reading texts that are too difficult and/or if they are not interested in the topic. On these occasions, they have to make an effort to get back on track. They suggested that while reading they need to turn off all their electronic devices and put things away, so that they may be able to keep focused on reading. This response may demonstrate the difficulty for L2 learners in interacting with English texts due to: (i) motivation given that readers may not have yet achieved the threshold L2 knowledge needed to read advanced English texts which support reading motivation (Dörney; 2015) resulting in lack of concentration; (ii) participants' identities as readers ("good reader," "not so good/bad a read"), given that a negative view of oneself as reader could lead the reader to believe that $\mathrm{s} / \mathrm{he}$ would not be able to comprehend the text despite their efforts resulting in difficulties to concentrate (Hall, 2012; 2010); and (iii) differences in intercultural rhetoric between participants' L1 language and English which would require cognitive effort from participants to understand the English text given that unique rhetoric conventions of L1 and L2 could interfere with comprehension (Sharp, 2010) resulting in lack of concentration. Further research is needed to investigate which of these factors may contribute to L2 readers' difficulties in concentrating while reading English texts.

Although there was no consensus among participants regarding the least perceived used reading strategies among the three categories in the SORS (GRS, PSRS, SRS), all groups pointed out support reading strategies as the least perceived used. Participants who identified themselves as beginner learners of English chose the support reading strategy: "when reading, I translate from English into my native language” (Q29) as the least used reading strategy. This result is not aligned with previous research, which has demonstrated 
that less-skilled readers tend to rely more on translation when reading English texts (Jiménez et al., 1995, 1996; Malcolm, 2009). Furthermore, as Zhang (2009) demonstrated in his study, support reading strategies depends in context. As participants in the second phase of this study also mentioned, they would not read aloud in situations where they were surrounded by other people. Thus, it is important to design more specific statements regarding the use of support reading strategies so as to better describe the contexts in which these strategies are used given that dictionary use, taking notes, and reading aloud may not always be possible, as for example, when taking tests. In this way, our understanding of the real use of support reading strategies by L2 learners may be extended.

Participants who identified themselves at the intermediate level reported the least used support reading strategy as: "when text becomes difficult, I read aloud to help me understand what I read" (Q5). Data analysis from the different L1s also showed this strategy to be perceived as the least used by Asian language speakers, Arabic speakers and Kazakh speakers. Nevertheless, Arabic participants in phase two mentioned this strategy as a very important strategy to achieve better comprehension. According to these participants, pronunciation raises comprehension because it helps them to link an unfamiliar word with its meaning. While reading aloud, they may be able to remember the exact moment in which the unfamiliar word was used, and the person who used it. As a result, they are able to mimic that person, and establish the connection between word and meaning (Zhou et al., 2016a, 2016b). Nevertheless, participants of phase two mentioned this strategy at the word level while Q5 seems to suggest that readers would read not only words, but also sentences and/or paragraphs. Therefore, the way the sentence was written must have caused some confusion for participants taking the survey. This demonstrates, once again, that the SORS needs to develop more specific/clear statements to better describe when such a strategy is used. Furthermore, it is important to take into consideration that the SORS places L2 learners in the 
same box without taking into consideration that English textual rhetoric may be seen differently by L2 learners from different L1s (Hinds, 1987; Sharp, 2010).

Participants who identified themselves at the advanced level chose: "I ask myself questions I like to have answered in the text” (Q26) as the least used strategy. Participants in phase two did not mention this strategy. However, not mentioning a strategy does not mean that participants were not using this strategy. It may mean that they were not aware of the use of this reading strategy and/or they were unable to verbalize such a reading strategy due to language barriers. Perhaps, in a think-aloud activity, this reading strategy would emerge as very useful. Given that RMAs may not be enough to display all reading strategies used by L2 learners, due to different cultural understandings of miscues and participants' lack of experience in explaining miscues, the addition of think-aloud protocols to a similar studies to this could potentially enable us to build on our knowledge of reading strategies used by L2 learners.

One-way ANOVA reported that participants of different language proficiency levels tend to prefer problem-solving reading strategies, support reading strategies, and global reading strategies, respectively. This result is in line with research studies that have demonstrated the same views of L2 learners regarding their perceived use of reading strategies while reading English texts (Alsheik, 2011, 2009; Alsheik \& Mokhtari, 2011; Mokhtari, 2008). ANOVA has not demonstrated any statistical significance among participants of different proficiency levels regarding their perceived use of reading strategies. Although ANOVA reported similar tendencies of perceived use among L2 learners of different proficiency levels, it is important to design research studies to challenge such results given that this study has demonstrated that perceived use of reading strategies does not translate into actual use of these reading strategies. Furthermore, this study has demonstrated that Arabic speakers use reading strategies not mentioned in the SORS. This could also be the 
case for L2 learners from different L1s. Therefore, there is a need to replicate this study with L2 learners from different first language backgrounds and with L2 learners of different proficiency levels.

\section{Research Question 3}

My third research question addressed the issue of the need for adult second language learners to learn and/or become aware of additional reading strategies to make sense of English texts, and which reading strategies are most frequently used. This research question was answered based on participants' responses in phase two. Data analysis demonstrated that they were able to mention some reading strategies during interviews, such as breaking down words into small parts, using parts of speech to figure out the meaning of unknown words, guessing word meaning based on the word's roots and/or use of context, re-reading for conventional pronunciation, adjusting speed as a text becomes easier or more difficult, looking closely at key words, summarizing, reading with a pen, using background knowledge, skimming, and scanning ${ }^{7}$. Nevertheless, being able to mention these reading strategies should not be interpreted as the ability of participants to use them while reading English texts. They may not even be aware of the use of these same reading strategies while reading.

For instance, participants did not make use of textual structure such as titles, subtitles, pictures, bold/italic words, capital letter, and punctuation. Fadil was the only participant to read the title and look over the picture in the texts. He argued that the title gives the reader the main idea, and guides the reader through the text. Emir and Casper said that they glance over the title, but that it is not important to read it because the main idea is in the text. Azim and Haddad argued that they forgot to read the title. Casper started his reading from the photo caption. When asked why he decided to start by reading the photo caption, he argued that he

\footnotetext{
${ }^{7}$ These reading strategies are presented according to participants' allusion.
} 
likes to know from where is the image. Participants' responses could be a reflection of their knowledge of L1 writing which was being transferred to the L2 reading situation (Kutoba \& Lehner, 2004). In other words, it is possible that rhetorical conventions of their L1 were interfering in how participants approached the text by focusing their attention on different rhetorical and textual features (Connor, 1996). Responses are also a reflection of participants' social and cultural development (Matsuda, 1997). During RMA, Emir argued that glancing over the text title was a technique learned in school. Furthermore, participants were not aware that knowing the text structure (genre) could have helped them prepare for what to expect from the text. Only Emir mentioned that knowing the IELTS textual structure helps him to comprehend the text better because he knows what to expect. His explanation is aligned with Connor's (2002) argumentation that when writer and reader share similar expectations, understanding is easily achieved. Using textual features to enhance comprehension are global reading strategies which support metacognitive awareness, meaning that, participants were not intentionally applying global reading strategies to monitor and/or manage their textual understanding. According to Matsuda (1997), it is important to teach the textual organizational structure of the target language to L2 learners and relate these to their own cultural conventions because knowing the organizational structure of texts in their own language does not guarantee that they will necessarily understand the conventions of the L2 writing system (Kaplan, 1988).

During reading aloud, it was clear that participants were using reading strategies when they read a word by breaking it into syllables and/or smaller parts. When words were broken down into syllables, participants were usually trying to pronounce an unknown word, then they would re-read the word a few times aloud or silently, look back over the previous text, remain silent for a moment, and then try to figure out the word meaning. By using this strategy, participants were relying on small grain size units to figure out pronunciation and 
meaning (Ziegler et al., 2005). When breaking words into small parts, participants usually knew the morpheme, and were trying to figure out its affixes and/or word parts as in compound words such as "headlines" and "breathtaking". By using this strategy, participants were relying on large grain size units to achieve comprehension (Ziegler et al., 2005). Breaking down words into syllables was one of the most used reading strategies by these participants.

They were also transferring reading strategies from their first language, which was not contributing to their understanding of the English texts. On the contrary, these reading strategies were impeding comprehension given that they would read a completely different word which impacted meaning. This was the case when they focused on consonants while ignoring vowels. Paying attention to vowels is an important English reading strategy that is imposed by the English language given that vowels in English carry lexical information (Hayes-Harb, 2006). It is important to prompt these learners to pay close attention to vowels when reading in English so as to achieve a better textual understanding. In other words, there is a need for Arabic speaker learners to learn this reading strategy in order to cope with English texts and achieve better textual comprehension.

Participants' attitudes towards reading also demonstrated that they were reading to be able to answer questions at the end of the text. This reflects an important skill when taking international English tests given that students' ultimate goal is to apply to university, and they will need a high score at those tests. However, it is important to bear in mind that at university level, they will need (we hope) to read more deeply, read between the lines, understand the writer's purpose, understand the discourses that have been (de)valued so that they may become critical readers, and consequently critical citizens (Freire \& Macedo, 1987).

The three reading strategies - breaking words down into small parts, focusing on consonants while disregarding vowels, and looking for important information to answer 
questions at the end of a text - were the most used reading strategies by this group of participants.

In light of these findings, research in the field of L2 reading comprehension should focus on exploring the use of reading strategies and metacognitive awareness depending on L2 learners' purpose while reading different genres; the reading strategies they transfer from their L1 to the L2 situation and how these reading strategies may support and/or impede comprehension; the need for L2 learners from different language backgrounds to become aware of and/or learn new reading strategies specific to the L2; and how the differences between intertextual rhetoric between L1 texts and the L2 texts may impact their comprehension in order to deepen our understanding of L2 reading comprehension.

\section{Research Question 4}

My fourth research question addressed the issue of adult English learners' understanding of their own use of reading strategies and metacognitive awareness. During reading aloud, it was evident that participants were monitoring their comprehension although at different levels given that they were at different stages in their development as readers in English. The monitoring was most evident when they slowed down their reading speed, reread a sentence and/or word, stopped at an unfamiliar/unknown word, looked back at the previous paragraph, and paused for a while on a sentence and/or word. These attitudes were visible when breakdowns in their understanding occurred. There were also moments in which participants just kept reading even though they knew that they were not making sense of the text. As a result, at the end of reading, they would give a percentage of how much of the text they had understood, and affirmed their difficulty in reading the texts due to complex vocabulary.

Participants knew about the possibility of using different reading strategies to support a better comprehension, but they were not purposefully activating those reading strategies to 
support their comprehension. As previously mentioned, they were able to use some reading strategies when breakdowns happened, but pre-reading strategies and/or post-reading strategies were not observable. In other words, they were making more use of problemsolving strategies, which are localized strategies to solve problems that occur during reading. They were not making use of procedures/strategies in advance so that they would be able to achieve better comprehension. So, action was taken only as local problems emerged, and breakdowns in understanding happened. Furthermore, participants were not completely aware of the reading strategies that they were transferring from Arabic to English, which can hinder comprehension. This lack of awareness of L1 reading strategy transference compromised comprehension. There were occasions in which participants were aware of their use of their L1 phonological knowledge while reading words in English, but for that to happen, the target word needed to be well-known by participants. This was the case when participants replaced /p/ by /b/, /v/ by /f/ and /g/ by hard /g/. It seems that participants were being metacognitively aware while dealing with issues at the word level, but not at the textual level. In other words, they were able to apply conscious reading strategies when breakdowns happened, and monitor their understanding at the paragraph level, but connecting the paragraphs to develop an interactional reading model was more complicated for these L2 learners at the intermediate language proficiency level. Hence, these results may vary depending on language proficiency. Therefore, more research studies are needed to confirm and/or refute these initial results.

In sum, the reality seems somewhat different than what participants in phase 1 reported in their answers of the SORS. In other words, participants were able to recognize/mention some reading strategies. Nevertheless, my sub-group in phase 2 demonstrated that it is much more complicated to put those reading strategies into use (Alsheikh et al., 2011; Mokhtari, 2008). Therefore, conducting research based only on data 
collection by surveys does not offer us a complete understanding of the reading strategies that L2 learners actually use to make sense of texts. Furthermore, the SORS seems not to incorporate reading strategies that L2 learners from different L1 backgrounds use while reading English texts. Therefore, a mix method seems to be more appropriate as it enables us to examines the actual uses of reading strategies as well. In this sense, this research challenges the practice of collecting data on the uses of reading strategies exclusively by administrating surveys and/or tests by demonstrating that these instruments do not adequately portray the actual uses of reading strategies by L2 learners or their metacognitive awareness.

\section{Limitations}

While the findings discussed above bring some enlightenment to our understanding of the use of reading strategies by L2 learners from different first language backgrounds and with different proficiency levels, there are some limitations that should be taken into consideration while interpreting the findings.

First, it is important to acknowledge the restricted number of participants in phase one. Although statistical analysis reported important findings, such as the fact that participants from different L1s perceived the use of GRS, PSRS, and SRS differently, it is important to collect data from a large sample size from different first language backgrounds as well as including different language proficiency levels, so that a better representation of these populations can be drawn.

Read-aloud and RMA are good tools to collect data given that they offer the opportunity for researchers to observe the reading process of L2 readers. Nevertheless, they also present drawbacks. For instance, participants from phase two reported their difficulties in making sense while reading aloud given that, sometimes, they were more concerned with having the "right" pronunciation, so that their audience (me) could understand their reading. In order to overcome this problem, it would be interesting to add other activities, such as 
silent reading while capturing participants' eyes movements, and think-aloud protocols, in which participants describe their own thinking, that is, their process of making sense of the text while reading. These three tools (read-aloud, silent reading, think-aloud protocols) could offer researchers in the field of second language reading a better understanding of the use of reading strategies employed by L2 leaners.

Language barriers constitute one of the possible drawbacks to the use of RMA to collect data given that participants may not be fully proficient in English. To solve this problem, participants could be given the opportunity to speak in their own language, which indeed they did for a few moments during this study. However, they may feel uncomfortable and/or foolish using a language that the researcher does not understand as Emir pointed out when I said that he could use his language to explain anything that he wanted. Furthermore, participants' inexperience with RMA procedures in addition to cultural understandings of miscues as errors were other drawbacks. Another limitation of using miscue analysis and RMA as tools to collect data is the fact that they have been used only in a few studies with L2 learners. As a result, such tools still need to be refined in order to better represent the L2 population. In addition, the limited number of participants for phase two is another limitation.

It is also important to bear in mind that participants in phase two identified themselves as intermediate L2 learners as they were placed at the intermediate level by their English program which classified this level between the A2-B1 language level according to the Common European Framework of Reference for Languages (CEFR). This framework describes language users according to their abilities in using languages other than their first language on a scale that ranges from A1-C2. A basic user (A1-A2) is someone who communicates with native speakers by using simple and everyday language while their listeners use a foreigner talk (simplified language), while responding to a basic user (Gass et al., 2008). An independent user (B1-B2) understands familiar matters to more abstract and 
complex ideas; communicates with a certain degree of fluency and spontaneity in cases where standard language is used. A proficient user (C1-C2) expresses with fluency and spontaneity in a range of different contexts as well as in relation to different subject matter; can differentiate finer shades of meaning (COE, n.d). These language user descriptions are measured based on the standard of English native speakers (Cook, 2016) who, in their turn, may also traverse across these descriptions given that language use differs depending on contexts as well as ideologies. In other words, a native speaker may also struggle with language use while communicating in an unfamiliar context and ideology (Cook, 1999). Therefore, the results presented in this study may vary among L2 learners with different proficiency levels, but also depending on different contexts and ideologies. Nonetheless, participants' results yield few similarities regarding their reading strategies, types of miscues, and similar explanations for their thinking. Therefore, having a moderate to large sample size of participants from different L1s and with different proficiency levels may produce more indepth results.

It is also important to bear in mind that L2 learners enrolled in international English programs have a goal of applying into graduate programs in the U.S. In order to be accepted onto a graduate program in U.S., these learners have to demonstrate their English knowledge through high scores at international English tests such as IELTS, TOEFL, and GRE. In light of this, the main goal of these learners is to improve their knowledge of English to perform well in these international tests. Such tests may not access comprehension per se, but rather the skills needed to get a high score in these tests. Therefore, it would be interesting to conduct a similar study with different populations such as immigrants and/or adult learners who may have a different purpose for learning English then the academic route in order to verify whether there is any difference in the reading strategies mentioned and metacognitive awareness by these L2 learners. 


\section{Implications for Practice}

The findings from phase one of this study revealed that L2 learners from different L1s and with different language proficiency levels perceive the use of reading strategies differently. In other words, they may apply different reading strategies to achieve comprehension.

Findings suggest that participants may have a high level of metacognitive awareness due to their high usage of perceived reading strategies. Furthermore, participants reported a tendency to use more PSRS. This finding is consistent with previous research. Nevertheless, it is important to add a qualitative phase for data collection given that the SORS represents the perceived use and not the actual use of reading strategy. The SORS also failed to identify different reading strategies that may be used by L2 learners from different language backgrounds as this research has demonstrated. However, it can be used by ESL teachers as an initial tool to understand the use of reading strategies and metacognitive awareness by their students as well as to raise L2 learners' awareness of the different types of reading strategies that can be used to achieve comprehension.

Phase two reinforced the findings from phase one by explicitly demonstrating the type of reading behavior and reading strategies that Arabic speakers tend to use while reading English text. Although some findings need further investigation due to the limited number of participants, they support the argument that different languages impose different needs in terms of reading strategies (Ziegler et al, 2005, 2006), and that characteristics of L1 influences L2 reading (Cummins, 1991; Geva \& Siegel, 2000; Gottardo et al., 2016)

These findings could be used by ESL teachers, ESL curriculum designers, and ESL directors to better understand L2 learners' use of reading strategies regarding reading comprehension. An English international program that understands L2 learners' use of reading strategies may better prepare students to the challenges of reading at 
college/university level, so that they may support the development of L2 learners' metacognitive awareness regarding the different types of reading strategies that can be used as well as how and when to apply reading strategies to improve their comprehension.

Likewise, ESL teachers can better attend to the needs of their L2 learners while gaining knowledge of the different reading strategies that L2 learners apply while reading in English; what types of reading strategies they transfer from their native language to the L2 reading situation; how the use of such reading strategies may support and/or impede L2 comprehension; how L2 learners view themselves as readers may impact the use of certain reading strategies; and how different intercultural rhetoric may support and/or impede comprehension.

\section{Implications for Research}

In addition to the practical implications mentioned above, my findings also shed light on second reading research. For instance, the field of second language reading may benefit in developing more mixed method designs that employ different methods to collect and analyze data given that the SORS reports only the perceived use of reading strategies and not the actual use of reading strategies. It is important to have more in-depth data collection, in which researchers observe the actual use of reading strategies as well. Thus, procedures such as read-aloud, silent reading, and think-aloud could better inform our understanding of the use of reading strategies by L2 learners. Moreover, it is important to engage L2 learners in this process, so that they may develop a better understanding of themselves as readers and of the reading process. As a result, they may be able to differentiate their use of reading strategies in different contexts while reading in different languages, so that they use more appropriate reading strategies while reading in different languages. Finally, using different genres at different degrees of difficulty could also yield interesting results to inform our understanding of second language reading. 
In order to extend our knowledge regarding reading in a second language, it is necessary to invite participants from different first languages for more in-depth data collection by adding qualitative designs to ascertain whether these participants mention the same reading strategies discussed by the Arabic participants in this study and/or different reading strategies as proposed in the SORS. Furthermore, it is also important to explore whether participants from different first languages would make different miscues and/or give (dis)similar explanations for their miscues during RMA than the participants in the second phase of this study. Such studies would support the development of more appropriate surveys to collect data about the different reading strategies and the metacognitive awareness of L2 learners from different language background. They would also inform reevaluations of the coding system for miscues by learners from different language backgrounds.

As the MMGT proposes this is a cyclical/ dialectical process in which developed research projects guide our understanding of the issue at hand - the use of reading strategies and metacognitive awareness by L2 learners from different language backgrounds - to a new and/or better understanding so that new research can approach the same issues from different paradigms. This would enable the testing of theories and instrumentations as well as the generation of theories that can better explain the problem based on cultural, temporal and structural contexts as well as the interactive process between researchers and participants (Greene, 2007; Greene and Hall, 2010; Johnson, 2008; Johnson et al., 2010; Shannon-Baker, 2016; Teddlie \& Johnson, 2009).

This study sheds light on the use of the predominant quantitative designs when collecting data regarding the issue presented in this study. It challenges the use of surveys that position all L2 learners as a homogenous group without taking into consideration how their first languages may play an important role in their use of reading strategies and in different textual organizational structure of the L2 in comparison with the textual 
organizational structure of L2 learners' first language. It also challenges the idea of administrating tests to evaluate L2 learners' comprehension without considering sociocultural aspects of reading. The uniquely quantitative approach to data collection sees reading as a decoding process. However, miscue analysis and retrospective miscue analysis demonstrate that comprehension involves much more than decoding skills as it is impacted by different factors such as readers' perception of themselves as readers and of the reading process, transfer, and intercultural rhetoric, among others.

Furthermore, this study sparked theoretical insights regarding the use of reading strategies by L2 learners from different language backgrounds such as the transfer of reading strategies at small grain size units to the English reading event in which the use of large grain size units would be more appropriate, different frequency usage of reading strategies as well as differences in the perceived use of reading strategies based on L1 backgrounds and language proficiency levels. The study has also demonstrated that Saudi-Arabian students applied reading strategies that were not accounted for in the SORS. Thus, this study demonstrates the need to reevaluate the SORS and/or the need to create specific instruments to address the different reading strategies used by L2 learners from different L1s. The study also demonstrates that it is important to consider that L2 learners miscue differently than English speakers, resulting in the need to create new codes for L2 learners' miscues to better describe their comprehension process.

\section{Final Thoughts}

Data analysis showed that L2 learners apply several and different reading strategies based on their L1 as well as their L2 proficiency levels. The use of reading strategies should not be interpreted as participants' metacognitive awareness given that sometimes they employed strategies borrowed from their L1 that interfered with comprehension. 
Miscue analysis and retrospective analysis can contribute to the area of second language reading by bringing a deeper understanding of reading strategies employed by L2 learners. Nevertheless, new codes may be necessary to better describe L2 learners' miscues. Furthermore, engaging L2 learners in this process supports their development in understanding the reading process, in understanding themselves as readers, and in identifying areas that they should improve in order to achieve better comprehension and become skilled readers in English.

Finally, this study has also revealed the benefits of applying psycholinguist grain size theory and a mixed method grounded theory design while investigating second language reading for research as well as ESL teaching. While applying the psycholinguist grain size theory (Ziegler et al., 2005) to L2 learners' comprehension processes, it was possible to verify that Arabic language participants were applying small grain size units as footprints from their L1 reading development. While applying a mixed method grounded theory, it was possible to compare and analyze data simultaneously while reconsidering previous theories regarding the use of reading strategies and grounding the generation of possible new theories on data. This research demonstrates the need for future research to develop our understanding regarding the impact of: (i) the use of reading strategies transferred from L1 to the L2 situation, (ii) the sociocultural aspects of reading in L1 and L2, and (iii) the intercultural rhetoric of L1/L2 in comprehending an L2 text. 


\section{REFERENCES}

Abbott, A. (2004). Methods of discovery: Heuristics for the social sciences. New York: W. W. Norton.

Abu-Rabia, S., \& Sanitsky, E. (2010). Advantages of bilinguals over monolinguals in learning a third language. Bilingual Research Journal, 33(2), 173-199.

Abu-Rabia, S. (2001). The role of vowels in reading Semitic scripts: Data from Arabic and Hebrew. Reading and Writing: An Interdisciplinary Journal, 14, 39-59.

Abu-Rabia, S. (1999). The effect of Arabic vowels on the reading comprehension of secondand sixth-grade native Arab children. Journal of Psycholinguistic Research, 28, 93101.

Abu-Rabia, S. (1998). Reading Arabic texts: Effects of text type, reader type and vowelization. Reading and Writing: An Interdisciplinary Journal, 10, 105-119.

Abu-Rabia, A. (1997). Reading in Arabic orthography: The effect of vowels and context on reading accuracy of poor and skilled native Arabic readers. Reading and Writing: An Interdisciplinary Journal, 9(1), 65-78

Abu-Rabia, S. (1995). Learning to read in Arabic: Reading, syntactic, orthographic and working memory skills in normally achieving and poor Arabic readers. Reading Psychology: An International Quarterly, 16, 351-394.

Actflorg., (2016). Actflorg. Retrieved from http://www.actfl.org/publications/all/worldreadiness-standards-learning-languages

Afflerbach, P., Pearson, P. D., \& Paris, S. (2008a). Clarifying differences between reading skills and reading strategies. The Reading Teacher, 61(5), 364-373. 
Afflerbach, P. Pearson, P. D., \& Paris, S. (2008b). Skills and strategies: Their differences, their relationships, and why it matters. In Mokhtari, K. Sheorey (Eds.), Reading strategies of first- and second language learners: See how they read,(pp 11-24). Norwood MA: Christopher Gordon Publishers, Inc.

Alexander, P., \& Fox, E. (2013). A historical perspective on reading research and practice, redux. In D.E. Alvermann, N.J. Unrau \& R.B. Ruddell (Eds.), Theoretical models and processes of reading, (6 ${ }^{\text {th }}$ ed., pp. 3-46). Newark, DE: International Reading Association.

Alhaisoni, E. (2016). Saudi EFL university students' metacognitive awareness of reading strategy use. Language Forum, 42(1),77-100.

Alhaqbani, A. \& Riazi, M. (2012). Metacognitive awareness of reading strategy use in Arabic as a second language. Reading in a Foreign Language, 24(2), 231-255.

Ali, E. M. T. (2015). The Elimination of Pronunciation Problems of English Vowels of Saudi Students of English Resulting from Complex Letter-Sound Relationship. International Journal, 3(1), 35-41.

Alvarez, C. J., Carreiras, M., \& Taft, M. (2001). Syllables and morphemes: Contrasting frequency effects in Spanish. Journal of Experimental Psychology: Learning, Memory, and Cognition, 27, 545-555.

Alsheikh, N. O. (2011). Three readers, three languages, three texts: The strategic reading of multilingual and multiliterate readers. The Reading Matrix, 11, 34-53.

Alsheikh, N. (2009). The strategic reading of Arabic native speakers in English: An examination of the metacognitive reading strategies used by Arabic native speakers when reading academic texts in Arabic and English. Saarbrücken, Germany: VDM Verlag Publisher. 
Alsheikh, N. O., \& Mokhtari, K. (2011). An examination of the metacognitive reading strategies used by native speakers of Arabic when reading in English and Arabic. English Language Teaching, 4(2), 151.

Anderson, R. C., \& Pearson, P. D. (1984). A schema-theoretic view of basic processes in reading comprehension. In R. Barr, M.L. Kamil, P. Mosenthal, \& P.D. Pearson (Eds.). Handbook of reading research, Vol. 2 (pp. 255-292). White Plains, NY: Longman.

Anfara, V., \& Mertz, N. (2006). Theoretical Frameworks in Qualitative Research. Thousand Oaks, CA: Sage Publications.

Atkinson, D.; Churchill, Nishino, T., \& Okada, H. (2007) Alignment and interaction in a sociocognitive approach to second language acquisition. The Modern Language Journal, 91(2), 169-188.

Atkinson, D. (2002). Toward a sociocognitive approach to second language acquisition. The Modern Language Journal, 8, 525-545.

Auerbach, E. R., \& Paxton, D. (1997). “It's Not the English Thing”: Bringing Reading Research Into the ESL Classroom. TESOL Quarterly, 31(2), 237-261.

Bailey, N., Madden, C., \& Krashen, S.D. (1974). Is there a "natural sequence" in adult second language learning? Language Learning, 24(2), 235-243.

Baker, L. (2008). Metacognitive development in reading: Contributors and consequences. In K. Mokhtari \& R. Sheorey (Eds), Reading strategies of first- and second-language learners: See how they read, (pp. 25-42). Norwood, MA: Christopher-Gordon Publishers.

Bateson, G. (1972). Steps toward an ecology of mind. Chicago, IL: University of Chicago Press.

Bernhardt, E.B. (2011). Understanding advanced second language reading. New York, NY: Routledge 
Bernhardt, E. B., \& Kamil, M. L. (1995). Interpreting relationships between L1 and L2 reading: Consolidating the linguistic threshold and the linguistic interdependence hypotheses. Applied Linguistics, 16, 15-34.

Bentin, S. \& Frost, R. (1987). Processing lexical ambiguity and visual word recognition in a deep orthography, Memory \& Cognition, 25, 13-23.

Berger, P. L., \& Luckmann, T. (1966). The social construction of reality. Garden City, NY: Doubleday.

Bialystok, E. (2007). Acquisition of literacy in bilingual children: A framework for research. Language Learning, 57(1), 45-77.

Bloome, D., \& King-Dail, A.R. (1997). Toward (re)defining miscue analysis: Reading as a social and cultural process. Language Arts, 74(8), 610-617.

Bloome, D. (1985). Reading as a social process. Language Arts, 62, 134-142.

Boddy, C. R. (2016). Sample size for qualitative research. Qualitative Market Research: An International Journal, 19(4), 426-432.

Brown, L. (2010). Politeness and second language learning: The case of Korean speech styles. $\S \quad$, 243-269

Boudreaux, M.K. (2016). Survey of developmental students' print and online metacognitive reading. Educational Research Quarterly, 39(3), 3-22

Caravolas, M., \& Bruck, M. (1993). The effect of oral and written language input on children' s phonological awareness: A cross-linguistic study. Journal of experimental child psychology, 55(1), 1-30.

Carspecken, P. F. (1996). Critical ethnography in educational research. New York, NY: Routledge.

Charmaz, K. (2014). Constructing ground theory: A practical guide through qualitative analysis. London: Sage 
Charmaz, K. (2013). Grounded theory methods in social justice research. Strategies of qualitative inquiry, 291-336.

Charmaz, K. (2011). Grounded theory methods in social justice research. In N. K. Denzin \& Y. S. Lincoln (Eds.), Handbook of qualitative research (3rd ed., pp. 359-380). Thousand Oaks, CA: Sage.

Charmaz, K. (2010). Grounded theory objectivist and constructivist methods. In W. Luttrell (Ed), Qualitative educational research readings in reflexive methodology and transformative practice (pp. 183-207). New York, NY: Routledge

Charmaz, K. (2005). Grounded theory in the 21st century: A qualitative method for advancing social justice research. In N. K. Denzin \& Y. E. Lincoln (Eds.) Handbook of qualitative research (3rd ed., pp. 507- 535). Thousand Oaks, CA: Sage.

Charmaz, K. (2006). Constructing grounded theory: A practical guide through qualitative analysis. London: Sage.

Charmaz, K. (2000). Grounded theory: Objectivist and constructivist methods. In N. K. Denzin \& Y. S. Lincoln (Eds.), Handbook of qualitative research (2nd ed., pp. 509535). Thousand Oaks, CA: Sage.

Charmaz, K. (1995). Grounded theory. In J. Smith, R. Harré, \& L. Langenhove (Eds.), Rethinking methods in psychology (pp. 27-65). London: Sage

Cho. K. W. (2016a). I can see what you are saying: Auditory labels reduce visual search times. Acta Psychologica. 170, 19-31.

Cho, K. W., \& Feldman, L. B. (2016b). When repeating aloud enhances episodic memory for spoken words: Interactions between production- and perception-derived variability. Journal of Cognitive Psychology.

Cho, K.S. and Krashen, S. (1995). Becoming a dragon: Progress in English as a second language through narrow free voluntary reading. California Reader 29, 9-10. 
Clark, V. \& Creswell, J. (2010). Understanding research: A consumer's guide. Upper Saddle River, NJ: Pearson Education.

Clapham, C. 2001. Discipline specificity and EAP. In Flowerdew, J., Peacock, N. (Eds.). Research perspectives on English for academic purposes, (pp. 84-100). Cambridge University Press, Cambridge.

Clarke, M. (1979). Reading in Spanish and English. Language Learning, 29, 121-150.

Caudle, S. L. (2004). Qualitative data analysis. Handbook of practical program evaluation, 2(1), 417-438.

Connor, U. (2002). New directions in contrastive rhetoric. TESOL quarterly, 36(4), 493-510.

Connor, U. (1996). Contrastive rhetoric: Cross-cultural aspects of second-language writing. Cambridge: Cambridge University Press.

Cook, V. (2016). Working definition of multi-competence 'the overall system of a mind or a community that uses more than one language'. Retrieved from: http://www.viviancook.uk/Writings/Papers/MCentry.htm

Cook, V. (1999). Going beyond the native speaker in language teaching. TESOL quarterly, 33(2), 185-209.

Council of Europe. (2001). Common European Framework of Reference for Languages: Learning, Teaching, Assessment. Cambridge: Cambridge University Press. Retrieved from: http://www.coe.int/t/dg4/linguistic/source/framework en.pdf

Creswell, J. (2014). Research design: Qualitative, quantitative, and mixed methods approach. ( $4^{\text {th }}$ ed.). Thousand Oaks, CA: Sage Publications.

Creswell, J. (2013). Qualitative Inquiry and Research Design: Choosing Among Five Approaches. ( $3^{\text {rd }}$ ed.). Thousand Oaks, CA: Sage Publications.

Creswell, J. (2012). Educational research: Planning, conducting and evaluating qualitative and quantitative research. ( $4^{\text {th }}$ ed.). Boston, MA: Pearson Education. 
Creswell, J. and Clark, V. (2011). Designing and conducting mixed methods research. $\left(2^{\text {nd }}\right.$ ed.) Thousand Oaks, CA: Sage Publications.

Crystal, D. (2003). English as a global language (2 ${ }^{\text {nd }}$ ed.). Cambridge, UK: Cambridge University Press.

Corbin, J., Strauss, A., \& Strauss, A. L. (2008). Basics of qualitative research. Sage. Cui, Y. (2008). L2 Proficiency and L2 reading: Consolidating the linguistic threshold hypothesis. Language \& Literacy Graduate Student Conference Proceedings, Victoria, BC, Canada.

Cummins, J. (2007). Rethinking monolingual instructional strategies in multilingual classrooms. The Canadian Journal of Applied Linguistics, 10(2), 221-240.

Cummins, J. (1991). Interdependence of first- and second-language proficiency in bilingual children. In E. Bialystok (Ed.) Language processing in bilingual children. (pp. 7089). Cambridge: Cambridge University Press.

DeCara, B., \& Goswami, U. (2003). Phonological neighborhood density: Effects in a rhyme awareness task in five-year-old children. Journal of Child Language, 30, 695-710.

Dehaene, S. (2010). Reading in the brain: The new science of how we read. New York, NY: Penguin Books.

Denzin, N., \& Lincoln, Y. (2000). Introduction: The discipline and practice of qualitative research. In N. Denzin \& Y. Lincoln (Eds.), Handbook of qualitative research (pp. 132) Thousand Oaks, California: Sage Publications.

Dörnyei, Z., \& Ryan, S. (2015). The psychology of the language learners revisited. New York, NY: Routledge

Dörnyei, Z. (2005). The psychology of the language learning: Individual differences in second language acquisition. Mahwah, NJ: Lawrence Erlbaum Associates. 
Dulay, H.C., \& Burt, M.K. (1974). Natural sequences in child second language acquisition. Language Learning, 24(1), 37-53.

Ellis, R. (2015). Understanding second language acquisition. ( $2^{\text {nd }}$ ed.). Oxford, Oxford University Press.

Ellis, R. (2008). The study of second language acquisition (2 ${ }^{\text {nd }}$ ed.). New York, NY: Oxford University Press.

English as a Second Language (ESL) $\mid$ Heartland Community College. (n.d.). Retrieved from http://www.heartland.edu/adultEd/esl/.

English Language Institute|Illinois State University. (n.d.). Retrieved from http://eli.illinoisstate.edu/.

Eskey, D.E. (2002). Reading and the teaching of L2 reading. TESOL Journal, 11(1) 5-9

Éva, G., \& Réka, O. (2013). The relationship between the first language phonological awareness and the second language reading ability and the cross-language transfer of first language phonological skills. Transylvanian Journal of Psychology, 14(2), 173 193

Fender, M., 2003. Word recognition and word integration skills of native Arabic and Japanese-speaking learners of English as a second language. Applied Psycholinguistics $24,289-315$

Fender, M., 2008. Spelling knowledge and reading development: insights from Arab ESL learners. Reading in a Foreign Language, 20(1), 19-42.

Field, A. (2013). Discovering Statistics using SPSS: (And sex and drugs and rock ' $n$ ' roll). ( $4^{\text {th }}$ ed). London: SAGE.

Freire, P (2005). Pedagogia do oprimido. (42 ${ }^{\text {nd }}$ edition). Rio de Janeiro, RJ: Editora Paz e Terra. 
Freire, P., \& Macedo, D. (1987). Literacy: Reading the word and the world. South Hadley, MA: Bergin \& Garvey.

Freeman, M. R., Blumenfeld, H. K., \& Marian, V. (2016). Phonotactic constraints are activated across languages in bilinguals. Frontiers in psychology, 7, 702.

Freshwater, D., \& Cahill, J. (2013). Paradigms lost and paradigms regained. Journal of Mixed Methods Research, 7(3), 3-5.

Frost, R., Katz, L., \& Bentin, S. (1987). Strategies for visual word recognition and orthographical depth: A multilingual comparison. Journal of Experimental Psychology: Human Perception and Perfomwnce, 13, 104-115.

Frost, R., \& Bentin, S. (1992). Reading consonants and guessing vowels: Visual word recognition in Hebrew orthography. In R. Frost \& L. Katz (Eds.), Advances in psychology, Vol. 94. Orthography, phonology, morphology, and meaning (pp. 27-44).

Gail, A. (2006) So, What's Behind Adult English Second Language Reading? The Journal of the National Association for Bilingual Education, 30(2), 245-264.

Gardner, R. (2010). Motivation and second language acquisition: The socio-educational model. New York, NY: Peter Lang

Gass, S. M. (2008). Second language acquisition: An introductory course. New York: NY, Routledge.

Geva, E., \& Siegel, L. S. (2000). Orthographic and cognitive factors in the concurrent development of basic reading skills in two languages. Reading and Writing, 12, 1-30.

Geva, E. (1995). Orthographic and cognitive processing in learning to read English and Hebrew. Scripts and Literacy, 277-291. Springer, Dordrecht.

Ghee, T. T., Ismail, H. N., \& Kabilan, M. K. (2010). Language learning strategies used by MFL students based on genders and achievement groups. US-China Foreign Language, 8(1), 50-58. 
Glaser, B. G. (1992). Basics of grounded theory analysis. Mill Valley, CA: Sociological Press.

Glaser, B. G., \& Strauss, A. L. (1967). The discovery of grounded theory: Strategies for qualitative research. New York, NY: Aldine De Gruyter.

Glesne, C. (2006). Becoming qualitative researchers: An introduction. Boston, MA: Pearson. (3rd ed.).

Goldenberg, C., Tolar, T. D., Reese, L., Francis, D. J., Ray Bazán, A., \& Mejía-Arauz, R. (2014). How important is teaching phonemic awareness to children learning to read in Spanish?. American Educational Research Journal, 51(3), 604-633.

Goldenberg, C. (2011). Reading instruction for English Language Learners. In M.L. Kamil, P.D. Pearson, E.B. Moje \& P.P. Afflerbach (Eds.), Handbook of reading research volume IV (pp. 684-710). New York, NY: Routledge.

Goodman, K. (2014). Reading: A psycholinguistic guessing game. In K. Goodman \& Y. Goodman (Eds), Making sense of learners, making sense of written language: The selected works of Kenneth S. Goodman and Yetta M. Goodman, (pp.103-112). New York, NY: Routledge.

Goodman, Y .M. (2014). Retrospective miscue analysis: Illuminating the voice of the reader. In K. Goodman \& Y. Goodman (Eds), Making sense of learners, making sense of written language: The selected works of Kenneth S. Goodman and Yetta M. Goodman, (pp. 205-221). New York, NY: Routledge.

Goodman, Y.M., \& Goodman, W.J. (2014). Eager young readers, a well-constructed text, and an insightful teacher. In K.Goodman \& Y. Goodman (Eds), Making sense of learners, making sense of written language: The selected works of Kenneth $S$. Goodman and Yetta M. Goodman, (pp.222-235). New York, NY: Routledge. 
Goodman, Y.M., Watson, D.J., \& Burke, C.L. (2005). Reading Miscue Inventory: From evaluation to instruction (2nd ed.). Katonah, NY: Richard C. Owen.

Goodman, Y. M., \& Marek, A. M. (1996). Retrospective miscue analysis. In Yetta M. Goodman \& Ann M. Marek. Retrospective miscue analysis: Revaluing readers and reading (pp. 39-48). Katonah, NY: Richard C. Owen Publishers, Inc.

Goodman, Y.M., Watson, D.; \& Burke, C. (1987). Reading miscue analysis: Alternative Procedures. New York, NY: Richard C. Owen Publisher, Inc.

Goodman, K. S. (1965). A linguistic study of cues and miscues in reading. Elementary English, 42(6), 639-643.

Goswami, U. (2010). A psycholinguistic grain size view of reading acquisition across language. In N. Brunswick, S. McDougall, \& P. De Mornay Davies (eds.). Reading and dyslexia in different orthographies (pp.23-42). Hove, East Sussex: Psychology Press.

Goswami, U. (2001). Early phonological development and the acquisition of literacy. In S. B. Neuman \& D. K. Dickinson (Eds.), Handbook of early literacy research (pp. 111125). New York: Guilford Press.

Goswami, U., Gombert, J., \& Barrera, L. (1998). Children's orthographic representation and linguistic transparency: Nonsense word reading in English, French, and Spanish. Applied Psycholinguistics, 19, 19-52.

Gottardo, A., \& Mueller, J. (2009). Are first- and second-language factors related in predicting second- language reading comprehension? A study of Spanish speaking children acquiring English as a second language from first to second grade. Journal of Educational Psychology, 101(2), 330-344.

Grabe, W. (2009). Reading in a second language: Moving from theory to practice. Cambridge: Cambridge University Press. 
Green, S. \& Salkind, N. (2011). Using SPSS for Windows and Macintosh: Analyzing and understanding data. Upper Saddle River, NJ: Pearson Education

Greene, J.C. (2010). Knowledge accumulation: Three views on the nature and role of knowledge in social science. In W. Luttrell (Ed), Qualitative educational research readings in reflexive methodology and transformative practice (pp. 63-77). New York, NY: Routledge

Greene, J. C. (2008). Is mixed methods social inquiry a distinctive methodology? Journal of mixed methods research, 2(1), 7-22.

Greene, J. C. (2007). Mixed methods in social inquiry. San Francisco, CA: Jossey-Bass.

Greene, J. C. (2000). Understanding social programs through evaluation. In N. K. Denzin \& Y. S. Lincoln (Eds.), Handbook of qualitative research (2nd ed., pp. 981-1000). Thousand Oaks, CA: Sage.

Greene, J., \& Hall, J. (2010). Dialectics and pragmatism: Being of consequence. In A. Tashakkori \& E. Teddlie (Eds.), SAGE handbook of mixed methods in social \& behavioral research (2nd ed.). Thousand Oaks, CA: Sage.

Guba, E. G., \& Lincoln, Y. S. (1994). Competing paradigms in qualitative research. In N. K. Denzin \& Y. S. Lincoln (Eds.), Handbook of qualitative research (pp. 105-117). Thousand Oaks, CA: Sage.

Guba, E. G., \& Lincoln, Y. S. (1985). Naturalistic Inquiry.

Guba, E. G., \& Lincoln, Y. S. (1989). Fourth generation evaluation. Thousand Oaks, CA: Sage.

Guba, E. G. (1990) The alternative paradigm dialog. In E. G. Guba (Ed.), The paradigm dialog (pp. 17-27) Newbury Park CA: Sage.

Gunning, T. (2013). Creating literacy Instruction for all students. (8th Ed). Boston: Ma, Pearson. 
Guo, Y., \& Roehrig, A. (2011). Roles of general versus second language (L2) knowledge in L2 reading comprehension. Reading in a Foreign Language, 23 (1), 42-64

Guthrie, J. T. \& Wigfield, A. (2000). Engagement and motivation in reading. In M. Kamil, P. Mosenthal, P. D. Pearson, \& R. Barr (Eds.), Handbook of reading research (Vol. 3, pp. 403-422). Mahwah, NJ: Erlbaum.

Hadley, A.O. (2001). Teaching language in context.(3rd ed.) Boston, MA: Heinle \& Heinle.

Haigh, C.A., Savage, R., Erdos, C., \& Genesse, F. (2011). The role of phoneme and onsetrime awareness in second language reading. Journal of Research in Reading, 34(1), 94-113.

Hall, L. A. (2012). The role of reading identities and reading abilities in students' discussions about texts and comprehension strategies. Journal of Literacy Research, 44(3), 239272.

Hall, L. A. (2010). The negative consequences of becoming a good reader: Identity theory as a lens for understanding struggling readers, teachers, and reading instruction. Teachers College Record, 112(7), 1792-1829.

Handsfield, L. (2015). Literacy theory as practice: Connecting theory and instruction in K12 classrooms. New York, NY: Teachers College Press.

Handsfield, L. \& André, A. (2016). The fluency factor: Authentic instruction and assessment for reading success in the common core classroom [Review of the book of same title, by T. V. Rasinski \& J. K. Nageldinger]. Teachers College Press, New York

Hassan, E. M. I. (2014). Pronunciation problems: A case study of English language students at Sudan University of Science and Technology. English Language and Literature Studies, 4(4), 31.

Hayes-Harb, R. (2006). Native speakers of Arabic and ESL texts: Evidence for the transfer of written word identification processes. TESOL Quarterly, 40(2), 321-339. 
Hinds, J. (1987). Reader versus writer responsibility: A new typology. In U. Connor \& R. B. Kaplan (Eds.), Writing across languages: Analysis of L2 text (pp. 141-152). Reading, MA: Addison-Wesley Publishing Company.

Homer, B. (2009). Literacy and metalinguistic development. In D. R. Olson \& N. Torrance (Eds.), The Cambridge handbook of literacy (pp 487 -500).

Hosenfeld, C. (1978). A preliminary investigation of the reading strategies of successful and unsuccessful second language learners. System, 5, 110-123.

Hullinger, J. (2016). The transcendental revelations of astronauts. Retrieved from http://theweek.com/articles/619451/transcendental-revelations-astronauts.

Hruby, G.G., \& Goswami, U. (2013). Educational neuroscience for reading researchers. In D.E. Alvermann, N.J. Unrau \& R.B. Ruddell (Eds.), Theoretical models and processes of reading (6th ed., pp3-46). Newark, DE: International Reading Association.

Intensive English Institute, College of LAS, University of Illinois. (n.d.). Retrieved from http://www.iei.illinois.edu/.

Jiang, N. (2007). Selective integration of linguistic knowledge in adult second language learning. Language Learning, 57(1), 1-33.

Jiang, N. (2004). Morphological insensitivity in second language processing. Applied Linguistics, 25(4), 603-684.

Jiménez, R. (1997). The strategic reading abilities and potential of five low-literacy Latina/o readers in middle school. Reading Research Quarterly, 32, 24-35.

Jiménez, R. T., García, G. E., \& Pearson, P. D. (1996). Opportunities and obstacles in bilingual reading: The reading strategies of bilingual students. Reading Research Quarterly, 31(1), 90-113. 
Jiménez, R. T., Garcia, G. E., \& Pearson, P. D. (1995). Three children, two languages, and strategic reading: Case studies in bilingual/monolingual reading. American Educational Research Journal, 32(1), 67-97.

Johnson, R. B. (2011). Do we need paradigm? A mixed methods perspective. Mid-Western Educational Researcher, 24(2), 31-40

Johnson, R. B. (2008). Editorial: Living with tensions. Journal of Mixed Methods Research, 2, 203-207.

Johnson, R. B., \& Christensen, L. B. (2004). Educational research: Quantitative, qualitative, and mixed approaches. Boston, MA: Allyn and Bacon.

Johnson, R. B., \& Gray, R. (2010). A history of philosophical and theoretical issues for mixed methods research. In A. Tashakkori \& E. Teddlie (Eds.), SAGE handbook of mixed methods in social \& behavioral research ( $2^{\text {nd }}$ ed., pp. 69-94). Thousand Oaks, CA: Sage.

Johnson, R. B., McGowan, M.W., \& Turner, L.A. (2010). Grounded Theory in Practice: Is It Inherently a Mixed Method? Research in the Schools, 17(2), 65-78.

Johnson, R. B., Onwuegbuzie, A. J., \& Turner, L. A. (2007). Toward a definition of mixed methods research. Journal of Mixed Methods Research, 1, 1-22.

Johnson, R. B., \& Onwuegbuzie, A. J. (2004). Mixed methods research: A research paradigm whose time has come. Educational researcher, 33(7), 14-26.

Johnson, R.B.\& Turner, L.A. (2003). Data collection strategies in mixed methods research. In A. Tashakkori \& E. Teddlie (Eds.), SAGE handbook of mixed methods in social \& behavioral research (2 ${ }^{\text {nd }}$ ed., pp/ 297-319). Thousand Oaks, CA: Sage.

Kaplan, R.B. (1988). Contrastive rhetoric and second language learning: Notes toward a theory of contrastive rhetoric. In A. Purves (Ed.), Writing across languages and cultures: Issues in contrastive rhetoric (pp. 275-304). Newbury Park, CA: Sage. 
Kantrowitz, B., \& Hammill, R. (1990). The reading wars.Newsweek, Fall/Winter, 8-14

Kádár, D.Z., \& Bargiela-Chiappini, F. (2011). Institutional politeness in (South) East Asia: An introduction. Journal of Asian Communication, 21(1), 1-9

Kaplan, R. B. (1972). The anatomy of rhetoric: Prolegomena to a functional theory of rhetoric; essays for teachers. Philadelphia, NJ: Center for curriculum development.

Keh, M.L. (2017). Understanding and Evaluating English Learners' Oral Reading With Miscue Analysis. Journal of Adolescent \& Adult Literacy, 60(6), 643-653.

Kennon, T. (2016). The scientific case of being super busy. Retrieved from http://theweek.com/articles/626188/scientific-case-being-super-busy

Kim, J. (2008). Research and the reading wars. Phi Delta Kappan, 89(5), 372-375.

Kim, M. (2010). Adult ESL Korean readers' responses about their reading in L1 Korean and L2 English (Unpublished doctoral dissertation). The University of Arizona, Tucson, AZ.

Kintsch, W. (2007). Meaning in context. Handbook of latent semantic analysis, 89-105.

Kintsch, W. (1998). Comprehension: A paradigm for cognition. New York: Cambridge University Press.

Kirchhoff, C. (2013). L2 extensive reading and flow: Clarifying the relationship. Reading in a foreign language, 25(2), 192.

Kleinman, S. (1991). Experiencing fieldwork. Newbury Park, CA: Sage.

Koda, K., \& Zehler, A. M. (2008). Introduction: Conceptualizing reading universal, crosslinguistic variations, and second language literacy development. In K. Koda \& A. M. Zehler (Eds), Learning to read across languages: Cross-linguistic relationships in first- and second-language literacy development (pp. 1-10). New York, NY: Routledge. 
Koda, K. (2007). Reading and language learning: Crosslinguistic constraints on second language reading development. In K. Koda (Ed.), Reading and language learning pp. 1-44. Malden, MA: Blackwell Publishing,

Koda, K. (2005). Insights into second language reading: A cross-linguistic approach. New York, NY: Cambridge University Press.

Koda, K. (1998). The role of phonemic awareness in second language reading. Second Language Research, 14(2), p. 194-195.

Koda, K. (1996). L2 word recognition research: A critical review. The Modern Language Journal, 80(4), 450-460.

Koda K. (1995). Cognitive Consequences of L1 and L2 Orthographies. In: Taylor I., Olson D.R. (Eds), Neuropsychology and Cognition, (vol. 7, pp. 311-326). Springer, Dordrecht

Koda, K. (1990). The use of L1 reading strategies in L2 reading: Effects of L1 orthographic structures on L2 phonological recoding strategies. Studies in Second Language Acquisition, 12(4), 393-410.

Krashen, S. D. (2004). The power of reading: Insights from the research: Insights from the research. ABC-CLIO.

Krashen, S. D. (2011). Free voluntary reading. ABC-CLIO.

Krashen, S. (1992). The Input Hypothesis: An Update.”. Linguistics and language pedagogy: The state of the art, 409-431.

Krashen, S. (1985). The Input Hypothesis. Oxford: Pergamon Press.

Kubota, R., \& Lehner, A. (2004). Toward critical contrastive rhetoric. Journal of Second Language Writing, 13(1), 7-27.

Kucer, S. B. \& Silvia, C. (2006). Teaching the dimensions of literacy. Mahwah, NJ: Lawrence Erlbaum Associates. 
Kurby, C. A., Magliano, J. P., \& Rapp, D. N. (2009). Those voices in your head: Activation of auditory images during reading. Cognition, 112(3), 457-461.

Kvale, S. \& Brinkmann, S. (2009). Interviews: learning the craft of qualitative research interviewing ( $2^{\text {nd }}$ Ed.). Thousand Oaks, CA: Sage Publications.

Lanauze, M., \& Snow, C. (1989). The relation between first- and second-language writing skills: Evidence from Puerto Rico elementary school children in bilingual programs. Linguistic and Education: An International Research Journal, 1(4), 323-339.

Lantolf, J.P. (2000). Introducing sociocultural theory. In J.P. Lantolf(ed.), Sociocultural theory and second language learning (pp.1-26). Oxford, UK: Oxford University Press.

Larsen Freeman, D. (1975). The acquisition of grammatical morphemes by adult ESL students. TESOL Quarterly, 9(4), 409-419.

Lee, A. Y., \& Handsfield, L. J. (2018). Code-Meshing and Writing Instruction in Multilingual Classrooms. The Reading Teacher.

Lemke, J. L. (1997). Cognition, context, and learning: A social semiotic perspective. In D. Kirshner \& J.A. Whitson (Eds.), Situated cognition theory: Social, neurological, and semiotic perspectives (pp. 37-56). Mahwah, NJ: Erlbaum.

Lems, K. (2003). Adult ESL oral reading fluency and silent reading comprehension. Unpublished doctoral dissertation, National-Louis University, Chicago, IL.

Lev-Ari, S., \& Peperkamp, S. (2013). Low inhibitory skill leads to non-native perception and production in bilinguals' native language. Journal of Phonetics, 41(5), 320-331.

Lincoln, Y.S., \& Guba, E. (1985). Naturalistic inquiry. Newbury Park, CA: Sage.

Malcolm, D. (2009). Reading strategy awareness of Arabic-speaking medical students studying in English. System, 37(4), 640-651. 
Masgoret, A. M., \& Gardner, R. C. (2003). Attitudes, motivation, and second language learning: a meta-analysis of studies conducted by Gardner and associates. Language Learning, 53(1), 123-163.

Matsuda, P. K. (1997). Contrastive rhetoric in context: A dynamic model of L2 writing. Journal of second language writing, 6(1), 45-60.

Maxwell, J. A. (2011). Paradigms or toolkits? Philosophical and methodological positions as heuristics for mixed methods research. Mid-Western Educational Researcher, 24(2), 27-30.

Maxwell, J. A., \& Mittapalli, K. (2010). Realism as a stance for mixed methods research. Handbook of mixed methods in social \& behavioural research (pp. 145168).

McClelland, N. (2013). Self-determination theory and L2- learning motivation in Japanese college students. Studies in English Language and Literature, 31, 191- 206.

Merriam, S.B. (2001). Qualitative research and case study applications in education. San Francisco, CA: Jossey Bass.

Mertens, D. (1998). Research methods in education and psychology: Integrating diversity with quantitative and qualitative approaches. Thousand Oaks, CA, Sage.

Mikulec, E. (2015). Reading in two languages: A comparative miscue analysis. The Reading Matrix, 15(1), 143-157.

Mills, C.W. (2010). On intellectual craftsmanship. In W. Luttrell (Ed), Qualitative educational research readings in reflexive methodology and transformative practice (pp. 139-145). New York, NY: Routledge. 
Mokhtari, K. (2008). Perceived and real-time use of reading strategies by three proficient triliterate readers: A case study. In K. Mokhtari \& R. Sheorey (Eds), Reading strategies of first- and second-language learners: See how they read, (pp. 143-160). Norwood, MA: Christopher-Gordon Publishers.

Mokhtari, K., \& Perry, B. (2008). Using rasch analysis to calibrate students' metacognitive awareness and use of reading strategies. In K. Mokhtari \& R. Sheorey (Eds), Reading strategies of first- and second-language learners: See how they read, (pp. 67-84). Norwood, MA: Christopher-Gordon Publishers.

Mokhtari, K., \& Reichard, C. (2004). Investigating the strategic reading processes of first and second language readers in two different cultural contexts. System, 32, 379-394.

Mokhtari, K., \& Reichard, C. (2002). Assessing students' metacognitive awareness of reading strategies. Journal of Educational Psychology, 94, 249-259.

Mokhtari, K. \& Sheorey, R. (2002) Measuring ESL students' awareness of reading strategies. Journal of Educational Development, 25(3), 2-10.

Mokhtari, K., Sheorey, R., \& Reichard, C.A. (2008). Measuring the reading strategies of first- and second-language readers. In K. Mokhtari \& R. Sheorey (Eds), Reading strategies of first- and second-language learners: See how they read, (pp. 43-66). Norwood, MA: Christopher-Gordon Publishers.

Mountaj, N., El Yagoubi, R., Himmi, M., Ghazal, F. L., Besson, M., \& Boudelaa, S. (2015). Vowelling and semantic priming effects in Arabic. International Journal of Psychophysiology, 95(1), 46-55.

Morgan, D. (2007). Paradigms lost and pragmatism regained: Methodological implications of combining qualitative and quantitative methods. Journal of Mixed Methods Research, 1(1), 48-76. 
Morse, J. M., \& Niehaus, L. (2009). Mixed methods design: Principles and procedures. Walnut Creek, CA: Left Coast Press.

Mushait, S. 2003. The Relationship of L1 Reading and L2 Language Proficiency with the L2 Reading Comprehension and Strategies of Saudi EFL University Students. Unpublished PhD thesis, University of Essex, UK.

Nagy, W. E., \& Scott, J.A. (2013). Vocabulary process. In D.E. Alvermann, N.J. Unrau \& R.B. Ruddell (Eds.), Theoretical models and processes of reading ( $6^{\text {th }}$. ed., pp. 458475). Newark, DE: International Reading Association.

Nation, P. (2001). Learning vocabulary in another language. Cambridge, MA: Cambridge University Press.

National Reading Panel (US), National Institute of Child Health, \& Human Development (US). (2000). Teaching children to read: An evidence-based assessment of the scientific research literature on reading and its implications for reading instruction. National Institute of Child Health and Human Development, National Institutes of Health.

Nassaji, H. (2007). Schema theory and knowledge-based processes in second language reading comprehension: A need for alternative perspectives. Language Learning, 57, 79-113.

Nergis, A. (2013). Exploring the factors that affect reading comprehension of EAF learners. Journal of English for Academic Purposes, 12, 1-9.

Noels, K.A., Pelletier, L.G., Clément, R., \& Vallerand, R.J. (2003). Why are you learning a second language? Motivational orientations and self-determination theory. Language Learning, 53, 33-63.

Onwuegbuzie, A. J. (2007) Mixed methods research in sociology and beyond. In G. Ritzer (Ed.), Encyclopedia of Sociology (Vol. VI, pp. 2978- 2981) Oxford: Blackwell. 
Onwuegbuzie, A. J. (2003) Effect sizes in qualitative research: A prolegomenon. Quality and Quantity: International Journal of Methodology, 37, 393-409.

Onwuegbuzie, A. J., \& Collins, K. M. (2007). A typology of mixed methods sampling designs in social science research. The qualitative report, 12(2), 281-316.

Onwuegbuzie, A. J., Johnson, R. B., \& Collins, K. M. (2009). Call for mixed analysis: A philosophical framework for combining qualitative and quantitative approaches. International journal of multiple research approaches, 3(2), 114-139.

Onwuegbuzie, A. J., \& Leech, N. L. (2007). A call for qualitative power analyses. Quality \& Quantity, 41(1), 105-121.

Onwuegbuzie, A. J., Leech, N. L., \& Collins, K. M. (2010). Innovative data collection strategies in qualitative research. The qualitative report, 15(3), 696.

Onwuegbuzie, A.J., \& Teddlie, C. (2003). A framework for analyzing data in mixed methods research. In A. Tashakkori \& C. Teddlie (Eds.), Handbook of mixed methods in social and behavioral research (pp. 351-383). Thousand Oaks, CA: Sage.

Ozasa, T., Weir, G., \& Fukui, M. (2007, December). Measuring readability for Japanese learners of English. In Proceedings of the 12th Conference of Pan-Pacific Association of Applied Linguistics (pp. 122-125).

Oxford, R. L., \& Burry-Stock, J. A. (1995). Assessing the use of language learning strategies worldwide with the ESL/EFL version of the Strategy Inventory for Language Learning (SILL). System, 23(1), 1-23.

Oxford, R., 1990. Language learning strategies: What every teacher should know. Heinle \& Heinle, Boston.

Paulson, E. J., and Goodman, K. S. (2008). "Re-reading eye-movement research: Support for transactional models of reading." Scientific Realism in Studies of Reading. Mahwah, NJ: Lawrence Erlbaum Associates, Inc, 25-47. 
Pearson, P.D. (2004). The reading wars. Educational Policy, 18(1), 216-252.

Peshkin, A. (1998). In search of subjectivity: One's own. Educational Researcher, 17(7), 1721.

Pérez, G. M. G. (2005). Perception of English vowels by native speakers of Spanish in a regular classroom setting. Revista Virtual de Estudos da Linguagem-ReVEL. Ano, 3.

Perfetti, C. A. (1992). The representation problem in reading acquisition. In P. B. Gough, L. C. Ehri, \& R. Treiman (Eds.), Reading acquisition (pp. 145-174). Hillsdale, NJ: Lawrence Erlbaum Associates.

Phakiti, A. 2003. A closer look at the relationship of problem-solving and global strategy use to EFL reading achievement test performance. Language Testing, 20(1), 26-56.

Pressley, M., \& Afflerbach, P. (1995). Verbal protocols of reading: The nature of constructively responsive reading. Hillsdale, NJ: Lawrence Erlbaum associates.

Rajab, H. (2013). Developing Speaking and Writing Skills of L1 Arabic EFL Learners through Teaching of IPA Phonetic Codes. Theory and Practice in Language studies, 3(4), 653-659.

Rogoff, B. (2003). The cultural nature of human development. Oxford, England: Oxford University Press.

Rogoff, B. (1998). Cognition as a collaborative process. In W. Damon (Ed.), Handbook of child psychology: Vol. 2. Cognition, perception, and language (pp. 679-744). Hoboken, NJ, US: John Wiley \& Sons Inc.

Rogoff, B. (1995). Observing sociocultural activity on three planes: Participatory appropriation, guided participation, and apprenticeship. In J. V. Wertsch, P. del Rio, \& A. Alvarez (Eds.), Sociocultural studies of mind (pp. 139-164). New York, NY: Cambridge University Press. 
Rosenblatt, L.M. (1994). The reader, the text, the poem: The transactional theory of the literary work ( $2^{\text {nd }}$ ed.). Carbondale, IL: Southern Illinois University Press.

Rossman, G. B., \& Rallis, S. (2003). Learning in the field: An introduction to qualitative research. Thousand Oaks, CA: Sage Publications.

Ryan, A., \& Meara, P. (1992). The case of the invisible vowels: Arabic speakers reading English words. Reading in a foreign language, 7, 531-531.

Ruddell, R.B., \& Unrau, N.J. (2013). Reading as a motivated meaning-construction process: The reader, the text, and the teacher. In D.E. Alvermann, N.J. Unrau \& R.B. Ruddell (Eds.), Theoretical models and processes of reading (6th ed., pp. 1015-1068).

Newark, DE: International Reading Association.

Rumelhart, D.E. (1994). Toward an interactive model of reading. In R.B. Ruddell, M.R. Ruddell, \& H. Singer (Eds). Theoretical models and processes of reading (4th ${ }^{\text {th }}$ ed., pp. 864-894). Newark, DE: International Reading Association.

Rumelhart, D.E. (1980). Schemata: The building blocks of cognition. In R.J. Spiro, B.C. Bruce \& W.F. Brewer (Eds.). Theoretical issues in reading comprehension (pp.3858). Hillsdale, NJ: Lawrence Elbaum Associates.

Saigh, K., \& Schmitt, N. (2012). Difficulties with vocabulary word form: The case of Arabic ESL learners. System, 40(1), 24-36.

Saiegh-Haddad, E., \& Geva, E. (2008). Morphological awareness, phonological awareness, and reading in English-Arabic bilingual children. Reading and Writing, 21(5), 481.

Saiegh-Haddad, E. (2003). Linguistic distance and initial reading acquisition: The case of Arabic diglossia. Applied Psycholinguistics, 24(3), 431-451.

Salkind, N. J. (2014). Statistics for people who (think they) hate statistics (5 $5^{\text {th }}$ ed.). Sage Publications. 
Salkind, N. J. (2010). Statistics for people who (think they) hate statistics ( $3^{\text {rd }}$ ed. - excel edition). Sage Publications.

Seymour, P. H. K., Aro, M., \& Erskine, J. M. (2003). Foundation literacy acquisition in European orthographies. British Journal of Psychology, 94, 143-174.

Shannon-Baker, P. (2016). Making paradigms meaningful in mixed methods research. Journal of Mixed Methods Research, 10(4), 319-334.

Share, D. L. (2008). On the Anglocentricities of current reading research and practice: The perils of overreliance on an "outlier" orthography. Psychological Bulletin, 134, 584615.

Share, D. L., \& Daniels, P. T. (2016). Aksharas, alphasyllabaries, abugidas, alphabets and orthographic depth: Reflections on Rimzhim, Katz and Fowler (2014). Writing Systems Research, 8(1), 17-31.

Sharp, A. (2010). Intercultural rhetoric and reading comprehension in a second language. Reading Psychology, 31(5), 472-491.

Sheorey, R., \& Baboczky, E. S. (2008). Metacognitive awareness of reading strategies among Hungarian college students. In K. Mokhtari \& R. Sheorey (Eds), Reading strategies of first-and second-language learners: See how they read (pp. 161-175). Norwood, MA: Christopher-Gordon Publishers.

Sheorey, R., Kamimura, Y., \& Freiermuth, M. R. (2008). Reading strategies of the users of english as a library language: The case of Japanese ESP students. In K. Mokhtari \& R. Sheorey (Eds), Reading strategies of first- and second-language learners: See how they read (pp. 175-185). Norwood, MA: Christopher-Gordon Publishers. 
Sheorey, R.. \& Mokhtari, K. (2008). Differing perceptions of reading strategies between native and non-native college students. In K. Mokhtari \& R. Sheorey (Eds), Reading strategies of first- and second-language learners: See how they read, (pp. 131-143). Norwood, MA: Christopher-Gordon Publishers.

Sheorey, R., \& Mokhtari, K. (2001). Differences in the metacognitive awareness of reading strategies among native and non-native readers. System, 29, 431-449.

Smagorinsky, P. H. (2013). What does Vygotsky provide for the $21^{\text {st }}$-century language arts teachers? Language Arts, 90(3), 192-204

Sandelowski, M. (1995). Sample size in qualitative research. Research in nursing \& health, 18(2), 179-183.

Spradley, J. P. (1980). Participant observation. New York: Holt Rinehart and Winston.

Strauss, A., \& Corbin, J. (1998). Basics of qualitative research: Techniques and procedures for developing grounded theory ( $2^{\text {nd }}$ ed.). Thousand Oaks, CA: Sage.

Strauss, A., \& Corbin, J. M. (1990). Basics of qualitative research: Grounded theory procedures and techniques. Thousand Oaks, CA, US: Sage Publications, Inc.

Street, B. (2003). What's "new” in new literacy studies? Critical approaches to literacy in theory and practice. Current Issues in Comparative Education, 5(2), 77-91.

Tajeddin, Z., \& Pezeshki, M. (2014). Acquisition of politeness markers in an EFL context: Impact of input enhancement and output. RELC Journal, 45(3), 269-286.

Taouka, M., \& Coltheart, M. (2004). The cognitive processes involved in learning to read in Arabic. Reading and writing, 17(1-2), 27-57.

Taylor, P.C., \& Medina, M.N.D. (2013). Educational research paradigms: From positivism to multi-paradigmatic. Journal for Meaning-Centered Education, 1. 
Teddlie, C., \& Johnson, R. B. (2009). Chapter 4: Methodological thought since the 20th Century. In C. Teddlie \& A. Tashakkori, Foundations of mixed methods research: Integrating quantitative and qualitative techniques in the social and behavioral sciences (pp. 62-82). Thousand Oaks, CA: Sage.

Teddlie, C, \& Tashakkori, A. (2009). Foundations of mixed methods research: Integrating quantitative and qualitative techniques in the social and behavioral sciences. Thousand Oaks, CA: Sage.

Trace, D. H., \& Morrow, L. M. (2012) Lenses on reading: An introduction to theories and models. New York, NY: Guilford Press.

Usó-Joan, E., (2006). The compensatory nature of discipline-related knowledge and English language proficiency in reading English for academic purposes. The Modern Language Journal, 90, 210 - 227.

Vajjala, S., \& Meurers, D. (2013). On the applicability of readability models to web texts. In Proceedings of the Second Workshop on Predicting and Improving Text Readability for Target Reader Populations (pp. 59-68).

Vajjala, S., \& Meurers, D. (2012). On improving the accuracy of readability classification using insights from second language acquisition. In Proceedings of the Seventh Workshop on Building Educational Applications Using NL P(pp. 163-173). Association for Computational Linguistics.

an der Veer, R., \& Bailey, R. (2014) Lev Vygotsky. London: Bloomsbury Publishing, Vogt, W.P., Gardner, D.C., \& Haeffele, L.M. (2012). When to use what research design. New York, NY: Guilford Press

Vygotsky, L. (1978). Mind in society: the development of higher psychological processes. (M. Cole, V. John-Steiner, S. Scribner, E. Souberman, Eds \& Trans.). Cambridge, MA: Harvard University Press 
Vygotsky, L. S. (1986). Thought and language, revised edition. Cambridge: MIT Press.

Wang, Y., \& Gilles, C. (2017). Reading in English and in Chinese: Case Study of Retrospective Miscue Analysis with Two Adult English Learners. Reading Horizons (Online), 56(2), 64-95.

Wightwick, J. (1998). Arabic Verbs \& Essentials of Grammar. Chicago, IL: Contemporary Publishing Group.

Willis, J.W. (2007). Foundations of Qualitative Research: Interpretive and Critical Approaches. Thousand Oaks, CA: Sage

Wright, P. (1996). Miscue Analysis. Basic Skills, 5-7.

Wolfram, W. and Schilling-Estes, N. (2006). American English: Dialects and Variation (2 ${ }^{\text {nd }}$ ed.). Malden, MA: Wiley Blackwell.

Worsnop, C. (1996). The beginning of retrospective analysis. In Yetta M. Goodman \& Ann M. Marek. Retrospective miscue analysis: Revaluing readers and reading (pp. 151156). Katonah, NY: Richard C. Owen Publisher, Inc.

Wu, C. P. (2005). An investigation of metacognitive reading strategies used by EFL Taiwanese college students to comprehend familiar versus unfamiliar Chinese and English texts (Unpublished doctoral dissertation). University of Idaho, ID.

Wurr, A., Theurer, J., Kim, K. (2008). Retrospective miscue analysis with proficient adult ESL readers. Journal of Adolescent \& Adult Literacy, 52(4), 324-333.

Xia, M., Kochmar, E., \& Briscoe, T. (2016). Text readability assessment for second language learners. In Proceedings of the 11th Workshop on Innovative Use of NLP for Building Educational Applications (pp. 12-22).

Yoshimi, T., Kotani, K., \& Isahara, H. (2012). Use of a New Set of Linguistic Features to Improve Automatic Assessment of Text Readability. Online Submission. 
Yüksel, I., \& Yüksel, I. (2012). Metacognitive awareness of academic reading strategies. Procedia-Social and Behavioral Science, 31, 894-898

Zhang, L. J. (2010). A dynamic metacognitive systems account of Chinese university students' knowledge about EFL reading. TESOL Quarterly, 44(2), 320-353.

Zhang, L. J., \& Wu, A. (2009). Chinese senior high school EFL students' metacognitive awareness and reading-strategy use. Reading in a Foreign Language, 21, 37-59.

Zhou, P., \& Christianson, K. (2016a). Auditory perceptual simulation: Simulating speech rates or accents?. Acta psychologica, 168, 85-90.

Zhou, P., \& \& Christianson, K. (2016b) I "hear" what you're "saying": Auditory perceptual simulation, reading speed, and reading comprehension, The Quarterly Journal of Experimental Psychology, 69(5), 972-995.

Ziegler, J.C. \& Goswami, U. (2006). Becoming literate in different languages: Similar problems, different solutions. Developmental Science, 9 (5), 429-453.

Ziegler, J.C. \& Goswami, U. (2005). Reading acquisition, developmental dyslexia, and skilled reading across languages: A psycholinguistic grain size theory. Psychological Bulletin, 131 (1), 3-29. 


\section{APPENDIX A: BACKGROUND QUESTIONNAIRE}

1. I identify my gender as: $\square$ Male $\square$ Female

2. Are you a(n): $\quad \square$ Undergraduate student $\quad \square$ Graduate student $\quad \square$ other

3. How old are you?

4. What is (are) your native language?

5. Where are you from?

6. What is your major (area of interest)?

7. How do you perceive your level of proficiency in English?

$\square$ Beginner $\square$ Intermediate $\square$ Advanced $\square$ Fluent (native like)

8. Do you speak any other language besides your native language and English?

No $\square$ Yes

If yes, which

one(s)?

What is your level of proficiency in this (these)

language(s)?

9. Have you taken any English course in your country? $\square$ No $\square$ Yes

If yes, how many hours a

week?

10. How long have you been studying English in USA?

11. What are your challenges of reading in English? 
12. How do you feel about yourself as a reader (Describe yourself as a reader)?

13. What are the similarities between reading in your language and in English, if any?

14. What are the differences between reading in your language and in English, if any?

15. What genres (e.g. newspaper article, biography, fiction, etc) do you think it is easier or more difficult to read? Why? 


\section{APPENDIX B: SRUVEY OF READING STRATEGIES}

Kouider Mokhtari and Ravi Sheorey, 2002

The purpose of this survey is to collect information about the various strategies you use when you read school-related academic materials in ENGLISH (e.g., reading textbooks for homework or examinations; reading journal articles, etc.). Each statement is followed by five numbers, $1,2,3,4$, and 5 , and each number means the following: ' 1 ' means that 'I never or almost never do this'; '2' means that 'I do this only occasionally'; '3' means that 'I sometimes do this'. (About $\mathbf{5 0 \%}$ of the time.); '4' means that 'I usually do this'; '5' means that 'I always or almost always do this'. After reading each statement, circle the number $(1,2,3,4$, or 5) which applies to you. Note that there are no right or wrong responses to any of the items on this survey.

\section{Statement}

1. I have a purpose in mind when I read. 12345

2. I take notes while reading to help me understand what I read. 12345

3. I think about what I know to help me understand what I read. 12345

4. I take an overall view of the text to see what it is about before reading it. 12345

5. When text becomes difficult, I read aloud to help me understand what I read. 12345

6. I think about whether the content of the text fits my reading purpose. 12345

7. I read slowly and carefully to make sure I understand what I am reading. 12345

8. I review the text first by noting its characteristics like length and organization. 12345

9. I try to get back on track when I lose concentration. 12345

10. I underline or circle information in the text to help me remember it. 12345

11. I adjust my reading speed according to what I am reading. 12345

12. When reading, I decide what to read closely and what to ignore. 12345

13. I use reference materials (e.g. a dictionary) to help me understand what I read. 12345 
14. When text becomes difficult, I pay closer attention to what I am reading. 12345

15. I use tables, figures, and pictures in text to increase my understanding. 12345

16. I stop from time to time and think about what I am reading. 12345

17. I use context clues to help me better understand what I am reading. 12345

18. I paraphrase (restate ideas in my own words) to better understand what I read. 12345

19. I try to picture or visualize information to help remember what I read. 12345

20. I use typographical features like bold face and italics to identify key information. 12345

21. I critically analyze and evaluate the information presented in the text. 12345

22. I go back and forth in the text to find relationships among ideas in it. 12345

23. I check my understanding when I come across new information. 12345

24. I try to guess what the content of the text is about when I read. 12345

25. When text becomes difficult, I re-read it to increase my understanding. 12345

26. I ask myself questions I like to have answered in the text. 12345

27. I check to see if my guesses about the text are right or wrong. 12345

28. When I read, I guess the meaning of unknown words or phrases. 12345

29. When reading, I translate from English into my native language. 12345

30. When reading, I think about information in both English and my mother tongue. 12345 


\section{APENDIX C: SEMI-STRUCTURED INTERVIEW}

1. How do you see yourself as a reader?

2. What makes a good reader?

3. How did you learn to read in your first language?

4. How did you learn to read in English?

5. How similar or different was to learn to read in your first language and in English?

6. What are the challenges that you face while reading in English? What are the difficulties of reading in English?

7. How do you overcome those difficulties of reading in English?

8. How similar or different is reading in English and in your first language?

9. Can you tell about any reading strategy that you think is specific for English reading?

10. Do you think there is anything you can do to become a better reader?

11. If so how would you proceed to become a better reader? 


\section{APPENDIX D: TEXT 1}

\section{The transcendental revelations of astronauts}

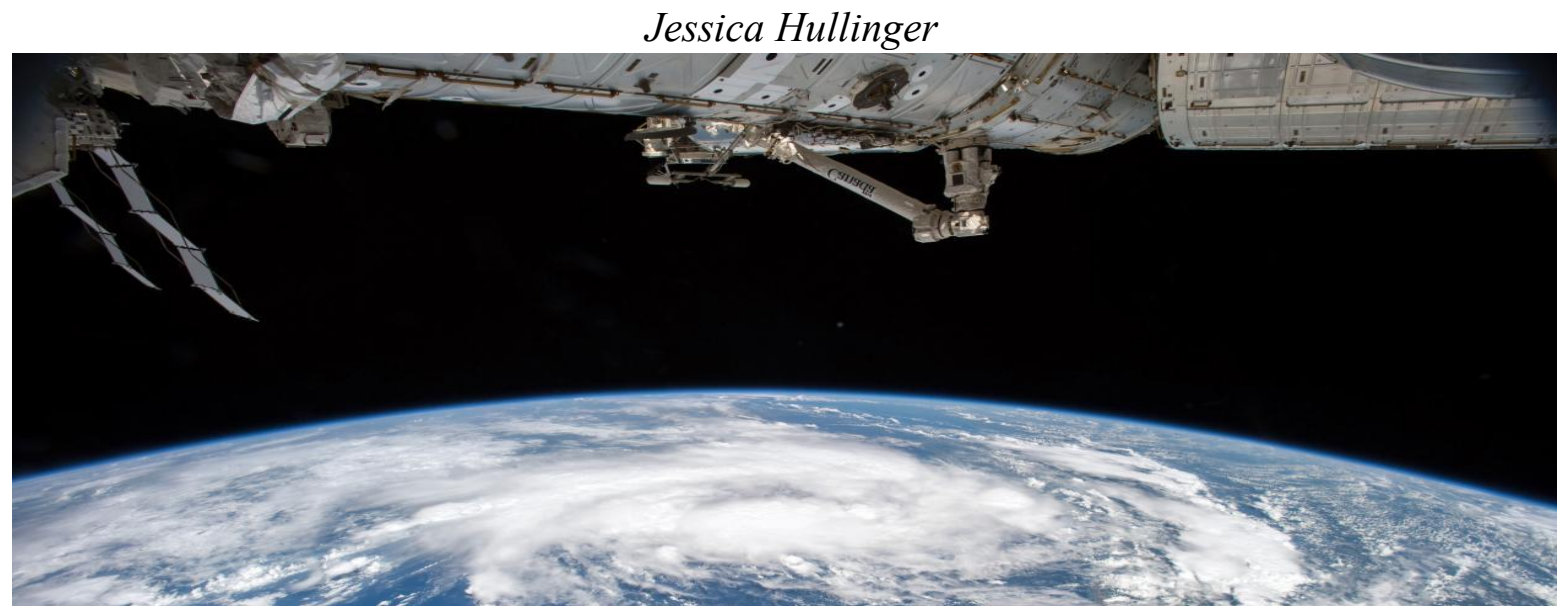

NASA

April 28, 2016

Astronaut Kjell Lindgren spent close to five months on the International Space Station last year serving as a NASA flight engineer and mission specialist. He still remembers the first time he saw the Earth from space.

"I saw this really bright white light coming through the small windows of the Soyuz capsule," he told The Week. "I took a peek and saw the beautiful blue and whites of the Earth below, and the curvature of the horizon. Getting to experience the whole disc of the Earth from that point of view, truly for me, it was this breathtaking experience. I got goosebumps."

Humans have been going to space for five decades now, and during that time, numerous astronauts have returned from orbit with reports eerily similar to Lindgren's. Theirs are tales of profound inspiration, overwhelming emotion, a sense of oneness, even transcendence.

"No amount of prior study or training can fully prepare anybody for the awe and wonder this inspires," wrote space shuttle astronaut Kathryn D. Sullivan. It's "one of the deepest, most emotional experiences I have ever had," said NASA astronaut Gene Cernan. "You realize that on that small spot, that little blue and white thing, is everything that means 
anything to you," said Apollo 9 astronaut Russell Schweickart. "All of history and music and poetry and art and death and birth and love, tears, joy, games, all of it on that little spot out there."

In 1987, this phenomenon was given a name: the Overview Effect. Here's how it's defined by the Overview Institute:

[The Overview Effect] refers to the experience of seeing firsthand the reality of the Earth in space, which is immediately understood to be a tiny, fragile ball of life, hanging in the void, shielded and nourished by a paper-thin atmosphere. From space, the astronauts tell us, national boundaries vanish, the conflicts that divide us become less important and the need to create a planetary society with the united will to protect this "pale blue dot" becomes both obvious and imperative.

Or, as Apollo 14 astronaut Edgar Mitchell perfectly and simply put it, "Something happens to you out there."

Indeed, for many astronauts, seeing the Earth from above does more than fill them with a fleeting sense of wonder. It changes them. Mitchell was so moved by his time in space that he launched the Noetic Institute to learn more about human consciousness. And Schweickart? He began practicing transcendental meditation upon his return. Others devote their lives to religion or find a renewed sense of faith.

But despite its life-altering potential, the Overview Effect has never really been studied empirically. David Yaden wants to change that. He's a research scientist at the University of Pennsylvania's Positive Psychology Center, where he studies spiritual and selftranscendent experiences through the lenses of psychology and neuroscience. He's also the lead author on a new paper published in the journal Psychology of Consciousness: Theory, Research, and Practice that examines what, exactly, the Overview Effect does to the mind, and how its powers could be harnessed to promote health. 
His conclusion? The Overview Effect elicits a sense of awe in its purest, most intense form. Emotion researchers have only recently begun studying the effects of awe, but they believe we experience awe when we are confronted with something vast, either physically big (the Grand Canyon, for example) or conceptually huge (like meeting your favorite celebrity). For a moment, this vastness confuses the mind, and forces the brain to accommodate by making room for what it's seeing.

"The Overview Effect seems to contain both of those aspects of awe," Yaden told The Week. "You're seeing an entire half of the planet all at once, which is vast beside the blackness of space. But on the conceptual side, Earth represents all we find meaningful as human beings. Many of the astronauts discuss this aspect as well, seeing the fragility and the beauty of the planet at once and having this epiphany or realization of how precious the planet is and how much we need to do more to protect it."

Back on Earth, awe has been linked to pro-social behavior, altruism, and inclusive thinking. But it's also been shown to have positive effects on everything from creativity to physical health. One study linked higher instances of wonder to lower levels of harmful, disease-linked inflammation markers, even more so than other positive emotions like love and joy. And indeed, awe can change people's lives. Many a come-to-Jesus epiphany religious or not — have been preceded by staggeringly awesome experiences.

Yaden believes the Overview Effect, and the awe it elicits, should be taken into consideration as we consider sending astronauts deeper into space on longer, more isolating missions. He hopes to work with space agencies like NASA on mission planning. "It's not just about avoiding mental illness," he says. "It's about promoting mental health. So as simple as it may sound, one implication of our research is, if you're gonna send people to Mars, you should have windows." 
Unfortunately, most of us will never have the privilege of going to space. How can we get a taste of the Overview Effect without leaving the confines of gravity? "We don't need to go to space to benefit from intense experiences of awe," Yaden says. "We can experience a little bit of the Overview Effect on mountain tops or by viewing a beautiful sunset. There are a lot of opportunities for these experiences that are all around us." So put down the smartphone. Go outside and take in the view. Glance up at the stars and ponder your very existence on our own pale blue dot, and let the awe wash over you. 


\section{APPENDIX E: TEXT 2}

The scientific case for being super busy

\section{Tammy Kennon}

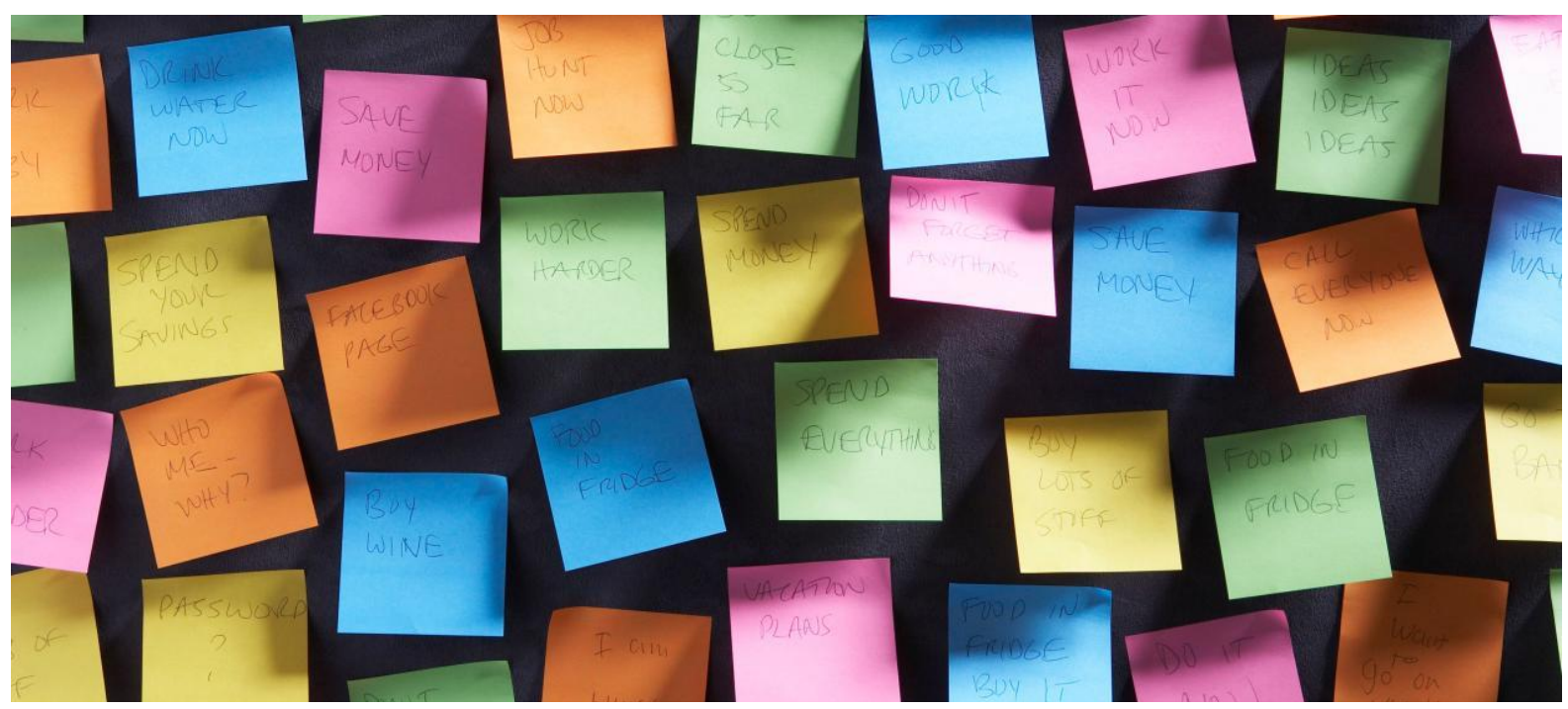

Radius Images / Alamy Stock Photo

May 26, 2016

At some point, our lives went from busy to super busy to crazy busy. But despite our packed schedules, we still seem to find ample time to complain about how busy we are. All this busyness distracts, causes stress, and undermines our health — or so we're told. We're constantly bombarded with headlines screaming at us to Slow down! Unplug! Be mindful! We have framed the act of being busy as a burden. Busy is bad.

But in a new study, scientists found evidence that keeping an active schedule might not be so bad, after all. In fact, it might actually improve cognitive function as we age. In other words, being busy may be good for the brain.

The findings, from the University of Texas at Dallas, show that maintaining a busy schedule later in life is directly associated with increased brain activity.

"Often busyness carries a negative connotation, as people tend to complain about their hectic schedules," the authors write. "Yet, little scientific work has been done to empirically investigate the construct of busyness and its associations." 
To fill that gap, the researchers devised a study to examine the relationship between busyness and cognition. More than 300 participants, aged 50 to 89, answered questions about their levels of "busyness," such as how busy they are on an average day and how often they are so busy they have to go to bed later than normal. Then they spent two to three hours over two days undergoing a battery of tests designed to measure various cognitive functions, such as processing speed, reasoning, working memory, and episodic long-term memory, which is memory of personal events and their context.

In one test, subjects had 45 seconds to identify whether two strings of up to nine digits were identical or different. In another, the subjects were asked to read aloud a series of words and then try to recall them afterwards.

The busyness questionnaire alone revealed some basic trends across age, gender, and education: Perhaps predictably, younger adults reported being busier than the elderly. Also, women were busier than men. In comparing levels of education, the data showed that the highly educated consistently reported the highest levels of "busyness."

But it was in comparing the busyness scale with the cognitive testing results where things got really interesting. Greater busyness was directly associated with higher cognition, and this was the case regardless of gender or education. And perhaps most interesting of all, the data showed that this relationship between busyness and cognitive acuity did not vary with age. A busy 89 -year-old person had the same cognitive sharpness as someone almost 40 years younger.

So can we say that living an active lifestyle after 50 means better brain function? Not quite.

"Living a busy lifestyle appears beneficial for mental function," says Sara Festini, the postdoctoral student who is lead author of the study. But it's not clear whether people with higher cognitive function seek a busier lifestyle in the first place, versus the idea that staying 
active results in improved brain activity. In other words, no cause-and-effect could be determined based solely on this study.

But there is a growing body of evidence suggesting activity and continued learning does positively affect the brain and memory. For instance, a 2013 study at the Center for Vital Longevity found that sustained engagement in learning new skills such as quilting or digital photography enhanced memory function in older adults. Just last year, a study at the University of Kansas Medical Center found that exercise improved brain function in older adults.

The challenge, it seems, is crafting an active lifestyle without stressing about it so much. An ever-increasing number of studies proclaim the harmful effects of stress, everything from accelerated aging to shortening lifespans to a higher risk of alcoholism and even an increase in our susceptibility to panic attacks. The list itself is stressful.

Maybe all it takes to mitigate our stressed-out reaction to being busy is a shift in mindset. The Mayo Clinic's stress management advice suggests "the positive thinking that typically comes with optimism is a key part of effective stress management." They go on to say the benefits of positive thinking include lower rates of depression, increased lifespan, greater resistance to illness, and reduced risk of death from cardiovascular disease.

Perhaps the best takeaway from this new study might be taking a second look at how we think about "busy." By acknowledging the potential benefits of an active life, busy becomes a positive — or at least not all bad.

Even though this study alone can't tell us conclusively that busyness increases cognitive function, maybe it can fundamentally shift our snarky relationship with our bustling lifestyles. Reframe crazy busy as pleasantly full. Doesn't that already sound less stressful? 
Name: P-1 -Azim Date: $6-24$

Title: The transcendental revelations of astronauts - Text 1

Words (read): 956 - he read 945 words. Started reading in the first paragraph

Genre: Scientific - informational

Text Features: Title; author's name; concrete image - on the bottom part of earth, top a spaceship, black space between spaceship and earth.

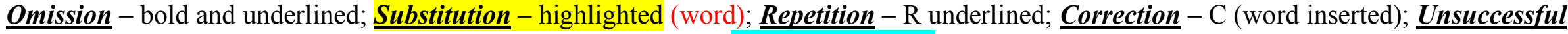

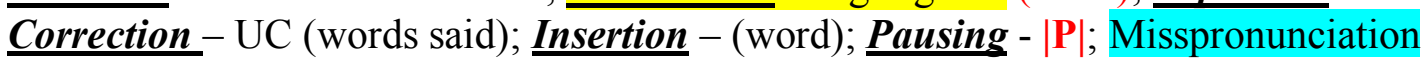

Started: 48:41 Finished

\begin{tabular}{|c|c|c|c|c|c|}
\hline $\mathrm{Pg} / \mathrm{Ln}$ & $\begin{array}{c}\mathrm{E}=\text { errors } \quad \mathrm{SC}=\text { self-correction } \\
\mathrm{M}=\text { meaning/semantics } \quad \mathrm{S}=\text { structure/syntax } \mathrm{V}=\text { visual }\end{array}$ & E & $\mathrm{SC}$ & $\begin{array}{l}\text { E } \\
\text { M S V }\end{array}$ & $\begin{array}{c}\text { SC } \\
\text { M S V }\end{array}$ \\
\hline $1-1$ & $\begin{array}{l}\text { 1Astronaut(\$Astonot) Kjell Lindgren spent close to five 2months on the International Space Station } \\
\text { last year serving as a }\end{array}$ & $1 ; 2$ & & $\begin{array}{l}\text { 1Pr; } 2 \mathrm{~S} \\
\mathrm{~V}\end{array}$ & \\
\hline $1-2$ & $\begin{array}{l}\text { NASA flight engineer and mission (UC) } 1 \text { specialist (1-\$sublie; 2-subcelest). He still 2remembers } \\
\text { (3that) the first time he saw the Earth from space. }\end{array}$ & $1 ; 2 ; 3$ & & $\begin{array}{l}1 \mathrm{PrM} ; \\
2 ; 3 \mathrm{~S}\end{array}$ & \\
\hline $1-3$ & $\begin{array}{l}\text { "I saw this really bright white light coming through the small 1windows of } 2 \text { the Soyuz capsule," } \\
\text { ( } \mathrm{he} \text { told The }\end{array}$ & 12 & & $1 \mathrm{M} ; 2 \mathrm{~S}$ & \\
\hline $1-4$ & $\begin{array}{l}\circledR W e e k \text {. "I took a 1peek /bi:k/and saw the beautiful blue and } 2 \text { whites of } 3 \text { the Earth } 4 @ \text { Cbelow (blue } \\
\text { ( below), and the }|\mathbf{P}| 5 \text { curvature (UC-1- con; 2-the conver; 3- covert)of the }\end{array}$ & $1 ; 2 ; 3$ & 4 & $\begin{array}{l}1 ; 5 \mathrm{Pr} \\
2 \mathrm{M} \\
3 \mathrm{~S}\end{array}$ & $\begin{array}{c}4 \\
\text { MSV }\end{array}$ \\
\hline $1-5$ & $\begin{array}{l}\text { horizon. Getting to experience } 1 \text { the (to) } 2 \text { whole (all) }(\text { disc (desk, disc) of the Earth from } 3 \text { (the) } \\
\text { that point of view, truly for me, it was this }\end{array}$ & 123 & & $1 ; 3 \mathrm{~S} 2$ & \\
\hline $1-6$ & Breath|P|taking experience. I 1 got (get) goosebumps." & 1 & & $\begin{array}{l}\mathrm{S} \\
\mathrm{ta}\end{array}$ & \\
\hline
\end{tabular}




\begin{tabular}{|c|c|c|c|c|c|}
\hline $\mathrm{Pg} / \mathrm{Ln}$ & $\begin{array}{cc}\mathrm{E}=\text { errors } & \mathrm{SC}=\text { self-correction } \\
\mathrm{M}=\text { meaning/semantics } & \mathrm{S}=\text { structure } / \text { syntax } \quad \mathrm{V}=\text { visual }\end{array}$ & $\mathrm{E}$ & $\mathrm{SC}$ & $\begin{array}{c}\text { E } \\
\text { M S V }\end{array}$ & $\begin{array}{c}\text { SC } \\
\text { M S V }\end{array}$ \\
\hline $1-7$ & $\begin{array}{l}\text { Humans have been going to space for five } 1 \text { decades (decedes) now and during that time, } \\
2 \text { nu }|\mathrm{P}| \text { merous }(\$) \text { 3astro }|\mathrm{P}| \text { nauts have }\end{array}$ & 123 & & $1 ; 2 ; 3 \operatorname{Pr}$ & \\
\hline $1-8$ & $\begin{array}{l}\text { returned from orbit with 1(the) 2reports } 3 \text { eeri|P|ly (early) similar to }{ }^{\circledR} \underline{\underline{\text { Lindgren's. }}} .|\mathbf{P}| \text { Theirs are } \\
\text { 4tales (talls) of profound 5inspiration, }(\mathrm{UC} \text { - ines, inespertation, inspertion; three times) }\end{array}$ & $\begin{array}{c}123 \\
45\end{array}$ & & $\begin{array}{l}1 \mathrm{~S} ; 2 \mathrm{M} \\
3 \mathrm{MV} ; \\
4 ; 5 \mathrm{Pr}\end{array}$ & \\
\hline $1-9$ & 1Over|whelming (overwarming) emotion, a sense of 2 (or) $|\mathbf{P}|$ one $\mid$ ness, ${ }^{\circledR}$ even $|\mathbf{P}|$ trans $\mid$ cendence. & 12 & & $\begin{array}{c}1 \mathrm{Pr} \\
2 \mathrm{MSV}\end{array}$ & \\
\hline $1-10$ & $\begin{array}{l}\text { "No amount of } 1 \text { prior } \$ \text { (perior) study or training can fully prepare anybody for }{ }^{\circledR} \text { the }(4 X) \text { 2awe } \\
\text { (Oh, this word!) and } 3 \text { wonder } \$(\text { wender) this } 4 \text { inspires } \$ \text { (inspire)," }\end{array}$ & $\begin{array}{l}1 ; 2 ; 3 \\
4\end{array}$ & & $\operatorname{Pr}$ & \\
\hline $1-11$ & $\begin{array}{l}\text { wrote space shuttle }{ }^{\circledR} \underline{\text { astronaut }}\left(3 X ; 1^{\text {st }} \text { read everything; } 2^{\text {nd }} \text { broke it down on syllables; } 3 \text { read at }\right. \\
\left.\text { once) Kathryn } \mathbb{C} \text { D } \text {. }^{\text {st }} \text { the }(d e \text { in his language }), 2^{\text {nd }} \text { doc; } 3^{\text {rd }} D\right) \text { Sullivan. It's "one of the } 2 \text { deepest } \\
\text { /thebest/, most emotional 3experiences I }\end{array}$ & $2 ; 3$ & 1 & $\begin{array}{l}2 \mathrm{PrM} \\
3 \mathrm{M}\end{array}$ & $1 \mathrm{Pr}$ \\
\hline $1-12$ & $\begin{array}{l}\text { have ever had," said NASA astronaut Gene Cernan. "You realize that on that small 1spot (part), } \\
\text { that little blue and }\end{array}$ & 1 & & M & \\
\hline $1-13$ & $\begin{array}{l}\text { white thing(s), is everything } 1 \text { that (it's) } 2 \text { means anything to you," said Apollo } 9 \text { astronaut Russell } \\
|\mathbf{P}| \text { Schweickart (I don't know. All of the names confuse me). "All of }\end{array}$ & 12 & & $\begin{array}{l}1 \mathrm{M} \mathrm{S} \\
2 \mathrm{~S}\end{array}$ & \\
\hline $\begin{array}{l}1-14 \\
1-15\end{array}$ & $\begin{array}{l}\text { history and music and poetry and art and death and } 1 \text { birth (breath) and love, 2tears (trees), joy, } \\
3 \text { games, all of it } 4 \text { on that little } \\
\text { spot out there." }\end{array}$ & $1 ; 2 ; 3$ & & $\begin{array}{l}1 ; 2 ; 3 \mathrm{M} \\
\mathrm{V} ; 4 \mathrm{~S}\end{array}$ & \\
\hline $1-16$ & $\begin{array}{l}\text { In } 19 \mid 87 \text {, this phenomenon was given a name: The Overview Effect. 1Here's how it's } 2 \text { defined } \\
\text { (defend) by the Overview }\end{array}$ & 12 & & $\begin{array}{c}1 \mathrm{~S} \\
2 \mathrm{MV}\end{array}$ & \\
\hline $1-17$ & Institute: & & & & \\
\hline $1-18$ & $\begin{array}{l}\text { [The Overview Effect] refers to the experience of seeing firsthand } 1{ }^{\circledR} \text { the reality (C3times - the } \\
\text { relea, reale, rality) of the Earth in space, which is }\end{array}$ & 1 & & $\operatorname{Pr}$ & \\
\hline $1-19$ & $\begin{array}{l}\text { immediately understood to be a } 1 \text { tiny (teny), } 2 ® \text { frag/g/ile ball of life, hanging }{ }^{\circledR} \underline{\underline{\text { in the }}} \text { void, } 3 \\
\text { shielded (UC, } 2 \text { times; } 1^{\text {st }} \text { chil; } 2^{\text {nd }} \text { shelded) and nourished by a }\end{array}$ & $1 ; 2 ; 3$ & & $3 \operatorname{Pr}$ & \\
\hline
\end{tabular}




\begin{tabular}{|c|c|c|c|c|c|}
\hline $\mathrm{Pg} / \mathrm{Ln}$ & $\begin{array}{cc}\mathrm{E}=\text { errors } & \mathrm{SC}=\text { self-correction } \\
\mathrm{M}=\text { meaning/semantics } & \mathrm{S}=\text { structure/syntax } \quad \mathrm{V}=\text { visual }\end{array}$ & $\mathrm{E}$ & $\mathrm{SC}$ & $\begin{array}{c}\text { E } \\
\text { M S V }\end{array}$ & $\begin{array}{c}\text { SC } \\
\text { M S V }\end{array}$ \\
\hline $1-20$ & $\begin{array}{l}\text { paper- } 1 @\left(1^{\text {st }} \text { than; } 2^{\text {nd }} \text { thin) (than) thin atmosphere. From space, the astronauts tell us, }{ }^{\circledR} \underline{\underline{\text { national }}}\right. \\
2 \text { boun|daries(banderias) vanish, the conflicts that }\end{array}$ & 2 & 1 & $2 \mathrm{Pr}$ & $1 \mathrm{MSV}$ \\
\hline $1-21$ & $\begin{array}{l}\text { (R) } 1 \text { divide(David) us become less important and the need to create a planetary } 2 \text { society (sociate) } \\
\text { with the 3Cunited (3X; } 1^{\text {st }} \text { - united; } 2^{\text {nd }} \text { unit; } 3 \text { united) will to protect }\end{array}$ & $1 ; 2$ & 3 & $\begin{array}{l}1 \mathrm{MSV} ; \\
2 \mathrm{Pr}\end{array}$ & $\begin{array}{l}3 \text { proce } \\
\text { ssing } \\
\text { meani } \\
\text { ng }\end{array}$ \\
\hline $1-22$ & $\begin{array}{l}\text { this "pale }(C) 1 \text { blue }\left(1^{\text {st }} \text {-below; } 2 \text {-blue }\right) \text { dot" } 2 \text { becomes }\left(1^{\text {st }}-\text { become; } 2^{\text {nd }} \text { becomed }- \text { corrected Pron }\right) \\
\text { both obvious and imperative. }\end{array}$ & 2 & 1 & $2 \mathrm{~S}$ & $1 \mathrm{MSV}$ \\
\hline $2-1$ & $\begin{array}{l}\text { Or, as Apollo } 14 \text { astronaut Edgar }|\mathrm{P}| \text { Mitchell perfectly and simply put it, "Something 1happens to } \\
\text { you out }\end{array}$ & 1 & & $1 \mathrm{~S}$ & \\
\hline $2-2$ & there." & & & & \\
\hline $2-3$ & $\begin{array}{l}\text { Indeed, for many lastronauts } \$ \text {, seeing the Earth from above does more than } 2 \text { fill (file) them }|\mathrm{P}| \\
\text { with a fleeting sense of }\end{array}$ & 12 & & $\begin{array}{l}\text { 1Pr } \\
\text { 2VMS }\end{array}$ & \\
\hline $2-4$ & $\begin{array}{l}\text { wonder. It } 1 \text { changes } \text { them. }{ }^{\circledR} \text { Mitchell was so moved by his time in space that he } \\
\text { 2launched(lanched) the Noetic 3Institute (inestitute) }\end{array}$ & 123 & & $\begin{array}{l}1 \mathrm{SV} ; 2 \\
3 \mathrm{Pr}\end{array}$ & \\
\hline $2-5$ & $\begin{array}{l}\text { to learn more about human } 1(\mathrm{UC}) \text { consciousness }\left(1^{\text {st }} \text { conse; } 2^{\text {nd }} \text { consequences; } 3 \text { consequences). }\right. \\
\text { And Schweickart? He began } 2\left(\mathrm{C} / \mathrm{p} / \text { racticing }{ }^{\circledR} 3 \text { transcendental (breaking down the word) }\right.\end{array}$ & $1 ; 2$ & & $1 ; 2 \operatorname{Pr}$ & \\
\hline $2-6$ & $\begin{array}{l}\text { 1meditation (mediation) upon his return. Others devote their lives to religion or find a } \subseteq 2 \text { renewed } \\
\text { (new; renewed) sense of faith. }\end{array}$ & 1 & 2 & $1 \mathrm{MV}$ & $2 \mathrm{MV}$ \\
\hline $2-7$ & $\begin{array}{l}\text { But } 1 \text { despite(despete) its } 2 \text { life (lie)-altering potential, the Overview Effect has never }{ }^{\circledR} \text { really been } \\
\text { studied } \mathbb{C} 3 \text { empirically (1-empirical, empirically). David }\end{array}$ & $1 ; 2$ & 3 & $\begin{array}{l}\text { 1Pr; } \\
2 \mathrm{MV}\end{array}$ & $3 \mathrm{VS}$ \\
\hline $2-8$ & $\begin{array}{l}{ }^{\circledR} \text { Yaden 1wants to change that. He's a }{ }^{\circledR} \text { research } 2 \text { scientist ( } 3 X \text {; science, scientist, scientist) at the } \\
\text { University of }|\mathrm{P}| \text { Pennsylvania's (not count as miscue because it's a noun) }|\mathrm{P}| \text { Positive }\end{array}$ & 1 & 2 & $1 \mathrm{~S}$ & $2 \mathrm{~S}$ \\
\hline $2-9$ & 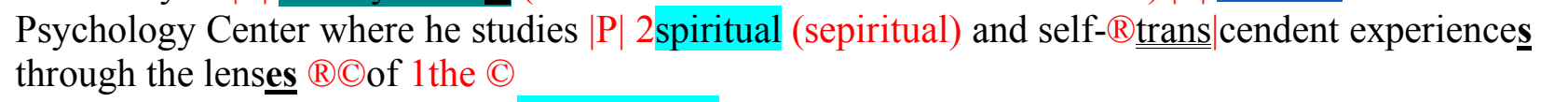 & 1 Ins & & 1S & $1 \mathrm{~S}$ \\
\hline $2-10$ & $\begin{array}{l}\text { psychology and }|\mathrm{P} 58: 22-58: 31| \text { neuroscience } 1 \$ \text { (newosense). He's also the lead }(\mathrm{C} 2 \text { author (other; } \\
\text { author) on a new paper published in the journal } 3 \text { Psychology (Psychologies) }\end{array}$ & $1 ; 3$ & 2 & $\begin{array}{l}1 \mathrm{Pr} \\
3 \mathrm{M}\end{array}$ & $2 \mathrm{MSV}$ \\
\hline
\end{tabular}




\begin{tabular}{|c|c|c|c|c|c|}
\hline $\mathrm{Pg} / \mathrm{Ln}$ & $\begin{array}{cc}\mathrm{E}=\text { errors } & \mathrm{SC}=\text { self-correction } \\
\mathrm{M}=\text { meaning/semantics } & \mathrm{S}=\text { structure } / \text { syntax } \quad \mathrm{V}=\text { visual }\end{array}$ & $\mathrm{E}$ & $\mathrm{SC}$ & $\begin{array}{c}\mathrm{E} \\
\mathrm{M} \mathrm{S} \mathrm{V}\end{array}$ & $\begin{array}{c}\text { SC } \\
\text { M S V }\end{array}$ \\
\hline $2-11$ & $\begin{array}{l}\text { of } 1 \text { Consciousness(consequences): Theory, Research, and Practice that examines what, exactly, } \\
\text { the Overview Effect does }\end{array}$ & 1 & & $1 \mathrm{M}$ & \\
\hline $2-12$ & to the mind, and how its powers could be ${ }^{\circledR}$ harnessed to ${ }^{\circledR}$ promote health. & & & & \\
\hline $2-13$ & $\begin{array}{l}\text { His conclusion? The Overview Effect }{ }^{\circledR} 1 \text { elicits (elekts)a 2(UC)sense (science) of awe in its } \\
3 \mathrm{p} / \mathrm{b} / \text { urest, most 4@intense (inno; intense) } 5 \text { form (from). Emotion }\end{array}$ & $1 ; 2 ; 35$ & 4 & $\begin{array}{l}1 ; 3 \mathrm{Pr} \\
2 \mathrm{M} \\
5 \mathrm{MSV}\end{array}$ & $4 \operatorname{PrM}$ \\
\hline $2-14$ & $\begin{array}{l}\text { 1researchers have only recently } 2 \text { begun (begin) studying the } 3 \text { effects of awe, but they believe we } \\
\text { experience awe when }\end{array}$ & 123 & & $\begin{array}{l}1 ; 3 \mathrm{M} ; \\
2 \mathrm{SV}\end{array}$ & \\
\hline $2-15$ & $\begin{array}{l}\text { we are }{ }^{\circledR} \text { confronted with something 1 vast (vest, vast), either }{ }^{\circledR} \text { physically big (the Grand Canyon, } \\
\text { for example) or }\end{array}$ & & 1 & & $\operatorname{Pr}$ \\
\hline $2-16$ & $\begin{array}{l}\text { con }|\mathrm{P}| \text { ceptually huge (like meeting your } 1 \text { favorites celebrity). For a moment, this } 2 \mathbb{C} \text { vastness } \\
\text { (2vest; } 3 \text { vastness) } 3 \text { confuses the mind, }\end{array}$ & $1 ; 3$ & 2 & $1 ; 3 \mathrm{~S}$ & 2PrM \\
\hline $2-17$ & $\begin{array}{l}\text { and } 1 \text { forces the brain to } @ 2 \text { accommodate ( } \$ \text { accomande; accommodate) by making room for what } \\
\text { (it's seeing. }\end{array}$ & 1 & 2 & $1 \mathrm{SV}$ & $2 \mathrm{Pr}$ \\
\hline $2-18$ & $\begin{array}{l}\text { "The Overview Effect seems to }|\mathrm{P}|{ }^{\circledR} \text { con } \underline{\underline{\text { tain }}} \text { both of those } 1 \text { (these) aspects of awe," Yaden } \\
\text { told The Week. "You're seeing }\end{array}$ & 1 & & $1 \mathrm{~S}$ & \\
\hline $2-19$ & $\begin{array}{l}\text { an entire half of the planet all at once, which is vast } 1 \text { beside (based) the } \mathbb{C} \text { 2blackness (blank; } \\
\text { blackness) of space. But } 3 \text { on the }|\mathrm{P}| \text { conceptual }\end{array}$ & $1 ; 3$ & 2 & $\begin{array}{l}1 \mathrm{MSV} \\
3 \mathrm{~S}\end{array}$ & $2 \operatorname{Pr}$ \\
\hline $2-20$ & $\begin{array}{l}1 \text { side (said), Earth } 2 \text { represents all we find }(3) \text { meaningful (motion, meaningful) as human beings. } \\
\text { Many of the astronauts } 4 \text { discuss (decide) this aspect as }\end{array}$ & $1 ; 2 ; 4$ & 3 & $\begin{array}{l}1 \mathrm{SMV} ; \\
2 \mathrm{~S} ; 4 \mathrm{M}\end{array}$ & $3 \mathrm{M}$ \\
\hline $2-21$ & $\begin{array}{l}\text { well, seeing the } 1 \mathrm{frag} / \mathrm{g} / \mathrm{ility} \text { and the beauty of the planet at once and having this }|\mathrm{P}| \text { epiphany or } \\
\text { realization of how }\end{array}$ & 1 & & $1 \mathrm{Pr}$ & \\
\hline $2-22$ & pre cious 1 the (that) planet is and how much we need to do more to prote & 1 & & $1 \mathrm{~S}$ & \\
\hline $2-23$ & $\begin{array}{l}\text { Back on Earth, awe has been linked to pro-social behavior, }|\mathrm{P}| \text { altruism, and }{ }^{\circledR} \underline{\underline{\text { inclu }}} \underline{\underline{\text { sive }}} 1 \text { thinking } \\
\text { (thinks). But it's also }\end{array}$ & 1 & & $1 \mathrm{SV}$ & \\
\hline $2-24$ & $\begin{array}{l}\text { been } 1 \text { shown (showing) to have positive effects on everything from creativity to physical health. } \\
\text { One study linked }\end{array}$ & 1 & & $\mathrm{~S}$ & \\
\hline
\end{tabular}




\begin{tabular}{|c|c|c|c|c|c|}
\hline $\mathrm{Pg} / \mathrm{Ln}$ & $\begin{array}{cc}\mathrm{E}=\text { errors } & \mathrm{SC}=\text { self-correction } \\
\mathrm{M}=\text { meaning/semantics } & \mathrm{S}=\text { structure } / \text { syntax } \quad \mathrm{V}=\text { visual }\end{array}$ & E & $\mathrm{SC}$ & $\begin{array}{c}\text { E } \\
\text { M S V }\end{array}$ & $\begin{array}{c}\text { SC } \\
\text { M S V }\end{array}$ \\
\hline $2-25$ & $\begin{array}{l}\text { Higher }{ }^{\circledR} 1 \\
\text { inflammation } \\
\text { (2information; inflammation) markers, even more so }\end{array}$ & 1 & 2 & $1 \operatorname{Pr}$ & $2 \mathrm{MV}$ \\
\hline $2-26$ & $\begin{array}{l}\text { than other positive emotions like love and joy. And indeed, awe can change } 1 \text { people's lives. Many } \\
\text { a come- }\end{array}$ & 1 & & $1 \mathrm{SV}$ & \\
\hline $2-27$ & $\begin{array}{l}\text { to-Jesus }|\mathrm{P}| \text { epiphany - }{ }^{\circledR} \underline{\underline{\text { religious }}} \text { or not — have been } 1 \text { preceded (proceeded) by } \\
(\mathbb{C} \text { C2staggeringly 3awesome (wheresome) experiences. }\end{array}$ & $1 ; 3$ & $2 \operatorname{Pr}$ & $\begin{array}{l}1 \mathrm{MV} ; \\
3 \mathrm{Pr} \\
1 ; 3 \mathrm{SV}\end{array}$ & $2 \operatorname{Pr}$ \\
\hline $2-28$ & $\begin{array}{l}\text { Yaden } 1 \text { believes the Overview Effect, and the }{ }^{\circledR} 2 \text { awe } 3 \text { it's } 4(\mathrm{UC}) \text { eli|cits (elects), should be taken } \\
\text { into }{ }^{\circledR} \text { consi } \text { deration as we }\end{array}$ & $\begin{array}{l}1 ; 2 ; 3 ; \\
4\end{array}$ & & $\begin{array}{l}2 \mathrm{Pr} ; \\
4 \mathrm{Pr} ; \mathrm{M} \\
\mathrm{V}\end{array}$ & \\
\hline $2-29$ & $\begin{array}{l}\text { con|sider sen|ding }{ }^{\circledR} \text { astronauts } 1 \text { deep/b/er into space on longer, more } \mathbb{C} 2 \text { isolating (isolation; } \\
\text { isolating) } 3 \text { missions (musicians). He hopes to work with }\end{array}$ & $1 ; 3$ & 2 & $\begin{array}{l}1 \mathrm{Pr} \\
3 \mathrm{M}\end{array}$ & $\begin{array}{l}2 \text { proce } \\
\text { ssing } \\
\text { meani } \\
\text { ng }\end{array}$ \\
\hline $2-30$ & 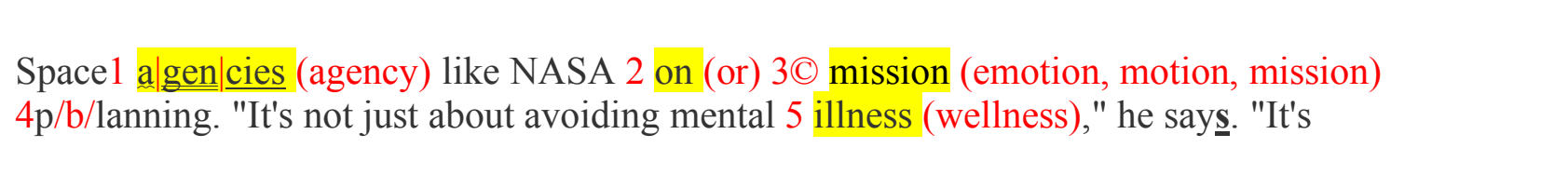 & $\begin{array}{l}1 ; 2 ; 4 ; \\
5\end{array}$ & 3 & $\begin{array}{l}1 \mathrm{MV} \\
2 \mathrm{SM} \\
4 \mathrm{Pr} \\
5 \mathrm{M}\end{array}$ & $3 \mathrm{M}$ \\
\hline $2-31$ & $\begin{array}{l}\text { about promoting mental health. So as simple as it may sound, one implication of our research is, if } \\
\text { lyou're }\end{array}$ & 1 & & $1 \mathrm{~S}$ & \\
\hline $2-32$ & gonna send people to Mars, $|\mathrm{P}|$ you should have windows." & & & & \\
\hline $2-33$ & $\begin{array}{l}\circledR \text { Unfortunately, most of us will never have the privilege of going to space. How can we get a taste } \\
\text { of the }\end{array}$ & & & & \\
\hline $2-34$ & $\begin{array}{l}\text { Overview Effect without leaving the confines of gravity? "We don't need to go to space to benefit } \\
\text { from }\end{array}$ & & & & \\
\hline $2-35$ & $\begin{array}{l}\text { intense experiences of }{ }^{\circledR} \underline{\underline{\text { awe }}}, "{ }^{\circledR} \text { Yaden says. "We can experience a little bit of the Overview } \\
\text { Effect on }\end{array}$ & $1 \mathrm{I}$ & & $1 \mathrm{~S}$ & \\
\hline
\end{tabular}




\begin{tabular}{|c|c|c|c|c|c|}
\hline $\mathrm{Pg} / \mathrm{Ln}$ & $\begin{array}{cc}\mathrm{E}=\text { errors } & \mathrm{SC}=\text { self-correction } \\
\mathrm{M}=\text { meaning/semantics } & \mathrm{S}=\text { structure } / \text { syntax } \quad \mathrm{V}=\text { visual }\end{array}$ & $\mathrm{E}$ & $\mathrm{SC}$ & $\begin{array}{c}\text { E } \\
\text { M S V }\end{array}$ & $\begin{array}{c}\text { SC } \\
\text { M S V }\end{array}$ \\
\hline $2-36$ & $\begin{array}{l}{ }^{R} \underline{\underline{m o u n t a i n}} \text { tops or by viewing a beautiful sun } \underline{\text { set. There are a lot of } 1 \text { opportunities (opportunity) }} \\
2 \text { for (or) these experiences that }\end{array}$ & $1 ; 2$ & & $\begin{array}{l}1 \mathrm{M} ; \\
2 \mathrm{SM}\end{array}$ & \\
\hline $2-37$ & $\begin{array}{l}\text { are all around us." So put down the smartphone. Go outside and take in the view. } 1 \text { Glance } \\
\text { (jealousness) up at the } 2 \text { stars and }\end{array}$ & $1 ; 2$ & & $\begin{array}{l}1 \mathrm{M} ; \\
2 \mathrm{M}\end{array}$ & \\
\hline $2-38$ & $\begin{array}{l}1 \mathrm{p} / \mathrm{b} / \text { onder your very } 2 \text { exis tence (extence) on our own } 3 \mathrm{p} / \mathrm{b} / \mathrm{a} / \mathrm{le} \text { (C) } 4 \text { blue (below, blue) dot, and let } \\
\text { the awe wash over you. }\end{array}$ & $1 ; 2 ; 3$ & 4 & $1 ; 2 ; 3 \operatorname{Pr}$ & 4MSV \\
\hline
\end{tabular}


APPENDIX G: MISCUE CODED SPREADSHEET

\begin{tabular}{|c|c|c|c|c|c|c|c|c|c|c|c|c|}
\hline 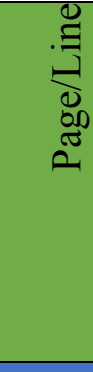 & 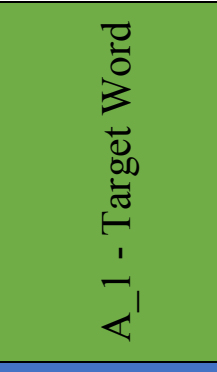 & $\begin{array}{l}\stackrel{0}{0} \\
\stackrel{0}{\mathscr{2}} \\
\stackrel{2}{\Sigma}\end{array}$ & 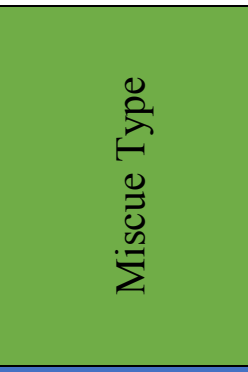 & 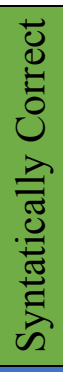 & 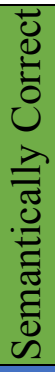 & 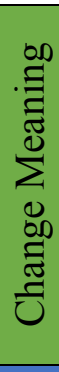 & \multicolumn{2}{|c|}{$\begin{array}{c}\text { Graphophonic } \\
\text { similarity } \\
\text { Graphic } \\
\text { Phonetic }\end{array}$} & 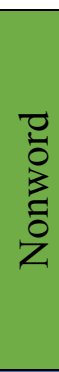 & 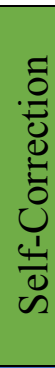 & 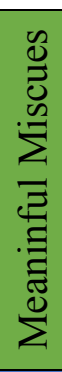 & 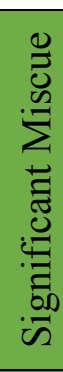 \\
\hline $\begin{array}{l}001- \\
1\end{array}$ & Astronaut & \$Astonot & Pronunciation & $\checkmark$ & $\checkmark$ & $* *$ & $\checkmark$ & 1 & $\checkmark$ & 1 & $* *$ & \\
\hline $\begin{array}{c}001- \\
1\end{array}$ & Months & Month & $\begin{array}{c}\text { Partial } \\
\text { Omission }\end{array}$ & 1 & $\checkmark$ & 1 & $\checkmark-s$ & $\sqrt{ }-\mathrm{s}$ & 1 & 1 & $\checkmark$ & 1 \\
\hline $\begin{array}{c}001- \\
2\end{array}$ & Specialist & \#subceleste & Pronunciation & 1 & 1 & $\checkmark$ & 1 & 1 & $\checkmark$ & 1 & 1 & $\checkmark$ \\
\hline $\begin{array}{c}001- \\
2\end{array}$ & Remembers & Remember & $\begin{array}{c}\text { Partial } \\
\text { Omission }\end{array}$ & 1 & $\checkmark$ & 1 & $\checkmark-s$ & $\sqrt{-s}$ & 1 & 1 & $\checkmark$ & 1 \\
\hline $\begin{array}{c}001- \\
2\end{array}$ & The & That & Substitution & $\checkmark$ & 1 & $\checkmark$ & $\checkmark$ & 1 & 1 & 1 & 1 & $\checkmark$ \\
\hline $\begin{array}{c}001- \\
3\end{array}$ & Windows & Window & $\begin{array}{c}\text { Partial } \\
\text { Omission }\end{array}$ & $\checkmark$ & $\checkmark$ & 1 & $\checkmark-s$ & $\sqrt{-s}$ & 1 & 1 & $\checkmark$ & \\
\hline
\end{tabular}




\begin{tabular}{|c|c|c|c|c|c|c|c|c|c|c|c|c|}
\hline 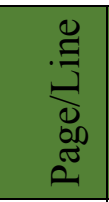 & 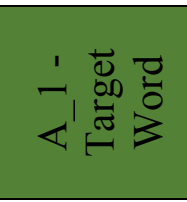 & $\begin{array}{l}\stackrel{0}{0} \\
.0 \\
\stackrel{\mathscr{D}}{\Sigma}\end{array}$ & 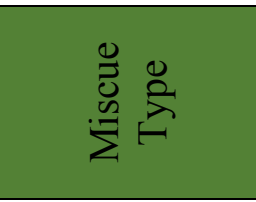 & 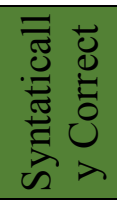 & 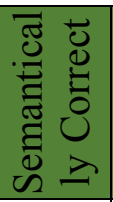 & 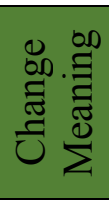 & $\begin{array}{c}\text { Graphophonic } \\
\text { similarity } \\
\text { Graphic } \\
\text { Phonetic }\end{array}$ & 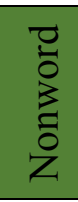 & 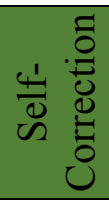 & 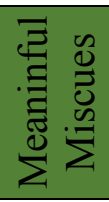 & 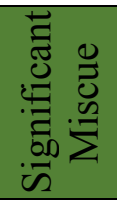 & \\
\hline $\begin{array}{c}001- \\
3\end{array}$ & the & 0 & Omission & $\checkmark$ & 1 & 1 & 0 & 0 & 1 & 1 & 1 & $\checkmark$ \\
\hline $\begin{array}{c}001- \\
4\end{array}$ & peek & /bi:k/ & Pron/L1 & $\checkmark$ & $\checkmark$ & 1 & $\checkmark$ & 1 & $\checkmark$ & 1 & $\checkmark$ & 1 \\
\hline $\begin{array}{c}001- \\
4\end{array}$ & whites & white & $\begin{array}{c}\text { Partial } \\
\text { Omission } \\
\end{array}$ & $\checkmark$ & $\checkmark$ & 1 & $\sqrt{ }-\mathrm{s}$ & $\checkmark-s$ & 1 & 1 & $\checkmark$ & 1 \\
\hline $\begin{array}{c}001- \\
4\end{array}$ & the & 0 & Omission & 1 & $\checkmark$ & 1 & 0 & 0 & 1 & 1 & 1 & $\checkmark$ \\
\hline $\begin{array}{c}001- \\
4\end{array}$ & below & blue; below & & 1 & 1 & $\checkmark$ & $\checkmark$ & 1 & 1 & $\checkmark \mathrm{Se}$ & 1 & $\checkmark$ \\
\hline $\begin{array}{c}001- \\
4\end{array}$ & curvature & $\begin{array}{l}\text { co; the conver; } \\
\text { carveture }\end{array}$ & Pronunciation & $\checkmark$ & $\checkmark$ & $* *$ & $\checkmark$ & $\mathrm{u}<\mathrm{a}$ & $\checkmark$ & 1 & $* *$ & - \\
\hline $\begin{array}{c}001- \\
5\end{array}$ & the & to & Substitution & $\checkmark$ & 1 & $\checkmark$ & 1 & 1 & 1 & 1 & 1 & $\sqrt{ }$ Sy \\
\hline $\begin{array}{c}001- \\
5\end{array}$ & whole & all & Substitution & $\checkmark$ & $\checkmark$ & 1 & 1 & 1 & 1 & 1 & $\checkmark$ & 1 \\
\hline $\begin{array}{c}001- \\
5\end{array}$ & disc & desk; disc & & $\checkmark$ & 1 & $\checkmark$ & $\checkmark$ & $\mathrm{i}<\mathrm{e}$ & $\checkmark$ & $\sqrt{ } \mathrm{Se}$ & 1 & $\checkmark$ \\
\hline $\begin{array}{c}001- \\
5\end{array}$ & that & the & Substitution & $\checkmark$ & $\checkmark$ & $\checkmark$ & $\checkmark$ & 1 & 1 & 1 & 1 & $\checkmark$ \\
\hline $\begin{array}{c}001- \\
6\end{array}$ & got & get & Substitution & $\checkmark$ & $\checkmark$ & 1 & $\checkmark$ & 1 & 1 & 1 & $\checkmark$ & 1 \\
\hline $\begin{array}{c}001- \\
7\end{array}$ & decades & \#decedes & Pronunciation & $\checkmark$ & $\checkmark$ & $* *$ & $\checkmark$ & 1 & $\checkmark$ & 1 & $* *$ & - \\
\hline $\begin{array}{c}001- \\
7\end{array}$ & numerous & $\begin{array}{c}\text { na; } \\
\text { \$namerous }\end{array}$ & Pronunciation & $\checkmark$ & $\checkmark$ & $* *$ & $\checkmark$ & $\mathrm{u}<\mathrm{a}$ & $\checkmark$ & 1 & $* *$ & - \\
\hline
\end{tabular}

